\title{
On the verge of poverty : welfare and economic transition in Latvia
}

Citation for published version (APA):

Gassmann, F. (2000). On the verge of poverty : welfare and economic transition in Latvia. [Doctoral Thesis, Maastricht University]. Datawyse / Universitaire Pers Maastricht. https://doi.org/10.26481/dis.20001117fg

Document status and date:

Published: 01/01/2000

DOI:

10.26481/dis.20001117fg

Document Version:

Publisher's PDF, also known as Version of record

\section{Please check the document version of this publication:}

- A submitted manuscript is the version of the article upon submission and before peer-review. There can be important differences between the submitted version and the official published version of record.

People interested in the research are advised to contact the author for the final version of the publication, or visit the DOI to the publisher's website.

- The final author version and the galley proof are versions of the publication after peer review.

- The final published version features the final layout of the paper including the volume, issue and page numbers.

Link to publication

\footnotetext{
General rights rights.

- You may freely distribute the URL identifying the publication in the public portal. please follow below link for the End User Agreement:

www.umlib.nl/taverne-license

Take down policy

If you believe that this document breaches copyright please contact us at:

repository@maastrichtuniversity.nl

providing details and we will investigate your claim.
}

Copyright and moral rights for the publications made accessible in the public portal are retained by the authors and/or other copyright owners and it is a condition of accessing publications that users recognise and abide by the legal requirements associated with these

- Users may download and print one copy of any publication from the public portal for the purpose of private study or research.

- You may not further distribute the material or use it for any profit-making activity or commercial gain

If the publication is distributed under the terms of Article $25 \mathrm{fa}$ of the Dutch Copyright Act, indicated by the "Taverne" license above, 


\section{ON THE VERGE OF POVERTY}

Welfare and Economic Transition in Latvia

Franziska Gassmann 
(C Franziska Gassmann, Maastricht 2000

ISBN 9052782903

Cover design: Riet de Wiet 


\title{
ON THE VERGE OF POVERTY
}

\section{Welfare and Economic Transition in Latvia}

\author{
PROEFSCHRIFT
}

ter verkrijging van de graad van doctor aan de Universiteit Maastricht, op gezag van de Rector Magnificus, Prof. dr. A.C. Nieuwenhuijzen Kruseman volgens het besluit van het College van Decanen, in het openbatar te verdedigen op vrijdag 17 november 2000 om 12:00 uur

door

Franziska Gassmann

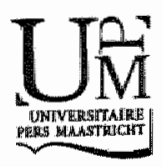


Promotor:

Prof, dr, C.J.N. de Neubourg

\section{Beoordelingscommissie:}

Prof. dr. I.G.A. van Mierlo (voorzitter)

Prof. dr. G. Esping-Andersen (Universitat Pompeu Fabra, Barcelona, Spain)

Dr. P. Keizer 


\section{Preface}

While writing my master's thesis on poverty, I regretted that I did not have the possibility to apply the theory to real-life data. But this endeavor would have been far beyond the scope of a master"s thesis. After my graduation, Chris offered me a position at the university that would allow me to combine working as a consultant for the World Bank, teaching some courses for the faculty and writing a dissertation. There was the chance to continue where my thesis ended. During my work in Latvia and Lithuania, I increasingly realized that the focus of the dissertation has to be on the social and economic effects of the economic transition on the people, and that the implementation of the poverty theory is only a necessary ingredient of the analysis.

The last four years have been exciting and everything but dull. It was the almost perfect combination between academic research and real-life experience. I had the chance to meet interesting people and to benefit form their knowledge and generosity. Of the many people that guided and believed in me, it is most and for all Chris to whom my gratitude goes. He introduced me to the World Bank team and took me to Latvia for the first time in 1995. Without his continuos support as a mentor and friend it would not have been possible to come so far. Thank you for everything!

While Chris was decisive in this part of the world, this study would not have been possible without my Latvian colleagues. They opened my eyes and helped me understand what it meant to live in a country in transition. Especially Inita, our most important counterpart in the Ministry of Welfare in Riga, who became a dear friend in the course of the years, would not get tired to discuss with me the findings of the study and put them into relation with the past. It is mainly thanks to her that the worst blunders were prevented from staying in the manuscript. Special thanks also go to Edmunds from the Latvian Central Statistical Bureau. He provided me with the survey data and was always willing to answer my many questions.

Part of this research was made possible by UNDP Latvia that financed a national project on poverty. I would like to thank UNDP for granting me permission to use the data from the poverty survey for my dissertation as well. Many thanks go also to the World Bank team, and especially to Louise and Philip who kept sending me to Latvia.

I owe thousand thanks to Denis, my informal co-promoter. His door was always open when I was struggling with a statistical problem. I learned a lot from him about data crunching and the like. Merci, mon ami.

For the finishing touch of the manuscript I could count on assistance from Caryn who read the whole draft and corrected my English, Judith and Marc Paul who made sure that the Dutch summary was not too infected with 'Swiss-Dutch', Scheltus who checked the layout for any inconsistencies, and Riet who designed the cover. Thanks a lot to all of you. I am the only one to be blamed for the remaining errors.

Last but not least. I would like to thank my family and friends for giving me moral support whenever I needed it. But Willem was the one who had to deal with my frustrations, uncertainties, doubts and moments of desperation. Thank you, my dear husband, for all your love and care.

\section{Paldies!}





\section{TABLE OF CONTENTS}

\section{PREFACE}

TABLE OF CONTENTS

\section{INTRODUCTION}

1.1 Why Latvia?

1.2.1 Geographical location

1.2.2 Brief historical background

1.2.3 Macro-economic and demographic situation

1.2 Poverty and transition

1.2.1 What we know so far? An overview of poverty in the region

1.2.2 Hypotheses for Latvia

1.3 Contributions and relevance of this study

1.4 Structure of the thesis

1.5 Destroyed illusions

2 CONSTRUCTING A WELFARE INDICATOR FOR THE ANALYSIS OF POVERTY

2.1 Introduction

2.2 Is welfare measurable? 16

2.3 From theory to practice: many choices to be made 20

2.3.1 A short introduction to the data used 20

2.3.2 Goods and services entering the welfare function 22

2.3.3 Specific problem 1: Imputing values for missing observations 25

$\begin{array}{ll}\text { 2.3.4 Specific problem 2: Seasonal variation } & 27\end{array}$

2.3.5 Specific problem 3: Price variation over region and time 31

2.3.6 From household to individual: the crux of equivalence scales 33

2.4 Testing the robustness of the indicator 35

2.5 Conclusion 39

Appendix 2A: Regression models for missing observations $\quad 40$

Appendix 2B: Tables B1-B2 43

3 LATVIANS MOST AT RISK 49

3.1 introduction 49

3.2 The burden of choice - which methodology to apply 50

3.2.1 Defining poverty 50

3.2.2 Poverty line $\quad 52$ 
32.4 Sensitivity analysis $\quad 55$

3.3 A poverty profile for Latvia

59

a) Poverty and geographicallocation

b) Household size, household composition and number of children per household 62

c) Education, income and employment

d) Gender and age $\quad 67$

Q) Land ownership 69

3.3.2 The findings in perspective $\quad 70$

$\begin{array}{ll}3.4 \text { The profile revisited } & 72\end{array}$

a) Poverty and geographical location $\quad 72$

b) Household size, household composition and number of children per household 73

c) income source, major activity and education

d) Gender and age $\quad 76$

e) Housing and land ownership

3.5 Risk factors

a) Selected risk factors

b) Marginal effects on poverty

\subsection{Conclusion}

\section{THE DYNAMICS OF GAINING AND LOSING}

4.1 Introduction

4.2 What do we know from other countries? Trends and experiences 86

4.2.1 The transition and the dynamics of living standards in general 86

4.2.2 The old and the new poor $\quad 87$

4.2.3 What explains the changes? 88

4.3 The poverty survey - data and methodology 90

$\begin{array}{ll}4.3 .1 \text { The survey } & 90\end{array}$

4.3.2 Methodology $\quad 91$

4.3.3 Summarizing poverty $\quad 92$

4.4 The perception and dynamics of gaining and losing 94

4.4.1 Feeling worse off, being worse off 94

4.4.2 Who gained, who lost? 97

4.4.3. Why they gained or lost - The role of incidents 101

4.4.4 Better off before 1991, worse off during the transition? 102

4.4.5 What does it mean to have gained or lost?

4.4.6 What makes a winner a winner and a loser a loser? 108

$\begin{array}{ll}4.5 \text { Conclusion } & 110\end{array}$

Appendix 4A: Comparing expenditure aggregates and merging two data-sets 112

Appendix 4B: Sample profile $\quad 116$

\section{COPING WITH LITTLE MEANS}

5.11 Introduction

5.2 Coping and survival strategies

5.2 .1 Coping in the East

5.2.2 A classification 
5.3 Coping with powerty and low incomes in Latvia $\quad 424$

5.3.1 How prevalent are coping strategies in Latvia?

a) Income-generating activities $\quad 125$

b) Household production 127

c) Economizing 128

d) Assistance from the social network $\quad 129$

e) Crisis activities 131

5.3.2 Coping strategies and standards of living $\quad 132$

5.3.3 Determinants for the various coping strategies 135

5.3.4 Giving and receiving: who is doing what? 138

$\begin{array}{ll}5.3 .5 \text { Consumption habits } & 140\end{array}$

$\begin{array}{lr}5.4 \text { Conclusion } & 143\end{array}$

$\begin{array}{lr}\text { Appendix 5A: Table A1 } & 145\end{array}$

6 TURNING TO THE STATE FOR HELP 147

$\begin{array}{ll}6.1 \text { Introduction } & 147\end{array}$

$\begin{array}{lr}6.2 \text { The current system } & 148\end{array}$

6.2.1 What has happened since independence? 148

6.2.2 Social assistance schemes $\quad 149$

6.2.3 Administration and financing $\quad 152$

6.2.4 Effectiveness of the current system

a) Measures of effectiveness

b) Experiences with the decentralized system $\quad 155$

6.3 Latvian perceptions $\quad 156$

6.3.1 What people know about local social assistance $\quad 156$

6.3.2. Where people get information about local social assistance services $\quad 159$

$\begin{array}{ll}\text { 6.3.3 Visitors and non-visitors } & 161\end{array}$

6.3.4 Social Assistance visitors and the benefits they apply for $\quad 163$

6.3.5 Attitudes towards local Social Assistance Office 164

6.3.6 Conclusion $\quad 165$

6.4 Evaluation of the situation and first attempts towards a solution 165

a) Transparency and effectiveness for the clients $\quad 165$

b) Incentives 166

c) Centralized versus decentralizad administration $\quad 167$

d) Adjudication $\quad 167$

e) Social policy monitoring and evaluation $\quad 168$

6.5 Keep it simple but effective $\quad 168$

6.5.1 Introducing a Unified Monthly Benefit $\quad 169$

a) Recapitulating the current system 170

$\begin{array}{ll}\text { b) The concept } & 170\end{array}$

c) An imaginary decision process $\quad 171$

d) Simulation of a possible GMI level for Latvia $\quad 172$

6.6 Conclusion 
Household Budget Survey Questionnaire and Dairy

Poverty Survey Questionnaire 


\section{INTRODUCTION}

A decade ago the world was confronted with the phenomenon of the collapsing communist system in the Soviet Union and other Central and Eastern European countries. The fall of the wall in Germany in 1989 marked the start of economic and political turmoil in this vast geographical area a unique event in modem history. We were celebrating the victory over communism and the freedom the people in the East regained. We were convinced that these were the first days of a better future for these countries. And indeed, soon after, the familiar pictures of people queuing in order to get some basic goods disappeared from our television screens. The shelves in the shops were filled with a variety of products - the market economy made it all possible. The people were finally free and could travel wherever they wanted to. They must have been so happy and grateful for the change in their fate. In the event of the first years, we accepted that there was a price attached to the newly gained independence and the abolition of an old system. The output in these countries collapsed, unemployment, which was formerly "unknown', became a reality. The majority of the people had a hard time adjusting to the new situation and making ends meet. We thought this was acceptable. Everything has its price, and most people are willing to sacrifice now in order to be better off later. Everybody was convinced that the initial downturn would only last for a short period before the real recovery would start. Now, ten years later, we have to ask ourselves whether the developments in the countries in transition confirm our expectations and what happened to the people during the years of transition. This knowledge may help us to understand the current political and social situation in these countries. It may provide lessons for the future. Simultaneously, there are economic lessons for us in the West: a market can only develop and work properly if institutions and regulations are established and agreed upon, property rights defined, laws enforced and tax compliance strengthened. These ingredients, among others, have proven to be essential for a market economy.

Latvia, a part of the Soviet Union prior to 1991, regained its independence when the USSR officially ceased to exist. The little country on the shores of the Baltic Sea embarked on a transformation from a centrally planned economy to a market economy as did most of the other countries in the region. The breakdown of the former system brought not only political freedom and democracy but also economic distress. Efforts of privatization, liberalization of prices, the abandonment of most subsidies, and the disruption in trade and financial links with Russia affecting the total output of the economy, had their impact on the Latvian population. Standards of living dropped due to decreasing real wages and rising unemployment. Evidence from various sources (Venesaar and Hachey, 1995; UNDP, 1995, 1996, 1997, 1998h; Aasland, 1996) pointed towards increasing poverty rates in Latvia.

In this study we estimate and analyze the impact of the economic transition in Latvia on the standard of living in general, and on poverty in particular. 
Reform policies and their immediate effects influenced the living conditions of families during the transition: falling wages, elimination of food subsidies, rising prices that reduced the spending power of households, deteriorating employment prospects, and cut-backs in social services dwe to light government budgets as well as welfare system reforms. Until today there has been only limited information available on the effects of the economic transformation on the citizens in economies in transition. The performance of stabilization policies on the macroeconomic level has been studied quite extensively (see, e.g., World Bank, 1993; Banerjee, B., et al, 1995; MMF, 1999; EBRD, 1999). But a nation and its economy consist not only of enterprises, government, output, trade ete; survival and the success of the transition depend most of all on the citizens living in the country. It is important to know how individuals and households thave been affected by the change of the economic system and whether and how they have adjusted their behavior. Ignorance carries inherent risks since it prevents a timely reaction by the government on changes in the standard of living.

In order to achieve the objective of this study which is to analyze the impact of the economic transition on poverty and the standard of living in Latvia, four sub-questions have been distinguished:

1. How can we construct a welfare indicator that reflects a household's welfare as realistically as possible using Household Budget Survey data?

2. Who are the winners and the losers of the economic transition?

3. How do households cope with the avalable means?

4. Is the Latvian social policy effective in providing a safety net for the poor?

Question 1: How does one construct a welfare indicator that reflects a household's welfare as realistically as possible wsing Household Budget Survey data?

For a starter we need to measure the welfare of households. The indicators used have to allow comparisons between different (groups of) households and individuals. Welfare is an expression of well-being, and the question is then how well-being can be measured in order to make it comparable. While consumption is the preferred concept to estimate well-being (Deaton \& Muellbauer, 1980; Deaton, 1997), it is usually not observable. ${ }^{1}$ For convenience, physical consumption has to be approximated by, for example, monetary expenditure. Data from the Latvian Household Budget Survey (HBS) serve as the source of information for the creation of an indicator. The emphasis is on the ranking of the households according to their level of welfare. The indicator used in this study is not only adjusted for price variations over region and time but also takes into account seasonal differences in the consumption of certain goods. This adjustment proves to be relevant for the ranking of the households. The development of an appropriate welfare indicator for Latvia provides the basis for the subsequent analysis.

\section{Question 2: Who are the winners and losers of the economic transition?}

The extent and depth of current poverty as well as information about poverty under the former regime is needed to draw conclusions about the old and the new poor, to identify winners and losers. There is little information about poverty levels for the period before 1991 since the existence of poverty was officially denied during Soviet times. Atkinson \& Micklewright (1992) did pioneering work with their detailed overview on poverty and income distribution in the former Soviet Republics and other Eastern European countries: they defined the groups that were most at risk. More information is available on the 'new' poor, and a comparison of the groups at risk before and

\footnotetext{
This statement is not completely contect. Consumption would actually be perfectly observable, be it at very high costs. Imagine what it means to watch only one household (and all its members) continuously during a certain period of time.
} 
after the initial transition allows some cautious conclusions about winners and losers. The present study provides for the first time an indication of the winners and losers from the subjective point of view of the population. The information gained in this study can validate the earlier findings that were based on a quantitative assessment.

\section{Question 3: How do households cope with their awrilable means?}

The economic transition does not only affect the living standard of the population, or the welfare of a household; it can also have an impact on the strategies a household can use in order to make ends meet. Furthermore, we have to take into account the fact that the overall welfare level in Latvia. is rather low (GDP per capita is for example the lowest of all Baltic countries). While queuing is a prominent example of coping in a shortage economy such as under the former regime, the new economic order may have given rise to other coping strategies. Information on the extent and depth of poverty alone is not sufficient for a comprehensive assessment of the impact of the transition. Knowledge about how people react and adapt is equally important, not at least from a policy point of view. This leads us to the last sub-question:

\section{Question 4: Is the Latvian social policy effective in providing a safety net for the poor?} The Latvian social security system was fully integrated with the social policy of the Soviet Union until 1991. Simultaneously with the economic transition, a new social security program was initiated. New pensions, family and unemployment benefits have been introduced one after the other, but too much was demanded of the system for it to act effectively as a safety net for the most vulnerable parts of the population. Several reforms have been implemented since the beginning. If poverty indeed increased during the transition, it is crucial for the state to be able to provide a safety net for the population in order to soften its impact.

The remainder of this introductory chapter addresses the following issues: first, an introduction to Latvia provides summary information about the geographical, historical and economic background. $\mathbb{N e x t}$, after the definition of terminology, a first overview on poverty in transition economies based on previous studies allows a formulation of hypotheses about poverty for Latvia. The final section discusses the social and scientific relevance of this study and provides details on the other chapters.

\subsection{Why Latvila?}

The reader may wonder why this study is concemed with Latvia in particular. Data availability is the major reason for this choice, in addition to personal interest and the conviction that Latvia can serve as a case study for Central and Eastern European countries. The reference to and comparison with other countries in the region put Latvia into a broader context. The comparison with and the extension of gained insights to other former Soviet republics is not in all cases warranted regarding the existing conditions in these republics. It is mainly the European part of the former Soviet Union for which Latvia can serve as a reference. The countries in the Caucasus region are not suitable for a comparison because of the civil wars and other armed conflicts these countries have had to and still hawe to endure, resulting in completely different (starting) conditions. As far as the Central Asian republics are concemed, their economic development lags behind to such an extent that a meaningful comparison is hardly possible. The results from the current study will allow conclusions to be drawn for other transition countries with similar economic development and demographic characteristics. 


\subsubsection{Geographical location ${ }^{2}$}

Latvia is situated in Eastern Europe on the Eastern coast of the Baltic Sea with a coastline of more than 500 kilometers. It covers an area of 64,589 square kilometers of which approximately $27 \%$ is arable land $\mathrm{d}_{\mathrm{x}}$ and more than $40 \%$ is covered by forests and woodlands. Almost the entire country is less than 300 meters above sea level with the highest point at 312 meters. More than 3,000 lakes and about 750 rivers of more than 10 kilometers lie between lowland plains and rolling hills. The Latvian climate is temperate maritime and continental with mild winters and moderately warm summers. The country has only minimal natural resources of its own of which amber is probably the best known. It has common borders with Estonia in the North, Russia and Belarus in the East, and Lithuania in the South.

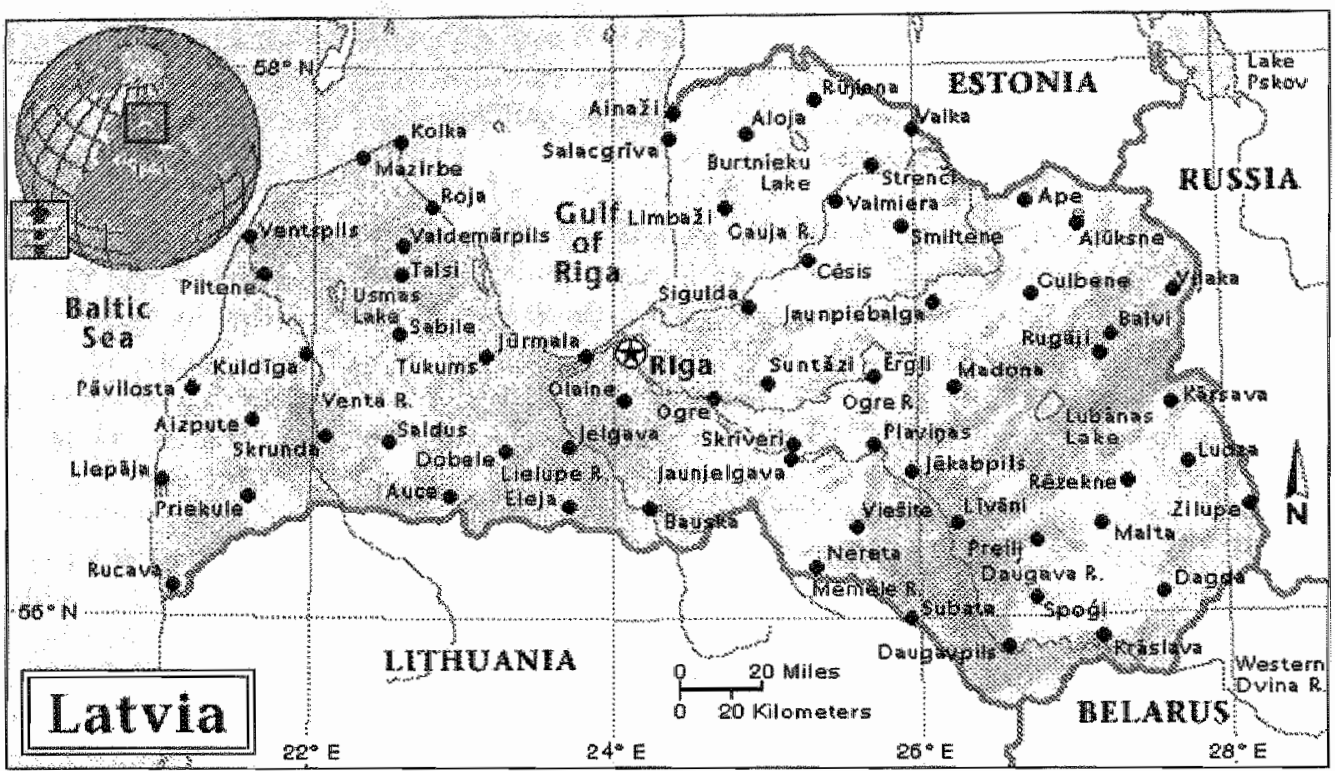

Figure 1.1. Map of Latvia

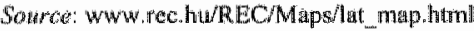

\subsubsection{Brief historical background ${ }^{3}$}

The ancestors of the Latvians arrived at the Baltic Sea already in the Second Millennium BC. Present-day Latvian history started in the $12^{\text {th }}$ century when German crusaders of the military Order "Knights of the Sword" invaded the Baltic Region. They landed at the shore of the Daugava river, which was throughout history an important trade route from East to West. Riga was founded in 1201 by Bishop Albert. During the following centuries the Order ruled Latvia and christianized its population. The Polish-Swedish war in the $16^{\text {th }}$ century ended with the Swedes ruling over Northern Latvia whille the South and West became part of the Polish-Lithuanian empire. At the beginning of the $17^{\text {th }}$ century, the Swedes occupied Riga and ruled Latvia until their defeat by the Russians at the beginning of the $18^{\| \mathrm{t}}$ century. Peter the Great guaranteed the privileges and local authority of the

'Sources: CIA, 1999; The World Bank, 1999; LDA, 1999.

${ }^{3}$ Sources: Lieven, 1994; Gerberding et al, 1995; Riga In Your Pocket, 1998. 
Baltic German nobility, and the Russians controlled the country until the first World War.

Latvia became involved in the firs: World War after the Russian Revolution. In 1918, Lenin allowed Latvia to make their own decisions regarding their state, and on 18 November, 1918, Latvia declared its independence. This was the first time that Latvia appeared as an independent country on the maps of Europe. The League of Nation accepted Latvia as a member in Jamuary 1921. Independence ended with the Molotow-Rippentrop pact, wherein the division of Eastem Europe was determined. Soviet troops invaded the country in 1940. Mass deportations to Siberia followed. One part of the Latvian population fought in the Russian army. When the Germans occupied the country in 1941, the remaining part was forced the join the German army. In fact, the Latvians were fighting: on both sides of the war, but while they were fighting against each other, they were only thinking about the liberty of their own country. The Soviet Army recaptured Latvia in 1945. General collectivization and mass deportations followed, for example, in 1949 when on one day 42,000 people were deported to Siberia (March 25, 1949). The following decades took place against the background of 'Russification': Russian workers were brought into the country, the Latvian language was suddenly a minority language, and certain cultural events were banned.

In the second half of the 1980 s the Soviet regime softened due to Gorbachev's policy of 'glasnost' and 'perestroika'. The people started to feel that changes may be possible, and the Warsaw pact countries outside the Soviet Union especially saw liberation movements emerge. The solidarity movement in Poland, 'Solidarnost', was followed by people's movements in Czechoslovakia and then the German Democratic Republic.

In Latvia, the first demonstrations against Soviet rule took place in 1987 when the people participating were still punished. Already in 1988 the large demonstrations were generally accepted. During the same period, the national-demographic Popular Front was created. First calls for independence were made in 1989 by the Latvian Supreme Council, but it took another two years and more suffering before Latvia declared independence on May 5, 1991. The factual independence was regained on August 21, 1991, when the counter-revolution in Moscow failed.

\subsubsection{Macro-economic and demographic situation}

The new freedom and independence were accompanied by a major economic shock. The implementation of stabilization programs and the introduction of market reforms led to a dramatic decrease in output. In 1992, Gross Domestic Product (GDP) declined by one third and inflation rose to more than $900 \%$ after the liberalization of prices. It took the Latvian economy several years to recover from the dramatic drop in output. Since 1996, growth rates have recovered and reached $3.3 \%$ in 1996 and $8.6 \%$ in 1997 (according to CSB, 1999a). Inflation rates declined significantly after 1993, and are currently well below 10\% (see table 1.2). Official unemployment rates are increasing slightly every year. In 1998, 9.2\% of those looking for work were officially registered as unemployed. Labor Force Survey statistics provide unemployment rates of $14 \%$ for 1998 (job seekersi).

Table 1.1. Latvia: Output development before and after independence, $1990=100$

\begin{tabular}{llllll}
\hline & 1988 & 1989 & 1990 & 1991 & 1992 \\
\hline Real Gross Domestic Product index & 91.0 & 97.2 & 100 & 89.6 & 58.4 \\
\hline
\end{tabular}

Source: CSB, 1997f. 
Table 1.2. Latwia: Main Economic Indicators, $1993-1998$

\begin{tabular}{|c|c|c|c|c|c|c|}
\hline & 1993 & 1994 & 1995 & 1996 & 1997 & 1998 \\
\hline $\begin{array}{l}\text { Gross Domestic Product: } \\
\text { - current prices (million LVL) }\end{array}$ & 1467.0 & 2042.6 & 2360.7 & 2829.1 & 3275.5 & 3773.5 \\
\hline - constant 1995 prices (min LVL) & & & 2349.2 & 2427.7 & 2636.8 & 2730.5 \\
\hline - growth rate in \% & -14.9 & 0.6 & -1.6 & 3.3 & $8.6^{2}$ & 3.6 \\
\hline Exchange rate LVL per USO' & 0.674 & 0.560 & 0.528 & 0.551 & 0.581 & 0.590 \\
\hline Inflation rate, \% & 109.2 & 35.9 & 25.0 & 17.6 & 8.4 & 4.7 \\
\hline Unemployment rate, \% & 5.8 & 6.5 & 6.6 & 7.2 & 7.0 & 9.2 \\
\hline Jab seekers, \%\% & n.a. & n.a. & ma. & 19.4 & 14.8 & 14.0 \\
\hline Current account balance, min LVL & 289.0 & 112.3 & 18.2 & -154.2 & -201.1 & -417.4 \\
\hline $\begin{array}{l}\text { Goverinment budgat deficit, min } \\
\text { LVL }\end{array}$ & -2.1 & -37.9 & $=89.9$ & -31.1 & 59.0 & 8.4 \\
\hline
\end{tabular}

Average per year

Note: real growth in 1997 is according to other sources only $6.5 \%$ (The World Bank Group, 1999; MoE, 1998).

Source: CSB. 1996, 1999 a.

In 1993, Latvia introduced its own currency, the Lat. Since 1994, the Lat has been pegged to the SDR (the IMF's Special Drawing Rights) and has remained stable. The economy was confronted with two serious shocks since the economy started to recover. In 1995, a banking crisis disrupted economic growth and resulted in the loss of $40 \%$ of banking assets and the closure of 15 banks. Saving deposits dropped by one quarter (World Bank, 1999). The second crisis was related to the Russian financial crisis in August 1998 and the effects were transmitted to Latvia via trade and financiall links with Russia. ${ }^{4}$ As a resull, economic growth slowed down to $3.6 \%$ in 1998, and was negative in the first quarter of 1999 (World Bank, 1999). Nevertheless, the government is determined to continue its strict fiscal and monetary policies.

Although privatization initially lagged behind compared to other countries in transition, it gained momentum in 1997. The share of the private sector in GDP increased to more than 60\% in 1998. EU accession remains the top priority and influences the reform of the economic and legal settings of the country.

From a demographic point of view, Latvia is confronted by a steadily declining population. The negative natural growth rate is the main cause of the decrease. In the first three years after independence, more than 130,000 Latvians left the country, most of whom emigrated to Russia and other fomer Soviet republics (CSB, 1995). A relatively low fertility rate and a high mortality rate contribute to the negative demographic trend. The fertility rate is one of the lowest in Europe with 1.1 births per women (see Table 1.3). Life expectancy rates have been increasing again since 1996, but the difference between men and women remains significant. The sex ratio of various age groups mirrors this trend. For the group 65 years and older, the ratio is 0.47 male per female. At birth, this ratio is equal to 1.05 male per female babies. The decline in the male relative share is without doubt also a result of the two World Wars and the mass deportations during Soviet times. On the other hand, Latwa is confronted with a dramatic increase in mortality rates, peaking in 1994 . Especially the mortality rate among working males is causing concern. The majority of deaths are due to cardio-vascular diseases (56\% in 1994). Alcohol consumption (16.5 deaths per 100,000 in 1994), homicide (24.7 per 100,000 in 1994) and suicide (40.5 per 100,000 in 1994) contribute to the high mortality rates as well (Vasaraudze, 1996). With respect to the ethnic distribution of the Latvian

\footnotetext{
"Russia was among the top three trade partners. In 1997, $21 \%$ of Latwa's export went to Russia. Main export commodities are wood amd wood products, machinery and equipnent, textiles and foodstuffs. (CIA, 1999).
} 
population, 56\% are ethnic Latvians and 30\% are Russians (CIA, 1999). This distribution has regularly caused political problems since Latvia regained independence. ${ }^{5}$

Tabie 1.3. Latwa: Demographic Indicators $1993-1998$

\begin{tabular}{|c|c|c|c|c|c|c|}
\hline & 1993 & 1994 & 1995 & 1996 & 1997 & 1998 \\
\hline Population (in thousands) & 26066.2 & 2565.8 & 2529.5 & 2501.7 & 2479.9 & 2458.4 \\
\hline Natural increase & -12438 & $-1750 t$ & -17336 & -145318 & -14703 & -15790 \\
\hline Net migration & -27884 & -18810 & -10547 & -7252 & -6764 & -3168 \\
\hline \multicolumn{7}{|l|}{ Life expectancy } \\
\hline maile & 64.61 & 60.72 & 60.76 & 63.94 & 64.2 & 64.1 \\
\hline female & 73.84 & 72.87 & 73.10 & 75.62 & 75.9 & 75.5 \\
\hline Fertillty rate & 4.5 & 1.4 & 1.2 & 1.2 & 1.1 & 1.1 \\
\hline Infant imortalify, per 1,000 live births & 15.9 & 15,5 & 18.5 & 15.8 & 15.2 & 14.7 \\
\hline
\end{tabular}

Source: CSB, 1996, 1999a; MoW, 1998, 1999a.

\subsection{Poverty and transition}

This study is concerned with the impact of the economic transformation from a centrally planned economy to a market economy on poverty. Economic transformation means a set of reforms designed to replace all the key elements and mechanisms of a centrally planned economy with a market system. The reforms fall into four categories: (i) privatization of collectively owned enterprises; (ii) marketization of goods, services and production factors (e.g. price liberalization); (iii) stabilization of the economy; and (iv) institution-building, i.e. establishing a legal and institutional framework for a market system (Brown \& Neuberger, 1994:381).

A centrally planned economy is an economic system where (i) most means of production are owned collectively; (ii) governmental agencies engage in planning and control of most aspects of economic life in response to the planners' sovereignty; and (iii) where resources are allocated by administrative commands in physical terms (Bornstein, 1994:355). On the contrary, a market economy (or capitalist economy) is an economic system where (i) most means of production are owned privately; (ii) decisions about the allocation of resources and production are made via a price-system; and (iii) where economic gains are the guiding forces in decisions about investments and production (Bomstein, 1994:69). A mixed market economy combines competitive private enterprise with some degree of central control by the govermment. Governments may intervene by means of monetary and fiscal policies, (progressive) taxation and welfare legislation.

Poverty can be defined along various lines: absolute versus relative, or income versus basic needs. Absolute poverty is having less than an objectively defined minimum that is independent of the generall welfare level or its distribution in a society. Relative poverty idientifies those people who are poorest within the overall pattern of the income (welfare) distribution within a given society. It is related to norms and average standards of living prevailing in a society. According to the income (expenditure) perspective, a persion is poor if, and only if, her income (expenditure) level is below the defined poverty line. Following the basic needs perspective, powerty is the deprivation of material requirements for the fulfillment of minimal human needs, including food (UNDP, $1997 \mathrm{~b}: 16)$.

"We should keep in mind the events of $25 \mathrm{March}, 1949$, when 42,000 people were deported to Siberia on one day. Almost every single Latvian family had one member deported, and the memory of this tragedy is still wivid today. 
The capability approach offers an alternative and defines poverty as the fallure of basic capabilities to reach certain minimally acceptable lewels of well-being. A person's welfare depends on his capability to meet nutritional requirements, to escape avoidable disease, to be sheltered and clothed, to be able to travel and to be educated (Sien, 1984:336). The concept can be applied to both absolute and relative poverty concepts. Poverty is an absolute notion in the space of capabilities which can take a relative form regarding commodities. ${ }^{6}$

\subsubsection{What we know so far? An overview of poverty in the region}

While information on poverty under communism was scarce, the opposite is true for poverty in the present era. Most information is provided by international organizations such as the World Bank and UNDP (United Nations Development Programme). These organizations have regional offices in most countries in Central and Eastern Europe (CEE) and the former Soviet Union (FSU). They are involved in numerous projects with many of them targeted towards the alleviation of poverty. They subsidize and promote data collection on households thereby providing the countries with reliable data on households and individuals and stimulating the analysis of the data. The World Bank policy entails a poverty assessment as a compulsory part of their country strategy. These are usually one-fime snapshots using the data of one survey round providing a quantitative poverty profile of the country plus some policy analysis and recommendations (see, e.g., World Bank, 1996a, 1996b, 1996c, 1997a, 1998b). Increasingly, the World Bank supports and implements qualitative poverty assessments that are in-depth interviews with a sanpled selection of poor households (see, e.g., Dudwick, 1995; IPS, 1998). Most regional offices of UNDP publish annual national Human Development Reports which cover various issues relating to human development in general and poverty in particular (see, e.g., UNDP 1996, 1997a, 1997b, 1998a-h).

Next to the publications stemming from international organizations, the number of papers on poverty in CEE and FSU countries published in international journals or as books or working papers has increased as well ( Rose, 1995, 1996, Seeth et al. 1998, Spéder, 1998, Vecernik, 1996, Zahoori et al. 1998, Milanovic, 1998, to mention only a few ").

From all these studies, we can get a good picture of the groups most at risk of being poor in the countries analyzed. All the studies agree that poverty increased during the transition, although it is not possible to compare the results between the countries since both data and the methodology used to calculate poverty differ. The groups at risk are not necessarily the same in all countries where we have information at our disposal. Sometimes, it is possible to distinguish a group of countries that have similar characteristics, while in other cases countries with the same group at risk seem to be random. A cautionary note is appropriate: if a group is not mentioned in a poverty assessment as at risk, this does not necessarily mean that this group is not vulnerable. It can mean that either the analysis did not cover the group separately, or that other conclusions were more important. In this section we will restrict ourselves to giving a first summary overview on poverty in the region as an introduction. Each subsequent chapter has its own literature review where the studies relevant for the topic of the respective chapter are discussed.

Population groups are usually formed along certain characteristics of a household, such as location, household composition, educational level, income, gender, age or asset ownership. From all the publications mentioned above, we can conclude the following about poverty in countries in CEE and FSU:

\footnotetext{
${ }^{6}$ More details on poverty defirutions and their application is provided in chapters two and three.

${ }^{7}$ See the bibliography for an overview of those publications used for this study.
} 
- Urban households have thigher poverty risk than rural households in Amenia, Belarus, Georgia and Ukraine (World Bank 1996a, 1996c, 1999; UNDP 1998c).

- The opposite is the case for Hungary, Estonia, Lithuania and Poland (World Bank 1995, 1996c; UNDP 1998e; Lazutka 1999; Milanovic 1998).

- Children have always been a vulnerable group. Already in socialist times, families with three or more children were particularly at risk of living in poverty. Braithwaite (1995) as well as Atkinson \& Micklewright (1992) report this fact for the Soviet Union. The same is known for Czechoslovakia (Vecemik, 1996; Atkinson \& Micklewright, 1992) and Poland (Atkinson \& Micklewright, 1992).

- Families with children are still at risk nowadays in Amenia, Hungary, Belarus, Russia, Ukraine, Uzbekistan, Lithuania, Poland, Kazakhstan, Kyrgyz Republic, and Estonia (World Bank 1995, 1996a-c, 1998a-b, 1998g; UNDP 1998c, 1998e; Braithwaite 1995; Lazutka 1999; Milanovic 1998).

- Large families are generally more vulnerable to poverty, except for Armenia, where small households have an increased poverty risk (World Bank 1996a; Braithwaite 1995).

- Single-parent families belong to the old and the new poor in Russia. This group is also explicitly mentioned for Hungary and Lithuania (Braithwaite 1995; Speder 1998; Lazutka 1999).

Education, income and employment became important determinants of poverty in the aftermath of the transition, whereas these variables were not decisive under the former socialist regimes. New poverty is characterized by a negative correlation between education and poverty. The higher the completed education, the lower the poverty risk. Examples are Kazakhstan, Belarus, Russia, Czech Republic, Hungary and Poland (World Bank 1995, 1998b; UNDP 1998c; Braithwaite 1995; Vecernik 1996; Spéder 1998; Milanovic 1998). Another major group living in poverty is formed by households with an unemployed household head or other unemployed household members. We have evidence for Kazakhstan, Belarus, Georgia, Azerbaijan, Russia, Poland, and Hungary (World Bank 1995, 1997a, 1998b, 1999; UNDP 1998c, Braithwaite 1995; Spéder 1998; Milanovic 1998). Having employment is no guarantee of being able to make ends meet due to the low wages and wage arrears. The working poor are a considerable group in Armenia, Belarus, Azerbaijan, Russia, Ukraine, Poland and Hungary (World Bank 1995, 1996a, 1996c, 1997a; UNDP 1998c; Braithwaite 1995; Speder 1998; Milanovic 1998).

The gender and age of the household head are two determinants with no decisive relation to poverty. Female-headed households have, for example, a lower poverty risk in the Kyrgyz Republic (World Bank 1998a), but are more vulnerable than their male counterparts in Belarus and Georgia (World Bank 1998c, 1999). In Russia, it is the group of female pensioners living in rural areas that is very vulnerable (Braithwaite 1995). With respect to the elderly, evidence is mixed. In Armenia, Russia, Hungary, Azerbaijan, Poland and the Kyrgyz Republic, the elderly generally have a comparatively low poverty risk, whereas in Belarus, Ukraine, Kazakhstan and Lithuania the elderly are more vulnerable (World Bank 1995, 1996a, 1996c, 1997a, 1998a, 1998b; UNDP 1998c; Braithwaite 1995; Spéder 1998; Lazutka 1999). Young adults face an explicit risk in Hungary and the Czech Republic (Speder 1998; Vecernik 1996).

Another determinant of poverty is the ownership of assets. Land ownership especially can be decisive with respect to the vulnerability of a household since it allows for subsistence agriculture. Access to land reduces the poverty risk in Georgia, Russia and Armenia (World Bank 1996a, 1999; Braithwaite 1995). 


\subsubsection{Hypotheses for Latvia}

Based on the mixed experience in other transition countries, it is difficult to establish hypotheses on poverty in Latvia. It is not possible to group the countries according to a common determinant such as region or income level. Nevertheless, based on the stated evidence, we expect the following groups to be most at risk of living in poverty in Latria:

- Households with children;

- Households with unemployed nembers;

- Houscholds with low pay employment;

- Large households;

- Rural households, since Latvia is expected to be more similar to Estonia, Lithuania or Poland.

- We expect a negative correlation between education and poverty risk.

With respect to the elderly, no clear hypothesis can be formulated regarding the very mixed evidence in countries around Latvia.

\subsection{Contributions and relevance of the study}

From an academic point of view, the novelty in approach and method resides in the following aspects. First of all, it is an empirical analysis of poverty in one country. This on its own is not new, but the development of the poverty indicator in this study based on diary data from the Household Budget Survey contains mew ellements. None of the empirical studies mentioned above adjusted the data for seasonal variation. This is an important adjustment when survey data of one survey round are collected over the period of one year. Most studies only 'report' that they adjusted for price variation over regions, but none of them provided explicitly the methodology actually used.

A new element is the questionnaire that we developed in order to gain other information than only the purely monetary aspects of Latvian households' way of living during the transition. Since there are no data available covering the whole period of (and ideally even a few years prior to) the transition, it is hardly possible to say anything about the impact of the transition on people"s standard of living. With the questionnaire we have been able to estimate the impact in a more qualitative way by trusting people's own perception of the last decade. The combination of the two data sets offers a method to evaluate the impact of the transition on poverty and on the way people make ends meet. The ideritification of winners and losers of the transition became possible. The questionnaire is easily adaptable in other countries. It provides a tool for the analysis of the effects of the economic transition on people's lives. The results found in the present study are applicable to other countries in the region in similar circumstances.

We have to be aware of the fact that research on the effects of the transition is rather new. No wonder considering the short time frame we are talking about. Only ten years have passed since the transformation started in CEE and the FSU. From a historical perspective, this is still a short period. It also indicates why we hardly know what happened to the people living in these countries. We know how the economies developed and we have a rather good view on the macro economic impact of the transition. On the household level, the situation is different. Although there have been numerous studies on poverty in these countries, the time frame analyzed covers usually a one-year period or even less. They are snapshots. We know only little about the effects of the transition at the household level, and we hardly know how the households have been dealing with the presumably harsh economic situation in their daily life. Parts of our study are so new that we have no benchmark to which we can relate and evaluate our findings. To our knowledge, this is the first 
study of this kind providing evidence of the dynamics of the transition at the household level and of the perception of the households with respect to their current situation in relation to the past.

The relevance of the study from a social and political point of view is maybe even more important. It is important for a country to know how individuals and households have been affected by the change of the economic system. A poverty assessment provides information on changes in the general standard of living, the severity and depth of poverty, the causes of poverty and it provides input into the design and/or re-design of govemment policies. Not knowing about and not being able to react to changes in the standard of living carries inherent risks. A young democracy might be endangered by unstable and worsening living conditions. Effective policies targeted at the citizens can soften the impact of unpopular policies and create goodwill. But for this purpose, knowledge about poverty and the general standard of living is essential and should be monitored and evaluated on a regular basis.

Parts of this study have been released before in the form of background papers in the context of a UNDP project or as notes written on behalf of the Latvian government. "The nesults of the study have provided input and support to:

- the development of a national poverty strategy in Latvia;

- knowledge transfer through seminars and on-the-job training to Latvian government officials and researchers;

- academic discussions of poverty-related issues in Latvia;

- the creation of awareness in the Ministry of Welfare of the Republic of Latvia of measurement issues;

- the discussion of data collection and treatment issues with the Central Statistical Bureau of the Republic of Latvia;

- a proposal on the simplification of the social assistance benefit system in Latvia.

\subsection{Structure of this study}

This book consists of five main chapters in addition to the introduction (Chapter One) and the final discussion (Chapter Seven). Table 1.4 provides an overview. Each chapter can be regarded as a selfcontained study of a research question with its own literature review, methodology, analysis and discussion. Jointly, the chapters provide the necessary input to answer the main problem as formulated at the beginning of the chapter.

Chapter two concentrates on the process of creating a welfare indicator starting with raw data from the Latvian Household Budget Survey. The indicator finally chosen and tested for its robustness serves for the further analysis in the other chapters, but most prominently in chapter three. On the road to this comprehensive measure, we have various decisions to take, starting with the concept underlying our welfare function. The choice to rely on expenditures as a proxy for consumption is based on theoretical as well as practical considerations. The chapter turns then to the actual development of the indicator. We decide which commodities enter the welfare measure. Three specific problems have to be dealt with in order to create an aggregate that represents the real ranking of households as realistically as possible: missing observations, seasonal differences in consumption behavior and price differences over region and time. The chapter provides a formall solution to the problem of seasonal variation taking heating expenditures as an example. The adjustment for regional price differences is formalized as well. Before the indicator is ready for analysis, the step from household level to individual level has to be made since we are interested mainly in the comparison of individual welfare. This is a hot topic among poverty researchers, but 
until now no satisfactory method has been developed to chose an appropriate equivalence scale in order to adjust for household size and composition. It is beyond the scope of this study to go further than a short discussion of various methods and the rationale for the choice of per capita measures.

Table 1.4. Structure of the sudy

\begin{tabular}{|c|c|c|c|}
\hline Chapter & Research Cueston & Methodolagy & Results \\
\hline 1 & Mtroduction & & \\
\hline 2 & $\begin{array}{l}\text { How to comstruct a welfare } \\
\text { indicator using micro data } \\
\text { that reflects a household"s } \\
\text { welfare as closely ans } \\
\text { posisible? }\end{array}$ & $\begin{array}{l}\text { Data: HES diary } 1996 \\
\text { Analysis: econometric models, } \\
\text { robusiness tests, mobility } \\
\text { matrices }\end{array}$ & $\begin{array}{l}\text { Value imputation, formalization } \\
\text { of price adjustments, seasonal } \\
\text { adjustment methodology, } \\
\text { preferred welfare indicator }\end{array}$ \\
\hline 3 & $\begin{array}{l}\text { Who and where are the poor } \\
\text { in Latwa? Who is most at risk } \\
\text { from a money-metric point of } \\
\text { Whew? }\end{array}$ & $\begin{array}{l}\text { Data: HBS } 1996 \text { and } 1997 \\
\text { Analysis: descriptive statistics, } \\
\text { ecorometric models; } \\
\text { hypotheses testing }\end{array}$ & Poverty profile \\
\hline 4 & $\begin{array}{l}\text { Who are the winners and who } \\
\text { are the losers of the } \\
\text { trawsition? }\end{array}$ & $\begin{array}{l}\text { Data: Poverty survey } 1998 \\
\text { Analysis: descriptive statistics, } \\
\text { econometric models, } \\
\text { hypotheses testing }\end{array}$ & $\begin{array}{l}\text { Proflle of winners and losers of } \\
\text { the transition. }\end{array}$ \\
\hline 5 & $\begin{array}{l}\text { How do Latvians cope with } \\
\text { their IIttle means? }\end{array}$ & $\begin{array}{l}\text { Data: Powerty survey } 1998 \\
\text { Analysis: descriptive statistlics, } \\
\text { aconometric models, testing } \\
\text { hypotheses }\end{array}$ & $\begin{array}{l}\text { Relevance of coping strategies } \\
\text { to make ends meet. }\end{array}$ \\
\hline 6 & $\begin{array}{l}\text { Do Latwlans furn to the state } \\
\text { for assistance? }\end{array}$ & $\begin{array}{l}\text { Data: Poverty surwey } 1998, \\
\text { HBS } 1997 \\
\text { Analysis: descriptive statistics, } \\
\text { acomometric models }\end{array}$ & $\begin{array}{l}\text { Perception of the Latvian } \\
\text { population: } \\
\text { Proposial for a simplified } \\
\text { benefit system. }\end{array}$ \\
\hline 7 & Discussion & & \\
\hline
\end{tabular}

The objective of chapter three is twofold: first, to put our preferred indicator into practice in the measurement of poverty, and second, to establish a detailled poverty profile for Latvia that identifies those groups most at risk of being poor. The availability of two full survey rounds (1996 and 1997) allows the comparison of the situation over two years. From the first chapter we know who the poor in other countries in the region are and we derived hypotheses for Latvia. We conclude that the hypotheses are correct, i.e. nural areas have a higher poverty risk than urban areas; individuals living in large households or households with three or more children, households with a young or unemployed breadwinner, and households depending on income from agriculture or social transfers are most at risk of being poor in Latvia. The negative correlation between poverty and education as well as between poverty and age is apparent in Latvia as well. An important and worrisome conclusion is that poverty has worsened over the two years, be it in terms of the number of poor people or in the depth and severity of poverty.

Chapter four and five use a completely new data set. The empirical analysis in this and the subsequent chapters is based on a special poverty survey held in 1998. We developed the questionnaire with the aim of identifying the dynamics of the transition as well as the coping strategies of the population. Chapter four concentrates on the dynamics and has the aim of identifying the winners and losers of the economic transition by comparing the current situation with the one before 1991. As an introduction to the chapter, we review general trends in the transitional impact on standards of living and the dynamics in other countries in the region. Based 
on the literature describing the situation in other coumtries, we derive some general aspects of the transition and its effect on liwing standards. The analysis of the data provided through our questionnaire provides a more subjective point of wiew on how the Latvian population perceives the changes of the last decade, and whether they perceive themselves to be among the winners or the losers. The main conclusion is that $75 \%$ of the Latvian population feels that they have lost. The chapter provides the necessary differentiation of this rather disturbing conclusion.

The subsequent question discussed in chapter five is then how households cope with the little means they have. Experience from other countries in similar circumstances indicate that coping strategies can make a difference to the daily struggle to survive. First, we define groups of coping strategies and establish a new classification system based on the literature extending other existing systems. Subsequently, the relevance of various coping strategies is analyzed using the data from the poverty survey already introduced in the previous chapter. A rather interesting conclusion is the finding that similar coping strategies are applied by the majonty of households independent of their welfare position. The distinction with poor households is the number of various coping strategies applied. For example, while richer households economize on one item, poor households economize on several products and services. They produce more than one good on their own, and they are engaged in several informal income-generating activities. Using information from the Household Budget Survey in addition, we find evidence that a change in food consumption patterns is a way to deal with worsening living standards. The poorest change their diet and increase the share of goods from own production or received through the social network.

Chapter six addresses three issues: first, is the Latvian social assistance system effective in reaching the poor and does it indeed work as a safety net, secondly, do Latvians turn to the state for hellp when they need it, and thirdly, how can the system be reformed if it proves to be ineffective. The chapter starts with a description of the current social assistance system in Latvia from the administrative point of view. Using again results from the poverty survey, the chapter illustrates how the Latvian population perceives the assistance system. The main conclusion is that a large part of the population is not informed about the services and benefits offered at the local government level. An evaluation of the current situation concludes that the system is not effective in reaching the poor. It is not the objectives of the Latvian social assistance system that are to blame, but its structure and implementation. The chapter finishes with a proposal on the simplification of the current benefit system in Latvia based on a budget-driven guaranteed minimum income concept.

The final chapter brings all the results and conclusions together in order to formulate an aswer to the main problem statement of the effects of the transition on living standards and poverty in Latvia.

\subsection{Destroyed illusions}

The first issue to be aware of is the tremendous decline in overall welfare in Latvia and other countries that have undergone a similar transition. While GDP per capita was more than 4,400 USD (1998 prices) in 1989, it was only 2,622 USD in 1998. At its lowest level in 1995, it was half the size it had been in 1989 (EBRD, 1999). Ten years ago, we were so arrogant as to think that Western style wealth would arrive soon, and that the initial drop was only temporary. But already the pure numerical facts in the form of GDP figures prove the opposite. It took the Latvian economy five years to produce positive growth rates and the price paid by the Latvian people was tremendous. For the poorest Latvians, the standard of living was still declining seven years later. Only a small proportion of the Latvian population managed so far to recover completely and benefit fully from the new market economy with its opportunities. The majority had to give up a lot. It is not only the 
monetary aspect in the form of wages and incomes that is worth considering and that counts. Other aspects weigh equally heavily. Next to the fact that norms and values have been changing rapidly, it is the loss of everyday security that contributes to the individually perceived loss of (social) wellbeing. A majority has lost faith in the state and the community. The daily struggle to make ends meet has become tougher. To put it differently, for the majority of the population life has just continued more or lless as it was, except that the level of insecurity increased.

Some groups in Latvia have been especially badly affected by the transition. Families with children, for example, often have problems to make ends meet. This may explain, together with general insecurity, why so few women decide to have children. Although the state is trying to stimulate families and assist them in different ways, people have lost their trust in state facilities and often do not even ask for assistance although they would be entitled to it. $75 \%$ of the population says it has lost compared to ten years ago, but the older generation in Latvia perceives the 'gains" of the transition to be particularly negative. Although they are not that badly off relative to other groups, $_{,}$they feel they have lost during these ten years relatively more often. This is partly explained by the life cycle, changing from an employment situation to retirement. They had to lose a lot. Some of them feel betrayed because they seem to be deprived of their well-deserved 'old days' with a secure pension.

Despite the comparatively high poverty rates according to our Western standards, no one is starving in Latvia. Everybody is surviving, but the question is "how'. The use of various coping strategies makes it possible. In this respect, not so much has changed with the change of the economic system. In order to have a "decent' life during Soviet times, the creative mind was challenged. Now, ten years later, the same still applies. It may even be the decisive factor explaining why someone is poor or not. The study shows that a majority of Latvian households is still making. use of different strategies in order to increase or maintain their standard of living. Besides having the possibility to grow food for subsistence or economize on consumption, it is especially the existence of a well-functioning social network that makes a difference. The very poor households seem to be those that cannot rely on assistance from relatives or acquaintances, those that have no possibility to economize further, because they already cut back as much as possible and those that have to create debt because they can no longer pay their rent.

These findings are the reason why this study is important. On the one hand it reveals that the idea that the transition was something like the redemption of evil, is merely an illusion. People are still struggling, and most of them are hardly in a position to take advantage of the gains of the transition. On the other hand it shows where government policies can intervene in order to ease the lives of the poorest in the society. Those that have exhausted all means to make ends meet are the ones that need assistance, but it is the wholle population that needs support and encouragement to continue and hold on until better times come. 


\section{CONSTRUCTING A WELFARE INDICATOR FOR THE ANALYSIS OF POVERTY}

\subsection{Introduction}

The measurement and interpretation of welfare has been studied by many economists. Different schools of thought emphasize different aspects of a household's well-being resulting in different welfare indicators. Such an indicator is, for example, necessary to perform poverty and inequality analysis, to assess the impact of social policies or merely to rank households or countries according to their standard of living. Welfare is an expression of well-being, or in an economist's terminology utility. Utility is then an expression of the level of satisfaction and happiness representing a household's well-being. But utility as such is difficult to measure. It requires knowledge about people's preferences and the satisfaction they get from their choices. One possibility would be to observe what people consume. This is valid under the assumption that consumers make rational choices. Then, the commodities they consume represent their choices. Following from that, we can estimate an individuals's welfare for a given period based on what has been consumed.

Since data on actual consumption on an individuall level are hardly ever available, an estimate has to be found that proxies consumption best. Data on household expenditures provide estimates that represent household consumption rather closelly. Although the approach is rather straightforward, many decisions have to be taken in the creation of a welfare measure based on household expenditures. This chapter studies the problems involved in the creation of a welfare indicator. It aims to answer the question of how to construct a robust welfare indicator using micro data that reflects the households" welfare as realistically as possible and that can be used for poverty analysis. Numerous decisions have to be taken on the road from micro-data to a sensible welfare indicator. The commodities to include, the imputation of values for goods not obtained in the market, and the adjustment for regional price variation and inflation are some of the major problems involved. What we aim to obtain in the end is a monetary measure, which is as comprehensive as possible, and that allows us to rank households from rich to poor.

The chapter is organized as follows: first, theoretical aspects of welfare and its measurement will be discussed providing a background for the practical implementation of the methodology. We can only measure welfare if we agree that welfare is measurable. The following section makes the step from theory into practice using the Latvian data as the empirical playground. All the decisions involved in the creation of the welfare indicator for Latvia, that will serve as our measure in the following chapters, will be discussed step by step. The result is a weliare indicator that is comprehensive and will be used for the poverty analysis in the subsequent chapters. It is tested for its robustness in another section. The chapter finishes with some concluding remarks. 


\subsection{Is welfare measurable?}

The aim to evaluate the standard of living of a population or just of an individual calls frrst for answers to the problem of the definition of welfare. The problem can be approached from a theoretical point of view using slandard microeconomic theory where welfare is expressed in terms of utility. Based on available means the utility level expresses the choice or the preference for goods that gives the highest utility or satisfaction to an individual. The higher the utility level, the higher the economic welfare. But welfare is not only economic well-being. A less utilitarian but more comprehensive approach to the definition of welfare would also include other aspects of well-being.

What determines a household's welfare? On the one hand, there are monetary aspects such as income, and on the other hand there are factors that are not always easily expressed in monetary terms. Housing, nutrition, and the possession of durable goods can be translated into monetary terms, but what about educational altainment or health status? It is an old and enduring question (similar to the chicken and the egg): who is better off - the rich with cancer or the poor with perfect health. Amartya Sen devoted many pages in his writings to this question $(1981,1987,1992)$. In order to answer this question we would have to value the quality of life. But this is a very personal and subjective issue that differs among human beings. There are also psychological considerations such as happiness that determine someone's well-being. Take for example political freedom which is definitely relevant in the Eastem European context and therefore also in Latvia. There seems to be a trade off that people are willing to accept between freedom of the society and worsened economic living conditions. ${ }^{1}$ The recent bistory in these countries indicates that freedom is valued higher than pecuniary wealth. The natural environment determines welfare as well, but it is not possible to attach a value to clean air or unpolluted water, although attempts are made to incorporate such notions into the calculation of national accounts (see, e.g., Hamilton 1994; UNDP, 1995 ). Expectations regarding the future, uncertainty and riskiness etc. are also ingredients that determine the well-being of an individual. These are also not quantifiable in terms of money and can be very subjective, depending on someone's own situations, his/her education, upbringing and living conditions. Some people would, for example, value the presence of children for the increased psychologic welfare.

Sen $(1984,1987)$ offered an approach summarizing the various notions of welfare. He recognized that income or consumption are not the only bliss although they enter his concept indirecly. Concepts such as utility, choice and pleasure are part of the definition of welfare, but the emphasis is on capabilities rather than commodities. It is the capability to feed oneself, to dress, to have a roof over one's head, to get oneself an education, etc. that determines an individual"s position. Although goods and commodities are necessary, it is what can be done with them that counts: "...the constituent part of the standard of living is not the good, nor its characteristics, but the abillity to do various things by using that good or those characteristics, and it is that ability rather than the mental reaction to that ability... that...reflects the standard of living.' (Sen, 1984:334). Although such a welfare concept is comprehensive, its practical application is rather cumbersome since the identification and measurement of an individual's capabilities is very difficult, if not impossible.

\section{Objective of the welfare indicator}

The question is: which aspects of welfare should be incorporated in a welfare indicator so that it is able to properly mirror the standard of living of an individual and allows the comparison and ranking of individuals? This states at the same time the conditions that a welfare indicator has to

\footnotetext{
tWithou! making any judgment about how long whe a situation is acceptable.
} 
fulfill in our case ${ }^{2}:$ i) it should mirror the standard of living, ii) it should make welfare levels comparable and allow a ranking among individuals, and iii) it should be as comprehensive as possible. A 'substitute' has to be found that approximates the level of welfare of an individual most closely. It should be objectively measurable and without subjective value judgements. ${ }^{3}$

\section{A menu of indicators}

There is a longstanding debate among researchers about which indicator best represents an individual's well-being. The above-mentioned aspects of welfare can roughly be divided into monetary and non-monetary based. Starting with the latter, social and psychological factors can be distinguished. Education and health are traditionally considered to be social indicators and efforts have been made to incorporate these aspects into welfare indicators. The Human Development Index developed by UNDP and first presented in 1990 , for example explicitly takes these factors into account by including literacy, life expectancy, and infant mortality in addition to income. The idea is rooted in the basic-needs approach, which can be related to the hierarchy of needs theory as developed by Abraham Maslow, stating that each individual is guided by certain needs and motivations. Together with biological, cultural and situational factors, they determine individual behavior. Physiological needs are lowest on the scale and dominate the other needs. If they are not fulfilled, they would drive the individual's life. Once these physiological needs are fulfilled, safety needs would become the motivating factors. On the next higher levels are the need for love, esteem and self-actualization (Miner, 1980). Maslow's hierarchy of needs became prominent in organizational behavior and marketing studies. In development economics the concept of "basic needs' is used for the definition of living standards for policy development. An example of the former application is the composition of a bundle of basic commodities and services that each individual should have in order not considered to be poor. On the policy level, the "basic-needs" approach to development was first postulated by the ILO in 1976 as the strategy to alleviate poverty and promote development (Palmer, 1977). Basic needs such as food, housing and education need to be covered first and the absence, or rather insufficient satisfaction of one or more would constrain an individual to make his/her own decisions. Several problems render this approach difficult in its application to welfare analysis. The translation of such social indicators into one single indicator that would determine an individual's welfare poses serious problems to the researcher since he has to decide on which variables to include, appropriate weights, standards and units. A certain arbitrariness is inwolved too since basic needs have to be determined first (Streeten, 1984; Glewwe and Van der Gaag, 1990; Ravallion and Bidani, 1994).

A different strand of literature advocates the concept of relative deprivation. Standard of living is expressed in terms of commodities and activities related to the society in question. The presence or absence of certain commodities that are "normal" in a given society and the possibility to actively participate in the community determine the standard of living of an individual. Festinger (1954) contributed to the development of the theory of social comparison processes in the context of opinions and abilities. He states that an individual compares his/her opinions/abilities with someone close to him-/herself. Runciman (1966) elaborated on the concept of relative deprivation and

\footnotetext{
${ }^{2}$ The emphasis could also be put on other aspects. Consider, for example, indicators needed for social policy purposes, where one may prefer the emphasis on access to and consumption of public goods. Or an indicator for "absothte" poverty antalysis may as well concentrate on basic needs only.

These judgments are those of the researcher, and it should not be confused with the subjective poverty approach, where poverty is anallyzed based on judgements of households (see, e.g., Hagenuars, A.J.M. \& varu Praag, B., 1985; Hagernaniss, A.J.M, \& de Vos, K., 1988)
} 
prowided evidence for the theory. Individuals tend to compare their own wealth with that of the others. The smaller the difference between individual wealth, the larger the tendency to compare. Townsend contributed prominently to the application of the theory to poverty analysis at the end of the '70's (Townsend, 1980). For each specific society a welfare indicator is developed based on values and norms prevalling in the community. Welfare in this context is defined in terms, for example, of the possession of certain commodities, e.g. consumer durables and the frequency with which certain activities take place within a household, e.g. inviting guests for dimer, going to the movie theater, etc ${ }^{5}$ An adwantage of such indicators is the inclusion of psychological well-being in the measure. Depending on the questions asked, various aspects of a human's life can be included and households compared. An example of such an approach is the NORBALT project that studies living conditions in the Baltic region (Aasland, et. al., 1997) ${ }^{6}$ The subject of this study is not only welfare but living conditions in a broader sense, including questions of housing, ownership of capital goods, education, labor market participation and conditions, informal economic activities, health, crime, migration, social networks and political opinions (FAFO, 1995). The same disadwantage as with the social indicators applies in this case. In order to build a single welfare indicator, arbitrary decisions have to be taken about the inclusion of variables. Choice and preferences patterns of households and individuals provide another bias to the estimated results (Callan \& Nolan, 1991).

Monetary welfare indicators seem to be more appealing at first sight since they do not have the disadvantages mentioned above. Motrey-metric measures of welfare are in the strand of the utilitarian approach to welfare. The higher the income, for example, the higher the standard of living assuming that an individual is pursuing the highest possible utility level regarding his budget constraint. As will be shown, monetary indicators need not be strictly one-dimensional. The most prominent money-metric indicators are either based on the income or the expenditures of an individual. This general statement needs some specification since it is not as simple as it sounds. Even under the assumption of perfect information, i.e. perfect data availability, the concepts of income and expenditures relevant for the measurement of welfare have to be identified.

Income is a quite commonly used indicator of living standards. In many developed countries, income data are easily accessible. The question is, what kind of income is included and whether income is the appropriate measure under al" circumstances. There are various income sources that generate reverues, and thus welfare. Income from labor, i.e salaries and wages, income from property such as dividends or rent, income from social transfers as pensions or, social benefits and income from own production sum up to the total income of an individual or household. Some data are better accessible and easier to measure than others. Welfare comparisons based on income are often based on income from labor, property and social transfers. Income in-kind, including access to free or subsidized services and income from own production, is more difficult to account for since the data requirements are considerably more extensive. A possible effect is that the welfare of an individual could be underestimated. It may not mirror the true standard of living.

Besides the problem mentioned above, other factors render the use of income as a welfare indicator problematic, some of which are especially relevant in economies in transition in particular and less developed countries in general. People have to be willing to provide information on their income. In the case of collecting information with a household survey, people may be reluctant to

\footnotetext{
"Runciman gives the credit of coining the term "relative deprivation" to Stouffer, $S$. A. et al., the authors of The American Soldier, a large-scale social-psychological sutdy of the Amnericam army carried out during the Second World War (Runcionen, 1966:10).
}

SSee for example Desai and Shah (1988) for an example of a welfare indicator based on deprivation.

"The NORBALT project is in tam based on Scandinavian living condition studies. 
reveal their true income to the interviewer (or fill it in on the form), or the provided information may not be accurate. Many people are not able to recollect the exact amount of income when asked, or they forget to mention fringe benefits, for example. Others may mistrust the objectives of the survey and fear that the provided information will end up in hands other than those of the statistician. Tax evasion, informal work, a second job, or wery high income are possible reasons why an individual may not be willing to answer or may indicate a lower figure. Another problem is the variability of income of certain socio-economic groups. Farmers are the most prominent example of variable incomes depending on the season. This holds also for people not regularly employed. In such cases, the survey data will not reveal the long-term average well-being that is of interest.

Income does not benefit a household until it is consumed. What provides a better indication of well-being, the amount of income someone has, or how much he/she consumes? The ability to generate income depends on the opportunities awailable in the market and on the 'employability' and creativity of the individual. A high income does not unconditionally mean a high standard of living. Income translates into well-being when it is consumed, i.e. the opportunities to spend income have to be present. In poor countries, for example, this fact is not self-evident. ${ }^{7}$ In terms of income, someone may be well-off. But if there is no access to goods and services, the same person may be poor compared to someone else that has access but has a lower income.

One strand of argumentation in favor of consumption as an indicator for well-being is based on the permanent income hypothesis. Since income may fluctuate and since utility within one period depends on the consumption within the same period, an indicator based on consumption is preferable to income data based on one period of observation (Lipton \& Ravallion, 1995). Another solution would be to have information about personal income at other points in time. Borrowing and saving opportunities allow a household to smooth its consumption over time independent of current income. According to Deaton (1997), the permanent income hypothesis is a weak argument to prefer consumption over income. Households may smooth their consumption over short periods but not over a lifetime. The absence of a well-functioning capital market and the availability of borrowing opportunities constrain the possibilities to smooth consumption. ${ }^{8}$ And just like income, consumption is not constant over a lifetime. Preferences and needs shift together with wealth and age. In an extreme case, a rich person could prefer to live very modestly. His/her consumption behavior might resemble that of a poor person, thereby shifting his/her ranking in the welfare distribution.

Assuming that consumption best represents the preferences of an individual and his welfare, we can estimate the level of well-being for a given period based on what has been consumed. Consumption, though, is not directly observable or only observable at very high costs. Total expenditures of an individual is a substitute and if properly measured provides a satisfying estimate of total consumption. It is only a proxy since buying a good does not mean that it is consumed immediately.

It is mainly the trustworthiness of the data that makes a strong point in favor of a welfare indicator based on expenditures. Data quality is usually better since people are less suspicious to provide detailled information about their spending habits. Diaries allow the researcher to observe what people consume, c.q. spend, over a certain period. Assuming that people make rational choices, then the commodities they consume represent their preferences. Based on that, the level of welfare for a given period of time can be estimated. This argument is along the line of Deaton

It was also not self-evident in command economies. Everyone remembers the loniz queucs in front of shops in order to obtain, e.g, a pair or shoes.

Ewen in well-functioning capital matkets, the poor will face borrowing constraints since they lack collaterall in order to get a lowin. This weakens the argument even more in the context of poverty assessments. 
and Muellbauer (1980), who stated that the most convenient scale to measure welfare is the expenditures necessary, at constant prices, to maintain a certain welfare level. Measuring welfare in monetary terms is only possible if money and welfare are uniquely linked. Since this statement is only valid for goods and services purchased on the market, the measure is limited in the sense that a household"s consumption basket is more than the total of market goods.

\section{Rationale for money-metric indicator}

The choice of the indicator depends on the objective of the analysis. It affects the results and can make a substantial difference in the identification of the poor. The ranking can be different, the population living in poverty can differ depending on the indicator applied to measure welfare (see Anand and Harris, 1994; Glewwe and Van der Gaag, 1990). Most poverty specialists nowadays agree on the preference of expenditures over income in applied empirical work (Deaton, 1997; Ravallion, 1994, 1996; Anand and Harris, 1994; Glewwe and van der Gaag, 1990; Hentschel and Lanjouw, 1996; Grosh and Munoz, 1996; Chaudhuri and Ravallion, 1994). Still, there are many considerations involved in calculating a measure that fulfils the requirements stated with the objective.

In order to make a comparison between welfare levels, real total expenditures are of interest. This means that nominal measures have to be converted into real measures using a price index. Differences in the cost-of-living can occur over regions as well as over time. Because surveys usually collect data at the household level, some rule is needed in order to assign a standard of living to the individual since the well-being of the individual compared to others is of interest in welfare and poverty analysis. The problems involved in adjusting for cost-of-living differences and in distributing the wealth among the members of a household are discussed in the section on the practical construction of a wellfare measure for Latvia.

\subsection{From theory to practice: many choices to be made}

Assume that we know how the ideal welfare indicator for Latvia should look. The objective is to get a measure of the current standard of living that is as close as possible to the ideal indicator in order to compare, c.q. rank the individuals living in Latvia. This section is sub-divided into 6 sections which will guide us through the process of creating a measure starting from a raw data base. First of all, the Latvian Household Budget Survey will be introduced. It provides the necessary data for the task. One of the first steps is to decide which commodities will be included in the welfare measure, c.q. that will be excluded due to certain reasons that will be explained. The following three steps deal with three specific problems arising from the use of this kind of data. Concretely, the sections will discuss the treatment of missing observations, seasonal variations and adjustments for price differences. The final step is then to convert the obtained measure from the household levell to the individual level leading us to a discussion on the use or non-use of equivalence scales. At the end of section 2.3 we will have created welfare indicator for Latvia which is suited for the poverty analysis in sub-sequent chapters.

\subsubsection{A short introduction to the data used}

Although Latvia has a tradition of collecting survey data of households, the changing economic and political enviromment has made it necessary to revise the existing instruments. The first data similar to what is currently understood by household surveys were collected before World War II. The sample size was very small and the results only useful for scientific purposes. Under the Soviet regime, household surveys were started in 1.952 within the system of the former Central Statistical 
Board of the USSR, the Goskomstat. Access to the data of these Family Budget Swreys was linuted to a narrow circle of users due to the stringent confidentiality assigmed to such information. The sampling technique based on a sectoral breakdown of the economy and the longitudinal character of the survey (the same household was observed over as long a period as possible) were suitable in the context of a planned economy only.

The transition from a centrally planned to a market-oriented economy made it necessary to adapt the survey to the new circumstances. Preparation for a new survey instrument started in 1994 and the actual implementation took off in September 1995. The first complete set of data was gathered in 1996 (first round).

\section{The survey}

The basic data used for the illustration in this chapter come from the 1996 round of the Latvian Household Budget Survey (HBS). The analysis in chapter three will use the 1997 round as well, and chapter four and five will use a part of the 1998 survey round. The HBS is a multi-functional household survey prepared and implemented by the Division of Living Condition and Household Budget Statistics of the Social Statistics Department of the Central Statistical Bureau of Latvia (CSB).

The HBS is a continuous survey, i.e. information from households is collected every month. One survey round takes one year to complete. Every month 666 households are interviewed adding up to 7992 households per year. In 1996, full survey information was obtained for 7524 households (CSB 1997:5)." Intentionally, it was planned that 50\% of the households that took part in the first round would form a panell to be interviewed during the next three survey rounds. The sample would be refilled with $50 \%$ of newly selected households each round. Unfortunately, this plan was abandoned already in the second year due to problems with the data quality as a result of a low response rate among the panel households.

The survey consists of two main instruments: a questionnaire and a diary. The questionnaire provides information on the household and the individuals who live in this household ${ }^{10}$ Questions on household composition, economic activity of the members, income, employment status , housing conditions and consumer durables, and a self-assessment of the standard of living form the major parts of the questionnaire. It is completed by an interviewer visiting the selected households.

The diary reveals detailed information on the consumption behavior of Latvian households. During one month a household keeps track of all monetary expenditures as well as the consumption of goods received free of charge or obtained from own production. The diary is filled in by the household and collected by the interviewer."

\section{Sampling}

The sample design differs in rural and urban areas because of shortcomings of the population register. The target population of the survey are all persons living in Latvia except those living in institutions or homeless people. In the preparation of the survey, it was decided to use the population register for the sample design. Already in the pre-pilot stage, the CSB had to acknowledge that almost $10 \%$ of the register was outdated. The search for other sources provided

\footnotetext{
Starting in 1999 , the monthly sample has been reduced to half the number of households.

${ }^{19}$ A household is defined as " . a person or group of persons tied by relationship or other personal relation:, having common subsistertice expenditures and inhabiting the same living unit (house, flat, etc.), maintenance of wheh is covered by such persons jointly." (CSB 1997:6).

"The household receives actually two diaries: one for the first 15 days of the month, and one for the second part of the month. The interviewer visits the household in between in order to assist in completing the diary.
} 
a solution for the nural areas where some parishes already had complete lists of households. In the remaining parishes such lists could easily be formed. Since this approach was not feasible in urban areas, the urban area sample design still relies on the population register.

Two-stage stratified random sampling of households is applied in rural areas. First, primary sampling units (PSU) are selected within each stratum. Usually, one parish is equal to a PSU except if the parish has less than 300 inhabitants and is therefore merged with a neighboring parish. The probability of a PSU to be selected is proportional to the number of households in the PSU. The complete lists of households of each selected PSU forms the basis for the second stage of simple random sampling.

Urban areas are divided into strata according to their size and their location, with Riga being divided into 6 strata and each of the six largest towns being an additional strata. At the first sampling stage, the PSU's are selected with a selection probability according to the number of inhabitants in the PSU. The second stage involves simple random sampling of persons of 15 years and older based on the population register. The household of the sampled person is then surveyed. A more detailed description of the survey and the sample design is provided by the CSB (1997).

\section{Adjustments}

Considering the fact that the present survey was rather new in 1996, the experiences made during the first round of the survey resulted in adjustments to the questionnaire and the diary. For the purpose of the analysis presented in chapter three, it is important to know that the employment section of the questionnaire was completely revised after 1996. The respective information is therefore not comparable over the two years. Another change in 1997 is related to the information on the possession of consumer durables. While the 1996 questionnaire only asked for the presence of the good in the household, the 1997 version also asked about the functionality (see the complete 1997 questionnaire in Annex A). A major change was implemented in 1998. The length of diarykeeping was reduced to two weeks for food items, while information on non-food items is still collected for one full month.

\subsubsection{Goods and services entering the welfare function}

The completed diaries of the Latvian Household Budget Survey offer a rich body of data to construct a welfare indicator based on consumption and expenditures. The goal is to calcullate total actual consumption which is the sum of the values of all goods and services used by households in a given period of time, adjusted for price differences and variations in household composition (Grosh \& Munoz, 1996)

Total actual and implicit expenditures necessary to acquire the goods and services are used to estimate total household consumption. A household is defined as people sharing common resources. The period of observation is one month, and the prices are those experienced by the household. In case of a purchase, it is the actual price paid, and in case of own produced goods or goods received free of charge, it is the price the household would have to pay in the market indicated by the household itself. Expenditures are then defined as quantity times the price.

An important step in the construction of the welfare indicator is to define which commodities have to be considered and the expenditure items that enter the consumption function. In the microfiles of the diaries all items purchased ar received for free or taken from own production during the survey month are listed per household. The aim is to create expenditure aggregates for different commodity groups per household. The two main groups that usually account for the largest part of a household's expenditures are food and housing. Other expenditure groups that are part of the welfare function are health, transport, education, furnishing, leisure, and catering. Items that are not included due to several reasons are durable goods, taxes, and public goods. Also excluded are all 
goods purchased or used as a gift, since a gift is not necessarily consumed in the same household. Not excluding gifts could theoretically result in double-counting of the commodity at an aggregate level since it might appear in the receiving household as good received without charge.

\section{Food}

Food is a fundamental basic need and maybe the most important input into the consumption function. The share of food to overall expenditures or income is often used in poverty analysis to identify the poor population. This approach has a long tradition and goes back to Engel's pioneering work that he presented. in 1895. He observed that in poorer households a larger share of total expenditure is spent on food than in richer households (Deaton \& Muellbauer, 1980:193). Early poverty studies were based on Engel's idea to derive poverty lines that depend on the food-income ratio.?

More recently, other welfare indicators based on food hawe been developed. Anand and Harris (in Chaudhuri \& Ravallion, 1994:370) propose to use food consumption per capita as the solte welfare indicator since food consumption is less variable over time. The problem with this approach is the neglect of other basic needs such as clothing or shelter. The food-poor may not be poor with respect to other basic needs and vice versa. The propensity to consume food may vary between households (Gllewwe \& van der Gaag, 1990:805). In the case of a declining standard of living of: a household, the decision on what good's consumption should be reduced first depends on household composition, socio-economic factors and culture. Evidence from Latvia (Institute of Philosophy and Sociology, 1998) indicates that pensioners cut back on food first in order to be able to pay their housing and utility bills. Families with children, on the other hand, first reduce expenditures on everything else but food.

As mentioned above, the welfare indicator that will be used in this analysis will include more than food expenditures. Nevertheless, food remains an important commodity group and will later on be used to determine price indices (see section 2.3.5). All food items are included in prices and quantities as reported by the household. Since households estimate the value of food conmodities derived from own production or received free of charge by themselves, the price as indicated by the household is used for the calculation of the aggregate. Households are asked to attach the value they would face on the market when they would have to purchase the commodity. The approach is straightforward except for certain storable commodities. Taking potatoes as an example, some households report within the reference period a quantity purchased or received from own production that exceeds the possible consumption within one month. It is obvious that the commodity is stored and consumed during more than one reference period. The question is whether this forms a problem in this context and how these oufliers should be treated. Unfortunately, the available survey instrument does not provide any information about the actual consumption within the month of observation or whether the good has been purchased with the intention of later use. Any decision by the researcher on the treatment of such values is arbitrary and based on judgement. If only the consumption of potatoes would be at stake, the values could be left as reported assuming that over the whole survey period of one year, the effect would be averaged since some households are not reporting any consumption of potatoes within their reference period. But if these values enter the welfare function, the ranking of households in terms of their standard of living is affected. There are only two goods that cause concern in the Latvian data: potatoes and eggs. A small number of households reported a purchase or receipt far above the average amounts of these products. Experts

\footnotetext{
${ }^{12}$ Rowtmee with his study of powerly in York in 1899, and Orshansky with lyer poverty standard for the United States in 1960 are among the most prominent examples (Atkinson, 1983).
} 
from the CSB forwarded the following possible reasons for such outlers: ${ }^{3}$

i) Urban houscholds receive quite often potatoes and other agricultural goods from their relatives or friends living in the countryside. Quantities can exceed 50 kilograms a time.

ii) During harvesting season, urban households purchase large quantities of potatoes and cabbage at a low price as stock for the winter.

iii) Employees of egg processing companies and the households living in their neighborhood have the possibility to purchase lump quantities of eggs at a low price.

iv) Undiscovered mistakes in the data set, e.g. When agricultural output was recorded in the diary section for personal consumption.

A decision had be taken on the treatment of such outliers since they would seriously disturb the rank of these households. A graphical analysis using the logarithm of the per capita quantity of all households in the survey provided a guideline. An arbitrary cut-off point has been set for these goods and the values that exceeded the cut-off line were treated as missing observations in the further analysis.

\section{Housing}

Housing is another good that is considered to be a basic need. Housing costs consist of rent or an equivalent in case of privately owned premises and utilities. Utilities include expenditures for electricity, water, heating, gas and other fuels, and other services related to the dwelling. All these items enter the welfare function. Rent is only incurred by those households that actually rent their dwelling. People that own their house or apartment have no equivalent payments to make but they benefit from their dwelling in the same way as a renting household. In order to generate a comparable measure for the utility derived from housing services, all households have to be treated the same way. In the absence of any information about the walue of an owner-occupied house, a price has to be estimated that represents the rent a household would have to pay under the same conditions. On the imputation of rent, the reader is referred to section 3.3 .4 below.

\section{Durable goods}

Durable goods are defined as goods that will serve a household during a longer period of time, usually for a couple of years. Examples are refrigerators, cars, washing machines, stereo equipment, etc. The purchase of such a commodity can be regarded as an investment. Expenditures reported on the purchase of such items are deliberately not included in the welfare measure. If included they would distort the true ranking of the household. The standard of living would be overestimated due to the usually high value of such goods. Suppose a household happens to buy a car during the reference period. This expense might push the household toward the top of the welfare distribution although this does not represent its average standard of living. Nevertheless, a household that is equipped with a car, derives utility from its use. Therefore, it is more appropriate to include a measure of 'use' in the welfare indicator, such as an amortization value of the respective commodity (Slesnick, 1994; Grosh \& Munoz, 1996). In order to derive such a value, information on the presence of durable goods in each household, the year of purchase, and the price is needed. Unfortunately, the Latvian HBS data do not offer such information. Therefore, the decision to neglect the expenditures on durable goods has been taken.

\footnotetext{
"This information was provided by E. Vaskis, CSB Latvia, and mansfered by email (August 26, 1997).
} 
Taxes, social security contributions and public goods

Taxes as well as social security expenditures are not taken into account in the expenditure calculation because they are considered savings rather than consumption (Slesnick, 1994). Inclusion of tax payments would interfere with tax compliance in a country and conld thereby blur the comparison. The relative position between compliant and non-compliant households would be disturbed (World Bank, 1996b).

In the case of public goods, we are confronted with a valuation problem as well. Although it would be desirable to include the consumption of public goods, it is difficult to do so since wre would need information about the costs of these goods and the exact use made of them (Grosh \& Munoz, 1996).

\subsubsection{Specific problem 1: Imputing values for missing observations}

A closér look at housing costs reveals two different problems regarding missing observations. Furst, there are households living in private houses that obviously do not report rent expenditures. About one forth of Latvian households live in a private house or apartment. As discussed above, in order to arrive at a true ranking of households with respect to their standard of living, a value has to be imputed representing the rent they would have to pay for their apartment if the household would have to rent on the market. The solution to this first problem is rather straightforward. Based on actual reported expenditures for rent, values can be estimated for house owners taking into account various characteristics that influence the price of an apartment. A linear regression model provides estimates of the parameters that enter the welfare function. The ranking of households would be according to their standard of living.

$$
y_{i}=\beta x_{i}+\varepsilon, \quad \text { with } i=1,2, \cdots, n
$$

$$
\begin{array}{ll}
y_{i} & \text { actual reported expenditures of household } i \\
x^{\prime} & \text { a vector of explanatory variables } \\
c_{i} & \text { enor tem, with } \varepsilon_{j}-\mathbb{N}\left(0, \sigma^{2}\right) ;
\end{array}
$$

Model [2.1] is not completely satisfying regarding the variables included. A log-linear regression model is preferred regarding the distribution of the actually observed values. The logarithm of the reported expenditures has a more nomal distribution since extremely large values are proportionally smaller. The estimates will therefore better reflect reality. In order to have coefficients that are directly comparable, all continuous variables enter the model in logarithmic form. Categorical variables are transformed into dummy variables. The log-linear model takes then the form

$$
\ln \left(y_{i}\right)=\beta_{0}+\beta_{1} \ln \left(x_{1, i}\right)+\ldots+\beta_{k} \ln \left(x_{k, i}\right)+\alpha_{1} D_{1, i}+\cdots+\alpha_{i} D_{l_{k}, i}+E_{i}
$$

$$
\begin{array}{ll}
y_{i} & \text { achal reported expenditures of household } i \text { with } i=1,2, \ldots, N \\
x_{k, i} & k \text { explanatory continuous variables of household } i, \text { with } k=1,2, \ldots, K \\
D_{1, i} & \text { I dummy variables for household } i \text {, with } I=1,2, \ldots, L \\
\varepsilon_{i} & \text { error term, with } \varepsilon_{i} \sim N\left(0, a^{2}\right) \text {; }
\end{array}
$$

Model [2.2] is estimated with OLS using either quarterly or yearly data. The regression results (see appendix $2 \mathrm{~A}$ ) show that most of the variables included are not significant for the estimation of rent prices. Wald tests for various groups of variables indicate that the size of the settlement is not significant $(\mathrm{p}>\mathrm{F}=0.685)$ as opposed to house type $(\mathrm{p}>\mathrm{F}=0.000)$ and wall material $(\mathrm{p}>\mathrm{F}=0.002)$. 
All other variables are not significant at the $5 \%$ significance level. Not even the size of the rented premises has an influence. The next step is to predict values for those households that are living in privately owned houses or apartments. Table 2.1 summarizes the result after implementation of model [2.2].

Table 2.1. Laivia: Summary statistics for rent payments, first quarter 1996, not weighted

\begin{tabular}{llllll}
\hline & $\begin{array}{l}\text { Sample } \\
\text { size }\end{array}$ & $\begin{array}{l}\text { Mean } \\
\text { (std. dew.) }\end{array}$ & Median & Min. & Max. \\
\hline Observed rent of renting households & 801 & $\begin{array}{l}4.26 \\
(3.51)\end{array}$ & 3.53 & 0.90 & 40.00 \\
Estimated rent of renting households with & 478 & $\begin{array}{l}3.33 \\
(2.61)\end{array}$ & 3.21 & 0.72 & 53.36 \\
missing observations & & $\begin{array}{l}4.56 \\
(5.29)\end{array}$ & 3.15 & 0.70 & 79.72 \\
Estimated rent for priwately owned houses & 487 & & &
\end{tabular}

SOUrce: HBS 1996

The second problem is more difficult to deal with. As Table 2.2 shows, only about two thirds of the households living in a rented apartment actually report expenditures on rent. The same applies for other utilities.

Table 2.2. Reported expenditures for rent and main utilities as a proportion of households supplied with them (sample population).

\begin{tabular}{lc}
\hline 1 tem & Proportion reporting expenditures \\
\hline Rent & 62.4 \\
Electricity & 7.8 \\
Gas from network & 68.6 \\
Cold water & 51.7 \\
Hot water & 44.7 \\
Central heating & 50.4 \\
Teliephone & 74.8 \\
\hline
\end{tabular}

Source: HBS 1996

Several possible reasons could serve as an explanation. First, payments may not be monthly. In this case, if it happens that a household payed for rent and utilities just before or after the survey month, no expenditure is indicated in the diary. Second, a household may be in arrears with its payments. This is a realistic assumption regarding the Latvian situation as experts from the Central Statistical Bureau indicated. Accumulating debts is one of the coping strategies applied by households as chapter tive will show. It is impossible based on the survey data to gain any information about delays in payment. Does it matter? A possible argumentation would go as follows: even if households do not pay their bills, they enjoy the utility of their housing. They are creating debt, consuming the service now, but paying for it later. It is exactly the same argument as why consumption is preferred to income as welfare indicator. In this sense, the households should be treated as if they pay for their housing, i.e. rent is imputed based on an estimated model as is the case with privately owned houses. Another argument in favor of this approach is derived from the fact that we do not know whether the reported payments are payments for the actual month or a payment for an arrear. Model [2.2] is therefore also applied in this case. The dependent variable $y_{i}$ which represented rent in the section above, can be substituted by expenditures for electricity, gas or water. The explanatory variables will be chosen based on their possible influence on the expenditures in question. 
In the case that bills are usually paid bi-monthly, the situation is different. Two issues are at stake, i.e. the true standard of living and the ranking of the households. Starting with the latter, it can be argued, that it does not matter. Assuming that the reported observations are monthly payments (even if they are not), and estimating missing values based on the available sample, the ranking of the household is still correct because the underlying assumption is the same for all households. The other issue is the true standard of living expressed in monetary terms. These values may be overestimated in that case, since we add housing expenditures for two months instead of for one, therefore exaggerating the actual expenditures of the household. To solve this problem, a correction for the frequency of payments has to be developed and applied to the data, both the actually observed data and the estimated values. After this treatment, the values expressing the welfare gained from housing are better representing the actual utility.

First, the xverage payment frequency per month of an expenditure item, say rent, is calculated ${ }^{14}$.

$$
P_{m}=\frac{(\# \text { of households reporting rent in month } m)}{(\# \text { of households renting in month } m)}
$$

The monthly average payment frequency is then equal to

$$
P_{n}=\frac{1}{m} \sum_{m=1}^{12} P_{m} \quad m \in\{1, \cdots, 12\}
$$

After having estimated the rent using Model [2.2], the resuit has to be adjusted with the calculated payment frequency:

$$
\hat{y}_{i}^{\prime \prime}=\hat{y}_{i} P_{\overline{m i}}^{n}
$$

In the Latvian context it is safe to assume that the missing observations with respect to the payment of rent and utilities are due to payment arrears since it is customary to pay these bills monthly, which makes an adjustment as described with equations [2.3] - [2.5] redundant. As an example, appendix $2 \mathrm{~A}$ shows the results of the OLS estimation for the model for electricity expenditures. Houschold size and area are significant at the $1 \%$ significance level. A series of variables has been included in order to account for the presence of various electrical household appliances, assuming that they would lead to an increase in the electricity bill. Separately, the coefficients are not significant, but a Wald test rejects the hypotheses that all these variables together are equal to zero.

\subsubsection{Specific problem 2: Seasonal variation}

Nevertheless, the approach as described in section 2.3 .3 is not appropriate in all cases. An additional difficulty enters the model in the case of seasonal effects. Some expenditure categories show a seasonal pattern which creates a problem for the comparison of households that are interviewed at different points of time during the year. The best example are expenditures for heating which are naturally only observed during the cold seasons. Households that have been interviewed during the summer months hardly report expenditures on central heating. Does this mean, that the "winter" households are better off than the 'summer' households because they have on average higher expenditures? Purely analyzing their actual expenditures, we would be inclined to say so. In order to be able to compare households with each other, some basic conditions have to be the same for

\footnotetext{
${ }^{14}$ If the pattem proves the be highly irregular, it would be better to take the yarly average, $P_{y}$, and then divide by twelwe.
} 


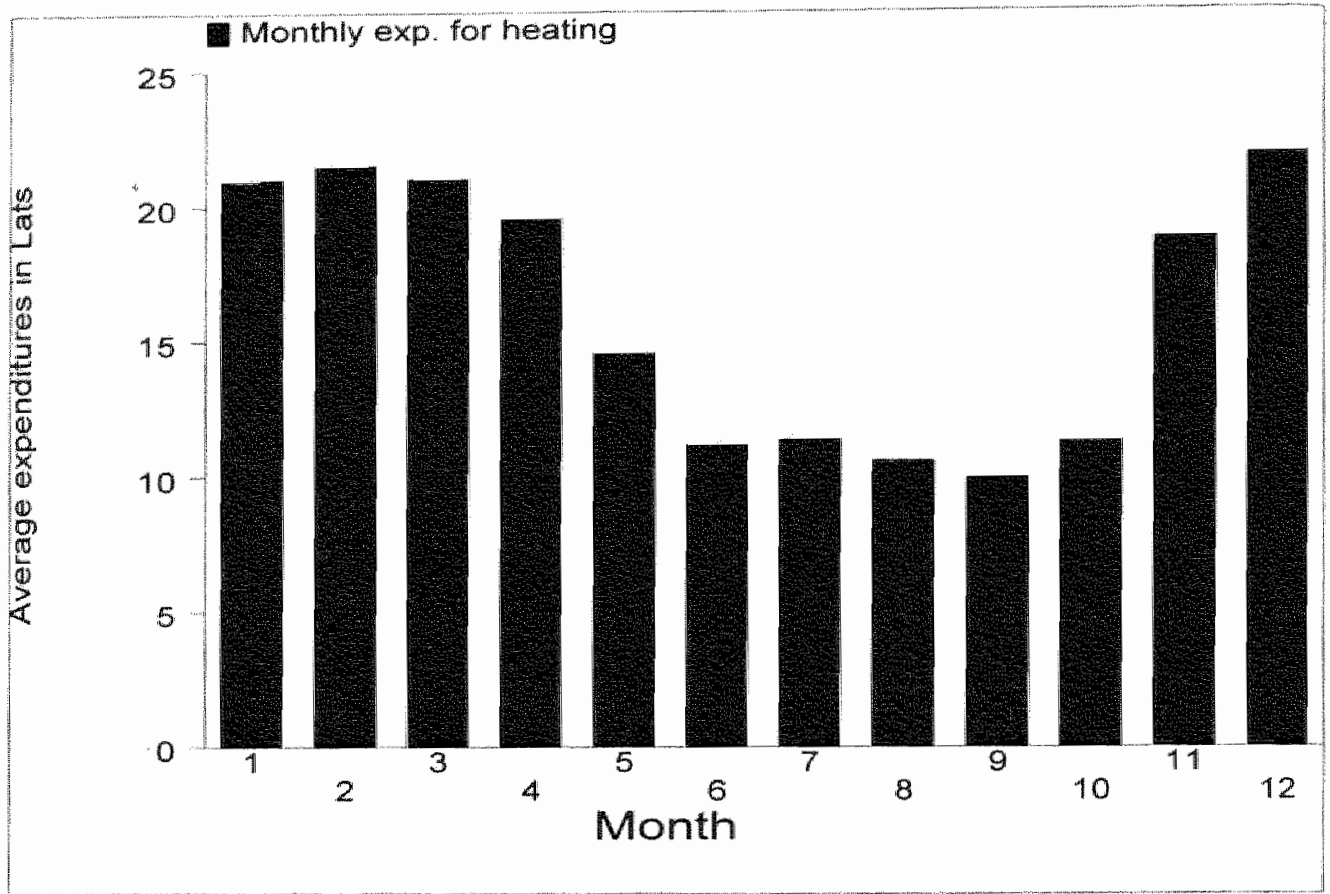

Figure 2.4. Seasonal pattem of central heating axpenditures, 1996

Souroe: HBS 1996

all households. This leaves two choices: either we compare only monthly or quarterly samples, or we adjust for differing conditions. The analogy can be found again in the example of the rented and owned apartments. We either compare only households that rent, or we impute a value for houses owned. Different possibilities are available to make the households comparable. First, as described above, we can estimate the heating costs of those households that report no expenditures based on the observed walues. We just pretend that all households have been interviewed at the same time. This would attach an average to those households with missing values. This approach has its disadvantages since the ranking would be affected and the estimated expenditures would be too high (or too low) for certain househoids.

A more sophisticated approach analyzes first the seasonal pattern of the heating expenditures. Figure 2.1 plots the average expenditures for central heating of the households in 1996.

Seasonality is a phenomenon regularly observed in data analysis. The literature usually treats the subject in the context of economic time series and business cycles (see Jaditz, 1994; Moehrle, 1994). Three main factors have been identified that are responsible for the emergence of a seasonal pattern: i) the weather has its influence through the various seasons and the prevailing temperature, ii) calendar events such as Christmas or Easter can influence consumption behaviour and iii) social conventions, e.g. taking vacation during school holidays, can boost certain expenditures.

In the case of heating expenditures weather is the explaining factor that influences a household's behaviour and the seasonal variation. The question is now, how to treat this seasonal effect. There are several possibilities. A reference month could be assigned, say January. Januaryhouseholds would then be used to estimate heating expenditures for all other households using econometric analysis to predict the expenditures for non-January households. This approach has the 
advantage that it is rather straightforward and easy to apply. But the disadvantage is far more serious. The number of observations available in January is only a small proportion of the total number of households for which a forecast has to be calculated. The result would not be very accurate. The proposed solution below takes several steps in order to arrive at a comparable variable. The idea is to estimate first the annual consumption of central heating based on the available data of all months. Having found the annual value, monthly expenditures are just a twelfth of the total and will be the amount entered into the welfare function.

Before starting, a further distinction has to be made between households that report expenditure on central heating and those that have no entries although they have heating at their disposal. In the case of the former, the procedure starts with estimating a model that explains central heating costs including dummy variables for the months. Again it has been decided that a logarithmic model better, represents the expenditure function.

$$
\mathcal{c}_{m}=\alpha_{m} D_{m}+\beta x^{n}+\varepsilon_{m} \quad \mathbb{E}_{m} \sim \mathbb{N}\left(0, \sigma^{2}\right), \quad m \in\{1, \cdots, 12\}
$$

$c_{m} \quad \ln \left(C_{m}\right)$ with $C_{m}$ equal to observed expenditures in month $m$ for one household;

$\mathrm{D}_{\mathrm{m}} \quad$ dummy variable; 1 in month $\mathrm{m}, 0$ otherwise;

$x$ vector of explanatory variables for the household;

Estimating the model with OLS, results in the following equation:

$$
\hat{c}_{m}=\alpha_{m} D_{m}+\beta x^{t}
$$

$c_{m}$ is the estimated expenditure for a given household based on various household characteristics and the month of observation. $\alpha$ is the estimated month effect that is dependent on the month of observation.

$$
c_{m}=\alpha_{m} D_{m}+\beta x^{\prime}+\hat{\varepsilon}_{m}
$$

The residual $\hat{\varepsilon}$ can be interpreted as the preference of a given household with respect to their heating consumption, i.e. the temperature, efficiency of the heating system, insulation or the presence of a meter. Given the average expenditures of all households with the same characteristics (i.e all $x$ are equal) surveyed in the same month, the residual accounts for the difference in preference. Appendix 2A shows the OLS results of model [2.8]. Except for February, March and December, all coefficients for the nonthy dummy variables are significant at the $1 \%$ level. The reason for the insignificance of February, March and December is most probably the result of similar heating expenditures as in the reference month January.

So far, only monthly expenditures thave been at stake. A procedure has to be developed in order to derive an estimate for yearly expenditures for a given household. Suppose there is one household observed in month $\mathrm{m}$. Its estimated consumption of heating in January would then be

$$
c_{1}=a_{1} D_{1}+\beta x^{\prime}+\hat{\varepsilon}_{m}
$$

Substituting for $\hat{\varepsilon}$ with $\left(c_{m}-\alpha D_{m}-\beta x^{t}\right)$ then results in 


$$
c_{1}=c_{m}+a_{1} D_{1}-a_{m} D_{s}
$$

For each month a similar equation can be written just by exchanging the subscripts with the number of the respective month. Using this set of equations the expenditure of a household can be estimated for each month of the year. In order to arrive at yearly expenditures, the monthly estimates have to be summed up and transformed from logarithms to the monetary equivalent by exponentiating the result. The annual central heating expenditures for one household, $\hat{Y}_{c / f}$, can then be expressed as

$$
\hat{Y}_{c k}=\sum_{k=1}^{12} e^{a_{m}}=\sum_{m=1}^{12} e^{a_{m} D_{m}+\beta x^{k}+\tilde{\varepsilon}_{m}}=e^{\beta x^{k}+\hat{\varepsilon}_{m}} \sum_{m=1}^{12} e^{\alpha_{m} D_{m}}=e^{c_{m}-\alpha_{m} D_{m}} \sum_{m=1}^{12} e^{a_{m} D_{m}}
$$

The monthly value that will enter the welfare measure is then simply the yearly expenditures divided by twelve.

$$
\begin{gathered}
\hat{C}_{\overline{m i}}=\frac{\hat{Y}_{c h}}{12} \\
\hat{c}_{7}^{\prime}=\alpha_{7} D_{7}+\beta x^{3}
\end{gathered}
$$

In case that households have not reported expenditures for central heating but say to be equipped with it, the average monthly consumption is based on the estimated monthly consumption as derived with equation [2.2]. The estimated consumption for such a household in the month July, as an example, would be equal toand the yearly estimated consumption is

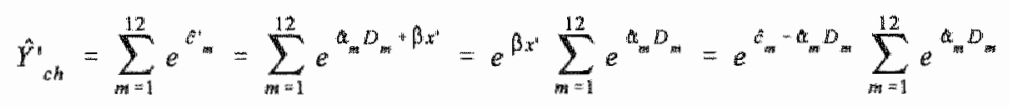

Finally, the average monthly expenditures for those households with missing observations are derived as in equation [2.7].

A final note has to be made with respect to seasonal patterns. Assume a household that happens to be interviewed in July or August. There are no heating costs incurred and it can be assumed that the household is aware of that since the summer season returns every year. Could it be that the household substitutes this 'saved' money with other expenditures? If this would be the case, then the adjustment for the missing heating costs would result in an overestimate of the real standard of living of this houselnold. It is difficult to make any inferences about this possibility. A look at the data indicates, that such a substitution does not seem to take place. Total average monthly expenditures per capita without utilities were compared. If substitution would take place, one would expect the average expenditure level to be higher in the hot season than during the winter months. This seemed not to be the case. 


\subsubsection{Specific problem 3: Price variation over region and time}

The cost of living usually varies across geographical areas due to price differences. Consider for example fish which may be cheaper along the shore than in the countryside. Rural areas usually have a lower cost of living than urban areas certainly as far as indigenous agricultural products are concerned. The opposite may be true for imported or processed goods that due to transportation costs have lower prices in urban areas. Geographical differences in the cost of living can be taken into account by adjusting the welfare measure with a regional price deflator assuming that most households purchase their commodities within the region they are living. The objective is once more to make welfare levels of households comparable and this means that regional price differences have to be taken into account and be adjusted to a national weighted average. One possible procedure for the calculation of a regional price deflator is described below. The notation to be used is as follows:

$\begin{array}{ll}\mathrm{p} & \text { price } \\ \mathrm{q} & \text { quantity } \\ \mathrm{a} & \text { expenditures with } \mathrm{a}=\mathrm{p}^{*} \mathrm{Q} \\ \pi & \text { price index } \\ \mathrm{i} & \text { subscript for commodity } \mathrm{i} \text {, with } \mathrm{i}=1,2, \ldots, \mathrm{N} \\ \mathrm{h} & \text { subscript for household } \mathrm{h}, \text { with } \mathrm{h}=1,2, \ldots, \mathrm{H} \\ \mathrm{r} & \text { subscript for region } \mathrm{r}, \text { with } \mathrm{r}=1,2, \ldots, \mathrm{R}\end{array}$

Store prices most accurately reflect the differences in cost of living with respect to the purchase of commodities a household is confronted with. In the absence of such information, the prices reported by the households themselves have to be taken as the base for the derivation of the deflator. The price is then equal to the unit value that is derived from the expenditures and quantities as reported by the household. The unit value of a commodity in one household is equal to the total amount spent on this commodity divided by its quantity. ${ }^{15}$

$$
P_{i, h}=\frac{a_{i, k}}{q_{i, h}}=\text { unit value }
$$

The national average price of commodity $i$ is equal to

$$
P_{i}=\frac{\sum_{h} a_{i, h}}{\sum_{h} q_{i, h}},
$$

which is a price average weighted by the quantity a household consumes of commodity $\mathrm{i}$. Households that consume a larger quantity have a greater weight in the determination of the national average price. Hence, price index for commodity $\mathrm{i}$ and household $\mathrm{h}$ is

$$
\pi_{i, h}=\frac{P_{i, h}}{P_{i}}=\frac{a_{i, h} / q_{i, h}}{\sum_{h} a_{i, h} / \sum_{h, h} q_{i, h}}
$$

\footnotetext{
${ }^{15}$ Arnount and quantity are defined as being the total amount and quantity of a good purchased as well as from own production or received free of charge.
} 
The regional average price for commodity is calculated using as a weight the quantity household h consumed of commodity i as a ratio of the total quantity of commodity i consumed by all households in region $r$.

$$
P_{i_{i},}=\sum_{h \in R} \frac{q_{i, h}}{\sum_{h \in R} q_{i, h}} P_{i, h}
$$

Similarly, the price index for commodity $i$ in region $r$ is the price of $i$ in region $r$ divided by the national average price $P_{i}$

$$
\pi_{i, r}=\frac{P_{i, r}}{P_{i}}=\sum_{h \in R} \frac{q_{i, h}}{\sum_{A \in R} q_{i, h}} \pi_{i, h}
$$

The final step is the aggregation over commodities in order to arrive at an overall regional price index. Since the various goods have different measurement units, the weight that will be used for the calculation of the index has to switch from a quantity based weight to a budget share weight. The sum over the budget shares of commodity $i$ in region $r$ multiplied by the regional price index for commodity $\mathrm{i}$ is the final overall regional price index that will be used for the adjustment of household expenditures:

$$
\pi_{r}=\sum_{i} \frac{a_{i, r}}{\sum_{i} a_{i, r}} \pi_{i, r}, \text { with } a_{i, r}=\sum_{\text {HeR }} a_{i, h}
$$

Under ideal circumstances, all goods that enter the welfare function would be used to calculate the above developed price index. In reality this is not possible since unit values cannot be derived in all cases from the survey data. Often, only expenditures have been recorded by the household without any information being given about the quantity purchased. After examination of the data, it had to be concluded that only food items could be used for the development of the regional price index since this was the only commodity group with sufficiently detailed information. In the context of the analysis to be performed, analyzing poverty, this fact does not constitute a problem. The poor are of most concern. Their expenditure pattern should anyway dictate the items included in the calculation of the deflator. Grosh and Munoz (1996), for example, propose to use the budget shares of the bottom 40 percent of the population or, even better, those of the poor to determine the cost of living index. In the Latvian case, budget share analysis shows that more than $70 \%$ of the households spend more than $50 \%$ of their monthly total expenditure on food (Gassmann 1998). The Central Statistical Bureau of Latvia even reports a share of more than $60 \%$ for food for the poorest $30 \%$ of the households (CSB 1997b:98).

Table 2.3. Regional price deflators per quarter, 1996

\begin{tabular}{lllll}
\hline & Q1 & Q2 & Q3 & Q4 \\
\hline Rigas region & 1.03 & 1.04 & 1.02 & 1.03 \\
Kurzeme & 1.01 & 0.99 & 1.00 & 1.00 \\
Vidzeme & 0.99 & 1.00 & 1.03 & 1.01 \\
Zemgale & 0.97 & 0.99 & 0.98 & 0.98 \\
Latgale & 0.97 & 0.94 & 0.96 & 0.96 \\
\hline
\end{tabular}

Source: HBS 1996 
Regional price deflators have been calculated for every quarterly sample and the household's expenditures have been adjusted respectively. Table 2.3 summarizes the regional price deflators calculated according to the presented method for the four quarters of 1996.

In the light of the Latvian survey set-up where households of one survey round are interviewed throughout one year, an adjustment for price variation over time had to be done as welt, taking into account the inflation rate of 13 percent for 1996 (Ministry of Economy 1997:19). The official consumer price index as published by the Centrall Statistical Bureau of Latvia has been used to deflate the welfare measure to the January 1996 level (CSB 1997c).

\subsubsection{From household to individual: the crux of equivalence scales}

At this point of our journey from raw data to a sensible welfare indicator a decision has to be made on how to make a transformation from household to individual level. Although the comparison of household welfare would be very simple it could provide rather misleading results with respect to the ranking of individual welfare. A rule is needed to attribute household welfare to the individual (Deaton \& Paxson, 1995). The subject is rather controversial since any rule has to make assumptions about how the resources are shared within a household.

The two most opposing points of view are to take total household expenditures as an expression of individual welfare or per capita household expenditures. The belief behind the former theory assumes that family size is a matter of free choice and therefore represents the preference of a household (van Praag, 1994). The latter wiew assumes an equal proportion of welfare had by each individual in the household independent of sex or age. It assumes perfect intra-household equality where everyone needs the same and gets the same. But most of the relevant literature agrees that a per capita division of welfare does not respect differences in household size and composition (see, e.g., Deaton, 1997; Ravallion, 1994; Lanjouw \& Ravallion, 1995). They assume that there is a relationship between total household welfare and demographic composition (e.g. the presence of chilldren) and household size. Deaton (1997) argues that per capita measures overstate the cost of children since they consume less, and understate the welfare levels of large families relative to small farmilies. The latter argument is based on the theory of economies of scale which can be realized with public goods. Examples for public goods in a household are rent, various utilities such as electricity, gas or water and transportation. With increasing household size, the consumption of these goods does not increase proportionally. To come back to the opposing points of wiew in terms of public versus private goods, total household welfare would be the appropriate standard if all goods consumed in a household were public. The per capita measure is the correct one if all goods were private, such as food. These are all arguments in favor of an equalization scale which is defined by Blundell et. al. as follows (1994:8): "Equivalence scales are defined as the proportionate increase (or decrease) in income necessary to maintain a certain level of household welfare in the face of some variation in demographic circumstances. The scalles are usually expressed in adult equivalents taking into account household size and composition. Normalizing total household welfare with the scale value provides then comparable welfare levels for one adult equivalent.

There have been various methods developed in order to create such an equivalence scale. On the one hand there are ad-hoc definitions such as for example the very popular and widely applied OECD three-value scale (Nelson, 1992). ${ }^{16}$ On the other hand there are methods that use household budget data in order to derive the appropriate scale. Deaton (1997) describes and criticizes the foodshare method based on Engel's law as a way to estimate equivalent scales for a population. According to the theory of economies of scale we expect the share of non-food expenditures to decrease with increasing household size. As a result, the food-share of these households increases

${ }^{16}$ OECD scale values family members as follows: 1 . adult $=1$; other adults $=0.7$; children $=0.5$. 
proportionately, which would then be interpreted as having a comparatively lower standard of living according to Engel but not according to standard adult equivalence scale theory. A slightly different approach, the Rothbarth method (see Deaton, 1997; Deaton \& Paxson, 1995) uses adult-goods only as non food items in order to estimate changes in consumption patterns between different households. Still, the results are not satisfying. According to Blundell et. al. (1994), we would need an inter-temporal setting to estimate correct equivalent scales. Only when we follow households over time including a change in composition, can the change in consumption be truly estimated. But such an endeavor is only possible in case of available panel data over a considerable period of time. Conniffe's argument against the calculation of standardized scales is that scales should vary with the income of reference houscholds. Rich households need a different scale to poor bouseholds regarding the differences in consumption patterns (Conniffe, 1992). Van Praag shares this opinion by stating that there is no scientific reason to assume a uniformly valid equivalence scale (van Praag, 1994).

Others recommend that the influence of various elasticities on the welfare ranking of households be estimated empirically by applying a selection of different scales between the two extremes (Lanjouw, et. al, 1999). This trial-and-error method should then indicate at which level relations are changing, i.e. where the ranking of households is changing due the application of different scales. The equivalent income (or expenditures) can be expressed formally as follows:

$$
E_{i}=\frac{y_{i}}{s_{i}^{\theta}}, \quad \text { with } 0 \leq \theta \leq 1 ; i=1,2,3, \ldots, n
$$

with $E_{\mathrm{i}}$ being equivalent income, $\mathrm{y}_{\mathrm{i}}$ total household income, $\mathrm{s}_{\mathrm{i}}$ being household size, and $\theta$ being the parameter representing the equivallence factor. If $\theta$ is equal to zero, then total household incone is the welfare measure, whille if $\theta$ is equal to one, per capita income is the result. Trial-and-error substitutes different values for $\theta$ for example, by increasing $\theta$ from zero to one by steps of onetenth. Obviously, comparing households of different composition, there is a point, c.q. a value of $\theta$, where the relationship between these households is going to change. Lanjouw et al. calculated the poverty incidence for various household types across a range of values for $\theta$ between zero and one for Russia, Estonia, Poland and other countries. They found their conclusion confinmed that per capita measures blur the real welfare ranking of households. According to their calculations, femaleheaded households which are very often not the most vulnerable ones when applying per capita measures, turned out to have a high poverty risk with decreasing $\theta$, and that the individuals living in such households are generally much poorer than the national average (p.26). Another switch in the ranking occurs between children and the elderly. The lower $\theta$, the larger the chance that households with an elderly head are poorer than households with children. Applying this method to the Latvian data results in similar conclusions with respect to children and the age of the household head. Indeed, the rankings change with a value of $\theta$ around 0.6 . As far as female-headed households are concemed, there is no significant change in the poverty incidence along the various values of $\theta .{ }^{17}$ It remains cumbersome to interpret the results from such an approach and it does not provide a satisfying or convincing choice of an equivalence scale. Ackland (1999) applied various scales as well when he analyzed poverty in Latvia. His conclusions about the groups most at risk do not differ significantly from what this study finds based on per capita measures.

The difficulty of finding the appropriate scale for a certain population is only one argument against the use of equivalence scales for the transformation from household to individual. The

\footnotetext{
${ }^{17}$ See appendix 2B, Table B1.
} 
choice of the scale is always based on assumptions and these are difficult to identify (Deaton \& Paxson, 1995). For example, how much does a child cost? We doubt that they always cost less than an adult because of the considerable expenditure on education in some societies. In addition, the data needed for estimating correct equivalence scales are immense. Budget data alone are not sufficient because they provide no information about preferences and utility values. The choice of the scale affects the poverty measures. The application of a reduced-cost-for-children approach would increase poverty rates for the elderly in a poverty analysis, although we do not know whether this conforms to the true standard of living. Therefore, the choice of the scalle is on the one hand arbitrary, and on the other hand involves ethical value judgements that are of a subjective nature. The difference in need which is interpreted by demographic differences may as well reflect intrahousehold inequalities (Lanjouw \& Ravallion, 1995).

In the Latvian case, we have decided not to use equivalence scales to normalize total household welfare but to use simple per capita measures. Several reasons justify this decision. Latvian households are small on average. More than $50 \%$ are one- or two-person households, and two-thirds of all households are without children. With respect to the public good argument, we have already seen that about one third of Latvian households does not pay the rent or utility bill anyway. This is especially true in poorer households. The imputations used to correct for such under-reporting already took into account household size. Until today, no equivalence scale has been calculated for Latvia. The CSB uses the OECD scale for their calculations, while Ackland experimented with various values for equivalence scales in his paper on poverty in Latvia (1999). A test comparing the robustness of the per capita indicator versus the $O E C D$-scale adjusted measure proved the ranking to be rather stable, thereby justifying the use of the per capita welfare measure (see section 2.4 ). There is no justification for a particular equivalence scale. Per capita measures have the big advantage of relying on a clear assumption with is easy to understand and interpret.

Summarizing, our preferred welfare indicator for Latvia, subsequently used for the analysis, has the following characteristics: The indicator is based on total monthly household expenditures for all goods and services purchased, from own production and received free of charge. Excluded are expenditures for durable goods, taxes and social security contributions. Missing observations for housing, electricity, gas and water are imputed and heating expenditures are seasonally adjusted. This total is adjusted for regional price differences and inflation. The final measure is the household average per capita.

\subsection{Testing the robustness of the indicator}

Based on the discussions in the preceding sections we identified our preferred welfare indicator for Latvia. In this section we will compare its ranking stability with respect to various other indicators that could be used for a poverty analysis in Latvia. They all differ by at least one property from the preferred indicator. The robustness tests will also tell something about the value added of the various adjustments made. There are two test groups:

i) Per capita indicator versus scale-adjusted indicator;

ii) A series of per capita indicators adjusted to various degrees for missing values, price differences and seasonal variation.

\footnotetext{
is The influence of value judgments has also been criticized by Triest (1998) and Lanjouw \& Ravallion (1995).
} 


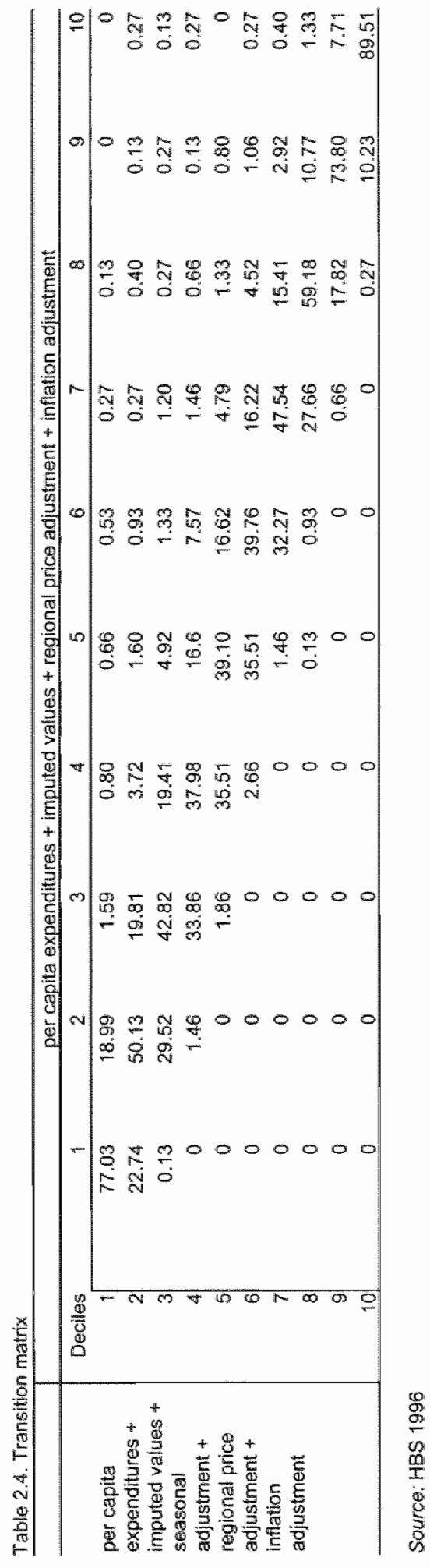


Two methods will be used to test the stability of the indicators. Next to a simple rank correlation measure (Spearman rank correlation coefficient), we will apply the mobility matrix as described in Hentschel \& Lanjouw (1996).

The rank correlation coefficient measures the degree of equal ranking in both distributions. If the coefficient is equal to one, the rankings of both distributions are a perfect match (see Table 2.5). The mobility measure as described in Hentschel \& Lanjouw measures the magnitude of offdiagonal cells in a transition matrix in order to compare the rankings based on two distributions. Table 2.4 contains a transition matrix comparing the ranking from the preferred indicator with a less comprehensive indicator.

The rows represent the distribution of all households across deciles from poorest (Decile 1) to richest (Decile 10) according to the most comprehensive version of average total household expenditures per capita. The columns represent the decile distribution according to a less comprehensive indicator. The difference between the wo indicators is whether expenditures have been seasonally adjusted for the consumption of central heating. The matrix shows the extent to which the ranking changes when a different welfare indicator is used. In the case of a perfect match of both rankings, the diagonal cells would have values equal to 100. The higher the values in offdiagonal cells and the more off-diagonal cells with a walue larger than zero, the higher the mobility between the two rankings. The non-zero off diagonal cells corresponding with a lower decile are of special concern. They indicate the change in the poverty profile that could be expected by changing the welfare definition. Fon example, $19.81 \%$ of the people that belong to the second decile according to the preferred indicator would be in the third decile according to the less comprehensive measure. Almost $4 \%$ would be part of the fourth decile. The matrix can be summarized as a mobility measure using the following formula, assuming that $n$, the number of fractiles is even:

$$
M D=\frac{\sum_{i=1}^{n} \sum_{j=1}^{n}(i-j)^{2} m_{i j}}{2 \sum_{i=1}^{m / 2}(i-n)^{2}}
$$

MD is the mobility distance measure, $i$ and $j$ refer to row and column fractiles and $m_{i j}$ is the value of ijth cell. According to Hentschel and Lanjouw, an MD with value zero would represent perfect immobility, that is all off-diagonal cells would be empty, c.q. equal to zero. If all cells would have the same value, i.e. that each individual would have an equal probability to appear in any cell, of that the rankings of the two distributions are completely uncorrelated, then MD would take the value 0.322. Therefore, the closer $\mathrm{MD}$ is to zero, the more stable the ranking of the preferred distribution is, the fewer individuals would change deciles under a different definition.

We compared six different welfare indicators with the most comprehensive (preferred) indicator. By analyzing the results in Table 2.5, we see that some adjustments to the data have more effect than others. ${ }^{19}$ It is obvious that the lowest correlation is between the preferred indicator and the most basic indicator, a per capita expenditure measure without any adjustment at all $(\rho=0.88$; $\mathrm{MD}=0.039$ ). Adjusting the basic indicator with imputed values for missing observations, the mobility measure decreases to 0.015 and the correlation coefficient increases to 0.96 . Althougli with each adjustment, the MD measure decreases and $\rho$ increases, the values are rather stable after the missing observations have been replaced with imputed values. It also becomes evident from Table 2.5 , that price adjustments - be they regional and/or for inflation - do not have a considerable effect

19The transition matrices underlying the mobility measure are attached in appendix $2 \mathrm{~B}$. 
on the rankings. They are so close to the most comprehensive measure that the correlation is almost $100 \%(\rho=0.99)$. The $\mathrm{MD}$ is very close to zero as well $(\mathrm{MD}=0.002$, c.q. $\mathrm{MD}=0.003)$. On the other hand we see that the seasonal adjustment has a noticeable effect on the rankings (as opposed to price adjustments). The correlation is 0.96 and the $\mathrm{MD}$ is 0.015 , which is relatively close to zero.

The last row in Table 2.5 refers to the decision on whether or not to use an equivalence scale for the transformation from household to individual level. ${ }^{20}$ The argument in section 2.3.6 was made in favor of a per capita division. The tests show that the rankings are relatively stable with a correlation coefficient of 96 and an MD measure of 0.015 . Regarding the uncertainties with respect to an appropriate scale for Latvia, using per capita values for the poverty analysis seems justified. ${ }^{21}$

Table 2.5. Robustness of vallous indicators

\begin{tabular}{|c|c|c|}
\hline & \multicolumn{2}{|c|}{$\begin{array}{c}\text { p.c. expenditures + imputed walues + seasonal } \\
\text { adjustment + feglonal price adjustment }+ \text { inflation } \\
\text { adjustment }\end{array}$} \\
\hline & $\begin{array}{l}\text { Spearman's rank } \\
\text { correlation coefficient }\end{array}$ & Moblity measure \\
\hline p.c. expenditures wlo any adjustments & 0.8879 & 0.039278 \\
\hline p.c axpenditures + imputed values & 0.9605 & 0.015884 \\
\hline p.c. expenditures + imputed values + seasonal adjusiment & 0.9969 & 0.003409 \\
\hline $\begin{array}{l}\text { p.c expenditures + imputed values + seasonal adjustment } \\
+ \text { regional price adjustment }\end{array}$ & 0.9986 & 0.002272 \\
\hline $\begin{array}{l}\text { p.c. expenditures + imputad values + regional price } \\
\text { adjustment }\end{array}$ & 0.9604 & 0.015879 \\
\hline $\begin{array}{l}\text { p.c. expenditures + imputed values + regional price } \\
\text { adjustment + inflation adjustment }\end{array}$ & 0.9606 & $0.0+5786$ \\
\hline
\end{tabular}

p.c. expenditures + imputed values + seasonal adjustment

\begin{tabular}{lll}
\hline p.c. expenditures wio any adjustments & 0.8864 & 0.039469 \\
p.c. expenditures \& imputed values & 0.9614 & 0.045492 \\
\hline
\end{tabular}

p.c. expenditures + imputed values:

$\begin{array}{lll}\text { p.c. expenditures wo any adjustments } & 0.9272 & 0.026466\end{array}$

p.c. expenditures + imputed values + seasconal adjustment * negional price adjustment + inflation adjustment

\begin{tabular}{|c|c|c|}
\hline $\begin{array}{l}\text { AES adjusted expenditures + imputed walues + seasonal } \\
\text { adjustment + regional price adjustment + inflation } \\
\text { adjustment }\end{array}$ & 0.9613 & 0.0156663 \\
\hline
\end{tabular}

\footnotetext{
The applied equilyalence scale is the OECD scale.

"Although the walues are almost equal to the robustness of the seasonally adjusted indicator, the argumentation is the opposite, as the reader may have noticed. In case of seasonal adjustment, clear assumptions and empirical estimation. allowed sedsonal differences to be taken into account. In the case of adult equivalence scales, the decision on the choice of the scale would be arbitrary ins indicated in section 2.3 .6 .
} 


\subsection{Conclusion}

In this chapter we followed the whole process of creating a welfare indicator starting from raw data stemming from the Latvian Household Budget Survey. The indicator that has been chosen and tested in the end for its robustness will serve as the main tool for the poverty analysis in the next chapter. It is a comprehensive measure which approaches the real situation as realistically as possible based on the present data. Still, the choice is always subjective. Some will argue that not all adjustments were really necessary considering their added value. Think for example of the price adjustments. Others will criticize the use of the per capita measure and would have preferred an indicator which is adjusted for household size and composition using an adult equivalence scale. It remains the researcher's decision, but at least we can say that the decision was an 'informed' one. It is not THE most important choice in poverty analysis. Although the exact poverty numbers might alter due to a change in the indicator, the aim of a poverty analysis is never to determine exact poverty numbers. This is not possible, because poverty is a multi-dimensional concept and secondly, the true ranking of all households will never be known. It will always remain an estimate. The main aim of the poverty analysis is to identify the groups that are most at risk of living in poverty. Regarding the results of our robustness tests in the last section, the groups will remain rather stable no matter which indicator we use. 


\section{Appendix 2A}

\section{Regression models for missing observations}

MODEL 2. Independent wariable: logfrent payments)

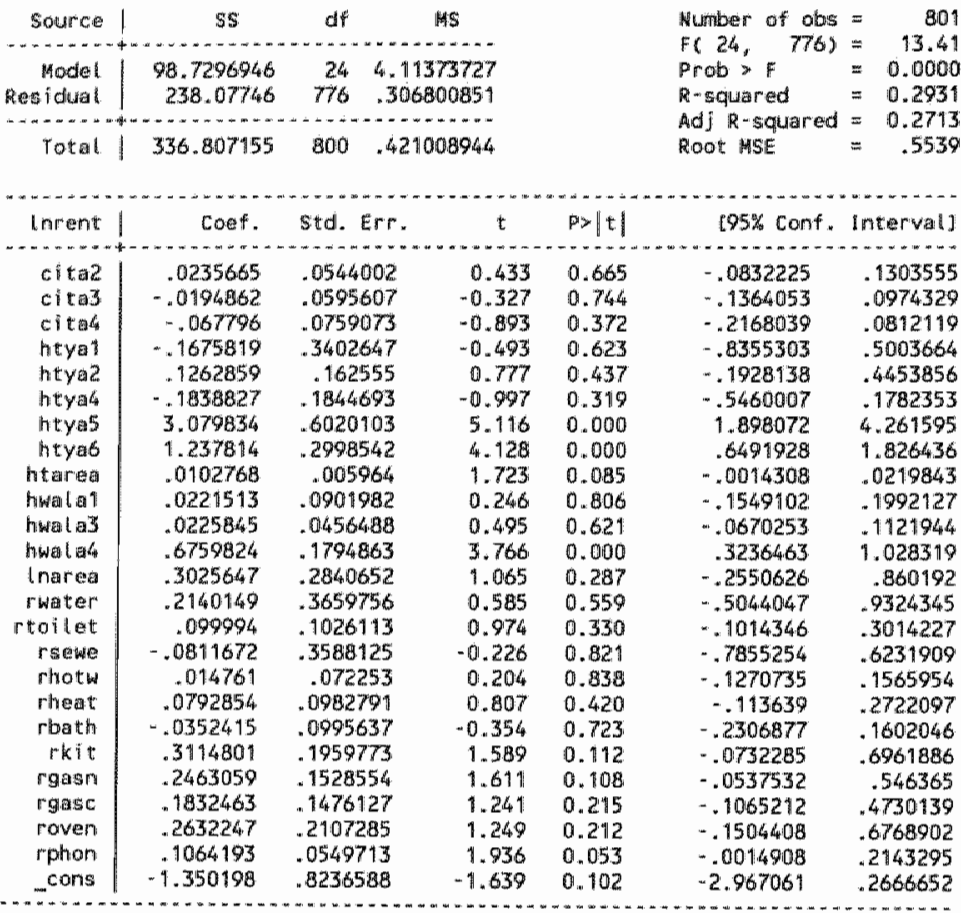

testparn cita*;

(1) $\operatorname{cita2}=0.0$

(2) $\operatorname{citas} 3=0.0$

(3) citar $=0.0$

$$
\text { P6 3, } \begin{aligned}
376) & =0.49 \\
\text { Prob }>F & =0.8865
\end{aligned}
$$

- testparm htyin;

(1) htyal $=0.0$

(i2) $h$ tyaz $=0.0$

(3) ntyat $=0.0$

(4) heyas $=0.0$

(.5) intyab $=0.0$

$$
\begin{aligned}
f(5,776) & =40.37 \\
\text { Prob } * F & =0.0000
\end{aligned}
$$

- tesceparth thata*:

(1) hwelal $=0.0$

(2) hwalas $=0.0$

(3) hwal a $=0.0$

$$
\text { f. } \begin{aligned}
3.776) & =4.76 \\
\text { Prob } F & =0.0027
\end{aligned}
$$


MODEL 2. indepencent wariable: log(electricity expenditures)

\begin{tabular}{|c|c|c|c|c|c|c|}
\hline Source & SS & $d f$ & & & Number of obs & 1471 \\
\hline & & & & & $\mathrm{FC} 33, \quad 1437)$ & 42.21 \\
\hline mociet & 233.265905 & 337.06 & 8378 & & Prob $\$ F$ & $=0.0000$ \\
\hline Resielual & 832.03484 & 14.37 & 0824 & & R-squared & $=0.2190$ \\
\hline & & & & & Adj R-squared & 0.2010 \\
\hline Total & 1065.30075 & 9470 & 4384 & & Root MSE & .76093 \\
\hline Inele & Coef. & std. & t & $p>|t|$ & 195\% Con & erval \\
\hline cita? & -.0537519 & .0609317 & -0.1892 & 0.378 & -.1732765 & .0657728 \\
\hline titas & .0133832 & .0596873 & -0.224 & & $-130: 4864$ & .1037201 \\
\hline citak & .0086094 & .0626671 & 0.137 & 0.891 & $\because 11.43195$ & .1345383 \\
\hline htyal & .0257603 & .100138 & 0.257 & 0.797 & $=9706721$ & $.222^{*} 192 \%$ \\
\hline htyaz & .0569507 & .109627 & 0.566 & 0.572 & -.140641 & .2543423 \\
\hline hotyar & .8868576 & .1225448 & 1.525 & 0.128 & -.0535282 & .4272434 \\
\hline hetras & -.4598372 & .7698349 & -0.597 & 0.550 & -1.969958 & 1.050283 \\
\hline hetyos & .3009469 & .4254415 & 0.707 & 0.479 & -.533606 & 1.1355 \\
\hline howiat 1 & .1469403 & .0924232 & 1.590 & 0.912 & -.0343584 & .3282391 \\
\hline hom: 2 & .044436 & .0955097 & 0.465 & 0.642 & $\because 4429174$ & .2347893 \\
\hline how: 4 & .4009556 & .491 .834 & 0.8115 & 0.4 & -.5638 & 1.365745 \\
\hline throons & .3483645 & .0590571 & 5.899 & 0.0 & .2325172 & .4642118 \\
\hline lnsize & .2814348 & .0422063 & 6.668 & 0.000 & .19846421 & .3642274 \\
\hline roven & .7012695 & .1447151 & $4.88_{4} 6$ & 0.000 & .4173944 & .9851449 \\
\hline xtweal & .1379773 & .0662763 & 2.082 & 0.0 & .0079686 & .267986 \\
\hline xtvbow & .0130673 & .0552389 & 0.237 & 0.8 & $-.0952 \pi$ & .1244247 \\
\hline xuideo & .0961186 & .0688531 & 1.396 & 0.163 & -0389467 & 2311799 \\
\hline$x$ tape & .0935244 & .0473283 & 1.976 & 0.048 & .0006843 & 1863644 \\
\hline xrec & -.023088 & .0524948 & -0.440 & 0.6 & $-1,260627$ & .0798866 \\
\hline xstereo & .0958988 & .046871 & 2.046 & 0.0 & .00395 & .1878497 \\
\hline xed & .9076429 & .1761048 & 0.611 & 0.541 & -.2378071 & .4530929 \\
\hline xradio & .041088 & .0424846 & 0.967 & 0.334 & -.0422504 & .1244264 \\
\hline xslitde & .0981459 & .0772078 & 1.271 & 0.204 & -.0533061 & .2495979 \\
\hline xfridge & .1782969 & .0948071 & 1.881 & 0.0 & -.0076782 & .3642721 \\
\hline Afreaze & .2349355 & .1127277 & 2.084 & 0.037 & .043807 & .456064 \\
\hline Xwiash & .0118908 & .0590072 & 0.200 & 0.8 & -1039388 & .1275603 \\
\hline$x$ sew & .0376931 & .0445277 & 0.847 & 0.397 & -.0496532 & .1250394 \\
\hline xwac & -.0286735 & .054265 & -0.528 & 0.597 & .1351205 & .07777735 \\
\hline xair & .1428379 & .1237905 & 1.154 & 0.249 & . .0999915 & .3856673 \\
\hline xmícro & -.1384963 & .136646 & -1.014 & 0.311 & -4065433 & .1295506 \\
\hline xdish & -3.384763 & .8429764 & -4.045 & 0.000 & .5 .038359 & -1.731167 \\
\hline xpot & -.1760323 & .2718897 & -0.647 & 0.517 & -.7093756 & .357311 \\
\hline xcomp & .3442549 & .3807944 & 0.904 & 0.366 & $=.4027 \| 74$ & 1.091227 \\
\hline cons & -.0699246 & .1058399 & -0.661 & 0.509 & -.2775418 & .1375926 \\
\hline
\end{tabular}

- testparm cit ta ;

(1) citaz $=0.0$

(2) citas $=0.0$

( 3 ) dita $=0.0$

$$
\text { F( } \begin{aligned}
3.1437) & =0.36 \\
\text { Probs }>F & =0.7846
\end{aligned}
$$

- testparm heva*:
(i) htyal $1=0.0$
(2) htyar $=0.0$
(3) htyiab $=0.0$
(4) htyas $=0.0$
(5) tyas $=0.0$

$$
\text { f( } \begin{aligned}
5,(437) & =0.69 \\
\text { prob }>F & =0.6334
\end{aligned}
$$

- Testparm howit:

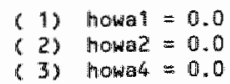

$$
\begin{aligned}
& F(3,1437)=1.05 \\
& \text { Prob }>F=0.3716
\end{aligned}
$$




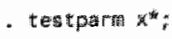

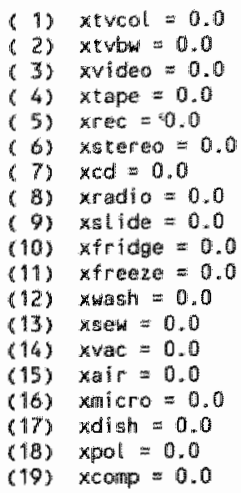

$$
\text { F( } \begin{aligned}
14,147) & =3.78 \\
\text { prob }>F & =0.10000
\end{aligned}
$$

\begin{tabular}{|c|c|c|c|}
\hline Source & 85 & $d f$ & $M S$ \\
\hline & & & \\
\hline Model. & 385.957414 & 27 & 21.7021264 \\
\hline Residulat & 1122.550 .48 & 2508 & .447587909 \\
\hline & & & \\
\hline Tota & 1700.50739 & 2535 & $=6 / 5967$ \\
\hline
\end{tabular}

MODEL 8: Undependent wariable: logicentral heating expenditures,

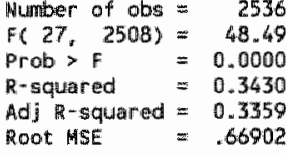

\begin{tabular}{|c|c|c|c|c|c|c|}
\hline 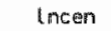 & Coef. & std. Err. & $t$ & Ps. $\mid$ & $195 \%$ conf. & Interval] \\
\hline & & & & & & \\
\hline$d_{-x}+1 t y z$ & -.1353052 & .035225 & -3.841 & 0.000 & -.2043782 & -.0662323 \\
\hline$d_{-} c i t y^{3}$ & .0031227 & .0367254 & 0.085 & 0.932 & -.0688924 & .0751378 \\
\hline detty & -1239556 & .057645 & -2.150 & 0.032 & -.2369922 & -.010919 \\
\hline detypez & -.0827013 & .366473 & -0.226 & 0.824 & -.8013219 & .6359194 \\
\hline d typez & -.3162505 & .2867614 & .4 .103 & 0.270 & .8785638 & .2460629 \\
\hline d type4 & -.3751622 & .2935664 & -1.278 & $0.20 \% 1$ & $* .9508196$ & 2004951 \\
\hline d types & -195335 & .5104935 & -0.383 & 0.702 & -1.196367 & .8056969 \\
\hline di typeb & -.1784135 & .5890479 & -0.299 & 0.765 & -1.331482 & .9705549 \\
\hline d_wall2 & .1239478 & .1414483 & -0.876 & 0.384 & -.4013151 & .1534196 \\
\hline d math 3 & -.1556064 & .1420213 & -1.096 & 0.273 & .4340975 & .1228847 \\
\hline 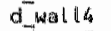 & -.4824489 & .2244896 & -2.149 & 0.032 & -.9226529 & $\because 0422449$ \\
\hline $\mathrm{d}$ on: & -.2094542 & .1100058 & -1.904 & 0.057 & -.4251658 & $.008257 \%$ \\
\hline andin 3 & .0070003 & .095822 & 0,082 & 0.934 & -.1799982 & .1957987 \\
\hline d. DWhin 4 & (dropped) & & & & & \\
\hline गए厂 & .4965783 & .0636467 & 3.089 & 0.002 & .0717728 & .3213838 \\
\hline Inarea & .5592867 & .0804077 & 6.956 & $0 ! 000$ & $.4016 \div 44$ & .7169589 \\
\hline lng I t & .1336509 & .0283101 & 4.721 & 0.000 & .0781373 & .1891645 \\
\hline $\mathrm{d}_{\mathrm{km}}$ minter & -.0540779 & .0633775 & -0.853 & 0.394 &. .1783554 & .0701997 \\
\hline di mon 3 & $\approx 0329131$ & .0636382 & -0.517 & 0.605 & -.1577019 & .0918756 \\
\hline d & -.1463953 & .0611619 & -2.361 & 0.018 & -.2643282 & -.0244623 \\
\hline difinons & $=5042267$ & .0649862 & -9.144 & 0.000 & -.7266589 & -.4667945 \\
\hline d. flnonos & -8520249 & .0672824 & $-12,663$ & 0.000 & -.9839597 & -7200902 \\
\hline ImDกา & - . 8820597 & .0676592 & -13.075 & 0.000 & -1.014341 & $=.7497782$ \\
\hline d mond & $\therefore 9111366$ & .0679188 & -13.415 & 0.000 & -1.044319 & -.777954 \\
\hline difiong & $\cdot .8733857$ & .0680516 & -12.685 & 0.000 & - H. 008598 & -.7383739 \\
\hline d & -.743768 & $.6624 \mathrm{Bu}$ & -11.894 & 0.000 & -.8658974 & -.0206562 \\
\hline d mant 1 &. .2900472 & .0625058 & -4.640 & 0.000 & -.426155 & .1674789 \\
\hline d rmon'12 & $* 0478701$ & .0617805 & -0.775 & 0.439 & $\cdots .1690161$ & .0732759 \\
\hline cons & .9924671 & .4172972 & 2.355 & 0.018 & .1643417 & .800593 \\
\hline
\end{tabular}
[95\% conf. Interval] 


\section{Appendix 2B Table B1}

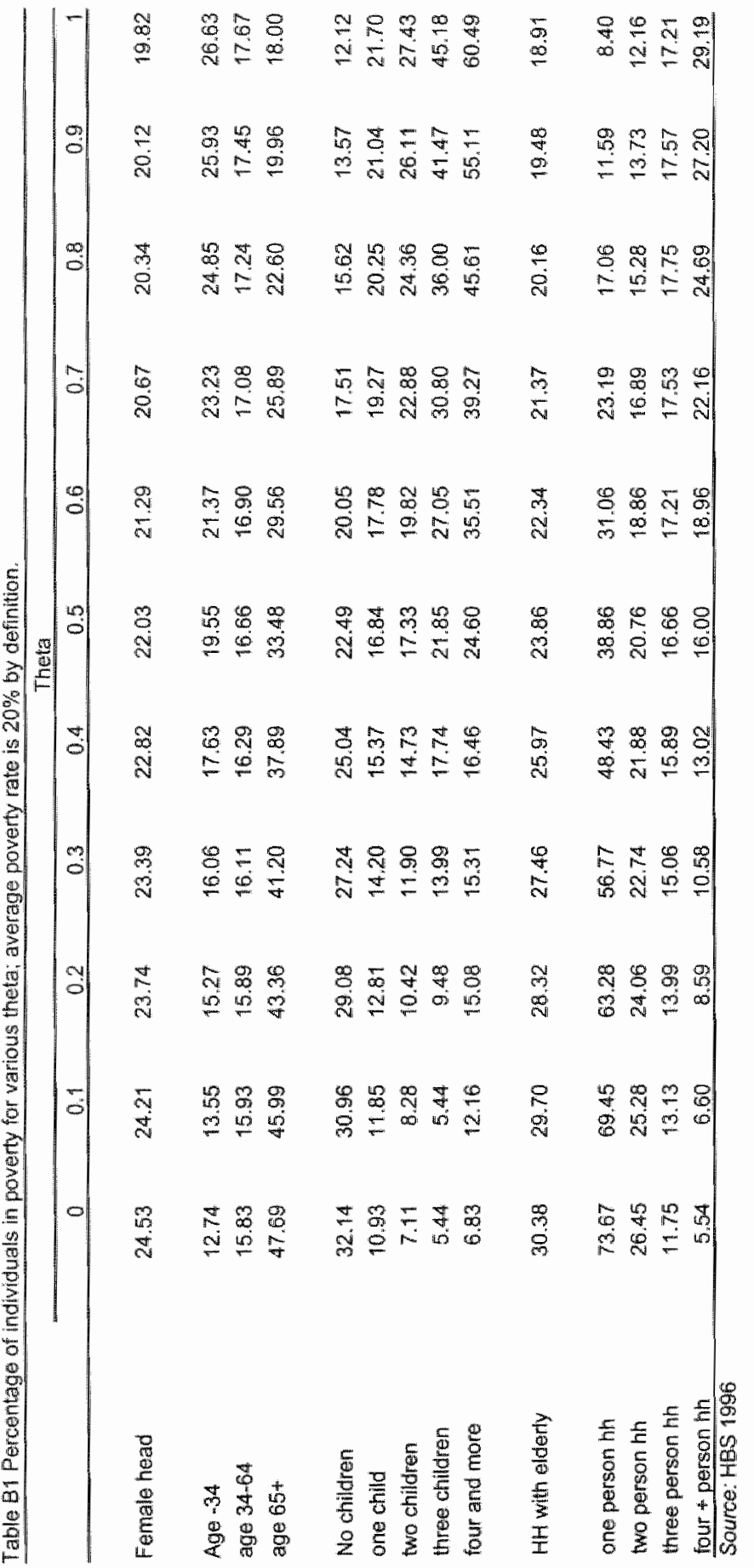


Table B2

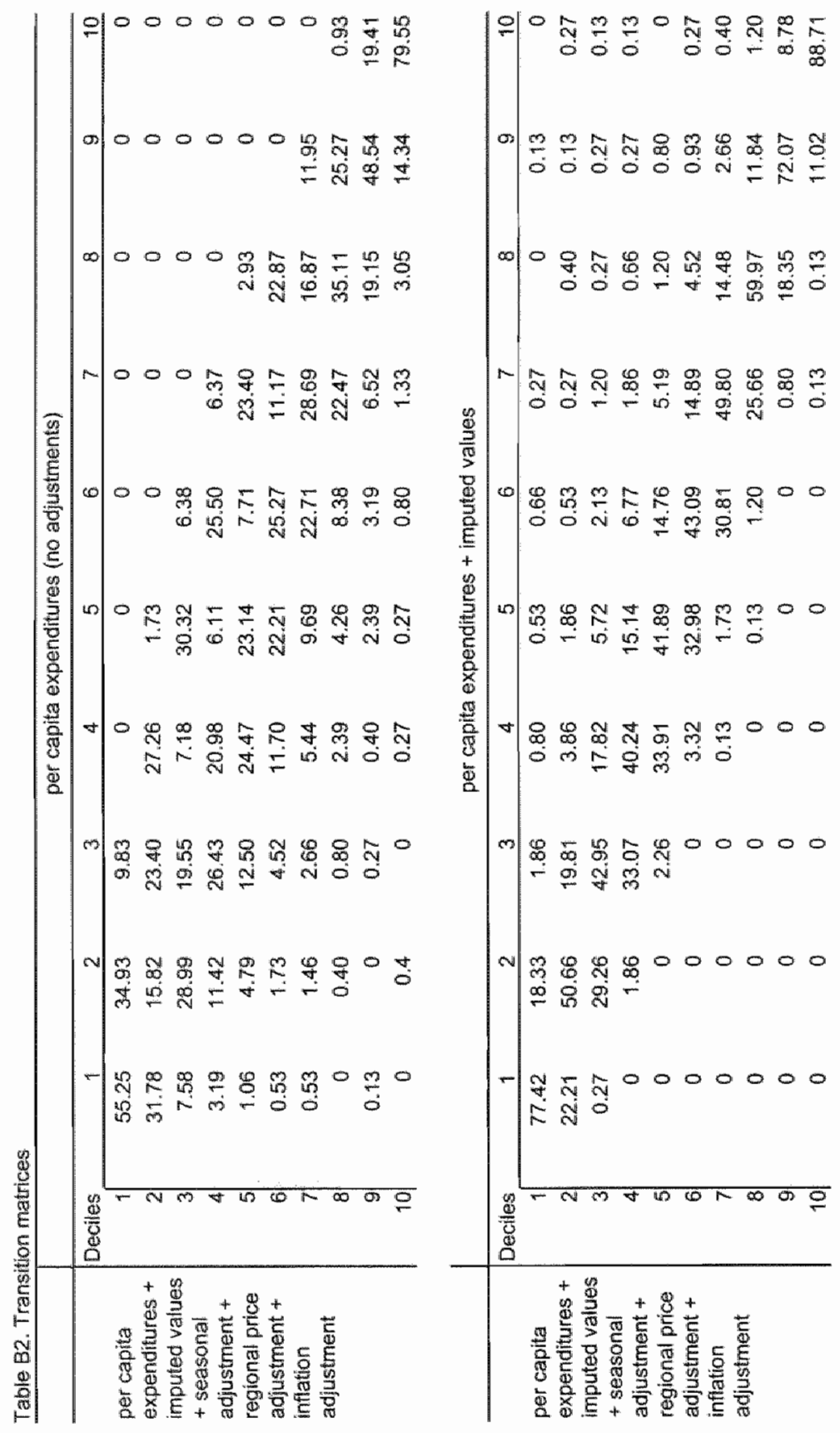


Table $B 2$

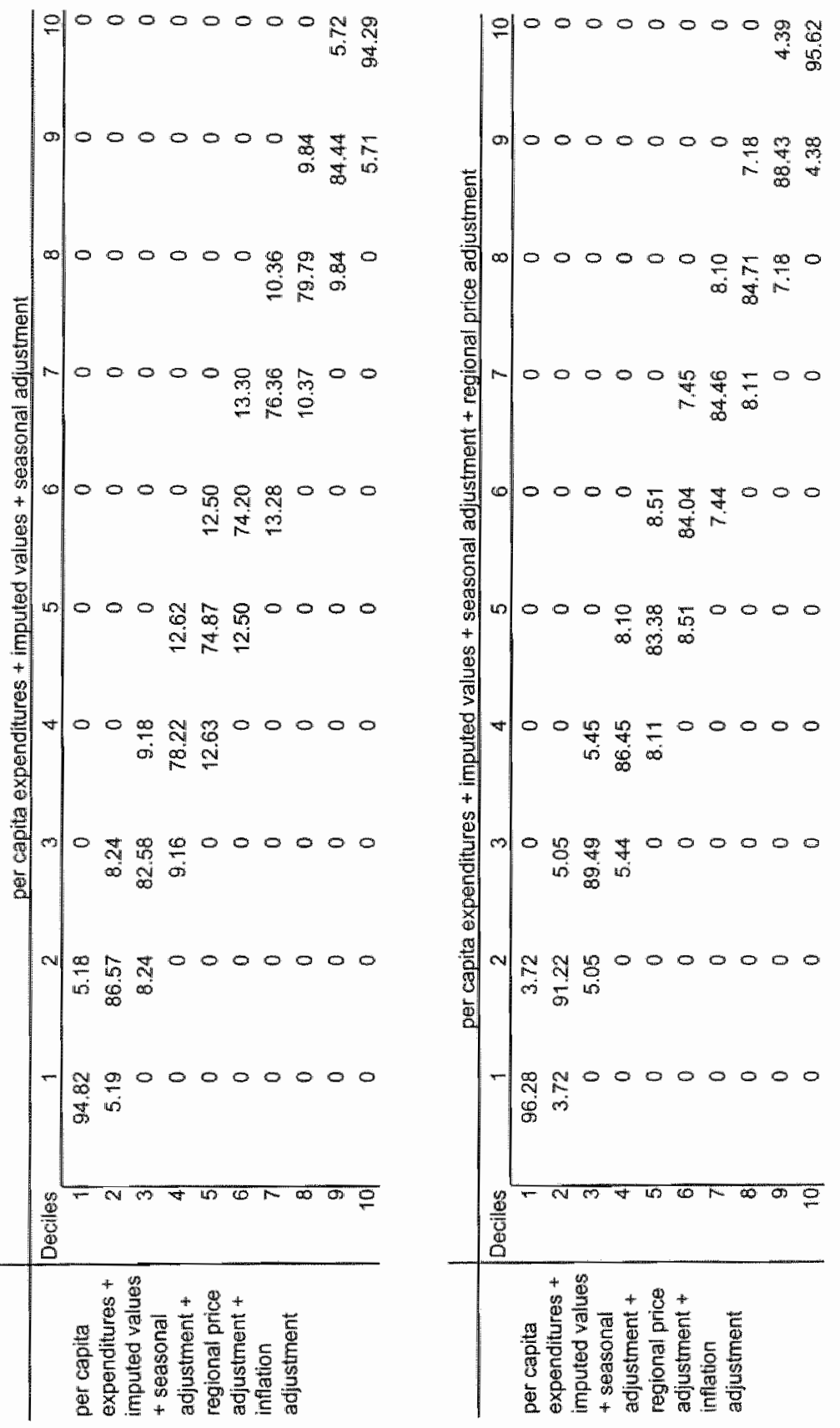




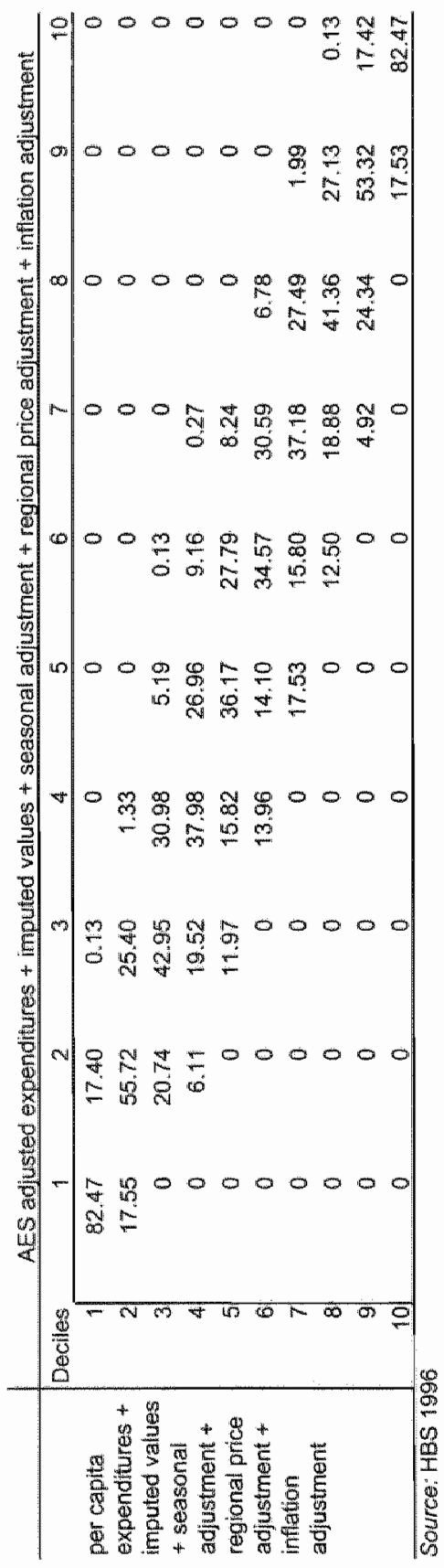




\section{LATVIANS MOST AT RISK - WHO AND WHERE ARE THE POOR}

\subsection{Introduction}

Although our main aim is to analyze the effects of the transition on poverty, which means that we would have to look at the past ten years, we now analyze poverty in contemporary Latvia. Furst of all, it is totally impossible to provide poverty rates for the last decade. Data are not available that would allow us to do that for Latvia. Still, we are lucky to at least have data covering two consecutive years. It allows to say something about the groups most at risk in the post-transition period. Data for two years tell us how Latwia is currently developing. Together with the results of the subsequent chapters, we will be able to answer the main question.

With the method developed in the preceding chapter, a welfare indicator was established for the households participating in the survey rounds of 1996 and 1997. The objective of this chapter is wofold: first, we want to apply the developed indicator in practice, using it for the measurement of poverty. The second objective is to establish a poverty profile for Latvia and provide insight into the extent and depth of poverty in Latvia. The profile will allow us to identify those groups most at risk of being poor. The availability of data for two years also permits us to say something about the dynamics in the sense that we can make statements about the increase or decrease of poverty in Latvia in general.

In chapter one (section 1.3) we provided an overwiew of the research on poverty in other countries in transition. Based on the material presented in chapter one, we expect the Collowing groups to be most at risk of being poor in Latvia:

- Rural households;

- Households with children;

- Large households;

- Houseliolds with an unemployed breadwinner or other unemployed members.

The following correlation is expected to hold in Latvia as well:

" The higher the educational level of the head, the lower the poverty risk;

The empirical analysis performed in this chapter uses the data from the Latvian Household Budget Survey for 1996 and 1997." The indicator measuring the standard of living of the surveyed households is established as described in the preceding chapter. It is based on monthly household expenditures and consumption of goods and services from own production or received free of charge (see section 2.3). In order to identify the poor among a certain population, a cult-off point has to be chosen. Three different poverty lines as well as various poverty measures will be used for the analysis in order to picture poverty from various points of view. 
The chapter is organized as follows: The next section will describe the methodology applied in greater detal. The choices made with respect to the poverty lines and poverty aggregation measures used will be explained. A sample profille will provide a summary view on the data and the respective households. Section three, four and five analyze poverty from different perspectives. Section three concentrates on the powerty incidence, i.e. the number of poor, their position with respect to the poverty line, and the degree of inequality among the poor. It also compares the results from 1996 with those from 1997. Different breakdowns provide insight into the poverty risk of population groups. Section four investigates the composition of poor households according to a selected poverty line. Where do the poor live, how is the household composed, and where does the main income come from, are only a few examples of the questions answered. Contrary to the third section, the analysis in this part is based on one poverty line only allowing a more detaled presentation. Section five then draws on the conclusions from the two preceding sections. Based on the uncidence analysis and the distribution of the poor, risk factors that could explain the probability of someone living in powerty are determined and analyzed in more detail. The concluding section of this chapter will discuss the main results and relate them to the hypotheses stated at the beginning. It answers the questions of who is most at risk of being poor in Latvia, whether these are the same groups as in other CEE and FSU countries and whether poverty has increased or decreased over the two years at stake.

A little warning to the reader may be appropriate at this stage. The present chapter provides a true information overflow. Innumerable facts are presented and the analysis is technical and detailed. Section 3.2 provides the technical background for the subsequent sections. The most important conclusions summarizing the main results of the poverty profile can be found in section 3.3.2, the last three paragraphs of section 3.4 and in section 3.5 where risk factors are discussed. The remaining sections are for the connoisseurs only.

\subsection{The burden of choice - which methodology to apply}

\subsubsection{Defining poverty ${ }^{2}$}

The starting point of every poverty analysis is the definition of poverty. Assuming that welfare is measurable (discussed in chapter two), we still have to define when a household or an individual is considered poor since the choice of the definition will influence the result. The two main strands in the poverty literature are based on either a relative or an absolute poverty concept. A third school of thought defines poverty according to people's own subjective perception.

Absolute or relative standards are the underlying principles of most poverty standards. The absolute approach to poventy is a very attractive concept due to its clarity and objectivity. It is defined regardless of the general welfare level or distribution in a society (Flik \& van Praag, 1991). Implementing this theory in practice reveals the problems inherent in the absolute concept. The determimation of poverty is never purely absolute or objective. Subjectivity is involved because a researcher or an agency determines the level separating the poor from the non-poor. Relativity is part of any poverty definition, even of the absolute concept, because the determination of what is considered to be poverty is never free of the contemporary values and norms of a given soctety. Rowntree was among the first to consider the problem of defining poverty in his poverty study of York in 1899 . Absolute poverty is in his terms "primary poverty", i.e. families whose income was insufficient to obtain the minimum necessities for the maintenance of merely physical efficiency

\footnotetext{
${ }^{7}$ This section is a summary of chapter 2 in Gassmann, F. (1995), Puzzling Poverty. An andytical Survey of Concepts and Merhods, Master"s Thesis, mimeo, Uniwersity of Limburg, Maastricht.
} 
were living in primary poverty (Atkinson, 1983). Rowntree calculated the minimum requirements of protein and calories and translated them into a diet at lowest cost. A minimum amount for clothing, fuel and other household needs as well as rent was added to the minimum expenditures on food. Whether Rowntree's poverty standard was indeed an absolute standard is not undisputed. According to Townsend (1980), it was relative because Rowntree's definition of nutritional deprivation was relative to the nutritional level believed to be required for members of the manual working class to function efficiently.

The absolute approach has its conceptual problems as Townsend recognized quite correctly. There is no such thing as a single subsistence level under which everyone is poor and which could be used as a poverty line. The level will always be subjective in a certain way because the investigator draws the line. There is also a disparity between scientific judgement and actual consumption belnavior. Rowntree had already recognized this fact and included tea in his basket of goods (in Atkinson 1983:226).

The main conceptual problem of the relative approach is that poverty is considered a phenomenon of inequality. There will always be a class of poor people. ${ }^{3}$ The role of contemporary living standards has also been recognized by Rowntree (Atkinson, 1983), who referred to it as 'secondary' poverty, a concept that changes with the ideas and values prevailing in a society. Townsend defined relative deprivation as "... the absence or inadequacy of those diets, amenities, standards, services and activities which are common or customary in a society. People are deprived of the conditions of life which ordinarily define membership of society. If they lack or are denied the resources to obtain access to these conditions of life they are in poverty... (Townsend, 1980:301). Hence, relative poverty is a moving concept which reflects the interdependence of standards of living.

A more comprehensive approach that bridges the concepts of absolute and relative poverty is offered by Sen's capability approach. ${ }^{4}$ Poverty in this context is defined by Sen (1992:109) as "... the failure of basic capabilities to reach certain minimally acceptable levels'. The capability approach can subsequently be applied to absolute and relative concepts of poverty. In Sen's terms (1984), poverty is an absolute notion in the space of capabilities which can take a relative form regarding commodities or characteristics. Relative deprivation is a failure in the commodity space, having the effect of an absolute deprivation in the capability space. With the increasing prosperity of an economy the resource needs will go up, and through this, the relativist view acquires plausibility despite the absolute basis of the poverty concept in terms of capabilities and deprivation. This quite theoretical concept can be made less abstract by considering some basic determinants of an individual's welfare. A person"s welfare depends on his capability to meet nutritional requirements, to escape avoidable disease, to be sheltered and clothed, to be able to travel and to be educated ( $\operatorname{Sen}, 1984: 336$ ). The commodities required to fulfill these capabilities do not differ significantly across communities, whereas there may be differences regarding other capabilities. Sen"s capability approach is a seductive concept due to the combination of the two more or less distinctive definitions of poverty. It is convincing in theoretical terms, but its practical applicability in the identification of the poor remains problematic. It is not the commodity side which provides the problem, but rather the identification and measurement of an individual's capabilities which are difficult to assess.

\footnotetext{
Theoreticaly this statement depends on the choice of the variable taken to determine the powerty line, i.e. whether it is an average wr median level. With the median it is statistically possible that no one remains below fraction of the median level. With an average, there will always be a proportion below, whess all incomes are equal.
}

"The capability concept has already been discussed in chapter two. 
Following the discussion in this chapter, poverty cannot be conceptualized in relative or absolute terms only. Relativity is always part of the absolute approach, and a certain absolutist core (Sen, 1984:332) is always part of the general idea of poverty: "The absolute achievement may depend on the relative position in another field' ( $\operatorname{Sen}_{3} 1984: 328$ ), and 'the fact that some people thave a lower standard of liwing than others (relative poverty) is certainly proof of inequality, but by itself it cannot be a proof of poverty unless we know something more about the standard of living that these people do in fact enjoy. ... The absolute considerations camot be inconsequential for conceptualizing poverty" (Sen, 1984:333).

\subsubsection{Poverty line}

Poverty analysis consists of two main steps, i.e. first the identification of the poor and, secondly, the aggregation within a community in order to evaluate the level of poverty. The choice of the welfare indicator is one part of the identification exercise, but the decision of the cut-off line, i.e. the poverty line, is the decisive step since it divides the poor from the non-poor.

Depending on the objective and use of the poverty line, the calculation and the setting of the appropriate cut-off point may vary. In the context of social policies, identification of the poor may be needed in order to target social benefits. For research purposes, any benchmark can theoretically serve as cut-off point.

A main distinction between poverty lines is whether they are based on a relative or absolute concept of poverty. Absolute powerty lines are best viewed as fixed in terms of the standard of living (Ravallion, 1994). This concept is the basis for official definitions of low income in most countries. There are various methods of how to set an absolute poverty line. In the Latvian case, the officially defined crisis subsistence minimum is an example of an absolute poverty level. ${ }^{5}$ It is based on the minimum costs to obtain a bundle of basic necessities and is an example of the budget standard method. Other methods to calculate an absolute poverty line are the food-energy method or the food-share approach. They are both based on a minimum nutritional level usually expressed in calorie-intake needed to maintaining body weight in various circumstances. The level of an absolute line can either be generous or stringent in terms of the living standard. The main characteristic of an absolute level is the fact that it is fixed in real terms and that all individuals with means less than the cut-off point are considered poor. ${ }^{6}$

A relative poverty line on the contrary is not fixed in the sense that a change in the average income of the population results in an adjustment of the poverty line. In general, poverty rates based on a relative poverty line depend strongly on the welfare distribution in a given society and the respective mean welfare level (Sen \& Foster, 1997). Therefore, relative poverty is closely related to the notion of inequality. Usually, a proportion of the mean or median income (or expenditure) is taken as the relative poverty line. Especially in the case of the mean income, the higher the average income the higher the relative poverty line. The use of relative poverty lines is more appropriate in an academic setting and for cross-country comparisons. Its usefulness for social policy purposes is limited.

However a poverty line is set, be it in absolute or relative terms, it is always an arbitrary choice. With respect to the relative approach, it is the proportion that needs to be set. And although the absolute approach may seem objective at a first glance, it has to be kept in mind that the goods entering the welfare function need to be chosen. This involves judgement which makes the choice arbitrary. A poverty line is also arbitrary in the sense that it denotes a cut-off point dividing the poor from the non-poor. But is the person having one dollar or lat more and living just above the poverty

\footnotetext{
"Although "oficially" defined, the standard is not used as an official poverty line (see below).

"For a more detailed description see, e.g., Rawallion (1994), Callan and Nolan (1991).
} 
line really better off than the person with one dollar or lat less? Poverty is not discontinuous. It varies in its gradation (Blackwood and Lynch: 1994). Therefore, the application of several poverty lines is usually wise. It allows the identification of various deprivation levels such as the very poor (the least well-off who are barely surviving), the poor (those who are slightly better off, managing to survive but are on the brink of severe poverty) and the rest.

Latvia does not have an official poverty line although there are regular calculations of various consumption baskets. Therefore, we had to look for other meaningful cut-off points. For this study, three different poverty lines were chosen. In the following, these three different lines will be presented. The first and lowest threshold is a relative poverty line which is set at 50 percent of the mean of the total monthly per capita household expenditures. This was equal to 23.75 LVL per capita per month in 1996 and to 25.12 LVL in 1997 (nominal terms). People living below this threshold could be considered the very poor. The second poverty line is the level of the official minimum wage which was $38 \mathrm{LVL}$ per month in both years. The reason for using the official minimum wage as poverty line is twofold: first, we were looking for an intermediate standard regarding the large difference between the relative poverty line value and the crisis subsistence minimum level, and secondly, the official minimum wage is a published, official and applied figure set by the Cabinet of Ministers of Latvia. The highest poverty line is the crisis subsistence minimum as calculated regularly by the Latvian Ministry of Welfare. "The value covers the cost of minimum diet plus an allowance of $5 \%$ of the total value for other goods and services. ${ }^{8}$ In 1996, its value was 52.18 LVL per capita per month, and 54.5 LVL in 1997 (nominal).

How can these poverty lines be qualified? According to Sen and Foster (1997), we have two descriptive and one preseriptive poverty line. The relative poverty line and the minimum wage powerty line are descriptive in the sense that they answer the question of 'who are the poor' given a certain standard of living. The crisis subsistence minimum is more of a prescriptive nature (athough not applied this way in Latvia), since it helps identify those people living below a threshold below which no one should fall. A poverty line would be fully prescriptive if the line would be applied for policy purposes, e.g. in order to determine social benefit eligibility. The term 'poverty line' may not be the appropriate wording for such a prescriptive threshold if politically applied. It identifies a minimum below which no one should live and where he/she gains the right to receive assistance at least up to that prescribed level. Such a threshold is often influenced by the state budget. This means, the government funds available for social assistance policies determine the level of the affordable minimum. As opposed to budget-driven, we can also distinguish rightsdriven and needs-driven poverty lines. Let us start with needs-driven since it is easier to define. An example of a needs-driven poverty line is the crisis subsistence minimum. It is equal to the costs of a consumption basket which contains basic food items plus a small allowance for other necessary goods and services. Although regularly calculated by the Ministry of Welfare in Latvia, its value is not used for anything other than statistical purposes. One argument against its use is the outdatedness of the basket. The composition of the basket dates back to pre-transition times and would not represent current consumption behavior. Its value also exceeds for example the official minimum wage level by more than one third. The Central Statistical Bureau of Latvia calculates a subsistence minimum which could be regarded as an example of a rights-driven poverty line. It could be interpreted as the amount an individual has a right to in order to cover his/her basic needs. The basket is more extensive than the one of the crisis subsistence minimum but also dates back to

\footnotetext{
'Exchange rate (Wune 1998): USD $1=L V L$ L. 0.58 .
}

According to the Mo W, this basket contains the following goods determined in minimum quantities necessary per year: bread, meat, milk, eggs, fish, sugar, oil and margarine, potatoes, vegetables, fruits and berries (Information provided by afticials of the MoWr). 
1991. "... [it] consists of the amount of goods and services which meets the needs of the minimum level of living standards accepted by society' (CSB, 1999a:56). Applying the subsistence minimum $(74 \mathrm{LVL}$ in $1996 ; 79 \mathrm{LVL}$ in 1997$)$ as poverty line leads to a poverty rate of more than $80 \%$ in 1996. This last threshold has not been included in the current analysis since it results in a situation where almost ewerybody is poor. Especially for social policy purposes such a result is useless. It does indicate though, that powerty is a serious problem in Latvia and that the overall standard of living is rather low. Table 3.1 summarizes the three poverty lines and puts them into perspective by setting them against other income indicators.

Table 3.1. Latwia: various income indicators, $1996-1998$, monthily average, in LVL

\begin{tabular}{llll}
\hline Indicator & $1996^{1}$ & $1997^{2}$ & $1998^{2}$ \\
\hline Average disposable income per caplat & 51.52 & 55.45 & 60.91 \\
Average net wages of employed & 78.65 & 88.34 & 97.47 \\
Average old-age pemsion & 37.81 & 41.79 & 50.45 \\
Subsistence minimum CSB & 73.78 & 78.78 & 8.2 .15 \\
Official minimum wage & 38.00 & 38.00 & 42.00 \\
Crisis subsistence minimum MoW & 52.18 & 54.50 & 55.69 \\
So\% of mean per caplta expenditures & $23.75^{3}$ & $25.12^{3}$ & \\
\hline
\end{tabular}

Sourco: 1: $\mathrm{CSB}, 1997 \mathrm{~d} ; 2: \mathrm{CSB}_{1} 1999 \mathrm{a} ; 3$ : own calculations based on the respective HBS data.

All three poverty lines applied in this study are diagnostic poverty lines to speak in Sen and Foster's terminology (1997:167). The choice of applying three poverty lines instead of only one cut-off threshold solves partly the conceptual problems. It allows us to study poverty from a relative as well as an absolute point of view, and it eliminates the discontinuity problem since various degrees of poverty are made visible. Still, the choice is partly arbitrary.

The analysis in section 3.3 will be based on these three poverty lines. But where the use of the three different poverty lines would only cause confusion or make the presentation illegible, the minimum wage line will be the standard.

\subsubsection{Counting the poor}

After the identification of the poor, an aggregate index of poverty puts the information received from the identification steps together. There is a large body of literature on the measurement of poverty. The most common and widely used powerty measures are the headcount-ratio, which is the proportion of the poor in the total population, and the poverty gap(-ratio), which is a measure for the distance of the poor to the poverty line. They are easily applicable and interpretable but they can best be considered partial indicators rather than overall measures of poverty. They are partiall because they ignore certain aspects of poverty that are relevant for any comparison. The headcount ratio neglects the depth of poverty, i.e. the shortfall of the income of those below the poverty line, as well as the severity of poverty, i.e. the income difference, c.q. the inequality among the poor. The poverty gap ratio is a measure for the depth of poverty since it measures the average incone shortall, but it says nothing about the number of poor nor about the distribution of income among the poor. Any income transfer from the very poor to the less poor would not show up in the poverty gap measure. Neither would it change the headcount ratio, although overall poverty has changed. The very port became even poorer.

An overall poverty measure should take into account not only the number or proportion of people living below the poverty line (headcount ratio), or the average income shortfall of the poor compared to the poverty line (poverty gap), but also the welfare distribution among the poor. It

\footnotetext{
'See for good overviews, e.g. Atkinson, 1987; Ravalion, 1994; Sen \& Foster, 1997.
} 
should be distribution-sensitive. The proposals made by Sen in 1976 (reprinted in Sen, 1982) with the so-called 'Sen index' gained much attention among the poverty scholars although Watts had already refined the partial indices in 1968 by normalizing the poverty gap (see e.g. in Atkinson, 1987). While Watts used a logarithmic transformation to normalize the income gaps, Sen included the Gini-coefficient, a measure of inequality, in his index in order to account for inequality among the poor. ${ }^{10}$ Following Sen's famous paper in 1976, poverty research gained momentum. Among the scholars which further extended and amended Sen's proposed measure, Foster, Greer and Thorbecke (FGT) provided a class of poverty measures that fulfilled the requested properties, were easily applicable and understandable (Foster, 1984), and which became popular for empirical poverty analyses. Not surprisingly, this study makes use of the FGT-class of poverty measures as well. The following equation defines the class of poverty measures $P_{t}$ :

$$
P_{\alpha}=\frac{1}{n} \sum_{i=1}^{q}\left(\frac{z-y_{i}}{z}\right)^{\alpha} \text { for } \alpha \geq 0
$$

where $z$ is the poverty line value, $y_{i}$ the welfare value of household $i_{n} n$ the number of people in the community and $\mathrm{q}$ the number of poor people in this community. $\alpha$ is the interesting parameter which makes this class of poverty measures very appealing. When $\alpha$ takes on the value $0, P_{0}$ becomes the headcount-ratio q/n. When $\alpha$ equals $1, \mathrm{P}_{\mathrm{j}}$ becomes the poverty-gap ratio. The partial and simple indicators are included as special cases in the $P_{\alpha^{-}}$measures. As soon as $\alpha$ is larger than 1 , the poverty gap of the poor is weighted, therefore taking into account the severity of poverty. The larger $\alpha$, the more weight is given to the poorest. In empirical poverty analysis, $\alpha$ usually takes the value 2 in order to get a measure of the severity. Values of $\alpha$ larger than 2 are not that easily interpretable anymore and therefore not widely applied. An additional and welcome property of the $P_{a}$ poverty measure is their additivity. Total poverty of the overall community can be decomposed into various sub-group poverty levels. By weighting the sub-group poverty by its population share, the contribution of this group to the overall poverty can be found (Sen \& Foster, 1997).

The subsequent empirical poverty analysis (section 3.3.) applies three different measures of the $\mathrm{P}_{c}$ class of poverty measures: $\mathrm{P}_{0} \mathrm{P}_{1}$ and $\mathrm{P}_{2}$ each representing one aspect of overall poverty in Latvia, i.e. the amount, the depth and the severity of poverty in Latvia.

\section{2 .4 Sensitivity analysis}

The quality and robustness of a poverty analysis is related to the welfare distribution of the society to be analyzed. If poverty is shallow, then the poor are closely gathered around the poverty line, and a small increase in the threshold would result in an above proportional effect on the headcount ratio. There are two ways to evaluate the sensitivity of the poverty measurement, numerically and graphically. Table 3.2 summarizes the results of various changes to the poverty line.

Starting with the relative poverty line equal to $50 \%$ of mean per capita expenditures, the poverty line is increased (decreased) by 5,10 and $20 \%$ respectively. Headcount ratios are calculated for the whole of Latvia as well as for urban and rural areas separately. A small increase in the poverty line results in a more than proportionate increase of the headcount ratio. For example, increasing. (decreasing) the poverty line with $5 \%$ results in an increase (decrease) of the headcount ratio of $11 \%(-9 \%)$ for whole Latvia. Although the effect is much more pronounced in urban areas, the increase in rural areas is still above proportion. Therefore, the choice of the cut-off line has a large

\footnotetext{
"ogen's index can be written as follows: $S=H^{*} I+H(1-1)^{*} G$, where $H$ is the headcount ratio, the neome-gap ratio, ahud G the Gini-coefficient of the poor (see e.g. in Sen, 1982; Sen \& Foster, 1997).
} 


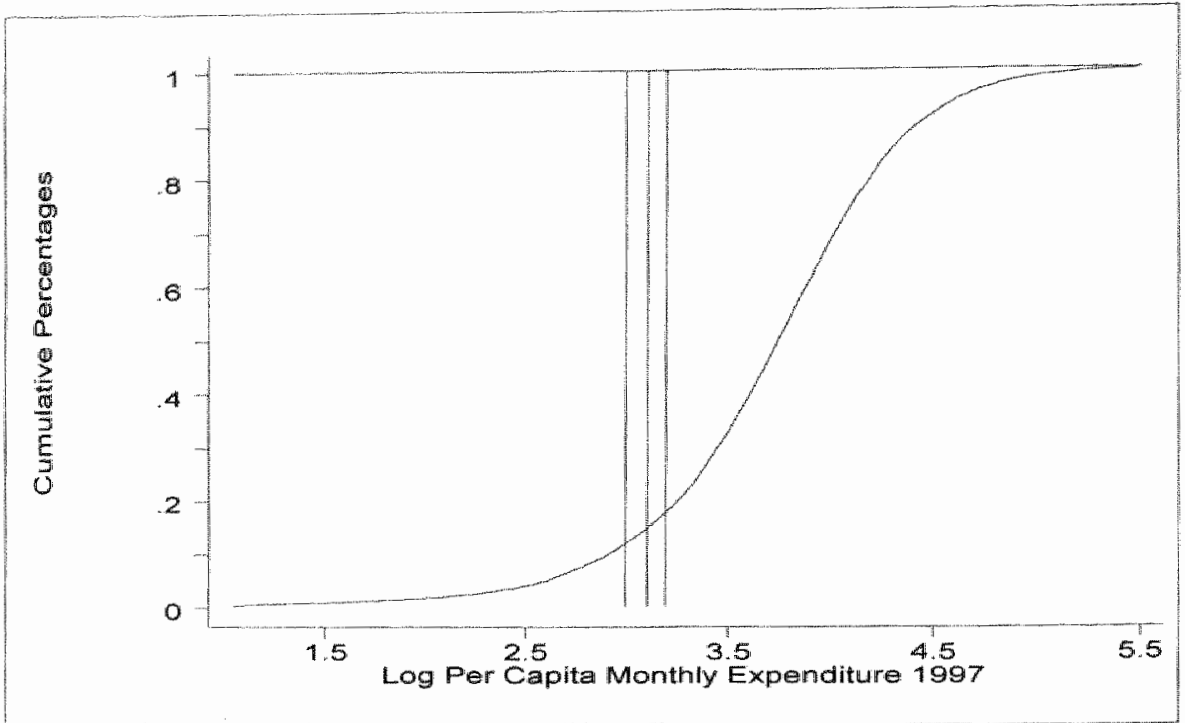

Figure 3.1. Cumulative distribution function of the logarithm of per capita monthly expenditure, Latvia, 1997 (HBS 1997).

Note: The vertical lines represent different powerty lines. The intermediate line is the relative poverty line ( $50 \%$ of mean per capita expenditure), the line on the left is $10 \%$ lower than the relative line, and the line to the right is $10 \%$ higher than the relative poverty line.

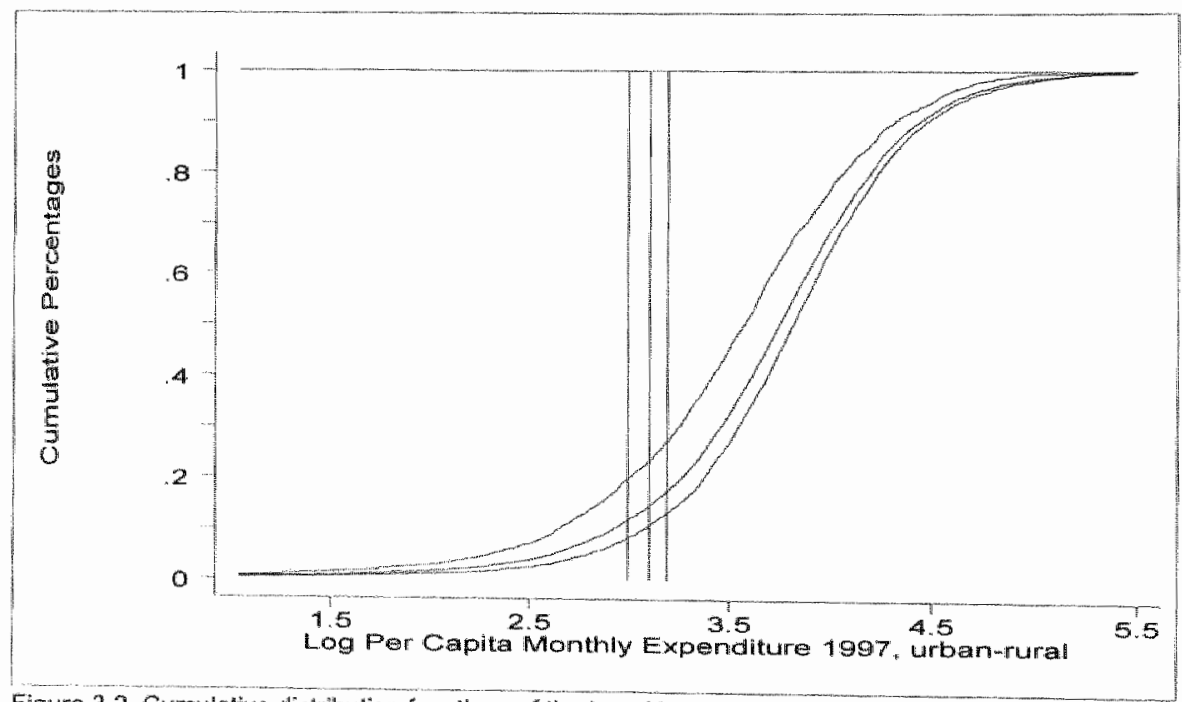

Figure 3.2. Cumulative distribution functions of the logarithm of per capita monthly expenditure, Latvia, 1997. unban versus rural (HBS 1997).

Note: The cdf in the middle represents the cdf for the whole of Latvia; the curve furthest to the right is for uban areas, and the curve furthest to the left is for rural areas. See also the note for fig. 3.1 for the
vertical lines. 


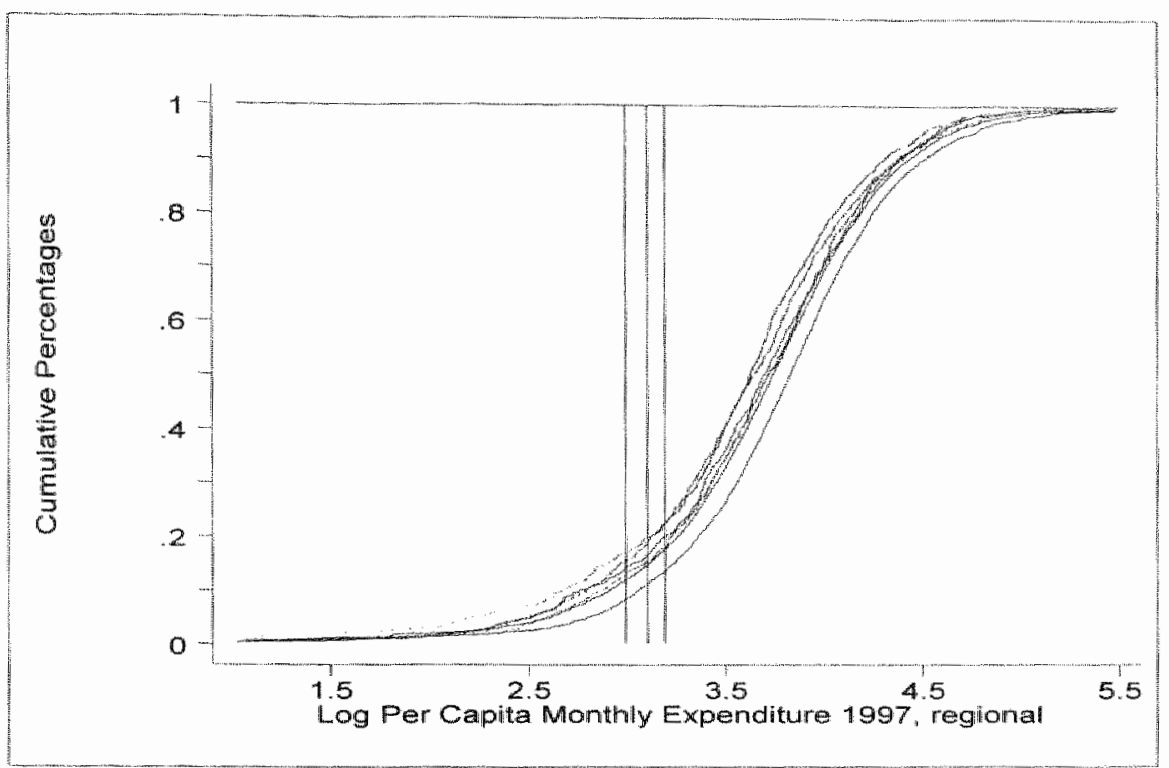

Figure 3.3. Cumulative distribution functions of the logarithm of per capita monthly expenditure. Latvia, "1997, by regions (HBS 1997).

Note. The coff furthest to the right is the cof for Rigas region. The second curve from the right is the cdff for the whole of Latwia. All other curves to the left represent the other regions. See also the note to fig. 3.1 for the vertical lines.

imfluence on poverty measurement in Latvia. Graphical analysis confirms this result. Figures 3.1 3.3 present cumulative distribution functions for per capita expenditures (in logarithm). The graphs show that a change in the powerty line (vertical lines in the graphs) has an above proportionate effect on the level of poverty. In Figure 3.2 we see three different functions representing al] of Latvia (the curve in between), urban (the curve to the right) and rural areas (the curve to the left). Although poverty results are sensitive to the poverty threshold, it holds true that rural areas are poorer than urban areas at all expenditure levels. The curves never cross each other. With respect to regional poverty (Figures 3.3), the conclusion is much vaguer. The curve most to the right represents the distribution in the region around Riga while the second right curve represents all of Luatvia. The blurred curves to the left are almost indistinguishable, crossing each other several times. These are distribution functions for the other regions. A change in the poverty line will rever affect the position of the Rigas region, but it will alter the ones of the other regions compared to each other. The rank of the remaining regions will be merely accidental. Therefore, the decision to apply three different poverty lines for most of the analysis represents a sensible choice given the close welfare distribution in Latvia. 
Table 3.2. Poverty line sensitwity measures (1997, nominal value)

Total poverty rate

Poverty line

Headcoumt \% increase

Headcount

\% increase

Headcount \% increaise:

\begin{tabular}{lrrrrrr}
$50 \%$ of mean pc exp & 14.75 & & 10.88 & & 23.57 \\
$5 \%$ higher & 16.39 & 11.12 & 12.38 & 13.79 & 25.55 & 8.40 \\
$10 \%$ higher & 17.77 & 20.47 & 13.48 & 23.90 & 27.57 & 16.97 \\
$20 \%$ higher & 21.05 & 42.71 & 16.23 & 49.17 & 32.07 & 36.06 \\
& & & & & & \\
$5 \%$ lower & 13.40 & -9.15 & 9.69 & -10.94 & 21.88 & -7.17 \\
$10 \%$ lower & 12.09 & -18.03 & 8.54 & -21.51 & 20.19 & -44.34 \\
$20 \%$ lower & 9.24 & -37.36 & 6.32 & -41.91 & 15.91 & -32.50 \\
\hline
\end{tabular}

Source. HES 1997

\subsection{A poverty profile for Latvia ${ }^{11}$}

This first part of the following poverty assessment concentrates on the incidence of poverty in Latvia. Using the three poverty lines identified above, we provide detailed estimates of the poverty risk for Latvia. The sample is divided into different groups according to various characteristics of the households and the individuals living in these households. We analyze whether it matters where someone is living, or the kind of household someone is part of, to mention two examples. The three poverty aggregation measures allow us to create a rather comprehensive picture of the poor living in Latvia. We calculate the number of poor as a proportion of the total or of a specific group; we estimate the difference between the poor's expenditure level and the respective poverty line; and we callculate and analyze the level of inequality among the poor. The results are representative for the country. At the end of this section, we want to be able to answer the question of whether the stated hypotheses at the beginning of this chapter are valid for Latvia, i.e. we want to identify the groups most at risk.

The unit of analysis is the individual living in a household with certain characteristics. Results are presented for two years, i.e. 1996 and 1997. The households have been made comparable by adjusting the 1997 figures to January 1996 using the official inflation rate as expressed by the consumer price index (CSB 1999b) thereby allowing to directly compare the poverty rates. Accordingly, the 1996 poverty lines have been applied to all data. ${ }^{12}$ All results are weighted according to the parameters provided by the Central Statistical Bureau of Latvia.

A lirst look at the population as a whole shows that almost $15 \%$ of the Latvian population was very poor in 1996, living below the lowest poverty line (see Table 3.3). This means, these individuals spent less than 24 LVL per month on average for food, clothing, housing and other necessities. According to the minimum wage poverty line, $42 \%$ of the population was poor. This figure increases to $68 \%$ when applying the highest poverty line, i.e. the value of the crisis subsistence mininum. More than half of the population had a standard of living somewhere between the low and the high poverty line. In 1997, the poverty rates increased between three and eight percentage points for all poverty lines. This means that Latvia was confronted with a real

\footnotetext{
"Results for 1996 have been presented carlier in a paper (Gassmann, 1998) written on behalf of UNDP Latwia in the context of the UNDP project 'Support to Dewelopment of a National Roverty Eradication Strategy' (LAT/96/551). Wote that the povery results differ due a change in methodology.

"Note that this adjustment to real values is in addition to the other adjustments as described in the previous chapter.
} 
increase in overall poverty. ${ }^{13}$ Although we could say there was a general decline of the standard of living of the poor with now $73 \%$ living below the CSM level, it seems that there was especially a shift at the lower end of the scale. There is still about the same proportion ( $55 \%$ ) of the population with a standard of living between the lowest and the highest poverty line, but the largest increase occurred for those living between the lowest and intermediate threshold.

The poor became poorer as well from 1996 to 1997 . While the overall poverty gap ratio was $13 \%$ according to the minimum wage threshold in 1996, it increased by five percentage points to $18 \%$ in 1997 , i.e. the average distance to the poverty line increased. Poverty severity also increased. within this year in Latvia. It seems that distribution among the poor became more unequal, i.e. there were more people at the lower end of the welfare distribution. Summarizing, there were more poor people in 1997 with a larger gap between their standard of living and the poverty line on average and with increased inequality among the poor"s level of welfare.

The following sections are very detailed providing a vast amount of information for various groups of households. It concentrates on geographical location, household size, income source, gender and housing. The reader interested in the main findings may skip section 3.3 .1 and move on to 3.3 .2 where the results are summarized and put into a regional perspective.

\subsubsection{The profile}

The three poverty measures presented in the tables can be interpreted as follows: the first meastre, the poverty headcount ratio provides an estimate of the poverty frequency, i.e. the percentage of individuals that are poor according to the respective poverty line. This measure can also be interpreted as the probability, or risk, of living in poverty. The higher the percentage, the bigger the risk. The second measure, the poverty gap ratio, provides an estimate of the depth of poverty, i.e. the average expenditure shortfall per capita of the poor with respect to the poverty line (in percentages). The larger the poverty gap, ceteris paribus, the deeper is the poverty, the lower are the average monthly household expenditures per capita of the poor. The third measure, the poverty severity ratio, expresses the level of inequality among the poor. The higher the index, the more severe poverty, i.e. the more poor individuals are living at the lower level of the welfare scale and are farther away from the poverty line. The characteristics of the household are related to the breadwinner who is defined as the main income contributor based on the survey information. ${ }^{1.4}$

\section{a) Poverty and geographical location}

A first division between urban and rurall areas indicates that poverty is more widespread, deeper and more unequal in rural areas. In rural areas, $52 \%$ of the people lived below the minimum wage poverty line in 1996 ( $38 \%$ in urban areas). The average expenditure shortfall of the poor with respect to the poverty line (poverty gap ratio) was $18 \%$ in rural, and $10 \%$ in urban areas in the same period. This means, relatively more people are poor in rural areas and they are on average poorer. The distribution among the poor is also more unequal in rural areas (poverty severity ratio). Comparing these results with 1997 , it is evident that there was an above average increase of poverty in rural areas. With respect to the lowest and intermediate poverty line, the poverty risk increased by five and eleven percentage point respectively in rural areas. More than one fourth of the rural population spent less than $50 \%$ of the average in 1997 . More than $60 \%$ lived on less than $38 \mathrm{LVL}$

\footnotetext{
${ }^{1}$ This is consistent with calculations of the CSB of Latvia, which state that the increase in disposable income as well as average household expenditures wass lower than the inflation. The purchasing power decreased from 1996 to 1997 (CSB, $1998: 162,170)$.

"The terms "breadwinner", "household head" and "main income contributor" will be used interchangeably throughoat the paper.
} 
Table 3.3. Poverty and Location 1996 -1997 (January 1996 prices)

\begin{tabular}{|c|c|c|c|c|c|c|}
\hline & \multicolumn{2}{|c|}{$50 \%$ of umean exp. } & \multicolumn{2}{|c|}{38 lats } & \multicolumn{2}{|c|}{52 lats } \\
\hline & 1996 & 1997 & 1996 & 1997 & 1996 & 1997 \\
\hline & \multicolumn{6}{|c|}{ Headcount } \\
\hline AH housshoids & 14.42 & 17.59 & 41.93 & 50.32 & 68.13 & 73.26 \\
\hline \multicolumn{7}{|l|}{ Location } \\
\hline urban & 10.86 & 13.27 & 37.61 & 44.95 & 65.14 & 70.00 \\
\hline rural & 22.34 & 27.44 & 51.52 & 62.59 & 74.76 & 80.71 \\
\hline \multicolumn{7}{|l|}{ By ragion } \\
\hline Riga: region & 10.09 & 13.46 & 34.63 & 43.55 & 6.2 .53 & 68.34 \\
\hline Kurzene & 18.03 & 20.17 & 46.63 & 53.36 & 72.27 & 73.91 \\
\hline Vidzeme & 20.81 & 22.54 & 49.12 & 56.03 & 73.52 & 77.98 \\
\hline Zemgate & 17.27 & 16.20 & 47.19 & 51.59 & 70.14 & 76.23 \\
\hline Lalgale & 16,05 & 22.61 & 48.15 & 61.22 & 73.94 & 80.40 \\
\hline \multicolumn{7}{|c|}{ By type of settlement } \\
\hline Riga & 9.37 & 11.99 & 33.46 & 41.54 & 61.73 & 66.74 \\
\hline Large citles & 11.16 & 13.12 & 39.52 & 46.61 & 67.80 & 71.11 \\
\hline Small cities & 12.93 & 15,42 & 42.29 & 48.91 & 68.22 & 74.21 \\
\hline \multirow[t]{2}{*}{ Rural } & 22.34 & 27.44 & 51.52 & 62.59 & 74.76 & 80.71 \\
\hline & \multicolumn{6}{|c|}{ Poverty gap } \\
\hline All households & 3.60 & 5.84 & 12.63 & 17.68 & 24.33 & 29.88 \\
\hline \multicolumn{7}{|l|}{ Location } \\
\hline urban & 2.66 & 4.11 & 10.37 & 14.41 & 21.63 & 26.31 \\
\hline rurral & 5.68 & 9.79 & 17.66 & 25.43 & 30.32 & 38.02 \\
\hline \multicolumn{7}{|l|}{ By region } \\
\hline Riga regiom & 2.41 & 4.08 & 9.43 & 14.14 & 20.15 & 25.69 \\
\hline Kurzene & 4.91 & 6.05 & 15. ㅂ. 8 & 19.59 & 27.63 & 31.79 \\
\hline Vidzeme & 5.68 & 8.85 & 17.07 & 22.38 & 29.17 & 34.96 \\
\hline Zemgale & 4.17 & 6.04 & 14.73 & 18.48 & 27.05 & 30.89 \\
\hline Latgale & 3.72 & 7.38 & 14.93 & 21.67 & 27.07 & 35.23 \\
\hline \multicolumn{7}{|c|}{ By type of settrement } \\
\hline Riga & 2.17 & 3.41 & 8.84 & 13.06 & 19.41 & 24.74 \\
\hline Large citlos & 2.94 & 4.44 & 10.99 & 14.79 & 22.75 & 26.84 \\
\hline Small cities & 3.20 & 4.95 & 12.23 & 16.22 & 24.16 & 28.77 \\
\hline \multirow[t]{2}{*}{ Rural } & 5.68 & 9.79 & 17.66 & 25.13 & 30.32 & 38.02 \\
\hline & \multicolumn{6}{|c|}{ Poverty' severity } \\
\hline All housaholds & 1.42 & 2.95 & 5.49 & 8.94 & 14.70 & 16.08 \\
\hline \multicolumn{7}{|l|}{ Location } \\
\hline urban & 1.03 & 2.02 & 4.29 & 6.85 & 9.87 & 13.32 \\
\hline rural & 2.27 & 5.07 & 8.14 & 13.73 & 15.76 & 22.37 \\
\hline \multicolumn{7}{|l|}{ By region } \\
\hline Riga region & 0.93 & 2.01 & 3.89 & 6.79 & 9.06 & 13.07 \\
\hline Kurzene & 2.01 & 3.57 & 6.98 & 10.18 & 13.90 & 17.66 \\
\hline Widzome & 2.50 & 4.96 & 8.02 & 12.31 & 15.24 & 20.20 \\
\hline Zemgale & 1.56 & 2.90 & 6.40 & 9.29 & 13.37 & 16.68 \\
\hline Latgale & 1.31 & 3.57 & 5.93 & 11.05 & 13.00 & 19.48 \\
\hline \multicolumn{7}{|c|}{ By type of satthement } \\
\hline Riga & 0.82 & 1.56 & 3.59 & 6.01 & 8.58 & 12.11 \\
\hline Large cities & 1.16 & 2.26 & 4.59 & 7.10 & 10.45 & 13.69 \\
\hline Small citles & 1.24 & 2.55 & 5.14 & 7.94 & 11.40 & 14.92 \\
\hline Rural & 2.27 & 5.07 & 8.14 & 13.73 & 45.76 & 22,37 \\
\hline
\end{tabular}

Sounce: HES 1996, 1997. 
Table 3.4. Foverty and household composition, 1996- 1997 (January 1996 prices)

\begin{tabular}{|c|c|c|c|c|c|c|}
\hline & \multicolumn{2}{|c|}{$50 \%$ of mean axp. } & \multicolumn{2}{|c|}{38 lats } & \multicolumn{2}{|c|}{52 lats. } \\
\hline & 1996 & 1997 & 1996 & 1997 & 1996 & 1997 \\
\hline & \multicolumn{6}{|c|}{ Headcount } \\
\hline All households & 14.42 & 17.59 & 41.93 & 50.32 & 68.13 & 73.26 \\
\hline \multicolumn{7}{|l|}{ Households with } \\
\hline o children & 8.29 & 12.67 & 31.91 & 40.75 & $5 B 86$ & 65.56 \\
\hline 1 child & 15.06 & 18.81 & 44.18 & 53.52 & 71.15 & 76.12 \\
\hline 2 children & 20.52 & 22.09 & 52.92 & 61.97 & 79.32 & 83.87 \\
\hline 3 children & 34.53 & 35.68 & 70.87 & 76.92 & 89.07 & $9 \% .46$ \\
\hline $4+$ children & 51.82 & 44.78 & 83.25 & 86.31 & 96.62 & 94.44 \\
\hline \multicolumn{7}{|l|}{ Household size } \\
\hline 1 & 5.12 & 8.12 & 24.26 & 32.22 & 54.70 & 56.56 \\
\hline 2 & 8.18 & 12.59 & 30.88 & 39.34 & 57.96 & 65.67 \\
\hline 3 & 11,79 & 16.67 & 39.13 & 48.14 & 66.70 & 72.17 \\
\hline 4 and more & 21.99 & 24.03 & 54.62 & 63.70 & 79.20 & 83.62 \\
\hline \multicolumn{7}{|l|}{ Mouseholds with } \\
\hline a dependants & 7.60 & 12.19 & 30.25 & 39.23 & 57.55 & 64.42 \\
\hline 1 dependant & 14.10 & 16.74 & 42.09 & 50.08 & 68.79 & 73.53 \\
\hline 2 dependants & 18.26 & 20.94 & 50.76 & 58.87 & 76.53 & 80.87 \\
\hline 3 dependants & 28.97 & 29.55 & 62.26 & 71.64 & 87.63 & 89.63 \\
\hline \multirow[t]{2}{*}{$4+$ dependants } & 41.89 & 43.54 & 76.55 & 87.91 & 89.34 & 95.58 \\
\hline & \multicolumn{6}{|c|}{ Poverty glap } \\
\hline All households & 3.60 & 5.84 & 12.63 & 17.86 & 24.33 & 29.88 \\
\hline \multicolumn{7}{|l|}{ Househalds with } \\
\hline 0 children & 2.09 & 4.10 & 8.40 & 13.31 & 48.60 & 24.39 \\
\hline 1 child & 3.45 & 6.04 & 13.24 & 18.65 & 25.36 & 31.26 \\
\hline 2 children & 5.21 & 7.61 & 17.21 & 22.49 & 30.81 & 36.40 \\
\hline 3 children & 8.92 & 12.24 & 25.07 & 32.44 & 40.46 & 46.97 \\
\hline $4+$ children & 15.53 & 17.12 & 35.64 & 38.95 & 51.15 & 53.54 \\
\hline \multicolumn{7}{|l|}{ Househoid size } \\
\hline 1 & 1.18 & 3.10 & 5.77 & 9.90 & 14.47 & 19.47 \\
\hline 2 & 2.04 & 4.01 & 8.17 & 13.02 & 18.30 & 24.00 \\
\hline 3 & 2.85 & 5.30 & 11.00 & 16.35 & 22,36 & 28.38 \\
\hline 4 and mone & 5.58 & 8.09 & 17.96 & 23.62 & 31.57 & 37.46 \\
\hline \multicolumn{7}{|l|}{ Households with } \\
\hline D dependants & 1.96 & 4.111 & 7.84 & 12.90 & 17.76 & 23.75 \\
\hline 1 dependant & 3.17 & 5.22 & $12.4 B$ & 16.87 & 24.27 & 29.21 \\
\hline 2 dependants & 4.58 & 7.04 & 15.94 & 21.12 & 29.11 & 34.46 \\
\hline 3 dependants & 7.41 & 10.08 & 21.42 & 28.60 & 36.38 & 43.12 \\
\hline \multirow[t]{2}{*}{$4+$ dependants } & 12.10 & 15.22 & 30.04 & 37.02 & 44.93 & 52.50 \\
\hline & \multicolumn{6}{|c|}{ Poverty severity } \\
\hline All housenolds & $\# .42$ & 2.95 & 5.49 & 8.94 & 11.70 & 16.08 \\
\hline \multicolumn{7}{|l|}{ Household's with } \\
\hline O children & 0.87 & 2.10 & 3.42 & 6.52 & 0.20 & 12.41 \\
\hline 1 child & 1.26 & 3.00 & 5.58 & 9.34 & 12.14 & $\$ 6.86$ \\
\hline 2 chilidren & 1.98 & 3.76 & 7.67 & 11.45 & 15.52 & 20.15 \\
\hline 3 cthildren & 3.36 & 6.08 & 12.08 & 17.66 & 22.13 & 28.39 \\
\hline 4 + children & 7.48 & 9.58 & 19.13 & 22.74 & 30.95 & 34.22 \\
\hline
\end{tabular}


Table 3. 4. cont.

\begin{tabular}{|c|c|c|c|c|c|c|}
\hline & \multicolumn{2}{|c|}{$50 \%$ of madn exp. } & \multicolumn{2}{|c|}{38 lats } & \multicolumn{2}{|c|}{52 Uats } \\
\hline & 1996 & 1997 & 1996 & 1997 & 1996 & 1997 \\
\hline & \multicolumn{6}{|c|}{ Poverty severity } \\
\hline \multicolumn{7}{|l|}{ Houserold size } \\
\hline 1 & 0.50 & 1.82 & 2.20 & 4.84 & 5.90 & 9.51 \\
\hline 2 & 0.78 & 2.09 & 3.31 & 6.41 & 8.03 & 12.17 \\
\hline 3 & 1.11 & 2.64 & 4.60 & 8.18 & 10.36 & 14.99 \\
\hline 4 and mope & 220 & 3.99 & 8.12 & 12.15 & $16 .+3$ & 21.06 \\
\hline \multicolumn{7}{|l|}{ Households with } \\
\hline Odependants & 0.82 & 2.18 & 3.19 & 6.41 & 7.73 & 12.09 \\
\hline 1 dopendant & 1.13 & 2.50 & 5.10 & 8.25 & 11.50 & 15.36 \\
\hline 2 depandants: & 1.78 & 3.48 & 6.96 & 10.70 & 14.44 & 18.95 \\
\hline 3 dopendanis & 2.76 & 5.10 & 10.12 & 15.15 & 19.18 & 25.21 \\
\hline $4+$ depondants & 5.53 & 7.95 & 15.46 & 20.78 & 26.21 & 32.54 \\
\hline
\end{tabular}

Source: HBS 1996, 1997 .

per capita. The increase in the poverty gap ratio and the severity ratio was also more pronounced in rural than in urban areas. Compared with the owerall picture, the inter-range shares between lowest and internediate threshold increased comparatively more.

As shown in Table 3.3, the Rigas region has significantly lower powerty rates than the rest of the country in all three cases and both years. Ten percent of the population living in this region are poor according to the lowest standard in 1996. But the Rigas region is also confronted by an increase in the poverty risk, although in all cases the figures are still below the national average. The values of the remaining regions are relatively close but develop differenty. The ranking changes from the lowest standard to the intermediate standard, which we expected following the sensitivity analysis in the previous section. In the first case, Vidzeme has the highest poverty rate in 1996 $(21 \%)$ followed by Kurzeme (18\%); Latgale is the region with the highest poverty rate in 1997 (23\%), followed by Vidzeme. Increasing the threshold moves Latgale into the position of having the highest poverty in most cases. The increase of the headcount ratio is also most pronounced in Latgale with, e.g., more than 13 percentage points from $48 \%$ to $61 \%$ with respect to the intermediate poverty line. With respect to the depth of poverty, a similar pattem emerges. The average expenditure shortfall of the poor is lowest in the Rigas region in all cases, but considerably higher in the rest of Latvia. Breaking the data down by size of settlement, the table shows that the smaller the town or village, the higher the poverty rate, the larger the poverty gap and the more inequality among the poor.

\section{b) Household size, household composition and number of children per household}

An average Latwian household has 2.42 members and 0.48 children (see also section 3.4, Table 3.10). In general, the risk of living in poverty increases with each additional household member (see Table 3.4). Compared to the national average, households with up to three members have lower poverty rates. Single households face the lowest poverty risk. Only five percent of these were living below the lowest poverty line in 1996, whereas more than twenty percent of the individuals living in households with four or more members were poor according to the lowest standard. Taking the crisis minimum as the reference point, headcount ratios varied between $52 \%$ for single households and $79 \%$ for households with four or nore members. Households with two members faced a more than proportionate increase of the headcount ratio in 1.997 with respect to the highest poverty line. The increasing risk for larger household sizes also applies for the poverty-gap and poverty-severity ratios. The larger the household, the bigger the average distance between the expenditure level and the poverty line, and the more unequal the distribution among the poor. The change from a three- 
person household to one with more members is especially considerable in terms of the average expenditure shortfall (poverty gap).

As Table 3.4 shows, the presence of children in a household increases the poverty risk for all members living in such households. Households with no children face the lowest poverty risk, although even in this case more than $59 \%(66 \%$ in 1997) are poor with respect to the highest poverty threshold. Considering the headcount ratios as presented in Table 3.4, each additional child contributes considerably to the poverty risk of the respective household. Especially households with three or more children are highly exposed to poverty,

$35 \%$ of all individuals living in three-children housebolds were living on less than $24 \mathrm{LVL}$ in 1996 ( $52 \%$ if four or more children are present). These rates are much higher for the intermediate poverty line based on the minimum wage, and even more than $90 \%$ are poor when taking the crisis minimum poverty line as the benchmark. Comparing these results to 1997 , it seems that the households with one or no children were confronted with the relatively largest increase in poverty risk. Although the table indicates a negative growth rate for households with four or more children, these figures have to be treated with caution because of the small sample. The average poverty risk for households with children is above average in 1997, and the poverty they are confronted with is deeper and more severe than in 1996. These figures are rather disturbing, but one should also take into account that only 3\% of all Latvian households have three or more children. $69 \%$ of all households are without children and $18 \%$ have one child (see Section 3.4, Table 3.11).

Besides household size and the number of children, the number of dependants in general can have an influence on a household's risk of poverty. A dependant is either a child or an adult household member without any form of own income. As expected, households with no dependants are best off and have the lowest poverty risk. Nevertheless, they had to face a considerable increase in poverty rates as well from 1996 to 1997 . It is also interesting to compare the specific presence of children with the presence of dependants in general in a household. It seems that having one dependant in a households is a better risk than having one child. The same is true for two dependants versus two children and holds with respect to expenditure shortfall and the distribution of the poor as well.

A more specific picture emerges when considering different household compositions. A child living in a houselhold together with one adult only or with two adults has more or less the same risk of being poor, except for those living at the lowest end of the income distribution. The risk for a single child increases when more than two adults live in the same household. The poverty rate for a household consisting of three adults and one child was $49 \%$ in 1996 with the poverty line equal to the minimum wage. This is clearly above the average for all households with one child. Three person-adults-only-households are better off than any other combination of three persons (one adult with two children or two adults with one child). The situation changes in the case of wo and more children. If they live together in a household with one adult, the poverty risk is considerably higher than in the case of two adults living with children. ${ }^{\text {is }}$

\section{c) Education, income and employment}

Table 3.5 a presents poverty rates according to the educational attainment of the household head. The higher the educational level of the breadwinner, the lower the poverty risk for all individuals liwing in such households. The largest increase in the poverty rate is from higher education to secondary education. The highest poverty risk is faced by households whose head has lower than primary or no education at all. Only the households with heads who have completed higher education have poverty rates below the national average. This is true for all poverty lines and for

\footnotetext{
". Note that there were very few households with this combination in 1997.
} 
Table 3.5a. Poverty and sducation and income, 1996-1997. (Januam 1996 prices)

\begin{tabular}{|c|c|c|c|c|c|c|}
\hline & \multicolumn{2}{|c|}{$50 \%$ of mean exp. } & \multicolumn{2}{|c|}{38 lats } & \multicolumn{2}{|c|}{52 lats } \\
\hline & 1996 & 1997 & 1996 & 1997 & 1996 & 1997 \\
\hline & \multicolumn{6}{|c|}{ Headcount } \\
\hline All housenolds & 14.42 & 17.59 & 41.93 & 50.32 & 68.13 & 73.26 \\
\hline \multicolumn{7}{|l|}{ Education of head } \\
\hline higher & 3.91 & 8.56 & 19.74 & 29.04 & 45.49 & 54.29 \\
\hline seconday & 14.44 & 17.47 & 43.40 & 51.34 & 70.28 & 74.91 \\
\hline vocational & 18.84 & 22.48 & 46.04 & 61.64 & 74.60 & 81.09 \\
\hline primary & 20.73 & 23.93 & 52.62 & 61.81 & 77.55 & 81.96 \\
\hline lower than primary & 23.17 & 27.81 & 59.24 & 65.46 & 82.03 & 85.76 \\
\hline no education & 50.69 & 54.47 & 61.31 & 74.96 & 80.97 & 90.18 \\
\hline \multicolumn{7}{|l|}{ Main income of head } \\
\hline Employment & 10.46 & 14.58 & 36.37 & 46.19 & 6.3 .52 & 69.23 \\
\hline Self-employed & 8.03 & 12.67 & 31.24 & 35.27 & 54.97 & 56.15 \\
\hline Agriculture & 27.06 & 33.91 & 58.11 & 69.00 & 78.85 & 84.73 \\
\hline Pansion: & 13.62 & 17.58 & 44.06 & 52.04 & 72.29 & 77.12 \\
\hline Social benefits & 40.39 & 26.45 & 64.89 & 67.88 & 81.12 & 84.39 \\
\hline \multirow[t]{2}{*}{ Other } & 41.26 & 30.99 & 68.11 & 63.12 & 84.89 & 86.76 \\
\hline & \multicolumn{6}{|c|}{ Poverty gap } \\
\hline All households & 3.60 & 5.84 & 12.63 & 17.68 & 24.33 & 29.88 \\
\hline \multicolumn{7}{|l|}{ Education of head } \\
\hline higher & 0.70 & 3.00 & 4.32 & 9.06 & 11.90 & 18.04 \\
\hline secondery & 3.39 & 5.59 & 12.74 & 17.66 & 24.93 & 30.24 \\
\hline wocationa: & 4.62 & 7.37 & 15.51 & 22.39 & 28.03 & 35.74 \\
\hline primary & 5.68 & 8.26 & 17.43 & 23.17 & 30.63 & 36.76 \\
\hline lower than primary & 7.02 & 9.00 & 19.58 & 25.40 & 33.90 & 39.22 \\
\hline no educatton & 15.41 & 16.53 & 29.88 & 37.53 & 41.75 & 49.18 \\
\hline \multicolumn{7}{|l|}{ Main income of head } \\
\hline Employment & 2.24 & 4.73 & 9.89 & 15.28 & 20.82 & 26.96 \\
\hline Self-employed & 1.73 & 5.18 & 7.39 & 12.78 & 17.61 & 21.99 \\
\hline Agriculture & 6.53 & 11.19 & 20.51 & 28.77 & 33.94 & 42.09 \\
\hline Pension & 3.66 & 5.70 & 12.83 & 18.06 & 25.48 & 31.05 \\
\hline Social benefits & 12.00 & 9.24 & 27.71 & 26.31 & 40.43 & $40: 26$ \\
\hline \multirow[t]{2}{*}{ Other } & 14.75 & 12.82 & 29.90 & 28.72 & 43.00 & 41.27 \\
\hline & \multicolumn{6}{|c|}{ Poverty severity } \\
\hline All household's & 1.42 & 2.95 & 5.49 & 8.94 & 11.70 & 16.08 \\
\hline \multicolumn{7}{|l|}{ Equcation of head } \\
\hline hogher & 0.21 & 1.56 & 1.51 & 4.50 & 4.58 & 8.77 \\
\hline secondary & 1.23 & 2.81 & 5.38 & 8.77 & 11.81 & 16.07 \\
\hline wocational & 1.79 & 3.54 & 6.92 & 11.34 & 14.01 & 19.92 \\
\hline primary & 2.58 & 4.27 & 8.11 & 12.19 & 15.77 & 20.80 \\
\hline lower than primany & 2.90 & 4.35 & 9.22 & 13.33 & 17.71 & 22.49 \\
\hline no education & 6.75 & 7.28 & 17.18 & 21.86 & 26.16 & 32.22 \\
\hline \multicolumn{7}{|l|}{ Main income of head } \\
\hline Employment & 0.75 & 2.38 & 3.91 & 7.49 & 9.36 & 14.04 \\
\hline Self-employed & 0.75 & 2.75 & 2.96 & 6.81 & 7.50 & 11.86 \\
\hline Agriculture & 2.42 & 5.15 & 9.40 & 15.62 & 48.01 & 25.23 \\
\hline Pension & 1.51 & 3.01 & 5.55 & 9.05 & 12.06 & 16.50 \\
\hline Social bemefits & 4.82 & 4.23 & 14.53 & 13.63 & 24.02 & 23.18 \\
\hline Other & 7.55 & 6.91 & 16.99 & 16.67 & 26.46 & 25.43 \\
\hline
\end{tabular}


both years. Nevertheless, the headcount ratio for the higher education group doubled in 1997 as well with respect to the relative poverty line. Still, the rates are low compared to the other groups. The powerty severity ratios show impressively how the distribution among the poor became more unequal in 1997.

The main source of income is defined as the main contributor to household income during the three months preceding the interview. Income from employment and pensions are the two most important income sources in Latwian households whether they are poor or not. According to Table 3.1, the average net wage of the employed in the total economy amounted to LVL 78.65 per month in 1996 (88.34 in 1997, nominal value). An average old-age pension paid out under the social insurance system to unemployed pensioners was LVL 37.81 per month in 1996 and LVL 41.79 in 1997.

Table 3.5a shows that people living in households that depend on income from agriculture on social transfers (excluding pensions) face the highest poverty risk taking into account the specified sources only. In 1996, 40\% of individuals living in households depending on social transfers had less than 24 LVL per capita to spend. The proportion of poor increases to $81 \%$ when the crisis minimum is taken as the reference point. For agriculture, the respective figures are $27 \%$ and $79 \%$ for 1996. Having income from employment or living on a pension as the main source of income reduces the poverty risk. The poverty rates for households living on pensions are close to the national average. This contrasts with the rather popular belief that pensioners belong to the most vunerable groups in terms of poverty. The lowest poverty rates are for individuals living in households where the main income comes from self-employment, but it has to be taken into account that only one percent of all households mention this source as the most important (see Section 3.4, Table 3.12). The poverty gap and poverty severity ratios move parallel with the headcount ratio. The higher the headcount, the larger the average expenditure gap and the more people who live far below the poverty line. The comparison with the results for 1997 show some significant changes. Households with social benefits as the main income source have improved their relative position especially at the lower end of the scale. It is one of the few cases where there was a negative trend in the poverty rate. The headcount ratio decreased with respect to the relative poverty line, and so did the other rates. The opposite happened with household living on agricultural income. They faced a considerable increase in their poverty risk. It is not only that more 'heads' are poor, but the average distance from the poverty line increased and the distribution became more unequal. This outcome is confirmed by the CSB in their analysis of the 1997 round of the HBS: *... the purchasing capacity of the population has declined by $0.6 \%$. That occurred mainly at the expenses of rural households, .... [which] can be explained by the fact that income from agricultural production lhas decreased.'(CSB, 1998:162).

Differences in the poverty rates are also found when disaggregating by income source and location. Overall, powerty rates are higher in rural areas for all income sources. The most significant differences in poverty rates are connected with income from agriculture, employment and social transfers where urban households are significantly less at risk than rural households with respect to the latter two categories. A change in position occurs among households that depend on agriculture as the main income source. While urban households had half the poverty risk of rural households in 1996 (14\%, c.q. $28 \%$ ), the situation changed in 1997 . Urban households with agriculture as the main income source surpassed their rural counterparts with a poverty rate of $39 \%$ versus $34 \%$.

Due to the changes made in the HBS questionnaire, it is not passible to compare poverty rates to employment status over two years. Therefore, both years are discussed separately. Looking at the major activity of the breadwinner in 1996, 50\% are working (see Section 3.4, Table 3.13). The poverty rates for individuals living in a household with a breadwinner with a job (working or not) are lower than the national averages under all poverty lines (see Table $3.5 \mathrm{~b}$ ). The highest poverty 
Table 3.56. Poverty and employment, 1995-1997 (January 1996 prices)

\begin{tabular}{|c|c|c|c|c|c|c|}
\hline & \multicolumn{2}{|c|}{$50 \%$ of mean exp. } & \multicolumn{2}{|c|}{38 liats } & \multicolumn{2}{|c|}{52 lats } \\
\hline & 1996 & 1997 & 1996 & 1997 & 1996 & 4997 \\
\hline & \multicolumn{6}{|c|}{ Headcount } \\
\hline All households & 14.42 & 17.59 & 41.93 & 50.32 & 68.13 & 73.26 \\
\hline \multicolumn{7}{|l|}{ Major activity of head } \\
\hline Working & 11.70 & & 37.83 & & 64.28 & \\
\hline Wittr a job but not at work & 10.19 & & 33.57 & & 62.36 & \\
\hline Looking for al job & 34.46 & & 65.42 & & 83.96 & \\
\hline Kespiry housw & 22.92 & & 51.19 & & 77.07 & \\
\hline Other & 15.60 & & 45.94 & & 73.15 & \\
\hline \multicolumn{7}{|l|}{ Employment status of head } \\
\hline Employed & & 15.84 & & 48.42 & & 79.44 \\
\hline Unernployed & & 30.53 & & 85.39 & & 85.63 \\
\hline Employed above working age & & 8.58 & & 26.93 & & 45.56 \\
\hline \multirow[t]{2}{*}{ Other } & & 20.44 & & 55.05 & & 78.67 \\
\hline & \multicolumn{6}{|c|}{ Poverty gap } \\
\hline AN housenolds & 3.60 & 5.84 & 12.63 & 17.68 & 24.33 & 29.88 \\
\hline \multicolumn{7}{|l|}{ Major activity of head } \\
\hline Working & 258 & & 10.72 & & 24.79 & \\
\hline With a job but not at work & 1.93 & & 8.81 & & 19.61 & \\
\hline Looking for a job & 9.88 & & 24.92 & & 38.75 & \\
\hline Keeping house & 7.92 & & 48.76 & & 31.52 & \\
\hline Other & 4.11 & & 13.95 & & 26.64 & \\
\hline \multicolumn{7}{|l|}{ Employment status of head } \\
\hline Employed & & 5.20 & & 16.31 & & 28.33 \\
\hline Uinemployed & & 11.115 & & 28.04 & & 41.29 \\
\hline Employed above working age & & 3.25 & & 9.46 & & 16.85 \\
\hline \multirow[t]{2}{*}{ Other } & & 6.76 & & 20.06 & & 33.07 \\
\hline & \multicolumn{6}{|c|}{ Poverty severity } \\
\hline All households & 1.42 & 2.95 & 5.49 & 8.94 & 11.70 & 16.08 \\
\hline \multicolumn{7}{|l|}{ Major activity of head } \\
\hline Working & 0.92 & & 4.37 & & 10.03 & \\
\hline With a job but not at work & 0.65 & & 3.48 & & 8.59 & \\
\hline Looking for a job & 4.23 & & 12.57 & & 21.93 & \\
\hline Koeping house & 3.86 & & 9.75 & & 17.13 & \\
\hline Other & 1.64 & & 6.13 & & 12.92 & \\
\hline \multicolumn{7}{|l|}{ Employment stetus of head } \\
\hline Employod & & 2.61 & & 8.09 & & 14.94 \\
\hline Unemployed & & 5.52 & & 15.44 & & $24 \cdot 68$ \\
\hline Employed above working age & & 1.69 & & 4.91 & & 8.82 \\
\hline Other & & 3.45 & & 10.30 & & 18.13 \\
\hline
\end{tabular}

Souroe: HES 1996, 1997.

risk is faced by those households where the breadwinner was looking for a job. The headcount ratio is more than thirty percent for the lowest threshold, $65 \%$ according to the intermediate poverty line and more than eighty percent in the case of the highest standard. Poverty is also deeper for this category compared to the other groups, i.e. the average distance to the poverty line is larger. The 1997 data allow a more standard breakdown according to the employment status of the household head. It is not the employed who have the lowest poverty rates, but the employed above the working age. This is related to the fact that persons above the working age receiving an old-age pension are 
still allowed to work which gives them a double-income. Households with an unemployed breadwinner are clearly most at risk of living in poverty. The headcount ratio is high, so are the poverty gap and severity ratios, indicating the very valnerable position of this group.

d) Gender and age

For the analysis of gender differences and poverty, male and female headed households are compared. The household head is still defined as the main income contributor (breadwimner) of the household according to the HBS data. ${ }^{16}$ Table 3.6 presents average poverty rates for male and female headed households. ${ }^{17}$ With respect to poverty, there is no conclusive relationship at first sight. A more detailed gender-based analysis of poverty reveals some differences between the risk of living in poverty depending on the characteristics of the breadwinner (see Table 3.7). Taking the official minimum wage as the poverty threshold, the headcount ratios for male and female headed

Table 3.6. Poverty and gender of the breadwinner, 1996-1997 (January 1996 prices)

\begin{tabular}{|c|c|c|c|c|c|c|}
\hline & \multicolumn{2}{|c|}{$50 \%$ of mean exp. } & \multicolumn{2}{|c|}{38 lats } & \multicolumn{2}{|c|}{52 iats } \\
\hline & 1996 & 1997 & 1996 & 1097 & 1996 & 1997 \\
\hline & \multicolumn{6}{|c|}{ Headcount } \\
\hline AN households & 14.42 & 17.59 & 41.93 & 50.32 & 68.13 & 73.26 \\
\hline Male thead & 14.76 & 17.31 & 40.92 & 49.34 & 68.42 & 73.31 \\
\hline \multirow[t]{2}{*}{ Femalle head } & 14.16 & 17.88 & 42.70 & 51.38 & 67.91 & 73.22 \\
\hline & \multicolumn{6}{|c|}{ Poverty gap } \\
\hline All trouseholds & 3.60 & 5.8 .4 & 12.63 & 117.68 & 24.33 & 29.88 \\
\hline Male head & 3.51 & 5.62 & 12.52 & 17.28 & 24.15 & 29.48 \\
\hline \multirow[t]{2}{*}{ Female head } & 3.67 & 6.08 & 12.71 & 18.11 & 24.47 & 30.30 \\
\hline & \multicolumn{6}{|c|}{ Poverty severity } \\
\hline All households & 1.42 & 2.95 & 5.49 & 8.94 & 11.70 & 16.08 \\
\hline Male head & 1.37 & 2.81 & 5.4 & 8.70 & 11.59 & 15.76 \\
\hline Female head & 1.45 & 3,11 & 5.52 & 9.18 & 11.78 & 16.42 \\
\hline
\end{tabular}

Source: HBS 1996, 1997.

households are almost equal ( $41 \%$ versus $43 \%$ in $1996,49 \%$ versus $51 \%$ in 1997$)$. Whether a household has children or not makes a difference. With an increasing number of children, poverty rates are higher in female headed households although they are almost equal in the case of no children (even lower in 1996). With respect to the household composition, only female-headed. households consisting of one adult and one or two children are performing better with respect to the powerty risk. The trend of increased poverty rates in 1997 affected all groups. With respect to household size, with each additional household member poverty rates increase faster in femaleheaded households. The opposite is the case in single households. Female households fared considerably better than their male counterparts in 1996 . Only $23 \%$ of single females were poor compared to $30 \%$ of male singles. This difference decreased in 1997: the headcount ratio of the female group increased to $32 \%$ while the male single household's risk rose to $34 \%$.

\footnotetext{
Whe definition differs from the one used in the HBS which is "Head of household is the member of the houschold which is considered as such by the members of the houschold, having decisive rights when solving common issues af the howsehold' (CSB, 1.997:8). 74.7\% of main income contributors are also household head as defined by the C.SB.
}

${ }^{7}$ A majority $(57 \%)$ of the households have a female breadwimner (see Section 3.4 , Table 3.15 ). 
Table 3.7. Povarty by gender (poverty line = 38 LVL), 1996-1997 (January 1996 prices)

\begin{tabular}{|c|c|c|c|c|c|c|}
\hline & \multicolumn{3}{|c|}{1996} & \multicolumn{3}{|c|}{1997} \\
\hline & Male & Female & All & Malle & Femalle: & All \\
\hline & \multicolumn{6}{|c|}{ Headcount } \\
\hline All households & 40.92 & 42.70 & 41.93 & 49.34 & 51.38 & 50.32 \\
\hline \multicolumn{7}{|l|}{ Households with } \\
\hline 0 children & 33.09 & 31.11 & 31.91 & 39.93 & 41.46 & 40.75 \\
\hline I child & 39.95 & 47.25 & 4.4 .18 & 50.28 & 57.12 & 53.52 \\
\hline 2 children & 46.34 & 58.82 & 52.92 & 59.13 & 66.53 & 61.97 \\
\hline 3 children & 68.42 & 74.01 & 70.87 & 70.88 & 86.12 & 76.92 \\
\hline $4+$ children & 80.60 & 87.20 & 83.25 & 82.18 & 93,64 & 86.31 \\
\hline \multicolumn{7}{|l|}{ Household size } \\
\hline 1 & 30.37 & 22.54 & 24.26 & 33.74 & 31.85 & 32.22 \\
\hline 2 & 29.32 & 31.94 & 30.88 & 34.10 & 44.34 & 39.34 \\
\hline 3 & 33.64 & 43.1 & 39.13 & 42.53 & 54.09 & 48.14 \\
\hline $4+$ & 50.52 & 59.01 & 54.62 & 60.66 & 69.17 & 63.70 \\
\hline \multicolumn{7}{|l|}{ Age of head } \\
\hline $15 \times 34$ & 45.55 & 50.26 & 48.06 & 53.34 & 55.57 & 54.26 \\
\hline $35-64$ & 39.38 & 39.46 & 39.43 & 48.15 & 48.89 & 48.50 \\
\hline \multirow[t]{2}{*}{65 and older } & 38.33 & 43.36 & 41.45 & 46.27 & 54.43 & 51.00 \\
\hline & \multicolumn{6}{|c|}{ Poverty gap } \\
\hline All households & 12.52 & 12.72 & 12.63 & 17.28 & 18.11 & 17.86 \\
\hline \multicolumn{7}{|l|}{ Households with } \\
\hline 0 children & 9.07 & 7.94 & 8.40 & 13.12 & 13.47 & 13.31 \\
\hline 1 child & 12.22 & 13.99 & 13.24 & 17.34 & 20.11 & 18.65 \\
\hline 2 children & 14.93 & 19.25 & 17.21 & 20.73 & 25.33 & 22.49 \\
\hline 3 children & 23.59 & 26.96 & 25.07 & 29.78 & 36.49 & 32,44 \\
\hline $4+$ children & 31.21 & 42.23 & 35.64 & 36.66 & 43.01 & 38.95 \\
\hline \multicolumn{7}{|l|}{ Household size } \\
\hline 1 & 9.19 & 4.81 & 5.77 & 11.37 & 9.55 & 9.90 \\
\hline 2 & 7.58 & 8.58 & 8.17 & 11.12 & 14.83 & 13.02 \\
\hline 3 & 9.21 & 12.31 & 11.00 & 13.94 & 18.91 & 16.35 \\
\hline $4+$ & 16.56 & 19.45 & 17.96 & 22.08 & 26.37 & 23.62 \\
\hline \multicolumn{7}{|l|}{ Age of head } \\
\hline $15-34$ & 94.74 & 16.75 & 15.81 & 19.57 & 20.51 & 19.96 \\
\hline $35-64$ & 12.01 & 11.18 & 11.54 & 16.83 & 16.60 & 16.72 \\
\hline \multirow[t]{2}{*}{65 and older } & 10.27 & 12.37 & 11.57 & 14.46 & 20.10 & 17.73 \\
\hline & \multicolumn{6}{|c|}{ Poverty severity } \\
\hline An households & 5.4 .4 & 5.52 & 5.49 & 8.71 & 9.19 & 8.94 \\
\hline \multicolumn{7}{|l|}{ Households with } \\
\hline 0 children & 3.79 & 3.17 & 3.42 & 6.47 & 6.57 & 6.52 \\
\hline 1 child & 5.18 & 5.87 & 5.58 & 8.67 & 10.09 & 9.34 \\
\hline 2 children & 6.57 & 8.66 & 7.67 & 10.42 & 13.01 & 11.45 \\
\hline 3 children & 10.68 & 13.86 & 12.08 & 16.01 & 20.17 & 17.66 \\
\hline 4 * children & 16.01 & 23.78 & 19.13 & 20.01 & 27.51 & 22.71 \\
\hline \multicolumn{7}{|l|}{ Household size } \\
\hline 1 & 4.30 & 1.61 & 2.20 & 5.76 & 4.63 & 4.84 \\
\hline 2 & 3,10 & 3.46 & 3.31 & 5.56 & 7.23 & 6.41 \\
\hline 3 & 3.68 & 5.28 & 4.60 & 7.04 & 9.37 & 8.18 \\
\hline 44 & 7,39 & 8.90 & B. 12 & 11.15 & 13.96 & 12.15 \\
\hline
\end{tabular}


Table $3,7$. cont.

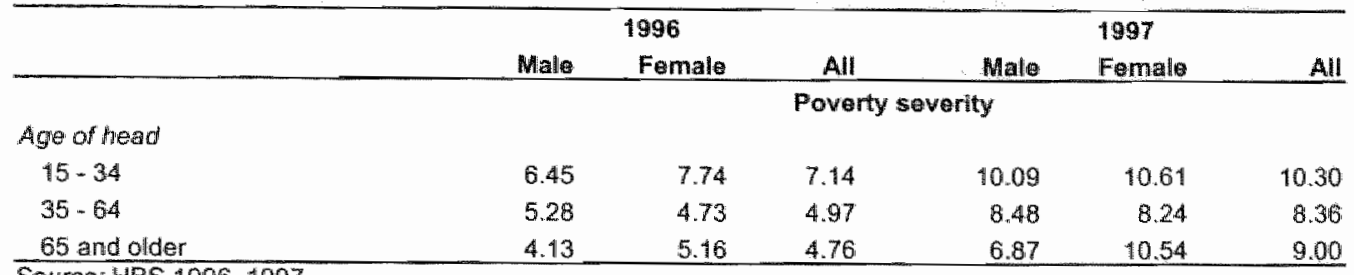

Source: HBS 1996, 1997.

The risk of poverty is negatively correlated with the age of the household head. Analyzing poventy by age and gender, female headed households have a higher risk in all age groups, but the negative relationship is stronger for male-headed households.

With respect to the civil status of the head (see Table Al in appendix $3 \mathrm{~A}$ ), it is interesting to note that the poverty rate for households with female heads who have never married ( $42 \%)$ is lower than the rate for the male equivalent ( $44 \%$ in $1996,53 \%$ in 1997$)$. The data would seem to indicate that the best option for female heads is not to get married since the poverty risk is higher in most other cases. This is quite the opposite with male headed households, although being manried and living together became the second-worst option for male households in 1997. Significant gender differences are related to divorce and widowhood. For female-headed households it means an increased risk of living in poverty while the male counterparts face diminishing risks in the same situation.

A gender-specific look at poverty and the main source of income reveals a lower risk for female-headed households whose main income is from agriculture or social benefit. While the poverty risk was higher for female households in all educational groups in 1996, households with female heads having completed higher education or primary education were surpassed by their male counterpart in 1997. The results and trends of the poverty gap and poverty severity ratios follow those of the poverty headcount ratio (see Table Al in appendix $3 \mathrm{~A}$ ).

\section{e) Land ownership}

In Latvia, $58 \%$ of the poor households have access to a plot of land ( $51 \%$ of non-poor households). poverty rates are generally higher for households with land, but this can mainly be attributed to the higher poverty rates in nural areas. While rural households with land performed better in 1996 than the households without land, their situation worsened in 1997. For urban houselnolds, access to land does indeed reduce the poverty risk. The breakdown in Table 3.8 shows again, that the standard of living deteriorated in rural areas especially in 1997. The headcount ratio for urban households with a plot of land is equal to $43 \%$ versus $46 \%$ for those without land in 1997 . In nural areas, the ratio is $63 \%$ for households with land and $56 \%$ for those without. This means that people who have access to a plot of land and living in a rural area have a higher risk of being poor than an individual without land living in a town. Except for rural households in 1997, the poverty gap is larger on average for households without land. The severity ratio indicates that the degree of inequality among the poor changed from 1996 to 1997. There are more severely poor among the households with a plot of land in 1997. 
Table 3.8. Poverty and access to land, 1996-1997 (January 1996 pricts)

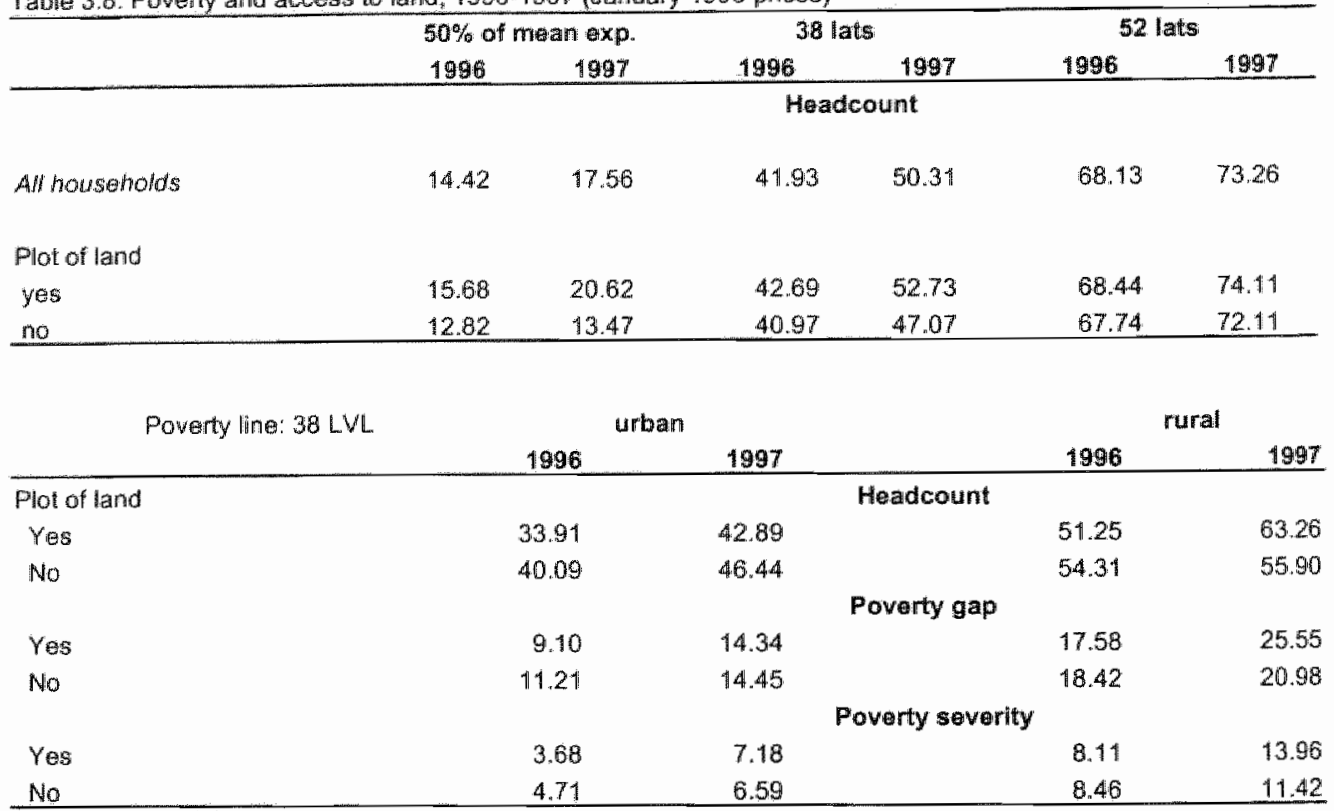

Source: HBS 1996, 1997.

\subsubsection{The findings in perspective}

Over the two years of the survey analyzed, poverty in Latvia has increased. A larger share of the population is experiencing poverty, and the distance between the average standard of living and the poverty line has increased. In other words, the poverty gap became larger. The results also indicate that there was a shift of the poor towards the lowest end of the welfare distribution, i.e. poverty became more severe.

The capital Riga and the surrounding region have significantly lower poverty rates than the other regions in Latvia. The fact, that the capital performs better with on average higher living standards is not umusual for countries in transition. Evidence for Poland (World Bank, 1995) and Hungary (UNDP, 1998e) confirms this observation. The opposite has been found for three oblasts in Russia, where urban areas in general, and the capitals in particular, were confronted with a higher poverty nisk than other areas (Seeth, 1998). In Latvia, rural areas have higher poverty rates than urban areas. The difference in poverty even increased over the years analyzed. A similar pattern has been round for the other Baltic countries, Poland and Hungary (UNDP, 1998e; Milanovic, 1998). The economic development is fastest in the capital. New employment is created, wages are on average higher than in rural areas, unemployment is lower.

The opportunity to work a plot of land is decisive for the poverty risk in some countries, as for example in Russia (Braithwaite, 1995), Georgia (World Bank, 1999) or Armenia (World Bank, 1996a). It provides an argument that in these countries rura! poverty is lower than urban poverty. But for countries such as Latvia, this relationship does not hold. Having access to a plot of land does not explain the poverty risk in Lavvia, although having land is very important for the daily subsistence of most Latvian households, irrespective of their position in the income distribution. It provides a means for the production of food for own consumption or even for the generation of some additional income. This finding illustrates at the same time that Latvia and its economy are relatively poor; that the majority of the population is confronted with relatively low liwing 
standards. The fact that more than $70 \%$ of the Latvian population lives with less than the crisis minimum basket per capita is sufficient evidence that a lot of households are employing every possible tool in order to make ends meet. Chapter five discusses in greater detail the importance of the own production of food as a means to cope (see section 5.3.1).

Related to these findings is the correlation between poverty and the dependence on income from agriculture. Latvian households relying on agriculture are very wulnerable and often live in poverty, as do farming households in Lithuania (Lazutka, 1999). Their situation worsened considerably in 1997. With respect to other income sources, $\mathbb{L}$ atrian households which depend on income from work, employed or self-employed, are best off. The highest poverty rates are found in households where the breadwinner is looking for a job (1996) or is unemployed (1997). The unemployed belong to the most vulnerable groups in the whole region. There is not one country study we looked at that did not identify the unemployed as a group at high risk of falling below the poverty line. These findings show that employment is crucial for avoiding poverty in countries in transition, although it is no guarantee, as we will show below. In Western European countries, it is usually only the group of long-term unemployed that face an increased risk of poverty thanks to rather extensive social insurance systems. In CEE countries and the FSU, the existing social insurance systems are still very young and coverage is not always comprehensive.

Education became a decisive factor for poverty. The higher the educational level attained, the lower the poverty risk in general. This trend holds not only for Latvia, but also for the Ukraine (Rose, 1995), Hungary (Spéder, 1998; Vecemik, 1996), Poland, Russia, Kazakhstan, and most other countries. ${ }^{18}$ Milanovic (1998) mentions, for example, low-skilled clerical staff with vocational education or the manual worker as very vulnerable. They are either unemployed (high risk group) or have to live on very low salaries.

The composition of the household is another factor influencing the poverty risk of a person. Size alone can have a positive as well as a negative effect on the household's welfare level. It may depend on the culture of a society. In the Ukraine and in Armenia, for example, it is the small household which is at risk, while in many other countries, the larger households are very vulnerable. The latter also holds for Latvia. The larger the household, the higher the proportion of people living below the poverty line and the poorer the household, i.e. the larger the average distance to the poverty line. Although single person households are the best-off in Latvia according to our calculations, they were confronted with a significant increase in their poverty risk in 1997. The presence of children in a household is, sadly enough, very often an indicator for poverty of the respective household. The more children, the larger the vulnerability with respect to poverty. "This relation holds in Latvia, and it holds in a majority of countries in CEE and the FSU. ${ }^{\text {"Contrary to, }}$ for example, the group of unemployed, children have always been a wulnerable group. Families with three or more children were highly at risk before the transition in the Soviet Union, Poland and Czechoslovakia (Braithwaite, 1995; Vecernik, 1996; Atkinson \& Micklewright, 1992). Their relative position did not improve during the transition.

Analyzing the poverty risk from a gender perspective, evidence from other countries presents a mixed picture as far as the poverty risk for male and female-headed households is concerned. In Armenia, no significant difference was estimated, while female poverty is clearly lower than male poverty in the Kyrgyz Republic. The opposite is the case in Belarus and Georgia (Braithwaite, 1995b; World Bank, 1998a, 1999; UNDP, 1998c). For Latvia, the poverty risk differs only various household compositions are taken into account. The larger the household or the more children per

\footnotetext{
"See the Bibliography for a list of World Bank and UMDP publications on the mentioned countries.

"We have evidence for Armeria, Belarus, Russia, Ukraine, Uzbekistan, Tajikistan, Kyrgyzstan, Lithuania, Estomia, Hungary, Poland and the Czech Republic (see Bibliography).
} 
household, the higher the poverty rates for female headed households as compared to male headed households.

The slightly negatiwe relation found between the age of the head and poverty in Latwia resembles the one found in Poland. Hungary, Russia, Armenia and Azerbaijan (Milanovic, 1998; Braithwaite, 1995a; World Bank, 1996a, 1997a). Young adults also face an above proportional poverty risk in the Czech Republic (Vecernik, 1996). It may be related to entry problems into the labor market for the young inexperienced worker, as well as with low wages.

Summarizing, we have found so far that the bypotheses as stated in the beginning of this chapter hold in Latvia. Rural households, households depending on income from agriculture, large households and those with children, and households with an unemployed breadwinner are the groups most vilnerable to poverty. A high educational level is beneficial for the standard of living, while being young can be a disadvantage.

\subsection{The profile revisited}

The previous section provided a detailed picture of poverty in Latvia. The poor have been counted, the depth of their poverty evaluated and the within-poor distribution has been compared. Some of the results presented were alarming. Take, for example, the powerty rates of households with three or four and more children. More than $70 \%$ of these groups were poor according to the mimimum wage poverty line. But this is only one part of the whole story. We do not know so far how many households in Latvia do have three or more children. This information is necessary to complete the profile and to be able to assess the situation comprehensively.

This section intends to provide insight into the characteristics and composition of poor households. The unit of analysis is the household and the tables provide the distribution of poor and non-poor households as well as of all households in total. The poverty line used to distinguish between poor and non-poor households is the official minimum wage ( 38 LVL), which was the intermediate threshold in the analysis above. The data presented in the tables are those for 1997 . We will only refer to 1996 in case of significant changes in the distribution in 1997. The characteristics of the household are again related to the breadwinner. The organization of this section follows the previous one. As in the previous section, we recommend the reader not interested in all the details proceed immediately to the end of the section, where a concise summary presents the main findings.

\section{a) Geographical location}

Looking at where the poor households live, the data in Table 3.9 indicate that almost two thirds $(62 \%)$ of all poor households live in urban areas. Compared to the overall distribution of all households, the proportion of poor households is higher in rural areas. There was also a shift of poor housetholds from turban into rural areas in 1997 (33\% in 1996 to $38 \%$ of all poor in 1997). Overall, the distribution of the households, according to the survey, is similar to the actual division of the population in urban and rural areas. At the beginning of 1997, 69\% of the Latvian population was living in urban areas (CSB, 1997e:25). Separating by region, $38 \%$ of the poor households are situated in the Riga region, $20 \%$ are settled in Latgalle, and $15 \%$ in Kurzeme. The distribution of non-poor households is very similar. The majority is live in the Riga region, followed by Latgale and Zerngale.

One third (33\%) of all households live in the capital Riga. Of the poor households, the largest share lives in rural areas (38\%), followed by Riga (26\%). The distribution of poor and non-poor households in large and small cities follows the overall distribution. 
Table 39. Geographical distribution of poor and non-poor households, 1997

\begin{tabular}{|c|c|c|c|}
\hline & \multicolumn{3}{|c|}{ Distribution of households $(\%)$} \\
\hline & Poor & Non-poor & All \\
\hline \multicolumn{4}{|c|}{ Urben - rural location } \\
\hline urban: & 61.75 & 76.09 & 70.91 \\
\hline \multirow[t]{2}{*}{ rural } & 38.25 & 23.91 & 29.09 \\
\hline & 100 & 100 & 100 \\
\hline \multicolumn{4}{|c|}{ Households per region } \\
\hline Riga region & 38.32 & 49.63 & 45.37 \\
\hline Kurrene & 15.29 & 42.92 & 13.78 \\
\hline Vidzeme & 13.52 & 10.20 & 11.40 \\
\hline Zemgalie & 13.15 & 13.04 & 13.08 \\
\hline \multirow[t]{2}{*}{ Latgale } & 19.72 & 14.48 & 16.38 \\
\hline & 100 & 100 & 100 \\
\hline \multicolumn{4}{|c|}{ Households by type of settlement } \\
\hline Rigiga & 26.46 & 36.09 & 32.61 \\
\hline Large cities & 16.25 & 19.17 & 18.12 \\
\hline Simall cities & 19.05 & 20.84 & 20.19 \\
\hline \multirow[t]{2}{*}{ Rural areas } & 38.25 & 23.91 & 29.09 \\
\hline & 100 & 100 & 100 \\
\hline
\end{tabular}

Tiable 3.10. Average household size and number of children of poor and non-poor households

\begin{tabular}{lccc} 
& Paor & Non-poor & Aill \\
\hline Average household size & 2.84 & 2.18 & 2.42 \\
female head & 2.49 & 1.81 & 2.06 \\
male head & 3.30 & 2.66 & 2.90 \\
& & & \\
Average dependency ratio* & 0.54 & 0.29 & 0.38 \\
female head & 0.34 & 0.25 & 0.35 \\
male head & 0.54 & 0.34 & 0.41 \\
& & & \\
Average number of children per household & 0.72 & 0.35 & 0.48 \\
female head & 0.48 & 0.25 & 0.38 \\
malle head & 0.85 & 0.48 & 0.62 \\
\hline
\end{tabular}

" (w of dependants) / (household sze - of dependants).

Source: HBS 1997.

b) Howsehold size, howsehold composition and number of children per household

Household size as well as the number of children per household vary between poor and non-poor households. Whereas poor households have on average 3 members, non-poor households have only 2.2 members (Latvian average is equal to 2.4). Latvian households have 0.48 children on average. In poor households, this number increases to 0.72 children, while non-poor households have 0.35 children on average (see Table 3.10). The dependency ratio for poor households is twice as large as for non-poor households. ${ }^{20} \mathrm{~A}$ dependency ratio of 0.5 means that for each household member without income there are two members with some kind of income. Interpreting the dependency ratio of 0.29 for the non-poor would mean that a houschold needs three income generating members on one dependant in order to stay above the poverty line of $38 \mathrm{LVL}$ per capita.

\footnotetext{
The deperidency ratio is calculated as follows: $d=$ (H of dependent household members) / (household size dependants).
} 
Table 3.11. Distribution of poor and non-poor household by household composition

\begin{tabular}{|c|c|c|c|}
\hline & \multicolumn{3}{|c|}{ Distribution of households $1 \%$ ) } \\
\hline & Poor & Non-poor & All \\
\hline \multicolumn{4}{|l|}{ Household size } \\
\hline one & 21.94 & 36.88 & 31.48 \\
\hline wo & 24.92 & 29.48 & 27.83 \\
\hline three & 21.00 & 18.00 & $19: 08$ \\
\hline \multirow[t]{2}{*}{ four or more } & 32.14 & 15.64 & $2 \pi .61$ \\
\hline & 100 & 100 & 100 \\
\hline \multicolumn{4}{|l|}{ Housenolds with } \\
\hline zero dependants & 49.54 & 68.31 & 61.52 \\
\hline one dependant & 22.72 & 18.68 & 20.14 \\
\hline two dependants & 18.66 & 10.45 & 13.42 \\
\hline three dependants & 6.61 & 2.18 & 3.78 \\
\hline \multirow[t]{2}{*}{ four or more dependants } & 2.46 & 0.39 & 1.14 \\
\hline & 100 & 100 & 100 \\
\hline \multicolumn{4}{|l|}{ Households with } \\
\hline no children & 51.90 & 75.36 & 68.52 \\
\hline one child & 24.72 & 15.70 & 18.33 \\
\hline wo children & 17.05 & 7.62 & 10.37 \\
\hline three children & 4.79 & 1.06 & 2.15 \\
\hline \multirow[t]{2}{*}{ four or more } & 1.55 & 0.27 & 0.64 \\
\hline & 100 & 100 & 100 \\
\hline \multicolumn{4}{|l|}{ Household campasition } \\
\hline Single adult & 21.94 & 36.88 & 31.48 \\
\hline 1 adult +1 child & 3.64 & 2.80 & 3.10 \\
\hline 1 adult $+2+$ children & 2.66 & 1.09 & 1.66 \\
\hline 2 adults & 21.28 & 26.68 & 2473 \\
\hline 2 adults * 1 child & 9.39 & 7.94 & 8.47 \\
\hline 2 adults $* 2+$ chilldren & 12.00 & 6.27 & 834 \\
\hline 3 adults & $9 ! .44$ & 9.15 & 9.25 \\
\hline 3 adults $* 1$ child & 6.04 & 3.78 & 4.60 \\
\hline 3 adults +2 t children & 4.03 & 1.00 & 2.09 \\
\hline \multirow[t]{2}{*}{ Other } & 9.57 & 4.41 & 6.27 \\
\hline & 100 & 100 & 100 \\
\hline
\end{tabular}

Source: HBS 1997.

Table 3.12. Main source of income of poor and non-poor households

\begin{tabular}{lrrr} 
& \multicolumn{3}{c}{ Distribution of households (\%) } \\
\cline { 2 - 4 } Main income of household head from & Poor & Non-poor & All \\
Employment & & & 48.02 \\
Self-employment & 42.54 & 51.13 & 1.14 \\
Agriculture & 0.80 & 1.32 & 5.18 \\
Pension & 7.99 & 3.59 & 40.40 \\
Social transtor & 41.31 & 39.89 & 1.72 \\
Other & 2.48 & 1.29 & 3.54 \\
& 4.87 & 2.79 & 100 \\
\hline
\end{tabular}

Source: HBS 1997 . 
The fact that poor households are larger and have more children and dependants on average is also reflected in the distribution of households according to size and number of children (see Table 3.11 ). $32 \%$ of the poor households have four or more members, which is considerably more than for the overall population ( $22 \%$ ). Only $22 \%$ of poor households are one person households. The distribution of non-poor households is just the opposite. The majority of non-poor households are either single $(37 \%)$ or two-person households $(29 \%)$. In the overall distribution of Latvian households, one-person households also take the largest share (31\%), followed by two-person households (28\%). These figures confirm the results of the preceding section and allow to conchude that large households are a vulnerable group with a high poverty risk that needs to be considered.

In the previous section, it was noted that poverty rates increase significantly with the presence of children in a household. Headcount ratios of more than $70 \%$ have been calculated for households with three or more children (see Tables 3.4 and 3.7). These figures are supported by the distribution of households according to the number of children as shown in Table 3.11 . Less than $3 \%$ of all Latvian households have three children or more, but of those, more than two-thind are poor. Most households in Latvia are without children $(69 \%)$, and only $18 \%$ have one child. This distribution changes when poor households only are considered. Although still $52 \%$ are without children, $25 \%$ of poor households have one child, and $17 \%$ have two children, whereas only $8 \%$ of non-poor households live with two children.

$62 \%$ of all Latvian households belong to the group with no dependant household members. This means that in almost two thirds of the households all members have some kind of income, be it from work or from the state. Owerall, the distribution is very similar to the one for the number of children. With respect to the household composition, there are comparatively few houseliolds with children and one adult only (less than $5 \%$ in total). Of poor households, $6 \%$ belong to this category compared to $4 \%$ of non-poor households.

\section{c) Income source, major activity and education}

Table 3.12 shows the distribution of households according to their main source of income. Whereas $51 \%$ of non-poor households mention employment as their main source of income, $43 \%$ of poor households do. $41 \%$ of the poor households have pensions as their main income source $(40 \%$ of non-poor households). Having employment is apparently no guaranteed protection against poverty because the headcount ratio for this category of households is $46 \%$ (see Table 3.5 ). Only $5 \%$ of all households ( $8 \%$ of poor households) mention agriculture as their main source of income. Only $2.5 \%$ of poor households depend on social transfers as their main source of income.

About $50 \%$ of all households have a main income contributor who is working (1996), c.q. 36\% are employed (1997) (Table 3.13). The main differences between poor and non-poor households are related to employment, unemployment and employment above the working age. "Unemployed" covers only those households with a registered breadwinner. The group 'looking for a job" for the 1996 data may be more representative in this respect, although this question also does not cover all the unemployed either. ${ }^{21}$ Nevertheless, $10 \%$ of poor households (as opposed to $5 \%$ of non-poor) indicated they have a breadwinner who is currently unemployed. A relatively larger share of those employed and above working age belongs to the group of the non-poor. Almost ten percent of poor households had a breadwinner who was looking for a job in 1996. The respective figure for nonpoor households is $3 \%$. There is a significant group of households (35\%) with no identified activity ('other'). The data support the idea that the majority of these households are headed by pensioners or retired people, non-registered unemployed people and/or students.

\footnotetext{
${ }^{31}$ According to the Labor Force Survey, the unemployment rate was 14.4\% in 1997 (18.3\% in 1996). Administrative labor data provide an official umemployment rate of 7.2 in 1997 (7.5 im 1996$)$ (MoW, 1998 ).
} 
Looking at the educational level of the main income contributor (Table 3.14), the majority has completed secondary education ( $52 \%$ ). Of poor households, only $9 \%$ have completed higher education as opposed to $20 \%$ of non-poor households. Only $0.2 \%$ of all households have a breadwinner with no education at all.

Table 3.13. Major activity/employment status of household heads *

\begin{tabular}{|c|c|c|c|}
\hline & \multicolumn{3}{|c|}{ Distritbution of nouseholds $(\%)$} \\
\hline & Poor & Non-poor & All \\
\hline \multicolumn{4}{|c|}{ Major activity of how sehold head 1996} \\
\hline Working & 43.93 & 53.38 & 50.02 \\
\hline With a job but not at work & 2.54 & 3.40 & 3.10 \\
\hline Looking for job & 9.25 & 3.59 & 5.60 \\
\hline Kereping house & 7.26 & 5.62 & 6.20 \\
\hline \multirow[t]{2}{*}{ Other } & 37.02 & 34.01 & 35.08 \\
\hline & 100 & 100 & 100 \\
\hline \multicolumn{4}{|l|}{ Employment stafus of head 1997} \\
\hline Entoployed & 32.09 & 38.67 & 36.29 \\
\hline Unemployed & 10.06 & 4.95 & 6.79 \\
\hline Employed above working age & 1.38 & 4.55 & 3.40 \\
\hline \multirow[t]{2}{*}{ Other } & 56.48 & 51.83 & 43.51 \\
\hline & 100 & 100 & 100 \\
\hline
\end{tabular}

* Wajor activity according to 1996 ; employment stalus according to 1997 .

Solfre: HBS 1997.

Table 3.14 Educational attainment of the breadwinner in poor and non-poor households

\begin{tabular}{lccc} 
& \multicolumn{2}{c}{ Distribution of households (\%) } & All \\
\cline { 2 - 4 } Education of head & Poor & Non-poor & \\
Higher & & & 15.92 \\
Secondary & 8.52 & 20.11 & 52.39 \\
Vocational & 52.03 & 52.60 & 3.54 \\
Primary & 4.29 & 3.12 & 2.35 \\
Less than primary & 27.15 & 19.64 & 5.45 \\
Without education & 7.46 & 4.32 & 0.34 \\
& 0.56 & 0.21 & 100 \\
\hline
\end{tabular}

Source: HBS 1997.

Table 3.15. Gender and household headship

\begin{tabular}{|c|c|c|c|}
\hline & \multicolumn{3}{|c|}{ Distribution of households $(\%)$} \\
\hline & Poor & Non-poor & All \\
\hline \multicolumn{4}{|c|}{ Household headship } \\
\hline male & 43.56 & 43.20 & 43.33 \\
\hline \multirow[t]{2}{*}{ fomalo } & 56.44 & 56.80 & 56.67 \\
\hline & 100 & 100 & 100 \\
\hline
\end{tabular}

Source: HiBS 1997.

d) Gender and age

A majority of Latvian households has a female breadwinner (Table 3.15). The figures for poor and non-poor households differ on]y slightly. Differences become visible when looking at the household size. In general, female headed households are smaller and have fewer children on average than male headed households (see Table 3.10). With respect to the dependency ratio, they only differ for non-poor households, where male-headed households have a clearly higher ratio $(0.32$ compared to 0.22 ), which means that they have on average more income contributors per dependlant. 
Table 3.16. Distribution of households according to gender and ather characteristics

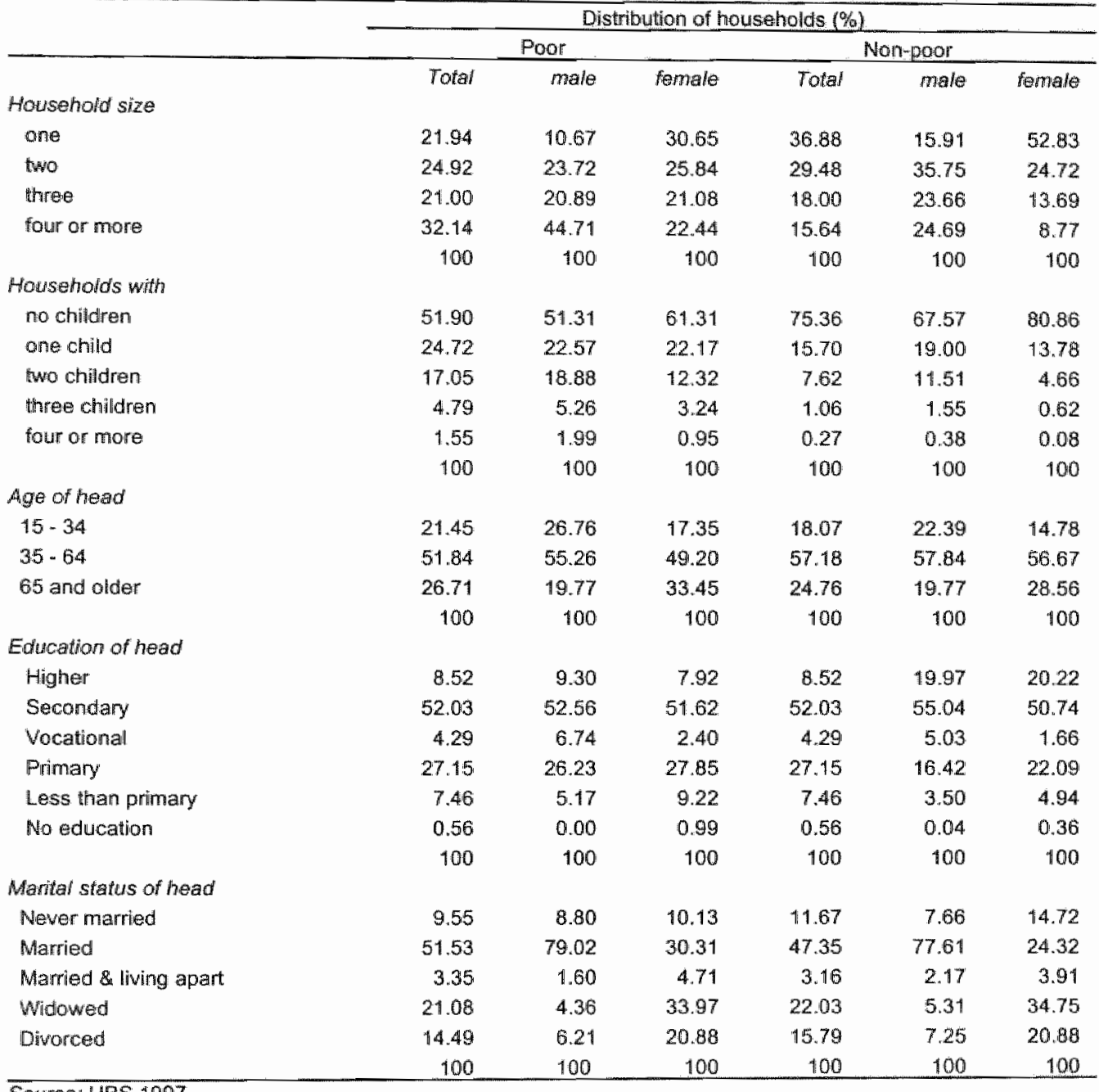

Source: HBS 1997.

As Table 3.16 shows, there are different distributional patterns among male and female poor and non-poor households. Whereas $53 \%$ of female-headed non-poor households are one person households, this is only the case for $16 \%$ of male-headed households. Two-person houstholds take the largest share in this group (36\%). With respect to poor houscholds, female-headed bouseholds are more or less evenly distributed over the various household sizes, although one-person households are at the top as well. On the other hand, male-headed poor households" largest share is with four or more household members $(45 \%) .81 \%$ of all non-poor female-headed lyouseholds are households without children, which is a considerably larger proportion as compared to non-poor malle-headed households $(68 \%)$.

Distributional differences can also be observed when looking at the age structure of the breadwinner. In the middle-age group (35 to 64 years old), the percentages are rather close for poor and non-poor households with male or female breadwinners. In all cases, plus-minus $50 \%$ of the 
households belong to the middle-age group. With respect to the two other age-groups, male and female-headed households behave differently. Whether poor or not, male-headed households have larger shares among the youngest group, while there are relatively more female-headed households among the oldest age-group. In the case of poor male-headed households, $27 \%$ belong to the youngest category and $20 \%$ to the oldest. The reverse is true for poor female-headed households where $17 \%$ is the share for the youngest group and $33 \%$ for the oldest group.

With respect to the marital status of the breadwinner it is interesting to note that $79 \%$ of poor malle breadwinners are married and $78 \%$ of the non-poor, whereas only $30 \%$ of poor female heads have the same civil status ( $24 \%$ of non-poor). Poor fermale household heads are often widowed $(34 \%)$ or divorced (21\%). In the case of non-poor households, the pattern is more on less the same although the share of never married female heads increases to $15 \%$ and the share of widows to $35 \%$.

e) Howsing and land ownership

A little more than half of all Latvian households owned a plot of land in $1997(53 \%)$. The share in rural areas is higher than in urban areas, although $40 \%$ of urban households still have a plot of land (Table 3.17). The distribution among the non-poor households in 1997 is almost equal to the distribution one year before. While in $199652 \%$ of poor households had land, this share increased to $58 \%$ in 1997. Especially urban poor households seem to have increased their access to land as can be seen from the fact that their share increased from $33 \%$ in 1996 to $39 \%$ in 1997 . But as the previous section has shown, access to a plot of land does not protect a household against poverty.

Table 3.17. Housing and access to land of poor and mon-poor households:

\begin{tabular}{|c|c|c|c|c|c|c|}
\hline & \multicolumn{6}{|c|}{ Distribution of households (\%) } \\
\hline & \multicolumn{3}{|c|}{ Poor } & \multicolumn{3}{|c|}{ Non-poor } \\
\hline & total & unban & rural & total & urban & nural \\
\hline \multicolumn{7}{|l|}{ Access to land } \\
\hline Households with land & 58.48 & 39.33 & 89.43 & 50.78 & 40.16 & 84.59 \\
\hline \multirow[t]{2}{*}{ Households without land } & 41.52 & 60.67 & 10.57 & 49.22 & 59.84 & 15.41 \\
\hline & 100 & 100 & 100 & 100 & 100 & 100 \\
\hline \multicolumn{7}{|l|}{ House ownership } \\
\hline Privately owned & 33.30 & 15.91 & 611.63 & 23.80 & 13.06 & 57.97 \\
\hline Semi-priwately owned & 4.07 & 3.62 & 4.79 & 6.57 & 7.35 & 4.09 \\
\hline Reented apartment: & 62.38 & 80.37 & 33.33 & 69.34 & 79.48 & 37.03 \\
\hline \multirow[t]{2}{*}{ Other } & 0.25 & 0.09 & 0.51 & 0.29 & 0.10 & 0.90 \\
\hline & 100 & 100 & 100 & 100 & 100 & 100 \\
\hline \multicolumn{7}{|l|}{ Typo of dwelling } \\
\hline Separate mouse & 23.87 & 10.38 & 45.65 & 15.70 & 7.20 & 42.85 \\
\hline Privalo shared house & 9.64 & 7.43 & 13.20 & 5.52 & 3.65 & 11.47 \\
\hline Separate apartment & 6268 & 76.16 & 40.92 & 75.43 & 84.91 & 45.13 \\
\hline Shared apartment & 3.26 & 5.28 & 0.00 & 3.09 & 4.04 & 0.08 \\
\hline Dwelling for employeas & 0.21 & 0.34 & 0.00 & 0.14 & 0.10 & 0.28 \\
\hline \multirow[t]{2}{*}{ Room or bed renled } & 0.34 & 0.41 & 0.23 & 0.12 & 0.10 & 0.19 \\
\hline & 100 & 100 & 100 & 100 & 100 & 100 \\
\hline \multicolumn{7}{|l|}{ Wall material of house } \\
\hline Wooden & 28.59 & $\$ 9.06$ & 43.97 & 14.84 & 8.48 & 36.13 \\
\hline Eriok & 44.78 & 49.85 & 36.59 & 46.02 & 48.95 & 36.64 \\
\hline Armored concrete & 23.69 & 29.23 & 14.73 & 36.28 & 41.16 & 20.69 \\
\hline \multirow[t]{2}{*}{ Other } & 2.94 & 1.85 & 4.71 & 2.86 & 1.71 & 6.54 \\
\hline & 100 & 100 & 100 & 100 & 100 & 100 \\
\hline
\end{tabular}


Table 3.18. Share of households with the respective amenities (1997)

\begin{tabular}{|c|c|c|c|c|c|}
\hline & Poor & Non-poor & All & Urban & Pural \\
\hline Electricity & 99.22 & 99.91 & 99.66 & 99.79 & 99.34 \\
\hline Water siupply & 70.74 & 87.47 & 81.32 & 92.95 & 53.29 \\
\hline Sew & 66.93 & 86.06 & 79.14 & 91.47 & 49.44 \\
\hline Tothet & 57.43 & 79.42 & 71.74 & 82.99 & 4.4 .14 \\
\hline Hot water supply & 36.65 & 65.94 & 55.35 & 69.12 & 22.44 \\
\hline Central heating & 44.30 & 78.30 & 66.01 & 79.73 & 33.27 \\
\hline Bathroom & 48.62 & 75.82 & 65.99 & 77.38 & 38.77 \\
\hline Katuctmen & 95.37 & 95.66 & 95.56 & 94.95 & 96.91 \\
\hline Gas from network & 37.70 & 57.25 & 50.18 & 66.07 & 11.87 \\
\hline Gas from containeir & 50.09 & 36.85 & 41.46 & 29.31 & 71.18 \\
\hline Telephone & 55.84 & 75.46 & 68.49 & 76.73 & 49.34 \\
\hline
\end{tabular}

Source: HBS 1997.

With respect to housing conditions, table 3.17 shows that in urban areas, the majority of households lives in rented apartments whether they are poor or not. In rural areas, owner-occupied houses are the main sort of residence. Most households live in a separate apartment (urban areas) or house (rural areas). With respect to the size of the housing, there are no significant differences between poor and non-poor households. The average total area per household is $53 \mathrm{~m}^{2}$ for non-poor and 52 $\mathrm{m}^{2}$ for poor households. The living area total is $35 \mathrm{~m}^{2}$ for all households, poor or non-poor, and the number of rooms is 2.28 on average for both groups. As far as the building material of the house us concerned, more poor households live in wooden houses (24\%), that are usually separate houses, than non-poor households (17\%).

Table 3.18 provides an overview of the availability of certain amenities in Latvian households. The distribution presented is according to poverty status and location. The questionnaire only asks whether households 'do have' these utilities and not whether they use them. Almost all households are connected to electricity. Water supply and sewerage is available in the majority of households too, but poor households and rural households have more often to do without. Regarding the supply of hot water, less than $50 \%$ of poor households have access to it.

This section provided information on the composition of poor and non-poor households allowing the assessment of the results from section two. In summary we can say that some of the earlier findings have lost a some of their 'urgency', while other results shed some new light on the previous conclusion. Although poverty rates were estimated to be lowest in the capital and the surrounding region, the majority of the poor households in Latvia live exactly in that area. Of course, this has to do with the fact that one third of the population lives only in Riga. Therefore, the numbers partly reflect the general distribution of the population.

Another characteristic of poor households is their larger size and the presence of more children compared to the non-poor households. The positive correlation between household size and poverty is confirmed when we see that one third of all poor households has four or more household members. That Latvian households are relatively small on average is also reflected by the proportion of households with children. Only one third of all households have children. The poverty rates shown in the previous section were especially alarming for households with three or more children. These findings are supported by the fact that only one in twelve poor families has three children or more.

While having income from (self-)employment has often been considered to be a protection against the poverty risk, the last section has made it clear that working is by no means sufficient to 
stay out of poverty. Income from employment is the main source of income for most of the poor and. non-poor households. This indicates, that Latvia has to deal with a significant group of working poor. Latvia is not alone in this respect. Most countries in CEE and the FSU are confronted by this phenomenon (see, e.g., UNDP, 1998a; Kuddo, 1998; Milanovic, 1998). One reason for this situation is the low level of real wages of workers in declining industries, and in the public sector, where wages are often below the subsistence minimum. On the one hand, the number of low-wage jobs has increased, whille on the other hand, wages have not been paid, or workers are on forced leave, and the wages that are paid are not sufficient in many cases to buy what is needed in many cases.

\subsection{Risk factors}

The previous two sections concentrated on the incidence of poverty and the composition of poor households in Latvia. This section's analysis approaches poverty from a third angle: risk. What are the factors that increase the risk that an individual will live in poverty? What are the marginal effects of certain household or breadwinner characteristics on the chance of being poor? The following part will try to find some answers to these questions. First, several risk factors are identified and households will be analyzed based on them. Next, an econometric model is estimated in order to measure the effects of selected variables on poverty. The analysis in this section is based on the 1997 round of the HBS.

\section{a) Selected risk factors}

Based on the poverty profile as presented in the previous sections, factors that increase art individual's risk of being poor have been selected. The following seven risks have been identified:

1. The household has four or more members (SIZE).

2. The household has a dependency ratio greater than or equal to 0.6 (DEP).

3. The age of the breadwinner is less than 35 years (AGE).

4. The completed level of education of the breadwinner is primary education or lower or vocational training (EDUC).

5. The main income source of the breadwinner is agriculture or social transfers (excluding pensions) (INCOME).

6. The household lives in a rural area (RURAL).

7. The breadwinner is unemployed (UNEMP).

Table 3.19 shows the distribution of the population over the risk factors. The diagonal cells contain the proportion of the whole population belonging to this group (in percent). For example, $40.3 \%$ of all Latvians live in households with four or more members (SIZE). Or, 25.8\% live in households where the breadwinner has a vocational or primary or lower educational level (EDUC). The offdiagonal cells provide information about the relation with other risk factors. All results have to be interpreted horizontally. For example, of all individuals living in households with four or more members (SIZE), 68\% have at the same time a dependency ratio equal to or exceeding 0.6 (DEP). and $36.9 \%$ of the "SLZE'-individuals live in rural households. We also see that $7.8 \%$ of people live "UNEMP'-individuals, almost half live in houshed (UNEMP, diagonal cell). Of all these Obviously, the rows do not sum up to 100 in households with a high dependency ratio (48\%). same time. 
Table 3.19. indwiduals at risk: relation between risk factors in tatal population, 1997

\begin{tabular}{l|rrrrrrr}
\hline & SIZE & DEP & AGE & EDUC & INCOME & RURAL & UNEMP \\
\hline SIZE & 40.35 & 668.04 & 32.57 & 17.41 & 14.63 & 36.94 & 8.82 \\
DEPP & 76.36 & $\mathbf{3 5 . 9 5}$ & 37.55 & 14.32 & 13.58 & 30.45 & 12.84 \\
AGE & 53.68 & 55.14 & 24.48 & 12.84 & 11.91 & 28.75 & 8.48 \\
EDUC & 27.26 & 19.85 & 12.20 & 25.78 & 10.72 & 46.17 & 6.43 \\
INCOME & 64.09 & 53.00 & 31.64 & 29.99 & 9.21 & 81.31 & 10.47 \\
RURAL & 48.91 & 35.93 & 23.10 & 39.05 & 24.58 & 30.47 & 3.94 \\
UNEMP & 45.70 & 48.29 & 26.65 & 21.29 & 12.38 & 15.43 & 7.79 \\
\hline SOUMCE-HBS 1997 & & & & & & &
\end{tabular}

Table 3.20 presents poverty rates (headcount ratios) for all risk groups plus every combination of two risk factors (poverty line $=$ LVL 38). The diagonal cells present the headcount ratio for each risk group disregarding the possibility of other risks. For example, $47.5 \%$ of all individualls living in a household with a young breadwinner (AGE) are poor. All off-diagonal cells provide the poverty rate for the respective combination of two risk factors. For example, people living in a household with a young breadwinner (AGE) who is unemployed (UNEMP) have a poverty risk of $58.6 \%$. The off-diagonal values are consistently higher than the diagonal values. This means, that a individual living in a household belonging to two risk groups at the same time has a higher risk of being poor. Considering the selected factors, the following combinations show the worst poverty risk:

1. Dependency ratio $>0.6$ and low educational level of the breadwinner: $81.5 \%$

2. Low educational level of the breadwinner and household size $>3: 78.5 \%$

3. Low educational level of the breadwinner and unemployed: $77.2 \%$.

With respect to the accumulation of risks, with each additional risk the poverty rate increases (see Table 3.21, column POOR). The majority of the poor lives in households that are exposed to one, two or three risk factors, with $31 \%$ being exposed to two risks simultaneously. $11 \%$ of all poor live in households that belong to four or more risk groups. Of those $25.8 \%$ individuals living in households that do not belong to any risk group, $20 \%$ are still poor. The share of the poor increases with every additional factor, but only from three risks or more does the share of poor individuals exceed $50 \%$.

Table 3.20. Poverty rates per combination of risks, 1997 nominal

\begin{tabular}{|c|c|c|c|c|c|c|c|}
\hline & SIZE & DEP & $A G E$ & EDUC & MACOME & RURA: & UNENP \\
\hline SUZE & 55.36 & 57.30 & 59.14 & 78.46 & 68.83 & 66.17 & 72.71 \\
\hline DEP & & 54.24 & 55.87 & 81.54 & 72.17 & 68.18 & 65.42 \\
\hline$\triangle M E$ & & & 47.46 & 67.24 & 65.76 & 63.73 & 58.64 \\
\hline EDLC & & & & 53.92 & 71.90 & 60.24 & 77.19 \\
\hline MOOME & & & & & 62.07 & 63.33 & 69.66 \\
\hline DUAL & & & & & & 55.15 & 71.27 \\
\hline UNEMP & & & & & & & 61.08 \\
\hline
\end{tabular}


Table 3.21. Accumulating risks: proportion of population by increas ing numbers of risks, 1997 mominal

\begin{tabular}{|c|c|c|c|c|c|}
\hline & All & $\begin{array}{c}\text { Share of total } \\
\text { poor }\end{array}$ & Non-poor & Poor & \\
\hline No risk & 25.81 & 1.4 .34 & 79.91 & 20.09 & 100 \\
\hline One risk & 32.90 & 28.28 & 68.93 & 31.07 & 100 \\
\hline TwO risks & 25.41 & 30.82 & 56.17 & 43.83 & 100 \\
\hline Throe risks & 10.21 & 15.29 & 45.86 & 54.14 & 100 \\
\hline \multirow[t]{2}{*}{ Four or more risks } & 5.67 & 11.27 & 28.19 & 71.81 & 100 \\
\hline & 100 & 100 & & & \\
\hline
\end{tabular}

Source: HBS 1997.

\section{b) Marginal effects on poverty}

Another method of testing the influence of specific variables on the risk of being poor is to estimate a probit model which best fits the binary dependent variable to be modeled, $_{3}$ i.e. the probability that someone will be poor or not. The model will estimate the impact of a change in a variable $\mathrm{x}$ on the probability that $y$ will occur. Such a model can be written as follows (Greene, 1997):

$$
\operatorname{Prob}[\mathrm{Y}=1 \mid x]=\Phi\left(\beta^{\prime} \mathrm{x}\right)
$$

with $\mathrm{Y}$ as the dependent variable, $\Phi$ representing a standard normal distribution function, $\mathrm{x}$ a vector of independent variables, and $\beta$ a vector of parameters to be estimated. In the present case the dependent variable is the probability that an individual will live in poverty, i.e. poor $=1$. The explanatory variables include variables on location of the household, size, number of children, sex, education, age and main source of income of the household head. Continuous independent variables. have been transformed into logarithmic values in order to account for the fact that a marginal increase in the nominal value does not necessarily lead to a respective increase in the dependent variable. This is valid for the variables age (measured in years), number of children and household size.

Applying probit estimation yielded the following results (see table 3.22): The effects of the various variables are as expected. The negative sign of the variable age confirms the negative relation between poverty and the age of the breadwinner, i.e. the risk decreases with increasing age. Having a breadwinner with higher education also reduces the poverty risk compared to the referemce case of secondary education, other things being equal. The results indicate that the regional location of a household is not decisive for the poverty risk except for the Latgale region where the poverty risk is significantly higher than the Rigas region (other things being equal). The gender of the breadwinner is significant as well and having a femalle breadwinner contributes to the poverty risk.

The marginal effect of each variable is particularly interesting in this context. In the case of the binary explanatory variables (dummy variables), the marginal effect relates to a discrete change of the dummy from zero to one. For example, living in a rural area increases the chance of being poor by $7.8 \%(0.078)$, holding all other variables constant. Or, living in a household with a breadwinner that has completed higher education decreases the probability of living in poverty for an individual by more than $20 \%(-0.203)$. In the case of continuous or metric variables, the marginal effect is a change in the probability of being poor as a result of an infinitesimally small change in the respective variable. For example, an increase in the number of household members by $10 \%$ would increase the poverty risk by $31 \%(0.308)$, ceteris paribus.

Having a closer look at the marginal effects, schooling proves to be particularly relevant with. respect to the poverty risk but there are differences depending on the level of schooling. Having a 
breadwinner with primary or vocational education increases the chance for being poor by more than $10 \%$. A lower education level increases the risk even more $(20 \%, \mathrm{c} . \mathrm{g} .26 \%)$.

Table 3.22. Probit estimation of poverty factors

\begin{tabular}{|c|c|c|c|c|c|}
\hline \multicolumn{2}{|l|}{ Variable } & $\begin{array}{l}\text { Marginal effect } \\
\quad \mathrm{dF} / \mathrm{dx}\end{array}$ & Standard error & z-value & $P>2$ \\
\hline \multicolumn{2}{|l|}{ Female breadiwinner* } & 0.105 & 0.013 & 7.780 & 0.000 \\
\hline \multicolumn{2}{|l|}{ Rural area* } & 0.078 & 0.016 & 4.920 & 0.000 \\
\hline \multicolumn{2}{|l|}{ Intage of breadwinmer) } & -0.069 & 0.026 & -2.640 & 0.008 \\
\hline \multicolumn{2}{|l|}{ In(household size) } & 0.308 & 0.016 & 18.940 & 0.000 \\
\hline \multicolumn{2}{|l|}{ In(number of children) } & 0.112 & 0.023 & 4.810 & 0.000 \\
\hline \multicolumn{2}{|c|}{ Breadwinner with higher educationt } & -0.203 & 0.017 & -11.120 & 0.000 \\
\hline \multicolumn{2}{|c|}{ - vocational training* } & 0.115 & 0.032 & 3.550 & 0.000 \\
\hline \multicolumn{2}{|c|}{ - primary education } & 0.138 & 0.018 & 7.680 & 0.000 \\
\hline \multicolumn{2}{|c|}{ - lower than primary* } & 0.204 & 0.030 & 6.620 & 0.000 \\
\hline \multicolumn{2}{|c|}{ - no education" } & 0.258 & 0.090 & 2.660 & 0.008 \\
\hline \multicolumn{2}{|l|}{ Income from agriculture } & 0.088 & 0.029 & 3.060 & 0.002 \\
\hline \multicolumn{2}{|c|}{ income from self-empioyment ${ }^{t}$} & -0.073 & 0.056 & -1.260 & 0.206 \\
\hline \multicolumn{2}{|c|}{ Income from pension* } & 0.158 & 0.021 & 7.490 & 0.000 \\
\hline \multicolumn{2}{|l|}{ Income from social transfer } & 0.125 & 0.056 & 2.250 & 0.025 \\
\hline \multicolumn{2}{|l|}{ Other income* } & 0.222 & 0.036 & 5.930 & 0.000 \\
\hline \multicolumn{2}{|l|}{ Kurzeme* } & $0.03 \%$ & 0.020 & 1.570 & 0.116 \\
\hline \multicolumn{2}{|l|}{ Vidzeme* } & 0.017 & 0.022 & 0.760 & 0.447 \\
\hline \multicolumn{2}{|l|}{ Zemgale* } & -0.006 & 0.020 & -0.280 & 0.779 \\
\hline \multicolumn{2}{|l|}{ Latgale* } & 0.090 & 0.019 & 4.730 & 0.000 \\
\hline \multicolumn{6}{|c|}{ Log likelihood $\quad=-4577.2445$} \\
\hline Mald Chi2(19) & $=1013.00$ & & & & \\
\hline Prob $>\operatorname{ch} 2$ & $=0.0000$ & & & & \\
\hline \multicolumn{2}{|c|}{$\begin{array}{l}\text { Pseudo R2 } \quad=0.1295 \\
\text { Number of observations: }\end{array}$} & & & & \\
\hline \multirow{2}{*}{\multicolumn{2}{|c|}{$\begin{array}{l}\text { Number of observations: } \\
\text { Dependent variable: }\end{array}$}} & 7713 & & & \\
\hline & & Poor=1, Non-poor & & & \\
\hline \multicolumn{2}{|l|}{ Reference base: } & $\begin{array}{l}\text { Male breadwinner, } \\
\text { employment, Riga }\end{array}$ & $\begin{array}{l}\text { urban area secon } \\
\text { egion }\end{array}$ & ducation & ome from \\
\hline
\end{tabular}

(") dFidix is for discrele change of dummy variable from 0 to 1

$z$ and $P>|z|$ are the test of the underlying coefficient being 0

Source: HBS 1997.

\subsection{Conclusion}

Based on the empirical analysis presented in this chapter, we can conclude that all hypotheses stated at the beginning of the chapter do apply to Latvia as well. More than $50 \%$ of the Latvian population lives somewhere between the lowest and highest poverty line used in this study. Except for the region around Riga which has a lower than average poverty rate, poverty is quite uniform and a definite ranking is not possible regarding the sensitivity of the poverty measures with respect to the poverty lines. What really makes a difference is whether someone lives in an urban or a rural area. The larger the town, the smaller the poverty risk. Nevertheless, in absolute terms, most of the poor live in and around Riga since one third of the Latvian population is living in the metropolitan area. Certain vulnerable groups face an above average risk of being poor confurning the stated 
hypotheses: large households, households with three or more children, households where the breadwinner is young or unemployed or has a low education, and households that depend mainly on income from agriculture or social transfers (except pensions) are more vulnerable to poverty. As in other transition countries, the working poor form a large part of the poor although the headcount ratios are lower for this group. As in the other countries, this can be attributed to low wages in the economy and underemployment. The poverty profile does indeed resemble other CEE countries such as Poland, Hungary, Lithuania and Estonia. One hypothesis which applies to all countries is the higli poverty risk for families with children and/or other dependant household members.

Comparing the results from 1996 with 1997 , we clearly have to conclude that poverty in Latvia increased. It not only increased, which resulted in a higher headcount ratio, but it also deepened and become more unequal. When both the poverty gap ratio and the headcount ratio increase, then one can conclude that not only more people moved into poverty, but that they are also farther below the poverty line on average. These two results together explain at the same time the increase in the poverty severity ratio, which means that the distribution among the poor became more unequal.

However, we have to be aware of the fact that this is only a snapshot of the two years covered. We do not know whether the poverty is transitory or permanent. In the former case, we would not be too concerned since we would know that better times lay ahead for these groups. The state would nevertheless still have a role to facilitate the endurance of such difficult times. Even though the poverty rates in Latvia are high in our Western eyes, Latvian households are surviving because they are employing every possible means to make ends meet.

Although this chapter provides rather detailed information on the extent of material poverty in Latwia, there are many open questions. The analysis covers only two years and says nothing about the dynamics and developments of living standards over the last ten years. We do not know how people cope with the situation in their daily life and the survival strategies they apply. We do not know how the poor perceive their situation. Another aspect that needs a thorough investigation is the social security system of the country. Is the Latvian safety net effective and able to work as a last resort? These questions will be at stake in the following chapters, starting first with the dynamics of the last decade, trying to identify the winners and losers of the transition. The subsequent chapter will investigate coping strategies used by Latvian housebolds, followed by a chapter analyzing the effectiveness of Latvian social assistance. 


\section{THE DYNAMICS OF GAINING AND LOSING}

\subsection{Introduction}

The preceding chapter identified those groups in Latvia that are currently most vulnerable and at a high risk of living in poverty. What we do not know is whether these are the same groups as before independence. Who gained and who lost in terms of their standard of living during the last decade? These dynamics of gaining and losing during the transition from a planned economy to a market economy are discussed in this chapter. The aim is to identify the winners and the losers of the economic and political transition in Latvia. In an ideal situation, longïtudinal data on household budgets would be available in order to estimate the development in a household's welfare over time. Unfortunately, such data are not available for Latvia, and therefore, we have to look for other sources and methods in order to answer the questions raised in this chapter. Although poverty has been studied rather extensively in countries in transition since the beginning of the $1990 \mathrm{~s}$, the dynamics of the living standards have hardly been investigated. We do not know how people perceive the changes and how they managed to "survive" the transition. Little is known about the dynamics of well-being of the households during the last decade. We do not know whether they have been able to improve their situation and how they perceive their gains and losses. Therefore, we had to look for a new approach in order to learn about dynamics.

Two complementary approaches are used. Based on literature describing the situation in countries in a similar situation to Latvia, we can draw some conclusions about the transition and its effect on living standards. There is information available on the pre-transitional situation with respect to poverty in the Soviet Union and other Central and Eastern European (CEE) countries which will allow us to identify the old and the new poor and the related changes (see, e.g., Braithwaite, 1995; Vecernik, 1996; Atkinson \& Micklewright, 1992). The second method is new and has been developed specifically for the study of the dymamics. It approaches the problem by using the opinions of the Latvian population on how they perceive the developments of the last decade and whether they consider themselves to be winners or losers. We designed a questionnaire that enabled us to collect information on the individual perception of the changes among a representative sample of Latvian households in 1998, and to draw conclusions with respect to the dynamics of the living standards. We asked the respondents to compare their situation in 1998 with their situation before 1991. We also asked them to describe what has happened in the meantime and to give their judgment on the changes that have occurred. The conclusions of the survey can then be compared with the results from previous research for other countries and the poverty profile as presented in chapter three.

The chapter is organized as follows: the next section reviews general trends of the effect of the transition on living standards and the dynamics in other countries in transition. Section three provides an introduction to the special poverty survey which is used for the analysis in the subsequent section on the perception and dynamics of gaining and losing in Latvia during the transition. A concluding section relates the results with the experiences of other countries. 


\subsection{What do we know from other countries? Trends and experiences}

During the last decade, a wide range of studies has been produced covering all possible aspects of the transition from a planned to a market economy. Issues such as poverty and living standards have been analyzed for numerous countries in Central and Eastem Europe (CEE) and the Former Soviet Union (FSU). Based on this vast material of the last couple of years, we have tried to establish some general trends with respect to poverty dynamics during the transition. Who was poor before the transition and who is poor now is one of the questions we answer based on existing research results. We assume that those that used to be poor but do no longer belong to this group are the relative winners of the transition, whille those that were not particularly wulnerable but are currently confronted with a high risk of living in poverty are the losers of the transition.

Before we start, some words about the change in the meaning of poverty are necessary. Some authors pay explicit attention to the fact that the concept of poverty in Soviet times is not the same as today (see, e.g., Cornia, 1994; Atkinson \& Micklewright, 1992). The East had a different understanding of poverty than the West, or, to put it differently, the meaning of poverty in a shortage-economy differs from the one in a market economy. Under a socialist regime, poverty was regarded as "pathologic" with the "poor" being personally responsible for their fate; poverty was not caused by a shortage of income (Sipos, 1994:224). Vecernik (1996) concludes the same when saying that poverty used to be demographically based and hardly related to income. It was transient over a person"s life-cycle, and changed with the economic status of the adults and the number of children in a household. According to Braithwaite (1995:3), poverty officially did not exist in the Soviet Union. Poor families were described as "under-positioned" since poverty was considered to be a capitalist phenomenon. The definition of poverty and the identification of the poor was blurred by the existence of multiple markets, one with state price controls, and the other private (and/or black). Due to these multiple markets it was almost impossible to calculate the value of a basket of goods since the price of a good depended on access to different markets. The shortage of goods, also a characteristic of a command economy and one that impacted most on the poorer segments of the society who could not buy in "dollar shops", led to forced savings since it was not unusual for income to exceed expenditures (Atkinson \& Micklewright, 1992).

The nature of poverty, and the understanding thereof, changed during the transition. Poverty became more visible and related to insecurity: "It is one thing to know that income is low but certain, as under the old system. It is quite another to face income which is falling and to be unsure how far it will fall." (Bart, 1994:81). The link is now made to income and family wealth as opposed to demographic characteristics only (Vecernik, 1996). Kutsar (1997:83) defines the poverty in terms of deprivation. Because of the lack of material. resources, one is unable to meet the new challenges of the consumer society, receive medical treatment, cover housing costs, socialize with friends. Deprivation means then the lack of freedom and choice as well as exclusion form one's customary way of life.

\subsubsection{The transition and the dynamics of living standards in general}

Information on poverty and living standards for Eastern Europe and the Soviet Union before the transition are scarce. Alkinson and Micklewright (1992) contributed significantly to the knowledge in this ficld with their collection of information on poverty and income distribution of the pretransition phase. In the Soviet Union, income and living standards were relatively low, but poverty incidence was also low by international standards. In 1989, the Baltic countries were the richest and Tajikistan and Uzbekistan the poorest "regions" in the UdSSR, according to Atkinson and 
Micklewright (1992). With the start of the turmoil, real incomes and wages started to decline rapidly. Russia, for example, had to face a decrease in real income of $23 \%$ between 1992 and 1996 (Zohoori et al., 1998:1979). Milanovic (1998) presents figures for the Baltic countries: Latvia "s real per capita income decreased by $45 \%$ from 1988 to 1995 , Estonia's by $37 \%$ (1988-1994) and the real per capita income of Lithuania declined by $42 \%$ in the same period. The fall in real GDP per capita for the three countries was $43 \%, 37 \%$ and $66 \%$ respectively (p. 34). These income developments were accompanied by increasing poverty rates as well as a widening income distribution and increasing inequality (Milanovic, 1998).

Reliable pre-transitional data on poverty are hard to find and the data that are available have to be treated with caution. This is especially the case for the Soviet Union as Braithwaite (1995) for example, warns the reader. Even if the presented figures have to be interpreted cautiously, it can be concluded that there is a consensus among the researchers, that poverty rates increased considerably in most countries of CEE and FSU during the last decade. ${ }^{2}$ Milanovic (1998) estimates an increase of poverty in Russia from $2 \%$ to $50 \%$ from 198788 to 1993 . For Latvia, he estimates an increase from $1 \%$ to $22 \%$, for Estonia from $1 \%$ to $37 \%$, and for Lithuania from $1 \%$ to $30 \%$ (Table 5.1, p. 68).

Real income and wage decreases result in lower standards of living. As a result, private savings erode, household consumption changes, and the shate of own production of goods increases (Kuddo, 1998; Zahoori, et al., 1998; Samorodov, 1998). In Romania, for example, the share of own production increased from $21 \%$ to $31 \%$ for worker farnilies and from $68 \%$ to $80 \%$ for peasants from 1989 to 1992 (Cornia, 1994:298). This substitution effect prevented lower incomes resulting in lower calorie intakes. The real and rapid income decline supported the growing importance of nonmonetary income sources. According to Zohoori et al. (1998:1980), non-cash income from informal sources became especially important for the poorest $20 \%$ of the population.

\subsubsection{The old and the new poor}

The preceding section was rather general with respect to poverty dynamics in countries in transition. It only allowed us to conclude that poverty increased during transition. We also know that poverty did exist, although it might have been otherwise called. In this section, the aim is to figure out who was poor under the old regime and who is poor under the new economic and political circumstances. Finally, we would like to identify the winners and losers of the transition.

The poor in pre-transition time were those that fell through the gaps of the social system. The old system was characterized by a narrow income distribution, low average wage rates and income levels and a social protection system. The gaps in this system explain the kind of poverty experienced under the old regime (Atkinson \& Micklewright, 1992:223). "The following groups could be identified as those that were generally at risk:

i) families with three or more children (Braithwaite, 1995; Vecernik, 1996, Atkinson \& Micklewright, 1.992);

ii) single parent families (Braithwaite, 1995; Atkinson \& Mickelwright, 1992);

iii) dual parent families with one parent not working or on leave (Braithwaite 1995 );

iv) pensioners and/or elderly (Braithwaite, 1995; Vecernik, 1996; Atkinson \& Micklewright, 1992):

w) wage earners employed in poorly paid jobs (Braithwaite, 1995);

wi) the homeless and persons released from institutions (Braithwaite, 1995).

\footnotetext{
"This statement is confirmed for 1990, with Latvia and Estonia being the richest, and Azerbaijan and Tajikistan the poorest "regions" (Kakwani, 1995).

'Sec, e.g.y Comia (1994) for CEE and Russia, 2ahoori, et al. (1998) and Brathwaite (1995) for Russia, Speder (1998) for Hungary.
} 
According to Braithwaite (1995), groups i) to iii) accounted for $50 \%$ of all the poor in Russiat. followed by elderly people and pensioners. The most wulnerable elderly were those living alone or lacking any other income source. In Russia, female single pensioners especially were highly at risk of being poor. Pensioners that were able to earn additional noney, which was legally allowed without losing the pension benefit, were better off. The group of wage eamers in poorly paid jobs was mainly formed by women working in feminized branches of the labor market, such as retail, education, health, arts and culture (Braithwaite, 1.995).

From chapter one and chapter three we know already the groups that are currently the most vulnerable in countries in transition in general and in Latvia in particular:

- Rural households;

- Houscholds with children;

- Large households;

- Single parent families;

- Unemployed persons;

- Wage eamers in low paid jobs;

- Households without access to assets;

- Young adults.

It is obvious from the above, that nowadays more social groups are vulnerable. Compared to the pre-transitional era, there are three major differences: i) the surge of unemployment which was virtually non-existent under the socialist regime, ii) age is no longer positively related with poverty, and iii) education has become much more important as a determinant of the poverty risk. With respect to ii), the young and the very old (70 years and older) are highly at risk, but a pensioner or elderly person between 60 and 70 years old has a below average poverty risk (Zahoori et al., 1998; Seeth, 1998; Milanovic, 1998). The existence of poor young adults has also been reported by Vecernik (1996) for the Czech Republic, and the UNDP (1998a) observes the trend in the whole region. Farmers and rural households in general form a new group of poor in many countries in CEE and FSU (see, e.g., UNDP, 1998a; Milanovic, 1998). In addition, households without access to assets, such as a plot of land, have an increased poverty risk in some conntries (Kuddo, 1998).

\subsubsection{What explains the changes?}

In order to understand the general increase in poverty levels and the composition of the poor, wa have to consider the effects of the economic transition and the resulting dynamics. The decline in output reduced real wages and fiscal revenues, created unemployment and inflation and eroded savings and social transfers (Barr, 1994). The surge in unemployment was not cushioned by unemployment benefits because they either did not exist or were too low to provide a safety net, therefore putting the unemployed at considerable risk. Due to the erosion of child allowances and other family benefits child poverty increased, too (UNDP, 1998a). The price and wage liberalization at the start of the transition caused a widening income distribution over time. The withdrawal of price subsidies for, e.g. housing, heating, and food, harmed the least well-off most since these subsidized goods counted for an above average share of their total consumption (Barr, 1994). The large share of working poor can be attributed to the raising share of low-wage jobs on the one hand, and wage arrears and forced unpaid leave on the other hand. Often, wage earnings are not sufficient to buy the basic necessities (Rose, 1995; Kuddo, 1998). Especially vulnerable in this respect are manual workers enployed in declining industries and low-skilled clerical staff with vocational 
education or less (Milanovic, 1998). ${ }^{3}$ Contrary to other social benefit recipients, pensioners did benefit, or at least they did not lose during the transition, because pensions were generally better indexed than wages or other social benefits. The decline in pension benefits was therefore usually less than the national average, leaving pensioners in a relatively better position. In addition most $^{2}$ countries allow pensioners to earn additional money without losing the right to receive the benefit. Unemployment also has less impact on a pensioner than on a prime age adult, for whom it is a major risk (Spéder, 1998).

Based on this overview, we can identify the winners and losers of the transition. Overall, it is undeniable that the largest part of the population has lost, and that there are very few real winners. Pensioners are only relatively better off, but they did not really win. The major social groups that have lost relatively more severely during the transition are:4

i) Women, because they carry the largest burden as they were the first to become unemployed, and form the majority of single-parent households (Barr, 1994),

ii) low educated workers, because their wage is below subsistence, their skills are not adapted for the new industries, and the unemployment rate is high;

iii) farmers; they lost almost everywhere compared to workers and pensioners (Milanovic, 1998);

iv) young adults, because they have difficulties finding a job and entering the labor market, and the wages are low;

v) those without access to assets, because they cannot substitute consumption with own production.

Most of the results presented in this section are based on some quantitative analysis of income or expenditure data of a country, thereby identifying the poor according to a monetary welfare measure. The range of vulnerable groups increased during the transition and we assume that this was also the case in Latvia. The analysis in chapter three confirms most of the conclusions about new poverty as described above. There are, though, exceptions. Ownership of assets, such as a plot of land, did not prove to be of importance in the Latvian case. As far as the position of women is concerned, the results of the poverty profile do not statements as strong as those above. Section 4.4 approaches the problem from a different angle. The people themselves are asked whether they consider themselves to have won or lost during the transition. The analysis of the special poverty survey, which is described in the next section, shows whether the groups match, and eventually distringuishes the pessimists from the optimists.

\footnotetext{
${ }^{3}$ Acourding to Milanovic (1998), low-skilled clerical staff used to be the most overstaffed professional category under socialism.

Wote, these are only the groups that lost. The old poor, i.e. large families, children, single-parent farmiltes and the working poor were confronted with deteriorating standards of living as well, but their relative position stayed more or less the same - they remained vulnerable.
}

In Russia, the share of unemployed women to men is 2.1 and the same applics to pensioners, of all singlle parent families, 94\% are female (Bar, 1994:80). 


\subsection{The poverty survey - data, methodology and overview}

\subsubsection{The survey}

The data underlying this and the next chapter are the result of a special powerty survey that we designed. The data were collected from August to October 1998 by the Central Statistical Bureau of Latwia (CSB). The representative sample consisted of 3200 households, of which 1200 were the regular households participating in the Household Budget Survey (HBS). These households were interviewed using the regular HBS and the poverty survey which we designed with the purpose of gaining information on the dynamics of the transition and the way people cope with their situation. The additional 2000 households were sampled according to the same principle as the HBS households, i.e. by two-stage stratified random sampling (see section 2.3.1). These additional households answered a recall survey, which replaced the HBS, and the poverty survey. The survey instruments, the actual sample size as well as the time frame are summarized in Table 4.1.

Table 4.1. Poverly Survey Sample

\begin{tabular}{lccc}
\hline Instrument & August 1998 & September 1998 & October 1998 \\
\hline $\begin{array}{l}\text { Household Burgett Survey \& } \\
\text { Poverty Survey }\end{array}$ & 627 & 624 & \\
Recall Survey 8 & & 906 \\
Poverty Survey & & 904 & 906 \\
\hline
\end{tabular}

Total number of intorvlewed households: 3061

Source: Powerty Survey 1998.

The HBS consists of a questionnaire and a diary as described in section 2.3.1. The questionnaire collects information on the household and the individuals living in this household, and the diary gathers detailed information on the consumption behavior in Latvian households during one month. ${ }^{7}$

The Recall Survey has two parts as well, i.e. a questionnaire which is identical to the one of the HBS and a recall part substituting the diary of the HBS. This recall survey was originally created by the World Bank with the purpose of controlling the results provided by the HBS. Respondents are asked to recall the value and quantity of food and non-food items their household bought or received during a certain period. These recall periods vary from two weeks for food up to 12 months for certain durable goods.

The decision to use the recall survey for the additionally sampled 2000 households was mainly due to practical and financial reasons. Using the full HBS for these households would have resulted in significantly higher costs as it would require several wisits by the interviewer to the participating household and higher administrative costs due to increased data entry and control needs. Nevertheless, for the identification of the poor households, c.q. the ranking of all households interviewed with the poverty survey according to their welfare level, information on the expenditures of all households was needed. The methodology for the creation of the expenditure aggregate for the HBS households had already been developed for the 1996 round of the HBS (see chapter two). Only small changes were necessary with respect to the inclusion or exclusion of certain goods in order to streamline the information provided by the recall survey which is obwiously less detailed. Otherwise, the same methodology was applied. With respect to the

\footnotetext{
"The survey was funded by the UNDP project "Support to Developnent of a National Poverty Eradication Strategy" (Lat $96 / 551)$

"Note that from April 1998 data on food items are collected during two weeks only.
} 
expenditure information coming from the recall survey, adjustments were necessary for those goods whose recall period exceeded one month.

Merging both samples has its drawbacks with respect to the analytical power of the data. It restrains the possibilities with respect to a quantitative poverty analysis based on a monetary indicator because of the remaining differences between the two data sets. A linear adjustment was applied to the recall expenditure aggregates in order to have a ranking of all households from poorest to richest that would represent a good estimation of the true ranking and allow us to draw conclusions about the various groups of households based on their standard of living. In case an analysis from the household level welfare point of view is required, the households are divided into five groups of equal size (quintiles) from poor to rich according to their total household expenditures per capita per month.

The Poverty Survey was the main reason for these additional interviews. All households were interviewed with this newly designed survey no matter whether they belonged to the HBS or the recall survey sample. The survey should provide answers to the questions that emerged after the quantitative and qualitative assessment of poverty in Latvia (Gassmann, 1998; Institute of Philosophy \& Sociology, 1998). We developed a questionnaire consisting of four modules. The first part contains questions related to the dynamics of the standard of living of the popullation since independence. The second module asks respondents about their coping strategies in order to find out how poor households especially make ends meet. The third module concentrates on local social assistance services, and the last module asks questions about the education of the children supplemented with some questions about health and related issues (see for the complete questionnaire of the poverty survey Annex B).

\subsubsection{Methodology}

The answers to the HBS and the recall survey are mainly used to distinguish between different socio-economic groups in the population and to analyze differences with respect to their answers to the poverty survey questionnaire. Groups are formed according to various criteria: characteristics of the household (e.g. household size, number of children, location, etc.), characteristics of the breadwinner, defined as the main income contributor (e.g. age, income source, educational attainment, civil status, etc.), or according to the characteristics of the respondent. This last classification is applied when the question is formulated in such a way that the properties of the respondent could influence the answer.

Cross-tabulations and descriptiwe statistical analysis are mainly used in the subsequent analysis. Where appropriate a more extensive model is estimated in order to test for the relevance of certain parameters. The significance of various determinants on the feeling of losing, c.q. winning during the transition is, for example, estimated using logistic regression analysis. The results are presented in section 4.4.6. Some of the questions allow a reliability analysis from which an appropriate scale can be developed and subsequently analyzed for different population groups. An example is question A05 (see Annex B) on the judgements and opinions of respondents towards specific items and statements (see section 4.4.5).

A sample profile is attached in Appendix 4B, presenting a detailed overview of the sample population. The results of the subsequent analysis are representative for the country. The weights applied have been provided by the Central Statistical Bureau of Latwia that carried out the survey.

\footnotetext{
See Appendix 4 A for a more detailled explanation of the merging process.
} 


\subsubsection{Summarizing poverty}

It is not possible to employ the same sort of poverty analysis with the present data as in the previous chapter because two different data sets with expenditure data have been merged (diary and recall). Using only the data from the HBS diary yields too small a sample since only the data of two months are available. We decided to summarize poverty by presenting the households according to the expenditure quintile they belong to. This should minimize measurements errors with respect to the ranking of a household as much as possible. The more reliable the underlying data are, the more detail in which rankings can be presented, i.e. the smaller the groups into which all households are divided can be. Considering the problems that emerged when merging the recall data with the diary data, a presentation of the households' welfare levels in terms of quintiles seemed the most prudent way (see appendix $4 \mathrm{~A}$ on the merging process).

Table 4.2 is organized as follows: for each indicator (column one), the national average is presented first (column two); the remaining five columns present the averages for each quintile, with quintile I representing the poorest households and quintile $\mathrm{V}$ the wealthiest.

The poorer the household, the larger its size. Also, poorer households have more children on average. With respect to the presence of children in a household, the table shows that there is a rather clear division between the two lowest quintiles and the three richest quintiles. $25 \%$ of the households in the first quintile hawe one child and $18 \%$ have two children. This is significantly above the national average of $17 \%$ of households with one child and $8 \%$ of households with two children. Or, to formulate it differently, the proportion of families with no children is clearly below the national average of $72 \%$ in the first and second quintiles (50\% and $66 \%$ respectively).

The average number of dependants per household is almost double the national average in the first quintile (1.04 compared to 0.56). Dependants are not only children, but all persons living in a household with no source of income of their own. This skewed distribution has, of course, direct effects on the average per capita expenditure level which is less than half of the national average. The share of single-parent households in the first and second quintile is also considerably above the national average. More than $16 \%$ of households in the first quintile belong to this category compared to $9.3 \%$ nationally. Single-parent families are defined as families with only one parent and children and with or without other adults living in the same household."

The position of households with young breadwinners is not that clear-cut anymore. Still, the share of young breadwinner households is largest in the poorest quintile, but this is also the case in the richest quintile. It seems as if there is a new generation of young breadwinners that performs rather well in terms of their standard of living. Exactly the opposite 'curve' is visible with respect to breadwinners belonging to the oldest age-group. Their shares are smallest at both ends of the welfare distribution.

Households that depend on income from agriculture are still the most vulnerable group when analyzing the main source of income. Although only $6 \%$ of all households indicate agriculture as their main source, this share increases to $14 \%$ in the first quintile. With respect to pensioners, their situation is unchanged since 1996. Due to the sample size, it is not possible to treat households depending mainly on social transfers as a separate group.

Finally, the earlier conclusion about the position of rural households is confirmed with the current data-set as well. Comparing the different quintiles with the total, where $72 \%$ of all households live in rural areas, the distribution in the first and fifth quintile is completely different. Only $57.7 \%$ of all households in the first quintile live in urban areas, whereas more than $80 \%$ of households in the fifth quintile are urban.

\footnotetext{
The identification of single-parent households in the survey became only possible in 1998 .
} 
Table 4.2. Latvian Households in 1998 (August - October) per Quintile

\begin{tabular}{|c|c|c|c|c|c|c|}
\hline \multirow[b]{2}{*}{ Indicator } & \multirow[b]{2}{*}{ Total } & \multicolumn{5}{|c|}{ Quintile" } \\
\hline & & $\Uparrow$ & $\|$ & 111 & IV & V \\
\hline Awerage household size (\#) & 2.32 & 3.16 & 2.44 & 2.18 & 2.12 & 1.90 \\
\hline Average number of children & 0.42 & 0.85 & 0.49 & 0.30 & 0.32 & 0.24 \\
\hline Average age of the breadwinner (years) & 51.77 & 49.73 & 52.16 & 54.78 & 53.84 & 48.41 \\
\hline Average number of dependants & 0.56 & 1.04 & 0.63 & 0.44 & 0.45 & 0.36 \\
\hline Aver. monthly household exp. per capita (LVL) & 70.86 & 27.04 & 41.93 & 55.75 & 74.24 & 139.13 \\
\hline Share of households with children $(\%)^{4}$ & 27.99 & 49.45 & 33.62 & 22.28 & 21.96 & 17.43 \\
\hline Share of household owning a plot of land (\%) & 47.39 & 55.45 & 46.86 & 44.97 & 45.89 & 45.24 \\
\hline Share of single parent families $(\%)$ & 9.30 & 16.76 & 12.32 & 7.83 & 6.80 & 4.62 \\
\hline $\begin{array}{l}\text { Share of households with female breadwinners } \\
(\%)\end{array}$ & 52.71 & 49.41 & 56.37 & 52.38 & 56.23 & 49.07 \\
\hline \multicolumn{7}{|l|}{ By number of children $n^{2,4}$} \\
\hline - one child & 17.26 & 24.73 & 20.95 & 15.71 & 14.24 & 12.58 \\
\hline - two children & 8.38 & 18.41 & 10.40 & 5,48 & 6.04 & 3.73 \\
\hline - three or more children & 2.35 & 6.31 & 2.27 & 1.09 & 1.68 & 1.13 \\
\hline \multicolumn{7}{|l|}{ By main income of breadwinner ${ }^{2,3}$} \\
\hline - (Selfijemployment & 47.58 & 38.05 & 42.30 & 42.00 & 47.25 & 64.56 \\
\hline - Agriculture & 6.08 & 14.24 & 6.44 & 5.49 & 3.34 & 2.65 \\
\hline - Pension or social transfers & 42.54 & 38.21 & 47.68 & 49.15 & 47.28 & 31.20 \\
\hline - Other & 3.80 & 9.50 & 3.59 & 3.36 & 2.12 & 1.58 \\
\hline \multicolumn{7}{|l|}{ By age-group 23} \\
\hline $15-34$ & 20.21 & 23.64 & 24.29 & 14.19 & 16.26 & 25.58 \\
\hline $35-64$ & 52.79 & 54.25 & 48.79 & 53.01 & 53.60 & 54.21 \\
\hline 65 and older & 27.00 & 22.12 & 29.92 & 32.80 & 30.14 & 20.20 \\
\hline \multicolumn{7}{|l|}{ By educational attainment ${ }^{2,3}$} \\
\hline - higher & 14.50 & 6.28 & 10.12 & 12.52 & 15.49 & 24.90 \\
\hline - secondary & 53.37 & 53.44 & 50.17 & 50.25 & 52.56 & 59.54 \\
\hline - vocational & 3.83 & 5.09 & 5.90 & 3.69 & 2.49 & 2.46 \\
\hline - primary & 20.88 & 24.72 & 23.22 & 26.95 & 21.06 & 10.47 \\
\hline - less than primary & 7.43 & 10.47 & 10.59 & 6.59 & 7.95 & 2.63 \\
\hline \multicolumn{7}{|l|}{ By marital status ${ }^{2,3}$} \\
\hline - mever marriad & $\$ 1.83$ & 7.57 & 12.78 & 8.98 & 111.12 & 117.38 \\
\hline - married & 47.89 & 57.54 & 48.54 & 49.09 & 44.74 & 41.86 \\
\hline - married, living apart & 3.34 & 2.87 & 2.71 & 3.54 & 3.84 & 3.59 \\
\hline - widowad & 20.20 & 17.79 & 21.54 & 22.02 & 22.16 & 17.45 \\
\hline - divorced & 16.75 & 14.22 & 14.43 & 16.38 & 18.14 & 19.72 \\
\hline \multicolumn{7}{|l|}{ By nationality 2,} \\
\hline - Latwian & $\begin{array}{l}55.71 \\
32.91\end{array}$ & $\begin{array}{l}52.85 \\
34.08\end{array}$ & $\begin{array}{l}5.3 .82 \\
35.12\end{array}$ & $\begin{array}{l}52.80 \\
34.93\end{array}$ & $\begin{array}{l}53.33 \\
34.45\end{array}$ & $\begin{array}{l}6.47 \\
26.92\end{array}$ \\
\hline $\begin{array}{l}\text { - Russian } \\
\text { - Other }\end{array}$ & 11.38 & 13.07 & 11.06 & 92.27 & 10,22 & 10.67 \\
\hline \multicolumn{7}{|l|}{ By urban-rural location ${ }^{2}$} \\
\hline - Lurban & $\begin{array}{l}72.40 \\
27.60\end{array}$ & $\begin{array}{l}57.71 \\
42.29\end{array}$ & $\begin{array}{l}72.27 \\
27.73\end{array}$ & $\begin{array}{l}70.99 \\
29.01\end{array}$ & $\begin{array}{l}76.94 \\
23.06\end{array}$ & $\begin{array}{l}80.69 \\
19.31\end{array}$ \\
\hline
\end{tabular}

1 Quintiles are based on total monthly househoid expenditures per capita.

2 Each quintie sums up to $100 \%$ (except for rounding errors).

3 Charactenistic relates to breadwinner.

4 Children are household members < 15 years.

Sounce: Powerty Survey 1998. 
Summarizing, these results indicate that based on the available data for 1998 the following groups are the most vulnerable ones with respect to poverty:

- Luarge households;

- Households with children;

- Households with an above average number of dependants;

- Single parent households;

- Households situated in rural areas;

- Houscholds depending on income from agriculture.

\subsection{The perception and dynamics of gaining and losing ${ }^{10}$}

Poverty and the feeling of being badly off are relative concepts for most people. They are the outcome of a series of events and actions and they are the conclusion of a string of thoughts and feelings. They are relative to place and time, meaning that they are related to the situation of other people and to a person's own situation in another period, in the past. The latter is very important. in the case of Latwia, being an economy in transition from a republic within the Soviet system to an independent country with a market economy. People within households may feel better off or worse off compared to before independence. In order to learn something about the changes between 1991 and 1998 and their determinants, we asked the respondents to compare their situation in 1998 with their situation before 1991 . We asked them to describe what happened in the meantime and to give their judgment on the changes that occurred. The purpose of this section is to investigate who is saying that he or she is better- or worse off. What is the profiles of the persons and. households that conclude to be better off and what are the characteristics of those concluding that they are worse ofr? Are these the same groups in Latvia as in section 4.2, and do these groups consider themselves winners or losers? We would like to get a better understanding of why they gained or lost, and what kind of events and behavior is associated with their relative position. We allso try to relate the changes in the situation of the respective households to their relative position before 1991.

\subsection{Feelling worse off, being worse off}

The basis for the analysis of the changes is formed by the questions $\mathrm{A} 02$ and $\mathrm{A} 03$ of the povery survey questionnaire (see Annex B). Respondents were asked the following questions:

A02: If you compare your standard of living before 1991 to now which statement characterizes you situation the best? The possible answers were 5 statements ranging from: "Now we can buy and afford much more than before" to "Now we can buy and afford much less than before";

A03: Have your possibilities concerning consumption changed in the same way since 1991? The possible answers describe different patterns over time (going up constantly, going down first then up, etc.).

\footnotetext{
107his section is based on joint worll with Chris de Neubourg. The results wane presented earher in a paper (Gassmann and de Neubourg, 1999) written on behalf of UNDP in the context of the project 'Support to Development of a National Poverty Entidication Strategy' (Lat/96/551).
} 
Trable 4.3. Companison of consumption possibillities: 1991 vs $1998^{\text {in }}$ percentages

\begin{tabular}{lr}
\hline Comparison of standarid of liwing before 1991 to present & Total \\
Consume more & 8.64 \\
consume same & 11.88 \\
consume littie less & 14.37 \\
consume much less & 61.70 \\
dionit know & 3.40 \\
Tolal & 100 \\
\hline
\end{tabular}

Sounce: Poverty Survey 1998.

Table 4.4. Patterns of changes in consiumption possibilities between 1991 and 1998 in percentages

\begin{tabular}{lr}
\hline Comparison consumption possibilibies after 1991 & Total \\
\hline constantly decreased & 51.00 \\
remained constant & 15.45 \\
Tirst up then down & 5.10 \\
dropped frst, then stayed the same & 11.66 \\
improved constantly & 9.46 \\
dont know & 7.32 \\
Total & 100 \\
\hline
\end{tabular}

Source: Poverty Survey' 1998.

Table 4.3 summarizes the frequencies of the first question. We reduced the number of categories to four for technical reasons (category 2 was too small to yield trustworthy answers). From the table it can be seen that the majority of the respondents $(62 \%)$ thinks they are much worse off (can consume much less) in 1998 compared to $1991.14 \%$ think they can consume a little less, while $12 \%$ say they can consume the same in 1998 as in 1991; only $9 \%$ state they can consume more now than in the past. Reducing the possible patterns over time, as measured by question A03, from eight to five, Table 4.4 reveals that half of the respondents $(51 \%)$ have seen their consumption possibilities decreasing constantly ever since 1991 , while approximately $10 \%$ saw their consumption possibilities improving over time $(9.46 \%)$. A considerable group saw their possibilities remaining constant $(15.45 \%)$, sometimes after an initial decline (another $12 \%$ ). A little more than $5 \%$ initially profited from the transition but saw their possibilities declining afterwards.

Cross-tabulating the answers to question $\mathrm{A} 02$ with those to question A03 reveals some interesting relations (see Table 4.5 ). Of those that say they consume more today, the majority ( $58 \%$ ) acknowledges that their consumption possibilities increased after 1991. But almost one third (27\%) feels that they remained the same. Of those households that say they consume much less today, the majority relates this to constantly deceasing consumption possibilities since $1991(70 \%)$. For $14 \%$ the drop in consumption occurred at the beginning and then remained. the same.

The answers to the questions $\mathrm{A} 02$ and $\mathrm{A} 03$ should be interpreted with care. They only reflect what the respondents are thinking. This does not necessarily correspond to what actually happened. We have no data to check for that, but we have the ranking of the households according to their actual expenditures in 1998 (see section 4.3.3). Cross-tabulation of the position of the households" income position in quintiles with the answers to question A02 can give some information about the adequacy of the answer on the latter question. Although we cannot expect the figures to match perfectly (after all the questions are different: how much you have spent against whether you gained or lost over the last seven years), we expect some correlation. The cross-tabulation as given in Table 4.6 illustrates that in fact the correlation is quite substantial. People with a higher level of expenditures in 1998 did indeed answer relatively more often that they now are better off than before 1991 . This gives some confidence over the quality of the data that we are using. Less than $3 \%$ of the households in the first (lowest) quintile are saying that they can consume more in 1998 
against $79 \%$ of them stating that they can consume much less. Or, of all the people stating that they can consume more in 1998, approximately half of them are belonging to the fifth quintile. It seems that the respondents have a fairly good understanding of their own place in the income distribution and that they have answered these type of questions in a trustworthy way. The fact that $42 \%$ of the households of the richesit decile indicate that they consume much less nowadays could be related to the decline in real income over the last seven years. It may be concluded that not only poorer households saw their consumption possibilities declining.

Table 4.5. Perceptons of changes in consumpton possibilities wersus pattern of changes

\begin{tabular}{|c|c|c|c|c|c|c|c|}
\hline & $\begin{array}{l}\text { consitantly } \\
\text { decreased }\end{array}$ & $\begin{array}{l}\text { remained } \\
\text { the same }\end{array}$ & $\begin{array}{l}\text { up them } \\
\text { down }\end{array}$ & $\begin{array}{l}\text { drop first, } \\
\text { then same }\end{array}$ & improved & $\begin{array}{l}\text { don't } \\
\text { know }\end{array}$ & total \\
\hline \multirow[t]{2}{*}{ consume more } & $6.31^{\circ}$ & 27.26 & $324^{*}$ & $1.05^{\text {ti }}$ & 58.08 & $4.06^{*}$ & 100.00 \\
\hline & $1.07^{7}$ & 15.24 & 5.49 & $0.78^{\circ}$ & 53.02 & $4.79^{*}$ & 8.64 \\
\hline \multirow[t]{2}{*}{ consume sarme } & 10.71 & 63.59 & 2.96 & $5.48^{*}$ & 12.16 & $5.110^{*}$ & 100,00 \\
\hline & 250 & 48.91 & $6.91^{*}$ & $5.58^{4}$ & 15.27 & $8.27^{*}$ & 11.88 \\
\hline \multirow{2}{*}{ consume little less } & 37.43 & 19.44 & 10.50 & 16.30 & 7.84 & 8.49 & 100.00 \\
\hline & 10.55 & 18.08 & 29.58 & 20.08 & 11.90 & 16.66 & 14.37 \\
\hline consume much & 70.15 & 3.97 & 4.79 & 13.66 & 2.45 & 4.97 & 100.00 \\
\hline less & 84.88 & 15.86 & 58.02 & 72.27 & 16.00 & 4.1 .87 & 61.70 \\
\hline \multirow[t]{2}{*}{ don't known } & $15.16^{i x}$ & $8.69^{k}$ & $0^{*}$ & $4.44^{\text {th }}$ & $10.59^{\prime \prime}$ & 61.11 & 100.00 \\
\hline & $1.01 \%$ & $1.91 *$ & $0^{*}$ & $1.30^{\text {th }}$ & $3.81^{\star}$ & 28.40 & 3.40 \\
\hline \multirow[t]{2}{*}{ total } & 51.00 & 15.45 & 5.10 & 11.66 & 9.46 & 7.32 & 100.00 \\
\hline & 100.00 & 100.00 & 100.00 & 100.00 & 100.00 & 100.00 & 10000 \\
\hline
\end{tabular}

") sample size n<20.

Source: Poverty Survey 1998.

Table 4.6. Parception on changes in consumption possibilities between 1991-1998 versus income-position af households in 1998

\begin{tabular}{|c|c|c|c|c|c|c|}
\hline \multirow[b]{2}{*}{ Position } & \multicolumn{6}{|c|}{ Division into quintile groups } \\
\hline & 1 & 2 & 3 & 4 & 5 & Total \\
\hline \multirow[t]{2}{*}{ consume more } & 5.54 & 8.38 & 13.98 & 22.35 & 49.79 & $\$ 00.00$ \\
\hline & 2.79 & 3.71 & 6.13 & 9.21 & 18.97 & 8.64 \\
\hline \multirow[t]{2}{*}{ consume same } & 7.45 & 13.04 & 19.78 & 23.78 & 35.94 & 100.00 \\
\hline & 5.17 & 7.94 & 11.92 & 13.47 & 18.85 & 4.88 \\
\hline \multirow[t]{2}{*}{ consume lithe less } & $11: 27$ & 18.09 & 24.92 & 24.25 & 24.47 & 100,00 \\
\hline & 9,45 & 13.32 & 15.97 & 16.61 & 15.52 & 9.4 .37 \\
\hline \multirow[t]{2}{*}{ consume rnuch less } & 21.93 & 22.80 & 20.22 & 19.56 & 15.49 & 100.00 \\
\hline & 78.99 & 72.09 & 63.26 & 57.55 & 42. 18 & 61.70 \\
\hline \multirow[t]{2}{*}{ don't thow } & 18.08 & 16,82 & 15.81 & 19.44 & 29.85 & 100.00 \\
\hline & 3.59 & 2.93 & 2.73 & 3.15 & 4.48 & 3.40 \\
\hline \multirow[t]{2}{*}{ Total } & 17.13 & 19.51 & 19.72 & 20.97 & 22.66 & 100.00 \\
\hline & 100.00 & 100.00 & 100.00 & 100.00 & 100.00 & 100.00 \\
\hline
\end{tabular}

Sounce: Poverty Suney 1998.

Cross-tabulation of the questions about pattems with the actual income position of the households shows that the majority of the households in the first three quintiles have seen their consumption possibilities decline since 1991. The category of households with an initial decline and a steady development afterwards could be categorized as the large middle class. The relatively richer 
households (quintiles 4 and 5) relatively more often found their possibilities constantly improving or faced constant income developments.

Table 4.7. Income position and patterns of change

\begin{tabular}{|c|c|c|c|c|c|c|}
\hline \multirow[b]{2}{*}{ Position } & \multicolumn{6}{|c|}{ Division into quintile groups } \\
\hline & 1 & 2 & 3 & 4 & 5 & Totall \\
\hline \multirow[t]{2}{*}{ constantly decreased } & 21.96 & 22.88 & 20.69 & 18.80 & 15.67 & 100.00 \\
\hline & 65.37 & 59.81 & 53.49 & 45.71 & 35.28 & 51.00 \\
\hline \multirow[t]{2}{*}{ remained constant } & 7.92 & 14.35 & 18.38 & 24.28 & 35.07 & 100.00 \\
\hline & 7.15 & 11.37 & 14.40 & 117.818 & 23.91 & 15,45 \\
\hline \multirow[t]{2}{*}{ up then down } & 9.81 & 18.67 & 19.66 & 27.20 & 24.67 & 100.00 \\
\hline & 2.92 & 4.88 & 5.08 & 6.61 & 5.55 & 5.10 \\
\hline \multirow[t]{2}{*}{ dropped then same } & 17.80 & 22.81 & 22.25 & 2195 & 15.19 & 100.00 \\
\hline & 12.12 & 13.63 & 13.16 & 1221 & 7.82 & 11.66 \\
\hline \multirow[t]{2}{*}{ improved } & 9.86 & 8.45 & 14.78 & 19.33 & 47.85 & 100.00 \\
\hline & 5.45 & 4.10 & 7.09 & 8.72 & $\$ 9.87$ & 9.46 \\
\hline \multirow[t]{2}{*}{ don't know } & 16.36 & 16.56 & 18.24 & 25.41 & 23.44 & 100,00 \\
\hline & 6.99 & 6.21 & 6.77 & 8.87 & 7.58 & 7,32 \\
\hline \multirow[t]{2}{*}{ Total } & 17.13 & 49.51 & 19.72 & 20.97 & 22.66 & 100.00 \\
\hline & 100.00 & 100.00 & 100.00 & 100,00 & 100.00 & 400.00 \\
\hline
\end{tabular}

\subsubsection{Who gained, who lost?}

Let us remember that only a small minority of Latvian households thinks that nowadays they can consume more than before the transition $(9 \%)$. The vast majority of the households $(77 \%)$ think that they have lost in the process either a lot $(62 \%)$ or mildly (14\%). Another group (1.2\%) saw their consumption possibilities unaltered. These are disturbing figures. Even if the reality is less grim than indicated by these estimates, it is still disturbing that this is the overall perception of the society on the gains from independence and the new market economic environment. On the other hand, the picture coincides with the economic reality of the first years of the transition with the decreasing real incomes and lower real wages. We will come back to this point at the end of this section and in the next section. In the current section we confime ourselves to understanding the differences between the households that gained and those that have lost.

Winners and losers are not randomly distributed over the population. Households with more consumption possibilities in 1998 than in 1991 are concentrated in certain groups; so are households that are worse off in 1998. The most important conclusion to note is that both improvement and deterioration are closely related to employment and employment possibilities. Individuals currently employed ( $45 \%)$ more often live in households that indicated they can consume more or the same. The opposite is the case for the unemployed (7\%), $80 \%$ of whom live in households that consume much less today than in 1991. The working pensioners are also above proportionally represented in the groups that consume more or the same. Subdividing households according to the change in consumption possibilities and the main source of income of the breadwinner reveals that lhouseholds with a main income earner who has a non-agricultural job are usually better off than households whose main income is from a non-employment source or with a job in agriculture. Table 4.8 further shows that those households with a main incone eamer working in the private sector or selfemployed, are relatively better off. Households with a main income source stemming from employment in agriculture or from pensions or social transfers are among the losers. A warning is 
important here: improvement, c.q. deterioration related to an income source does not mean that all people belonging to that group are better off, c.q. worse off. As the table shows, there is still a stgnificant number of people working in the private sector who are among the losers, just like there are (a small number on winners among the pensioners and social transfers recipients. It is aiso evident that the own perception of the people, c.q how they feel, does not necessarily coincide with the 'other' reality derived from quantitative data. Remember, e.g., that pensioners were not among the losers of the transition in most of the countries. Neither were they one of the groups most at risk in Latvia according to the poverty profile as presented in chapter three. At the same time there are many working poor (see Table 4.8). $52 \%$ of those households with a breadwinner whose main income source is from public sector employment and $46 \%$ of those working in the private sector indicate that they consume much less nowadays.

Besides the main source of income, people can supplement their household income with a secondary source of income. In general, th can be said that these secondary sources of income are not very important in explaining why people are (feeling) better off or worse off in 1998 compared to 1991 . In only $5.6 \%$ of the households does the main income eamer have a secondary job outside agriculture; pensions are by far the largest category here and their contribution in explaining the position of the household is very limited. One quarter of the households get some additional income out of agriculture but this income source has an inverse relationship with being better off. This implies that the better off the households are, the less they get supplementary income out of agriculture. It illustrates that additional income from agriculture is relatively marginal and has to be regarded as a coping strategy rather than as a substantial income generating activity. We will discuss this more extensively in chapter five on coping strategies.

So far we considered the income sources of the main income eamer only. Households, however, may have various income sources depending on their composition. Only $20 \%$ of the households in the sample have a single source of income, $38 \%$ have two sources, $19 \%$ have three sources, $14 \%$ have four sources, and $8 \%$ have five or more income sources. Constructing an indicator where the number of income sources is divided by the number of adults in the household reveals that the value of that indicator ranges from 5 to 3.25 , with high concentrations on certain values. By far the most important value is one, which indicates that on average every adult household member has one income source. This is true for $52 \%$ of the households. If the indicator is bigger than one, it means that there is more than one income source per adult in the household, a value of two means that there are wo income sources per adult in the household, while three means that in the household adults have on average 3 income sources. $10 \%$ of the households in the sample have on average 1.5 income sousces per adult household member and $17 \%$ have two sources per adult on average.

Cross tabulation of this indicator on the change in the consumption possibilities is done in Tablle 4.9. It can be seen from the table that households with higher values for the income indicator, i.e. with more income sources per adult household member, tend to regard their position in 1998 as worse than in 1991. While the households consuming more in 1998 than in 1991 add up to only $9 \%$ of the population, they represent $14 \%$ of the households with a number-of-income-sources-indicator below one. On the other hand the table illustrates that the category of households with a lower consumption level in 1998 than in 1991 is over-represented among the groups with higher values for the indicator, thus with relatively more income sources available. Apparently, the availability of muliple income sources is no guarantee for a high consumption level. It may indicate that the incone derived from these sources is too small to improve the consumption possibilities of at household significantly. The number of income sources can therefore be assumed to be negatively correlated with positively perceived changes between 1998 and 1991. 
Tabje 4.8. Changes in consumption possibilities versus major source of income of nain income earner

\begin{tabular}{|c|c|c|c|c|c|c|c|c|}
\hline & \multicolumn{8}{|c|}{ Major source of income } \\
\hline & $\begin{array}{c}\text { Agricul- } \\
\text { ture }\end{array}$ & $\begin{array}{l}\text { Public } \\
\text { sector }\end{array}$ & $\begin{array}{l}\text { Priwate: } \\
\text { sector }\end{array}$ & $\begin{array}{l}\text { Self- } \\
\text { empl. }\end{array}$ & Pension & $\begin{array}{l}\text { Social } \\
\text { transfer }\end{array}$ & other & Total \\
\hline consume more & $\begin{array}{l}3.31^{*} \\
4.74^{*}\end{array}$ & $\begin{array}{r}23.69 \\
9.29\end{array}$ & $\begin{array}{l}47.10 \\
17.60\end{array}$ & $\begin{array}{r}7.92 \\
32.19\end{array}$ & $\begin{array}{r}16.56 \\
3.50\end{array}$ & $\begin{array}{l}0.95^{*} \\
5.79^{*}\end{array}$ & $0.47^{*}$ & $\begin{array}{r}100,00 \\
8.70\end{array}$ \\
\hline consume same & $\begin{array}{l}2.68^{*} \\
5.27^{*}\end{array}$ & $\begin{array}{l}34.45 \\
18.52\end{array}$ & $\begin{array}{l}28.87 \\
14.79\end{array}$ & $\begin{array}{r}4.99^{*} \\
27.79 *\end{array}$ & $\begin{array}{r}25.87 \\
7.50\end{array}$ & $\begin{array}{l}0.41^{*} \\
3.41^{*}\end{array}$ & $\begin{array}{l}2.73^{*} \\
8.55^{*}\end{array}$ & $\begin{array}{r}100.00 \\
14.92\end{array}$ \\
\hline consume little less & $\begin{array}{r}4.24 \\
10.02\end{array}$ & $\begin{array}{l}25.13 \\
16.25\end{array}$ & $\begin{array}{l}28.17 \\
17.36\end{array}$ & $\begin{array}{l}1.42^{*} \\
9.49^{*}\end{array}$ & $\begin{array}{l}36.98 \\
12.90\end{array}$ & $\begin{array}{r}1.53^{*} \\
15.36^{*}\end{array}$ & $\begin{array}{l}2.54^{*} \\
9.55^{*}\end{array}$ & $\begin{array}{r}100.00 \\
14.34\end{array}$ \\
\hline consume much less & $\begin{array}{r}7.36 \\
74.86\end{array}$ & $\begin{array}{l}18.93 \\
52.62\end{array}$ & $\begin{array}{l}17.40 \\
46.11\end{array}$ & $\begin{array}{r}0.93 \\
26.65\end{array}$ & $\begin{array}{l}48.80 \\
73.18\end{array}$ & $\begin{array}{r}1.64 \\
70.68\end{array}$ & $\begin{array}{r}4.94 \\
79.88\end{array}$ & $\begin{array}{r}100.00 \\
61.64\end{array}$ \\
\hline don't know & $\begin{array}{l}9.10^{*} \\
5.09^{*}\end{array}$ & $\begin{array}{r}21.70 \\
3.32\end{array}$ & $\begin{array}{r}28.37 \\
4.14\end{array}$ & $\begin{array}{l}2.44^{*} \\
3.87^{*}\end{array}$ & $\begin{array}{r}35.31 \\
2.92\end{array}$ & $\begin{array}{l}2.00^{*} \\
4.76^{*}\end{array}$ & $\begin{array}{l}9.07^{*} \\
0.96^{*}\end{array}$ & $\begin{array}{r}100.00 \\
3.40\end{array}$ \\
\hline Total & $\begin{array}{r}6.06 \\
100.00\end{array}$ & $\begin{array}{r}22.18 \\
100.00\end{array}$ & $\begin{array}{r}23.27 \\
100.00\end{array}$ & $\begin{array}{r}2.14 \\
100.00\end{array}$ & $\begin{array}{r}41.11 \\
100.00\end{array}$ & $\begin{array}{r}1.43 \\
100.00\end{array}$ & $\begin{array}{r}3.8 .1 \\
100.00\end{array}$ & $\begin{array}{l}100.00 \\
100.00\end{array}$ \\
\hline
\end{tabular}

") sampie size $n<20$.

Source: Poverty Survey 1998.

Table 4.9. Changes in consumption passibilities versus number of income sounces per adult per household, in percentages

Number of income: sources/number of adults

\begin{tabular}{lrrrrrr} 
& $0<x<1$ & $x=1$ & $1<x<1.5$ & $1.5<=x<2$ & $x>2$ & Total \\
\hline consume more & 14.27 & 9.03 & 9.65 & 7.96 & 4.87 & 8.64 \\
consume same & 16.22 & 11.81 & 13.31 & 12.26 & 9.66 & 11.91 \\
consume little less & 16.55 & 13.92 & 11.30 & 131.27 & 15.98 & 14.37 \\
consume much less & 50.18 & 61.43 & 62.18 & 64.13 & 66.36 & 61.67 \\
don't know & $2.78^{*}$ & 3.81 & $2.93^{*}$ & $2.37^{*}$ & $3.13^{*}$ & 3.40 \\
Tolal & 100.00 & 100.00 & 100.00 & 100.00 & 100.00 & 100.00 \\
\hline
\end{tabular}

") sample size $n<20$

Source: Poverty Sunvey 1998.

When trying to identify the types of households that indicate their position in 1998 as better than before 1991 (or vice versa), we can use several indicators: household size, number of children, number of prime-age adults, number of seniors $(60+)$ and thousehold composition. For the latter, a clear pattern can be distinguished. The households consisting of two adults and two children and households with three adults, think more often that they are better off in 1998 than they were in 1991. Slightly less positive are households with two adults and one child and households with three adults and one child. Single adults, one parent families (both with one or two children) and twoadult households, feel that they are worse off. A higher number of children is found relatively more frequently among the winners. Households feeling that they consume more loday are on average larger, have more children, more prime age adults, but fewer elderly people. The fact that households with children feel better off actually contradicts the results of the poverty profile as well as the experience of other countries. Maybe it is not the material well-being that makes the world look rosier, but rather the psychological effects related to the presence of children. In general, households with seniors $(60+)$ among their members feel relatively worse of than others. This is to be interpreted in the light of the findings of the previous paragraph where it was said that employment seems to play an impottant role as a determinant. The general transition of the country 
and the retirement of the senior citizens happened at the same time (more or less). The elderly had to face a retreat from paid work into the stanus of a pension recipient. The pensions are low especially if compared to a regular salary. Therefore, pensioners feel worse off because they lost much at one lime.

When breaking down the categories into 5-year-age groups, it is quite clear that the younger households especially seem to believe they have profited more. Higher concentrations of people saying that they are now better off than before 1991 are found among the age-groups $20-24$ and especially 25 to 29 . This result is probably related to the life cycle in general. We are talking here about the generation that entered the labor market during the last decade. These young people are currently eaming their own money which partly explains their positive perception. Persons above 30 but younger than 50 are found particularly well represented in the groups of households that think they consume more or less the same or little less. Persons who think hey have lost rather than gained in economic terms are 50 and over. In fact in the higher age-groups between $63 \%$ and $70 \%$ of the respondents think that they consume less in 1998 than in 1991. Again, these findings are contrary to what we know from the quantitative analysis in previous studies for other countries and based on the poverty profile for Latvia. Some interpretation is needed here. First of all, the opinions of the younger age-groups should be reconsidered by the fact that in 1991 the oldest among them were 21 and the youngest twelve. This means that they have had few adult experiences under the Soviet system and thus their judgement about what they could afford before 1991 is definitely not based on long lasting experiences as an adult household member. Of course their judgment is not worthless, since they actually do have a valid view on consumption possibilities based on their parents" households. In addition, they might just have a more positive view on life and the new situation, feeling that it provides them with new opportunities. Nevertheless, their views do have a different basis those of the older age-groups. On the other hand the judgment of the older agegroups may be seriously influenced by the fact that they lost the income linked to employment firstly because they became pensioners and secondly because they have lost their jobs relatively more often. Their situation may now be characterized by much more uncertainty than under the old system. Some of them had more to lose than others. In fact, these households compare two different household situations before 1991 and in 1998. In the next section we will explore which type of events are more likely to be associated with which position.

Before doing so we want to explore first whether serious differences can be seen according to geographical location. Splitting up the population in households living in urban and rural areas, does not yield any differences, which is rather surprising regarding the conclusions from earlier sections that rural areas are considerably worse off today. Winners and losers are proportionally distributed over the urban and the rural areas, except for the real winners who live more often in urban areas. Distinguishing larger and smaller cities and Riga within the urban population, makes clear that households in Riga and in the maller cities especially show a different position. In both Riga and the smaller cities, there are more people counting themselwes among the winners compared to larger cities and rural areas. In the latter settlements the number of self-selected losers is more important This is especially true for the larger cities (excluding Riga) where more than $70 \%$ of the households state that they can consume less in 1998 than in 1991." Besides relatively more winners, Riga also has a relatively large proportion of households stating that they can consume a little less nowadays. A possible explanation for this outcome could be the fact that the large cities were home to manufacturing industries that suffered especially from a drop in output after $1991 .{ }^{12}$ Employment

\footnotetext{
"The six large cities are; Datgavpils, Liepaja, Jelgava, Wumala Vertspils, and Rezekne.

${ }^{12}$ Gross industrial ouput of manufacturing industries dropped until $\$ 994$ to only $37 \%$ of the output in 1990 (CSB, 1995:222).
} 
possibilities disappeared and the workers that used to be employed in these industries could not be easily retrained and re-employed in new sectors.

Regional differences are pronounced as can be seen from Table 4.10. Again Rigas region thas the most prominent position. Of all the wimers, $58 \%$ live in and around Riga (while $47 \%$ of the population lives in the capital region), and of all the losers $43 \%$ lives in Rigas region. While winners are over-represented and losers are under-represented in around the capital city, the opposite holds for the other regions. Latgale shows the worst situation with $5 \%$ of its households counting themselves as winners (against $11 \%$ in Rigas region) and with $73 \%$ of the households seeing themselves as losers (against 43\% in Rigas region). The other regions show an intermediate position, with Zemgale being relatively better off. These results may be related to the fact that large cities and Latgale have an above average proportion of unemployed (13\% and 10\% as compared to the national $7 \%$ as reported in official registration figures). In this context it is also interesting to note that, based on the survey data, unemployment in rural areas is below average. But this is equally true for the share of employed people, which is also clearly below average.

Tabie 4.10. Changes in consumption possibilities per region

\begin{tabular}{|c|c|c|c|c|c|c|}
\hline & \multicolumn{6}{|c|}{ Reglons of Latvia } \\
\hline & Rigas reg. & Kurzeme & Widzeme & Zengale & Liatgale & Total \\
\hline \multirow[t]{2}{*}{ cansume more } & 58.30 & 10.13 & 8.94 & 12.60 & 10.03 & 100.00 \\
\hline & 10.70 & 6.27 & 7.33 & 8.97 & 5.54 & 8.70 \\
\hline \multirow[t]{2}{*}{ consume same } & 53.53 & 14.71 & 10.54 & 9.00 & 12.25 & 100.00 \\
\hline & 13.47 & 12.48 & 11.81 & 8.78 & 9.28 & 11.92 \\
\hline \multirow[t]{2}{*}{ conisume littlla less } & 53.72 & 12.93 & 10.62 & 10.50 & 12.34 & 100.00 \\
\hline & 16.26 & 13.10 & 14.36 & 12.32 & 11.24 & 1434 \\
\hline \multirow[t]{2}{*}{ consume much less } & 43.05 & $14.8 \|$ & 10.38 & 13.20 & 18.56 & 100.00 \\
\hline & 56.00 & 65.00 & 60.31 & 66.55 & 72.72 & 61.64 \\
\hline \multirow[t]{2}{*}{ don't know } & 49.180 & 13.02 & 19.34 & 12.19 & 5.65 & 100.00 \\
\hline & 3.57 & 3.15 & 6.19 & 3.39 & 1.22 & 3.40 \\
\hline \multirow[t]{2}{*}{ Total } & 47.39 & 14.04 & $\nexists 0.61$ & 12.22 & 15.74 & 100.00 \\
\hline & 100.00 & 100.00 & 100.00 & 100.00 & 100.00 & 100.00 \\
\hline
\end{tabular}

\subsubsection{Why they gained or lost - The role of incidents}

In this paragraph we do not want to investigate all the possible determinants for the position of losers and winners. We do, however, want to relate the self-assessment on the relative changes between 1998 and 1991 to a series of events mostly outside the control of individuals. Most of these events have no relationship with the transition from a command economy to a market economy, although it may be true that the economic impact of the event upon the households may differ significantly in the two macroeconomic situations. In this paragraph we will confine ourselves to the impact of events largely outside the direct control of individual household members upon the relative changes between 1991 and 1998, such as a change in the household composition, the housing situation, or the disposition of assets (see question A.04 of the poverty questioninare). From Speder (1998) we know that a change in household composition can be a factor in the escape from or entry into poverty. According to his research on Hungary, he concluded that the presence of the first child is a reason for poverty. But if a child gets older, the woman can take on a job which helps the family to move out of poverty. The effect of a marriage is unclear, while its dissolution clearly has negative effects on the poverty risk. In case of divorce, the increase in risk may be temporary, 
while widowhood often results in lasting poverty. Any change in the number of eamers or in the activity status of the household member has an impact on the household's poverty risk (UNDP. 1998e). Table 4.11 lists a number of events as asked in question A04 providing the frequency of occurrence and whether the effect is positive or negative.

The incidence of two events have an above proportional negative impact on the economic situation in 1998 compared to the situation before 1991 in Latvia: the death of a family member and serious health problems of a household member. Among the households that saw their consumption possibilities grow or stay largely unaltered, about one out of five households is confronted with this problem; arnong the households that believe that their consumption possibilities have declined, one out of three households has experienced the death of a household member. A similar effect can be seen when serious health problems or accidents happen: relatively more people living in households in which health problems occurred are found among the households with a perceived declining standard of living between 1991 and 1998.

Other events with a negative impact on the relative changes are: divorce, a child leaving the household to live independently and the loss of financial support from outside the household. In all cases the negative impact is most probably to be attributed to the fact that in all cases an additional source of income disappeared. The loss of savings and bad harvests are of another category, but it is easy to understand how they affect household wealth negatively over time.

There are evidently also events with a positive impact on perceived changes in consumption possibilities. Not surprisingly, they are all related to extra sources of income. Marriage and the financial assistance from family members from abroad have a positive impact, as has access gained to private land. The central role of extra income sources for the household is best illustrated by looking at the impact of the fact that one of the parents joined the household between 1991 and 1998. This event can have both a negative and a positive impact. Although we have no firm data on why, it is plausible to assume that the actual effect depends on whether the "incoming" parent brought his/her own income sources with him/her.

Besides events outside the control of individuals, there are of course actions that could be taken by individuals or household in order to supplement income or to guarantee an extra income source. We will discuss all these actions and related events in the next chapter because they can be regarded as elements of coping strategies.

\subsubsection{Better off before 1991, worse off during the transition?}

It is plausible to assume that especially the people that were relatively better off undler the former system before 1991, would be found more often among the losers during the transition: they had simply more to lose compared to the others.

In general, this assumption is not supported by the survey results. The perception on whether changes in consumption possibilities are qualified as negative or positive, is hardly influenced by whether the main income earner had a job or a well-paid job prior to 1991 . This is also true for the possibility the members of the household had to earn extra money at their job. Table 4.12 summarizes the answers to question $\mathrm{A} 06$ and $\mathrm{A} 07$. The categonies are actually reduced to three main groups (well-paid job, the job gave the opportunity to earn additional income, and the job gave nonmonctary opportunities, such as influence) plus two reference groups (without a job in 1991 , with a job but without additional opportunities).

Especially those in the group that derived other than monetary opportunities from their job in 1991 count themselves as winners. On the other hand, those who had a well-paid job or related possibilities to earn some additional money indicate that they consume less nowadays. The items showing the positive relations in particular are: 
Table 4.11. Freguency and effect of certain events (since 1991)

\begin{tabular}{|c|c|c|}
\hline Event & $\begin{array}{c}\text { Frequency of } \\
\text { oncurrence (one or } \\
\text { several times) }\end{array}$ & $\begin{array}{c}\text { Positure effect ( } 4 \text { ) } \\
\text { Negative effect ( }) \\
\text { Neutral (o) }\end{array}$ \\
\hline Marnage of a household member & 13.6 & + \\
\hline Divorice & 11.8 & $\infty$ \\
\hline Death of parent/spouse/child & 28.8 & 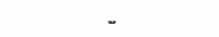 \\
\hline Wotherfiather joined the household & 2.4 & $+y-$ \\
\hline Child moved out to live separately & 21.8 & - \\
\hline Household member had health problem & 38.6 & - \\
\hline Household member had job/wage problem & 46.8 & - \\
\hline Household member got new job worse pail & 16.7 & - \\
\hline Household member got new job, better paid & 14.6 & + \\
\hline Stanted private business & 5.9 & $\frac{5}{8}$ \\
\hline Loss of saving|s & 30.9 & - \\
\hline Gat access to private land & 17.4 & * \\
\hline Assistance from relativesifriends abroad & 3.3 & + \\
\hline Household member started study & 24.6 & + \\
\hline Household member graduated & 46.9 & + \\
\hline Last support of relatives outside household & 7.9 & - \\
\hline Take care of relatives outside household & 24.4 & 0 \\
\hline Sold home-made/grown products & 7.1 & 0 \\
\hline Badi harvest & 10.2 & - \\
\hline Were able to pay back debts & 15.8 & + \\
\hline Could save some money & 5.9 & + \\
\hline Could sell certificates. & 50.5 & - \\
\hline Could use certificates to buy property & 22.8 & + \\
\hline Business actiluthes were not succesisful & 2.2 & + \\
\hline
\end{tabular}

Source: Poverty Survey 1998.

Table 4.12 Job in 1991 and related opportunities

\begin{tabular}{|c|c|c|c|c|c|c|}
\hline & $\begin{array}{c}\text { Well-paid } \\
\text { job }\end{array}$ & $\begin{array}{l}\text { Opportunity } \\
\text { for money }\end{array}$ & $\begin{array}{c}\text { Other } \\
\text { opportunity }\end{array}$ & $\begin{array}{l}\text { Whithout job } \\
\text { in } 1991\end{array}$ & $\begin{array}{c}\text { Witth job no } \\
\text { specials }\end{array}$ & Tiotal \\
\hline Consume more & $3.03^{*}$ & $6.08^{*}$ & 9.95 & 8.32 & $9.68^{*}$ & 8.63 \\
\hline Consume same & $9.01^{\text {. }}$ & 11.38 & $\| 3.52$ & 11.06 & $7.59^{*}$ & 11.90 \\
\hline Consume little less & 14.71 & 16.76 & 14.54 & 113.78 & $12.76^{\circ}$ & 14.36 \\
\hline Consume much less & 72.13 & 64.94 & 59.32 & 61.78 & 66.71 & 61.70 \\
\hline Donit know & $1.13^{*}$ & $0.84^{*}$ & 2.76 & 5.06 & $3.26^{*}$ & 3.40 \\
\hline Tollal & $\begin{array}{l}100 \\
(5.44)\end{array}$ & $\begin{array}{l}100 \\
(8,05)\end{array}$ & $\begin{array}{l}100 \\
(44.31)\end{array}$ & $\begin{array}{l}100 \\
(37.54)\end{array}$ & $\begin{array}{l}100 \\
(4.68)\end{array}$ & $\begin{array}{l}100 \\
(100)\end{array}$ \\
\hline
\end{tabular}

Isampte size $n<20$

Source: Powerty Survey 1998.

Table 4.13. Changes in perceived consumption possibilities vs. job characteristics prior to 1991

Job gave influence outside workplace

\begin{tabular}{lrrrr} 
& applied & did not apply & dlon't know & Total \\
\cline { 2 - 5 } consumen more & 11.86 & 7.76 & 12.61 & 8.83 \\
consume same & 16.72 & 11.43 & 11.65 & 12.41 \\
consume little less & 13.53 & 15.30 & 1.30 & 14.71 \\
consume much less & 55.05 & 63.58 & 57.90 & 61.65 \\
dont. know & 2.85 & 1.94 & 6.54 & 2.41 \\
Total & 100.00 & 100.00 & 100.00 & 100.00 \\
\hline
\end{tabular}

Sounce: Poverty Survey 1998. 
- holding job that gave influence ourside the workplace;

- holding a job that gave the possibility to get "difficult" things;

- holding a job with possibility for promotion;

- holding a position where people listened to one's advice;

- holding a position that allowed travel abroad;

- holding a position where one knew people who were able to assist one.

The impact is confintued by taking a look at the figures for the specific item presented in Table 4. 13. It shows that the percentages for the people that answered positively to the question whether they had a job or function that provided influence outside the workplace prior to 1991, are found relatively more often among the households that saw their consumption possibilities improve or remaining the same. People who answered that they were not in such a job or position are overrepresented in the households that saw their consumption possibilities decrease. The overall conclusion is ambiguous regarding the relationship between a good position in 1991 and a relatively good position in 1998.

\subsubsection{What does it mean to have gained or lost?}

In this paragraph we want to study the relation between the perceptions of changes in consumption possibilities and the material living conditions of households as investigated with question A0s. Most of the results points in the direction that could be expected: the more people think they gained between 1991 and 1998, the better their material living conditions. What is surprising, however, is the fact that this positive relation is also found for households that saw their consumption possibilities remain constant or even decline a little bit. This sheds some light on the way households described changes in their relative positions between 1991 and 1998. It indicates that people tend to be more pessimistic when asked the question about improvements in general, than when asked whether things improved or at least did not get worse with respect to a specific iten (food, clothing, equipment, etc.). However, it is important to know that the vast majority of the people think that in general life in Latvia has become more difficult: gains in terms of consumption possibilities are the privilege of the upper-income minority. For most people, consumption possibilities have declined in general and on specific items in particular. This is well illustrated in table 4.15. Table 4.14 on the contrary illustrates the phenomenon that for specific items gains are found among all groups, but relatively less among those households that judge their position as being considerably worse in 1998 than in 1991.

Table 4.14 illustrates this phenomenon quite well. The table shows a cross-tabulation of the perceived changes in the consumption possibilities and the households' opinion on whether they think they dispose of better household equipment nowadays than in 1991. The only category of households that say relatively more often that their equipment has not improved is the category of households that consider their consumption possibilities to have declined a lot. Alll other groups, including the one that says that their consumption possibilities declined somewhat, say that nowadays the equipment is better. "The same pattern is observed when questions are asked concerning:

- the quantity of food;

- the quality of food;

- the amounts of clothes available to adults;

- the amounts of clothes available to children;

- the availability of luxury goods;

- the number of days of holiday. 
Fable 4. 4. Perceived changes in consumption possibibities vs judgement an better equipment

\begin{tabular}{|c|c|c|c|c|}
\hline \multirow[b]{2}{*}{ Position } & \multicolumn{4}{|c|}{ Nowadays better equipment } \\
\hline & applies & does not & don't know & Total \\
\hline consume more & 29.75 & 3.29 & 16.68 & 8.63 \\
\hline consume same & 24.58 & 8.67 & 33.09 & 11.90 \\
\hline consume inttle less & 19.09 & 13.40 & 10.86 & 14.36 \\
\hline consume much less & 24.08 & 72.01 & 29.81 & 61.70 \\
\hline don't know & 5.50 & 2.63 & 9.56 & 3.40 \\
\hline Total & 100.00 & 100.00 & 100.00 & 100.00 \\
\hline
\end{tabular}

Source: Poverty Survey 1998.

Table 4.15. Judgments and opinions on comparison of the housethold consumption situation in 1998 and 1991 by incorne quintiles (percentage of households that answer "yes, applies" for every statement)

\begin{tabular}{|c|c|c|c|c|c|c|}
\hline \multirow[b]{2}{*}{ Statements } & \multirow[b]{2}{*}{ Total } & \multicolumn{5}{|c|}{ Quintlles } \\
\hline & & 1 & 2 & 3 & 4 & 5 \\
\hline We are consuming the same quantity of focd & 39.85 & 27.3 & 35.1 & 40.1 & 41.7 & 51.5 \\
\hline $\begin{array}{l}\text { Now the quality of our food is worse than in } \\
1994\end{array}$ & 55.52 & 73.7 & 62.7 & 59.4 & 51.9 & 35,6 \\
\hline $\begin{array}{l}\text { Now adults of the households have less } \\
\text { clothing }\end{array}$ & 60.70 & 73.9 & 66.9 & 65.1 & 58.7 & 43.3 \\
\hline Children have less clothing now & 22,08 & 41.5 & 24.8 & 22.1 & 15.8 & 10.9 \\
\hline $\begin{array}{l}\text { We have better household appliances } \\
\text { (kitchen, TV, etc.) }\end{array}$ & 18.43 & 8.1 & 12.7 & 15.0 & 18.8 & 33.8 \\
\hline We have a better car now & 12.74 & 7.6 & 8.9 & 9.0 & 11.7 & 24.1 \\
\hline We buy fewer durable goods than in 1991 & 83.18 & 90.6 & 88.2 & 88.8 & 83.8 & 68.0 \\
\hline We have the possibility to take more holidays & 13.19 & 14.0 & 12.4 & 15.0 & 10.5 & 16.5 \\
\hline We are buying fewer books than in 1991 & 84.53 & 90.1 & 98.0 & 87.4 & 84.2 & 74.5 \\
\hline $\begin{array}{l}\text { We are going less often to theater, opera and } \\
\text { concerts now }\end{array}$ & 04.52 & 88.1 & 67.8 & 87.8 & 87.4 & 73.6 \\
\hline \multicolumn{7}{|l|}{ Opinions } \\
\hline $\begin{array}{l}\text { Our children have more possibilities } \\
\text { mowadays }\end{array}$ & 22.55 & 20.3 & 21.3 & 18.8 & 22.5 & 28.7 \\
\hline $\begin{array}{l}\text { We have to think about money all the tirne } \\
\text { now }\end{array}$ & 90.63 & 95.9 & 93.6 & 92.6 & 90.2 & 82.6 \\
\hline Before 1991 we never thought about money & 38.89 & 43.3 & 42.0 & 40.6 & 36.5 & 33.6 \\
\hline Wo have to work harder now & 63.72 & 62.1 & 58.8 & 61.1 & 62.3 & 72.8 \\
\hline We are working fewer hours each week. & 6.05 & 11.2 & 7.6 & 4.7 & 4.8 & 3.2 \\
\hline
\end{tabular}

Source: Poverty Survey 1998. 
There are a couple of items where a majority thinks they are worse off nowadays compared to 1991. These items relate to cultural goods such as buying books and attending theater-and operaperformances.

The changes in consumption possibilities are also associated with opinions on the future. When asked to qualify whether nowadlays children have more possibilities compared to the situation before 1991 , only the category of households seeing their consumption as having declined seriously, answer relatively more often that they do not think that children have more possibilities today. It seems like pessimism has been entrenched in these households. The latter group also thinks more often that one has to think about money all the time nowadays. On the other hand, it is very important to note that more than $90 \%$ of the households agree with the statement that one has to think about money all the time nowadays. This is in sharp contrast with the answers we got when we asked whether money was a problem prior to 1991 . Only $40 \%$ of the respondents thought money was a major problem before 1991.

This indicates that the world has become harder and riskier between 1991 and 1998. This can also be observed when asked whether nowadays one has to work harder and more hours. In both cases the majority of the respondents agreed with the statements: $64 \%$ of the respondents thought they had to work harder, while $83 \%$ expressed the opinion that they have to work more hours.

When we calculate the cross-tabulation between these judgements and opinions and the position of households in the income distribution as given by quintiles, it can be seen that the higher the income, the better they think they are off on nearly all items. The higher the income, the better the quality of life in terms of food, clothing and equipment. The most striking observation when interpreting Table 4.15, however, is that even among the highest income group, a lot of people think they are worse off nowadays than in 1991. About half of the highest income quintile consume more food, but only $35 \%$ saw the quality of their food consumption not getting worse between 1991 and 1998. Still a lot of people believe that adults have less clothing and a minority judges itself as being better off when it comes to equipment. The consumption of cultural goods (books, theater, concerts, opera) is judged to be a lot worse in 1998 than in 1991 by everybody irrespective of their income position.

Table 4.16 presents the same opinions and judgements as Table 4.15 but broken down by location and age-group. Looking at the former, we see that rural households judge their food consumption more positively than urban households. Most other indicators are evaluated similarly. A noteworthy exception is the opinion about the children's opportunities which are more optimistically estimated by rural households. The breakdown into three age-groups provides some interesting results. Generally, the younger generation seems to be more optimistic than the older ones. Especially the seniors have a rather negative view on current life. The indicators for which the 'youth' answered strikingly differently are related to the quality of food, adult's clothing, household appliances, a new car and durable goods. They are all judged more optimistically. A larger share of the younger generation views the possibilities for children nowadays as better.

The statements as presented in question A05 are used to create a scale expressing the perception of the people of the present in relation to the situation in 1991. (see also Aasland, 1999). Following a reliability analysis, twelve items have been selected on which to base the creation of the indicator. ${ }^{13}$ Positive and negative statements were aligned in order to express the same negative direction. Counting the scores provided an index expressing the perception of the household. ${ }^{14}$ The higher the score (between zero and welve), the more negative a household's perception of the

\footnotetext{
"Alter the elimination of unconelated items, the model's alpha was equal to 0.79 .

"For each answer "does apply" to a negative statement, and "does not apply" to a positive statement, a household received one point. Answers with 'don" know' were neglected.
} 
current situation related to the past. The national weighted average score is 8.41 , i.e. more than eight out of twelve items have been evaluated negativaly on average. Large towns have a clearly higher score (9.3) compared to Riga (8.4) or nural areas (8.07). It confirms the conclusions drawn in section 4.4 .2 , where $70 \%$ of the households of larger towns stated that they can consume less nowadays than in 1991. Rural households see the present slightly more positively than urban households. The score is negatively correlated with the educational level of the breadwimer: the higher the education, the lower the score, i.e. the more positive the view on the changes. With respect to the main source of income of the breadwinner, the result is as we would expect: Having employment influences the perception to the positive, resulting in a lower score (7.9 for private, and 7.55 for public employment). Self-employment has the lowest score overall (5.12), indicating that more than half of the items have been evaluated positively. Pensioners on the other hand, have one of the highest scores $(9.19)$, followed by social transfer recipients (8.9). Male breadwinners evaluate the situation more positively than their female counterparts (7.9 versus 8.87 ). The larger the household, the younger the breadwinner and the wealthier the household, the lower the score, i.e. the more positive the perception. With respect to children, households with one to three kids evaluate the situation more positively than households with no or more than three children.

Tabie 4.16. Judgments and opmions by location and age group

\begin{tabular}{|c|c|c|c|c|c|c|}
\hline \multirow{2}{*}{ Stattements } & \multirow{2}{*}{ Total } & \multicolumn{2}{|c|}{ Location } & \multicolumn{3}{|c|}{ Age-groups } \\
\hline & & Urban & Rural & $<35$ & $35-64$ & $>64$ \\
\hline We are consuming the same quantity of food & 39.85 & 35.96 & 50.07 & 41.01 & 44.98 & 34.91 \\
\hline Now the quality of our food is worse than in 1991 & 55.52 & 59.95 & 43.90 & 42.10 & 55.25 & 66.07 \\
\hline Now adults of the househoids have less clothing & 60.70 & 62.64 & 55.63 & 47.82 & 63.25 & 65.38 \\
\hline Children have less clothing now & 22.08 & 21.40 & 23.89 & 20.79 & 26.03 & 15.30 \\
\hline $\begin{array}{l}\text { We have better household appliances (kitchen, } \\
\text { TW, etc.) }\end{array}$ & 18.43 & 19.07 & 16.73 & 33.43 & 18.54 & 7.06 \\
\hline We have a better car now & 12.74 & 11.63 & 15.64 & 24.30 & 13.82 & 2.05 \\
\hline We buy fewer durable goods than in 1991 & 83.18 & 81.76 & 86.91 & 69.10 & 84.61 & 90.98 \\
\hline We have the possibility to take more holidays & 13.19 & 13.35 & 12.77 & 12.74 & 12.41 & 14.96 \\
\hline We are buying fewer books than in 1991 & 84.53 & 84.21 & 85.36 & 76.99 & 85.35 & 88.62 \\
\hline $\begin{array}{l}\text { We are going less often to theater, opera and } \\
\text { conceris now }\end{array}$ & 84.52 & 84.60 & 84.34 & 77.24 & 85.60 & 87.92 \\
\hline \multicolumn{7}{|l|}{ Opinions } \\
\hline Our children have more possibilities nowadays & 22.55 & 20.85 & 27.01 & 30.18 & 25.13 & 14.79 \\
\hline Wo have to think about money all the time now & 90.63 & 89.87 & 92.63 & 85.66 & 91.18 & 93.35 \\
\hline Before 1991 we never thought about money & 38.89 & 39.13 & 38.24 & 37.74 & 37.74 & 38.05 \\
\hline We have to work harder now & 6.3 .72 & 62.51 & 66.91 & 84.68 & 71.74 & 32.60 \\
\hline We are working fewer hours each week & 15.05 & 5.14 & 8.46 & 4.79 & 6.39 & 6.36 \\
\hline
\end{tabular}

Soune: Poverty Sunvey 1998. 


\subsubsection{What makes a winner a winner and a loser a loser?}

The previous sections gave a rather good impression of who has won or lost according to their subjective perception. This section wants to model the factors determining whether a household considers itself to be a winner or a loser. Based on the answers to question A02 (the comparison of the current consumption possibilities with before 1991), a household is deemed a winner if the respondent answered that they consume more or the same as in 1991 . Households that answered that they consume a little less or much less are considered the losers of the transition. The variable winner/loser (binomial variable with loser $=1 /$ winner $=0$ ) is the dependent variable to be explained.

Explanatory variables entering the model are employment status, standard of living, educational level of the breadwinner, main source of income, age and gender of the breadwinner, various household composition variables, location, ethnicity, access to land and the dependency ratio (number of income sources/adult household members). Table 4.17 presents the results of the probit estimation of the model.

The signs of the coefficients are as expected from the previous analysis. A positive sign means that this specific wariable increases the probability of feeling that one has lost compared to one"s position in 1991, while a negative sign could be interpreted as an increased probability of the feeling of having won, all else being equal, and compared to the base model. Although the directions of the signs do confirm the contradictions with respect to the results from the poverty profile (e.g. pensioners, age of the breadwinner), the coefficients are not significant. Table 4.17 presents the marginal effects instead of the regression coefficients because their interpretation is more straightforward. The standard errors, the $z$-values and $p$-values are those of the underlying coefficients. It is obvious that not all variables are significant. Location of the household seems not to be decisive with respect to gaining or losing. Neither is the presence of children or the household size in general. Although the coefficients have the correct sign as expected, their influence does not differ significantly from zero. The educational variables as well as the income source variables have no single pattern. Higher education has a significant marginal effect of more than $10 \%$ on a household having gained, while primary education significantly increases the probability $(5.6 \%)$ that a household is among the losers compared to the reference case of secondary education. Other educational variables are not significantly different from the base case. The current wealth of the household represented by the expenditure quintile is significant $(p<0.1)$ and as expected. Those that are currently better off do have a more positive point of view on their position than those that are at the lower end of the welfare scale. Depending on income from agriculture increases the probability by more than $10 \%$ that a household considers itself to have lost over the last decade $(p<0.01)$, other things being equal, while self-employment has a 'winning' effect $(p<0.01)$. Older households, i.e. those that existed already before 1991, see their position significantly more negatively than households established during the last seven years. Interesting is the fact that the gender of the breadwinner is also a significant determinant of a household's perception. Maleheaded households have a more positive view of their possibilities than female-headed households. Ethnicity is decisive as well. The variables identifying Russian and other ethnic households influence a household's perception negatively. The chance that they consider themselves to be losers is $8 \%$ higher for Russians than for Latvians.

Table 4.18 surnmarizes the positive and negative marginal effects of all variables significant at the $10 \%$ level with respect to the base model. For simplicity, two groups have been created with an arbitrary setting of the boundary value. Large effects are those with marginall effects of more than $10 \%$, small effects are below $10 \%$. 
4. 77. Determinants of winning and losing (probit estimates)

\begin{tabular}{|c|c|c|c|c|c|}
\hline Variable & & $\begin{array}{c}\text { Marginal effect } \\
\therefore \text { dF/de }\end{array}$ & Standard error & $z$ & $P>2$ \\
\hline slatus 2 & (unemployed) & 0.1111172 & 0.042178 & 1.93 & 0.053 \\
\hline Stalus $3^{*}$ & (employed above working age) & -0.096211 & 0.0 .4884 & -2.7 & 0.03 \\
\hline statas $4^{\text {w }}$ & (other) & -0.0202612 & 0.046895 & -0.44 & 0.662 \\
\hline change $1^{\text {it }}$ & (increased household size) & -0.0144644 & 0.028903 & -0.51 & 0.6111 \\
\hline change: & (decreased household size) & 0.051073 & 0.017856 & 2.85 & 0.004 \\
\hline geinit1* & 11. Quintile) & 0.1474086 & 0.020418 & 5.87 & 0 \\
\hline quintz: & (2. Quintile) & 0.0667162 & 0.022781 & 2.7 & 0.007 \\
\hline quintf & (4. Qutintile) & -0.0503795 & 0.02726 & -4.93 & 0.05 .3 \\
\hline quints: & (5. Quintile) & -0.1648634 & 0.032026 & $-5,73$ & 0 \\
\hline schoott & (higher education) & -0.1238005 & 0.026891 & -5.07 & 0 \\
\hline schools* & (vocational school) & -0.031388 & 0.047331 & -0.69 & 0.489 \\
\hline school & (primary school) & 0.0566896 & 0.02226 & 2.36 & 0.018 \\
\hline schools & (less than primary) & 0.0207813 & 0.038227 & 0.53 & 0.599 \\
\hline lnage & (age breacwinner) & 0.0696719 & 0.037496 & 1.86 & 0.063 \\
\hline kids & $(1=$ household with kids) & -0.0377056 & 0.024426 & -1.56 & 0.12 \\
\hline mosize & (household size) & -0.0369217 & 0.023854 & -1.55 & 0.12 \\
\hline incoment & (agriculture) & 0.1168084 & 0.028588 & 3.11 & 0.002 \\
\hline income $3^{*}$ & (public employment) & -0.0162381 & 0.021947 & $=0.75$ & 0.454 \\
\hline income $4^{\text {ti }}$ & (selfomployment) & -0.2232213 & 0.06825 & -3.76 & 0 \\
\hline incomes & (pension) & 0.0480492 & 0.047185 & 0.98 & 0.326 \\
\hline income $6^{*}$ & (sociali transfer) & 0.043552 & 0.078322 & 0.51 & 0.61 \\
\hline income $7^{2}$ & (other) & 0.040338 & 0.052498 & 0.71 & 0.475 \\
\hline thest" & $(1=$ hh established before 91$)$ & 0.1342626 & 0.033938 & 4.39 & 0 \\
\hline utbruir & $(1=$ urban $)$ & 0.0212617 & 0.024126 & 0.89 & 0.372 \\
\hline gender" & $(1=$ male $)$ & $-0,0621031$ & 0.017183 & -3.56 & 0 \\
\hline $\operatorname{reg} 2$ & (Kurzeme) & $0.024: 464$ & 0.024142 & 0.97 & 0.331 \\
\hline $\operatorname{teg} 3$ & (Vidzeme) & 0.03811126 & 0.027504 & 1.31 & 0.19 \\
\hline reg4 & (Zemgale) & 0.0093681 & 0.026378 & 0.35 & 0.725 \\
\hline $\operatorname{reg} 5$ & (Latgale) & 0.0300964 & 0.024315 & 1.19 & 0.232 \\
\hline $\operatorname{pob} 1^{*}$ & (wellpaid job in 91 ) & 0.0326654 & 0,036599 & 0.84 & 0.398 \\
\hline ipob $2^{2}$ & (money opportunities) & 0.0258296 & 0.029578 & 0.84 & 0.401 \\
\hline lobs & (other opportunilies) & 0.0224425 & 0.019793 & 1.13 & 0.250 \\
\hline$j 005^{\circ}$ & (just job) & 0.0242942 & 0.036485 & 0.64 & 0.522 \\
\hline athnic2* & (Russian) & 0.0865241 & 0,01752 & 4.67 & 0 \\
\hline ethunicic $3^{*}$ & (other) & 0.0442148 & 0.024192 & $1.7 \%$ & 0.007 \\
\hline ownaghnd" & $(1=$ access to own land $)$ & -0.0131454 & 0.02117 & -0.62 & 0.535 \\
\hline suminet & (dependency ratio) & 0.064207 & 0.023443 & 2.73 & 0.006 \\
\hline
\end{tabular}

Log likelthood $=-1280.42$

Wald Chi2(37) $=465.01$

Prob $>$ chi2 $=0.0000$

Pseudo R2 $\quad=0.2043$

Number of households: 2943 (weighted)

Dependent variable:

Loser $=1 /$ Minner $=0$

Reference base:

employed, mo change in household size, 3 . quintile, secondary aducation, no kids, income from private employment, household established after 1991, rural, female, Rigas region, no job in 1991, ethnic Latvian, no access to land.

(") dF/dx is for discrete change of dummy variable from 0 lo 1

$z$ and $P>|z|$ are the test of the underlying coefficient being 0

Sounce: Ploverty Survey 1998. 
Table 4.18. Summary of marginal effects compared lo base model, all else equal

\begin{tabular}{|c|c|c|}
\hline & Large $>10 \%$ & Small $<40 \%$ \\
\hline $\begin{array}{l}\text { Foet that they } \\
\text { have lost }\end{array}$ & $\begin{array}{l}\text { Being unemployed } \\
\text { 1. Quintile } \\
\text { Man income from agriculture } \\
\text { Household established betore } 1991\end{array}$ & $\begin{array}{l}\text { Decreased household size } \\
\text { 2. Quinitle } \\
\text { Primary educiation } \\
\text { Age } \\
\text { Ethinicity other than Latyain } \\
\text { Dependency ratio }\end{array}$ \\
\hline $\begin{array}{l}\text { Foel that they } \\
\text { have won }\end{array}$ & $\begin{array}{l}\text { 5. Quirtile } \\
\text { Higher education } \\
\text { Main income from self employment }\end{array}$ & $\begin{array}{l}\text { Being employed and above working age } \\
\text { 4. Quintile } \\
\text { Male breadwinner }\end{array}$ \\
\hline
\end{tabular}

Base model: wmployed, no change in househoid size, 3. quintile, secondary education, no kids, income from private employment, household established after 1991, rural, female, Rigas region, no job in 1991, ethnic Latvian, no access to land.

Source: Powerty Survey 1998.

\subsection{Conclusion}

The overall conclusion on the dynamics of gaining and losing during Latvia's transition should be that more than $75 \%$ or the overwhelming majority of the population feels that they are among the losers. Whether this feeling corresponds to actual developments is difficult to judge from this study. There are some indications that reality indeed became harsh. There is the real decline in incomes, also reflected by the drop in real GDP per capita untill 1995, and chapter three provided evidence of decreasing real living standards for a majority of the population between 1996 and 1997, resulting in increasing poverty in terms of the number of poor, poverty depth and poverfy severity. It is also supported by findings from the Baltica Survey conducted in 1994 (Trapenciere, et al., 1998), where unemployment, poverty and crime evolved as the major problems as percevved by the Latvian population, be it at the country, community or family level. Asked about the prevalence of problems in the 1980s, the top problems at that time were considered to be alcoholism, smoking and enwironmental pollution. Poverly and unemployment were not on the top of people"s minds.

Although the big majority feels that they have lost, the foregoing analysis also allows us to draw some differentiating conclusions. Not all groups perceive their situation as equally pessimistic. The current perception of the past and its changes depends on where one stood before the transition. In general, those that had a lot to lose feel that they have lost relatively more often than those that did not have so much to lose. For example, pensioners judge the outcomes of the transition relatively pessimistically, although they are currently doing better than many other groups as the poverty profile has shown. Maybe they felt more secure under the old system in terms of income, maybe they retired in the meantime and had to switch from employment income to a pension benefit, or both. The argument is supported by the equally pessimistic feelings of the group that had a well-paid job in 1991. Such factors clearly inlluence the results of a survey such as the one used for this analysis, because the given answers are closely rellated to a person's perception of reality. On the other hand, those that had an influential position (outside the job) before 1991 evaluate their current position relatively more optimistically. Also more positively oriented are the younger generations and families with children. Although they have been identified as highly vulnerable groups both in the poverty profile for Latvia and in the respective literature on other CEE and FSU countries, their perception is relatively more often a positive one. Maybe they are focused more on the future expecting their situation to turn to the better. It could be an expression of their hopes, of their feelings that the currently low living standards are only of a transitory nature.

To summarize the results in short and in the most extreme version, we can say that those that 
feel that they have lost most, i.e. the losers, are either currently unemployed, farmers, or belong to the poorest $20 \%$ of the population. Those that feel most positive, i.e. the winners, are either selfemployed, have higher education, or belong to the richest $20 \%$ of the Latvian population. But the fact that a large group in the population feels to have lost is a political reality. It should cause concern to learn that most Latvians feel that they have lost, that they are worse off than ten years ago. A main conclusion from the survey is that life became more difficult and insecure, and that the future is uncertain. People not only became poorer, but also more pessimistic. It sheds light on the issue of poverty eradication policies. In a country where nearly everybody feels that he or she is losing, social policy targeted towards the very poor will meet political resistence. Poverty is a relative issue and it seems that the income distribution in the first eight or nine deciles is very compact. ${ }^{15}$ This compressed income distribution is reflected by how people judge their position and that of other groups. Moreover, small policy-induced changes in the relative position of households in the first deciles may change their relative position considerably including making other households worse off. It also raises the question how much more of the burden the population is willing to accept and what the political consequences will be.

While the macro-economic situation in the country has turned to the better since 1996, the developments at the household level are not yet moving in parallel. Despite the freedom of opinion, the full shelves in the stores offering a wide variety of products, the many new restaurants and small businesses that are taking off, people feel that they have lost. It seems as if the new liberties and achiewements are not appreciated as much now as right after the breakdown of the old system. Maybe they are taken for granted after ten years. The feeling of losing could also be connected to a human tendency to forget the bad memories and remember the positive events only. Evaluating the former regime in terms of Maslow's hierarchy of needs, we are inclined to say that the basic needs were satisfied. The state almost guaranteed those. Safety, a second level need, was also not an issue since the life cycle was more or less "planned" as well. People were then longing for freedom and self-determination. The transition fulfilled these latter needs, but at the same time the fulfillment of the physiological needs is no longer guaranteed at the same level. Currently, many Latvian households have to struggle with pure daily subsistence and the satisfaction of their basic needs. The achievements of the transition, freedom, democracy and self-determination are temporarily out of sight because the more basic needs have to be fulfilled first. Unfortunately, the survey did not ask about the perception and the valuation of the gained freedom and selfdetermination. But it definitely seems that the euphoria of the first years of the transition has faded. From the political perspective it means that providing security for the satisfaction of basic needs should be a priority. Therefore, the design, implementation and finally the effect of povertyreduction policies has to be considered carefully in the light of the findings presented in this chapter.

\footnotetext{
ISEe also chapter six on the effectiveness of the Lavian social policy.
} 


\section{Appendix 4A}

\section{Comparing expenditure aggregates of recall versus diary survey and merging the two data sets}

\section{A.4. Introduction}

The poverty survey offered the opportumity to compare two survey methods, both designed to measure househou expenditurem. The regular Howsehold Budget Survey (HBS) provides data since 1996. It uses the diary method to gather information on the expenditure pattem of Lavian households. The method has undergone some small changes during the period, such as reducing the diary period for food items from one month to two weeks (effective since April 1998 ). The recall survey was originally designed by the World Bark and was meant to check the results of the Household Budget Survey. For the purpose of the poverty assessment, the recall survey has been revived in order to increase the sample of the regular lyousehold survey and to get infomation about household expenditure levels.

\section{A4.2 The samples and some results}

The quantitatiwe poverty survey was implemented between August and October 1998 . The relevant survey instrumemt wred as well als the sample size are indicated in Table $A 1$.

Table A1: Sample

\begin{tabular}{|c|c|c|c|c|}
\hline & August 1998 & September 1998 & Octobier 1998 & Total \\
\hline Diary Survey & 627 & 624 & & 1251 \\
\hline Recall Survey & & 904 & 906 & 1810 \\
\hline
\end{tabular}

Total number of households interviewed: 3061

Diary: Diary for food and non-food items purchased and received free of charge or from own production.

Recall Survey: Recall survey for food and non-food items. Recall periods wary from two weeks for food items up to 12 months for certain durable goods.

Table A2. Recall sample: monthly total household expenditure per capita petotal

\begin{tabular}{|c|c|c|c|c|}
\hline $\begin{array}{l}1 \% \\
5 \%\end{array}$ & $\begin{array}{c}\text { Percontilles } \\
18.13583 \\
25.44167\end{array}$ & $\begin{array}{l}\text { 5nal Lest } \\
9.118486 \\
10.71523\end{array}$ & & \\
\hline $10 \%$ & 30.79 & 10.71616 & Obs: & 1809 \\
\hline $25 \%$ & 40.2648 & 12.98253 & Shitull of Wgt. & 1809 \\
\hline $50 \%$ & 56.46 & & Mear & 70,54999 \\
\hline $75 \%$ & 78.81586 & $\begin{array}{l}\text { Largest } \\
878.0767\end{array}$ & Std. Dew. & 89.63953 \\
\hline $90 \%$ & 114.169 & 1069.344 & Vare iance & $9035: 245$ \\
\hline 95 & 149.5506 & 2061.049 & Sikewness & 17.09896 \\
\hline $90 \%$ & 265.5024 & 2388.748 & Kurtasis & 395.0573 \\
\hline
\end{tabular}

Table A3. HBS sample: monthily total household expenditure per capita

\begin{tabular}{|c|c|c|c|c|}
\hline & Percerntilues & Snat I llest & & \\
\hline $1+y_{0}$ & 12.11377 & 7.703992 & & \\
\hline $5 \%$ & 21.95646 & 8.9751111 & & \\
\hline $10 \%$ & 27.73366 & 10.18386 & abs & 1249 \\
\hline 251 箬 & 38.54249 & 10.42213 & Sun of wgt. & 1249 \\
\hline $50 \%$ & 55.72772 & & Heam & 66.31185 \\
\hline $75 \%$ & 80.02673 & $\begin{array}{l}\text { Largest } \\
320.6256\end{array}$ & std. Dleve. & 44.37717 \\
\hline $90 \%$ & 114.8457 & 321.853 & Variance & 9969.333 \\
\hline 95 & 141.4686 & 394.21107 & skewrens: & 2.675674 \\
\hline $99 \%$ & 239.3708 & 444.3574 & Kurtosis & 14.94149 \\
\hline
\end{tabular}


As Table $A 2$ and $A 3$ indicate, the medians of botin samples are wery close. The means vary considerably due to some extreme values stemming from the recall survey. The four outliers were of such a magnitude that it has bean decided to whithaw these household from further analysis. The statistical monents inproved and the two samples became clloser. A comparison of the mean indicates that they are not significantly different $(p>\mid t)=0.613)$.

Table A.4. Recall sample after iremoval of four outliers

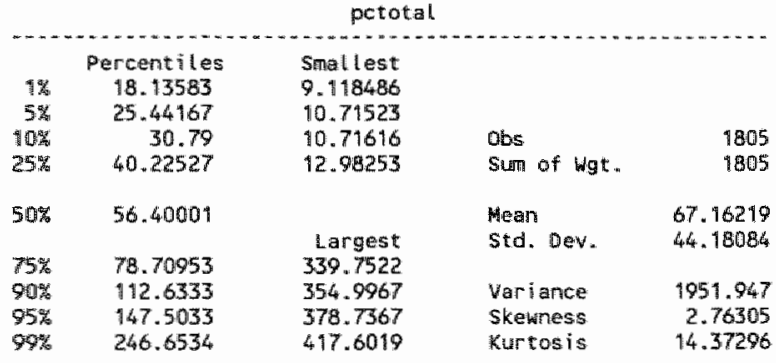

Table A5. Recall wersus HBS - weighted mean, median and standard deviation

\begin{tabular}{|c|c|c|c|}
\hline & mean(pctotal) & med(pctotal) & sd(pototal) \\
\hline $\begin{array}{l}\text { HBS } \\
\text { Recall }\end{array}$ & $\begin{array}{r}63.6014 \\
64.82188\end{array}$ & $\begin{array}{r}53.66188 \\
53.489\end{array}$ & $\begin{array}{r}42.71965 \\
43.35 .21\end{array}$ \\
\hline rotal. & 64.32265 & 53.54347 & 43.09869 \\
\hline
\end{tabular}

Overall, the results look very promising in the light of a future nerger of the two samples. But this conchusion changes as soon as a more detalled breakdown is presented. Disaggregating by deciles, table A6 shows that the results of the HBS versus recall diverge.

Table A6. Recall versus HBS: decille values

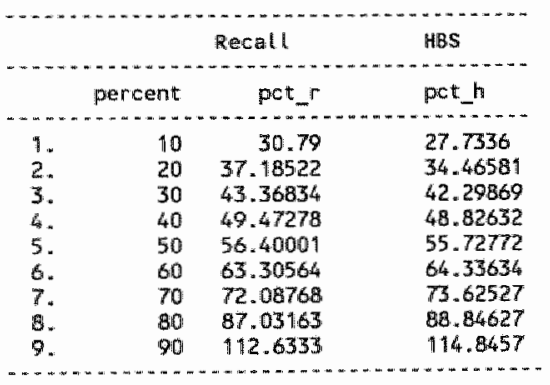

Up to the fifth decille, the values of the recall sample are larger than those of the HBS. From the sixth to the ninth decile, the HBS exceeds the recall. Comparison of the cumulative distribution functions of the two distributions confirms the funding that the recall results are biased towards the mean.

Differences between recall and HBS are also found when comparing average household expendiures per câpita of product categories. Expenditures are divided into the following groups: food, alcohol, tobacco, rent, utilities, aducation, clothing, health, transport, communication, leisute, accommodation and miscellaneous. Table A7 stummarizes the results. 
Table A7. Average household expenditures per capita per category

\begin{tabular}{lcc} 
Crategory & $\begin{array}{c}\text { average household expenditures } \\
\text { per capita - Recall }\end{array}$ & $\begin{array}{c}\text { average housenold expenditures } \\
\text { per capita - HBs }\end{array}$ \\
\hline Food & 33.55 & 26.63 \\
Alcohol & 3.54 & 0.85 \\
Tobacco & 2.79 & 0.81 \\
Reint & 3.15 & 3.23 \\
Utilties & 10.62 & 13.53 \\
Education & 2.61 & 6.24 \\
Clothing & 6.43 & 7.04 \\
Fumiture & 3.30 & 2.00 \\
Heallh & 3.17 & 4.46 \\
Transpont & 15.19 & 6.43 \\
Communication & 2.51 & 3.85 \\
Leisure & 2.95 & 3.21 \\
Accommodation & 4.21 & 4.96 \\
Miscellaneous & 5.19 & 2.45 \\
\hline
\end{tabular}

In order to interpret the data, it is useful to know the recall period per group. Food, alcohol and tobacco are recalled over tha previous two weeks. Rent and utilities as well as some transport items (fuel and transport services) have a 30 day recall period. Thee months is the period for all other groups except education. Education has a recall period of 12 months. In the HES, all expenditures (except food) are noted during one month. Recall data have been adjusted to the one month period.

According to Deaton (1997), we would expect an "amnesia" bias in the recall values. The longer the recall period, the larger the downward bias. Interpreting table A7, it seems as if households overestimate their food consumption when they are asked to recall consurnption over the last two weeks. Transport also scores considerably higher in recall than under the HBS. The downward bias (if it is a bias) is wisible with groups where the opposite hypothesis could be stated as well. The probabilify that a household purchases new clothing is expected to be larger in a period of three months (recall) than within a single month.

\section{A4.3 Merging the two data sets}

For the purpose of the analysis as in chapter four and chapter five, it was necessary to merge the two data sets. Because we wanted to analyze the dynamics and the coping, strategies from a welfare point of view, too, comparative information on a household's standard of liwing in the total sample was needed. Rather than using a complicated adjustment process based on the estimation of warious models, we decided to keep it sinmple and adjust the recall sample to the diary sample with a linear model. The model can be formally described as follows:

$$
y=a+b x
$$

where $y$ stands for the per capita expenditures of the HBS diary sample and $x$ for those of the recall sample. The parameters $a$ and $b$ are unknown and have to be calculated. The first and the third quartile values of each distribution are used as the benchmark for the adjustment. This provides two equations:

$$
\begin{aligned}
& y(.75)=a+b x(.75) \\
& y(.25)=a+b x(.25)
\end{aligned}
$$

Solving the equations provides the formulas for the unknown parameters:

$$
\begin{aligned}
& a=y(.75)-\frac{x(.75)[y(.75)-y(.25)]}{x(.75)-x(.25)} \\
& b=\frac{y(.75)-y(.25)}{x(.75)-x(.25)}
\end{aligned}
$$

Inserting the quartile values of the respective distribution provides the values needed for the linear adjustment of the 
per capita expenditures of the recall survey. The adjustment could be vice versa as well, but we prefer the adjustunent of the recall sample assuming that the HBS sample provided the more reliable expenditure data.

The decile values of the various distributions are summarized in Table A8. The adjusted recall distribution is now closer to the HBS sample. The final step is to merge the wo tata sets creating a unique ranking for all the households of the poverty survey sample.

Table AB. Adiusted recall wersus HBS: expenditure declle values

\begin{tabular}{|c|c|c|c|c|}
\hline & & mes & $\begin{array}{l}\text { Adjusted } \\
\text { Recall }\end{array}$ & $\begin{array}{l}\text { Original } \\
\text { Recall }\end{array}$ \\
\hline & ent & p hbs & P. new & prec \\
\hline 1. & 110 & 27.97153 & 28.04021 & 30.60021 \\
\hline 2. & 20 & 34.73803 & 34.6264 & 36.90705 \\
\hline 3. & 30 & 42.29593 & 41.62923 & 43.46702 \\
\hline 4. & 40 & 48.5792 & 47.65632 & 49.01382 \\
\hline 5. & 50 & 55.92273 & 55.51501 & 56.13056 \\
\hline 3. & 60 & 63.69247 & 63.3995 & 63.15796 \\
\hline 7". & 70 & 72.57621 & 73.5493 & 72.06306 \\
\hline $\mathrm{B}_{\mathrm{i}}$ & 80 & 88.23931 & 89.20088 & 85.53384 \\
\hline 9. & 90 & 113.4562 & 121.0924 & 112.2144 \\
\hline
\end{tabular}

Controlling for the means of the various decile groups, no conclusive statement is possible. Although the hypothesis that the overall mean of the adjusted recall sample is equal to the HBS sample has to be rejected now at the 10\% significance level, the group means are in some cases statistically equal and in other cases not equal. Comparing the HBS sample means with the adjusted recall, the means are in three cases significantly different at the $1 \%$ level, twice each at the $5 \%$ and $10 \%$ level. In three cases the decile means are not different. The reason to prefer the adjusted recall values lies in the fact that the lower deciles especially are the ones with statistically equal means. 


\section{Appendix 4B}

\section{Sample profile}

Table B4.1 prowides a profile of the households in the powerty survey sample. The main income contributor of thite housethold is used as an identifier to divide the houscholds into various groups. The breadwinner (main income contributor) is defined as the person who contributed most to the household income during the three months prior to the survey. The presented avurages, frequencies and proportions are not weighted as opposed to most of the analysis in the chapters. Therefore, discrepancies between the numbers presented here and results presented in other parts of the subsequent sections can occur. The weighted data are representative for the whole of Larvia, and the waighted indicators are close to the yearly averages as presented in the publications of the CSB on the various rounds of the HBS $(\mathrm{CSB}, 1997 \mathrm{~b} ; 1.998 ; 1999)$ and as calculated in chapter three.

Table B4.1. Sample profile $(n=3058)$

\begin{tabular}{lr} 
Undicator & Sample average \\
Average household size & 2.71 \\
Average number of children per household & 0.50 \\
Awerage number of dependants per household & 0.70 \\
Average number of pensioners per hausehold & 0.71 \\
Average number of social transfar recipients per household & 0.14 \\
Average age of the main income contributor (years) & 50.46 \\
\hline
\end{tabular}

By household:

Unban-rural location

- urbary

- rural

Regional location

- Rigas region

- Kurzeme

- Vidzeme

- Zomgalo

- Latgale

size of settement

- Riga

- Large citios

- Small citles

- Rural

Housaholo size

- one nnember

- two ringmbers

- threa members

- four and moro members

Number of children

- no children 
Tabse B4. 1 cont.

Household composition

- Single aduit

- II adull 81 child

- I adull \& 2 children

-2 adults

-2 adults $\& 2$ children

-3 adults

- 3 adults \& 1 child

- Other

Housefrolds

- whith chilidren

- without ohildren

Households

- with elderily

- wuitinoult elderly

Housieholds

- with social transfer reciplents

- wo social transfer reciplents

Housaholds

- with pension recipients.

-.without pension recipients

\section{By breadwinner:}

Age

$-15-34$

$-15-64$

- 65 and older

Nationality

- Latvian

- Russian

- Other

Genver

- Malle

- Famale

Civit status

- Newer married

- Married

- Married, lliving separately

- Divoread

- Widower

Educational attamment

- Higher

- Secondary

- Vocetionall 
118 | Chapter 4

Table 04.1 coint.

Wain sowce of income

- Employment (private sector)

- Employment (public sector)

14.59

- Selt-employment

1.15

- Agricullure

9.44

- Pension

- Social trangfer

- Other

Relation to household head

- Hear

- Spouse

- Child

- Parent

- Other rellative

- Other member

Employment status

- Employed

- Employed above working age

- Unemployed

- Other

Sounc: Powerty Survey 1998. 


\section{COPING WITH LITTLE MEANS}

\subsection{Introduction}

From chapter three we know that the overall standard of living of Latvian households is rather low. If decreased drastically after 1991 and it decreased further according to our results from 1996 to 1997. Besides this monetary evaluation of household welfare, chapter four provided some background on the individual perception of households with respect to their current siluation and by comparison to their way of living before the transition. The resulting picture was all but rosy. The older generation especially has a pessimistic view of their current life, while the youth seems to appreciate the changes in the society more and is adapting to the new situation more easily. Despite the relatively low incomes and the rather widespread powerty according to our Western standards, Latvians are surviving. It can only imply that people apply various strategies in order to make ends meet. We could say that in this respect, they had no need to adapt their behowior. Already under the former regime those households which were able to apply several coping strategies, and which had a functioning social network were the ones that were fittest for survival. Coping strategies must have become even more important in the light of the worsening living conditions.

Therefore, with respect to the generally low standard of living and the relatively high poverty risk for a large group of Latvian households, the picture would not be comprehensive without looking at the way households currently deal with their monetary situation. How do the poor cope with the little means they have? Do they apply specific strategies in order to make ends meet? Are such strategies a characteristic of the poor only and do they make a difference? These are the questions we address in the current chapter. Experience in other countries in simillar circumstances indicate that coping strategies are widely applied throughout the population and that they can make a difference in the daily struggle to survive. The sane data source as in the previous chapter provides the necessary information to analyze coping strategies in Larvia. A review of previous studies on coping strategies and how these are grouped into different categories opens the discussion. Since no classification system found in previous studies is convincing, we define our own groups. Subsequently, the relevance of various coping strategies is analyzed based on the data from the poverty survey. Next to simple counts, more sophisticated models are estimated in order to find out whether the application of coping strategies has a result on the household's welfare level and what the determinants of the various coping strategies are. In a sub-section we will also discuss in more detail the informal redistribution among households and what factors determine whether a household is a donor and/or recipient of assistance. The last section is devoted to food consumption habits in the sense that we want to get some more specific information on the amount of food obtained from own production or received free of charge. This information is drawn from an analysis of the HBS diary data, the same as we used for the poverty profile in Chapter Three. A concluding section summarizes the main results. 


\subsection{Coping and survival strategies}

The description and analysis of household coping strategies in times of economic crisis gaimed momentum in the aftermath of the debt crisis in the 1980 s and the implementation of structural adjustment programs, mainly in Latin America. Comia (1987), for example, describes three main groups of potential survival strategies a houschold can employ in order to make ends meet: i) strategies aimed at the generation of resources, ii) improving the efficiency of existing resources, and iii) extended family and migration strategies. Lately, the analysis of coping strategies has become relevant in the countries of CEE and the FSU where households were confronted with rapidly changing circumstances due to the transformation of the economic system. Not surprisingly, the literature on coping and survival strategies applied in these countries is continuously growing. The coping strategies are very similar to the ones described in the studies on Latin America (see, e.g., Cornia et al., 1987; Benería and Feldman, 1992). ${ }^{1}$

\subsubsection{Coping in the East}

Strategies to cope with shortages and relative poverty existed under the command economies as well (Kuddo, 1998). It was a way of supporting and supplementing a household"s well-being. Queuing was one of the strategies that households used to employ in Soviet times. The use of social networks to gain access to goods as well as home production were widely applied in former times as well (see, e.g., Seeth, et al, 1998). Networks that already existed before the transition were revived and used in order to obtain assistance in the daily struggle to make ends meet. Home production became even more important after the transition. Vecernik confirms the usefulness of the old strategies when he writes that "[a] paradoxically functional legacy of communism was the cultivation by individuals and houscholds of manifold adaptive capacities, skills and strategies for survival (Vecernik, 1996:172). Under the new situation, all resources have to be mobilized in order to improve the material situation, and household structures and individual capabilities to manage resources in the new context have become more important determinants of actual livelihood conditions' (Seeth et al, 1998:1614).

Multiple job holding, informal activities, petty trade or selling goods from own production are strategies encountered in all transition economies no matter the stage of transformation. Russian households are known to employ these strategies, as do Amenian or Ukrainian households (Kuddo, 1998; Seeth el al., 1998; Tchernina, 1998; Rose, 1995, 1996; Dudwick, 1995, The World Bank, 1996). Vecernik (1998) described the use of "inconemgenerating" strategies in the Czech Republic, and Kuddo (1998) in Estonia (among others). Subsistence agriculture, another common coping strategy, is considered by the World Bank (1996c) as the "... single most important informal sector activity lor coping with economic adversity ...' (p. 25). Examples of other coping strategies are to cut back on expenditures, change the diet, look for the cheapest food to buy, sell family assets, accumule debts, borrow money, exchange foreign currency, evade taxes, apply for social assistance benefits, etc. According to Tchernina (1998:17), market-oriented methods account for $51 \%$ of all coping strategies in Siberia, followed by household activities (47\%).

Based on the reviewed studies, it is cllear that coping strategies do not differ significantly among the various countries considered. Access to a plot of land is very common and important all over the FSU (Kuddo, 1998). It generates a stock of food that helps to smooth the effects of shocks. It is more or less independent of a household's social and economic position. Tchernina concludes that

\footnotetext{
Note that we do not rewiew studies on coping strategies applied in Nestern economies, since the circumstances of the poor in the West diverge too much from the situatior in the transition economies. Nevertheless, the classification system offered below will be applicable for the Western siuation as well.
} 
the own production of goods is very important in the situation of an unstable society. Even families with relatively high incomes engage in the yearly production of a stock of vegetables and berries which acts as a shock absorber against the whims of a market economy (1998:19). That the propensity to engage in active coping strategies is not purely explainable by socio-demographic characteristics is confirmed by Vecernik (1998:184) as well. He provides two main reasons why households engage in coping strategies: financial bardship and widened economic possibilities. Depending on the reason, the strategy is of a different nature: active or passive (re-active).

\subsubsection{A classification}

Classifications of coping strategies are abound. We already noticed that Tchernina differentiates. between market and non-market activities, while Vecernik makes a first division into active and passive strategies. For a future analysis it is desirable to a have a more refined classification which encompasses all observed strategies and combines them into distinctive groups. The relevant literature provides several proposals, but no division is completely satisfying. We first present three types of classifications commonly used; we then discuss their shortcomings before presenting the classification used in this study. Vecernik (1996) identified five types of coping behavior based on his research in the Czech Republic:

V.a. Offensive or market activities: earning more money through labor mobility, extra job, selling more home-made products;

V.b. Defensive or home production activities: doing more things at home, repairing old things;

V.c. Economizing activities: shopping around for goods at lower prices, reducing costs;

V.d. Crisis or rescue activities: pawning items, selling goods, requesting public assistance;

V.e. Borrowing money.

Richard Rose's research is based on data from the New Democracies Barometer surveys that were regularly held in several countries in CEE and the FSU. In a paper on the Ukraine (Rose, 1995), Rose divides the coping strategies into three main groups: the official economy which is legal and monetized, the social economy with extra-legal and non-monetized activities, and the underground or uncivil economy, which is monetized but illegal. In total nine different coping strategies ('economies' in Rose's terminology) are identified:

I. Official: R.a. Having a regular job;

R.b. Receiving pension, welfare benefits;

II. Social: R.c. Household production;

R.d. Exchanging help with family, friends;

R.e. Receiving/giving favors;

R.f. Queuing more than a hour per day;

III. Uncivil: R.g. Job in second/shadow economy;

R.h. Receiving/paying bribes;

R.i. Using foreign currency in own country.

Depending on the combination of the economies applied, a household strategy is either defensive (official and social economies), enterprising (official and uncivil), vulnerable (official only) or marginal (social only). The most common strategy in a destabilized official economy is defensive, according to Rose (1995:54f). 
In a paper on Amenia, Dudwick quotes a classification developed by Howell (Dudwick, 1995:13). According to this division, there are four major groups of coping strategies:

Da. Reductive: reduce consumption, substitute with cheaper altematives;

D.b. Depletive: use up household resources, savings, selling assets;

D.c. Mainaining: short-term survival, e.g., migration, agriculture, husbandry;

D.d. Regenerative: increase the household resource base, expand sources of regular income.

Each of the presented classifications is in itself incomplete and is not workable for our intended analysis. Together they contain the most prevalent strategies, but each author misses at least one category. For examplle, Rose's categories are not useful in the Latvian case. He misses trade and commerce of, e.g., own produced goods and services - an activity which is not necessarily illegal in our opinion. Neither does he account for the possibility to borrow money, or the accumulation of debts. In addition, his classification is rather complicated using three different concepts and divisions. Vecernik"s division is very appealing since the categories are clear and not too numerous. But even if we allow 'borrowing money' ( $V$.e.) to include the making of debt, he misses one important category. The power of the social network in smoothing a difficult period should not be underestimated as has been confirmed by several authors above. The possibility to receive assistance in the form of money, food or services from family or friends is considered to be an important strategy during hard times, and should definitely be included as a separate category. The division used by Dudwick has the same shortcoming. It also misses a category for making debts and borrowing money and the social network is also not explicitly included as a specific group.

Based on the proposals found, we establish another classification of coping strategies which is thought to be more comprehensive. It will serve as an identifier for the analysis of coping strategies in Latvia in subsequent sections. The categorization can be considered to be an extension of Vecernik's proposal. It identifies the following five groups:

a. Income-generating activities: having a second job, selling goods and services, (petty) trade;

b. Household production for own consumption: food, services, clothes, etc.;

c. Economizing activities: buying cheaper food, save on heating, do not buy new clothes etc;

d. Assistance from outside the household: food, money, work, services, etc. from family or friends (social network) not living in the same household;

e. Crists activities: accunulating debts, applying for social assistance, borrowing money for basic consumption, selling/pawning household assets.

Although the categories speak for themselves, some comments may be necessary with respect to the fifth category. Social assistance is considered to crisis activity because people tend to apply onlly in case of need. Social assistance benefits are considered a means of last support by the govenument and are frequently means-tested. The amount available, c.q. the size of the benefit, is usually so small that it is only helpful in a crisis situation. Borrowing money in order to cover basic needs, is also considered a crisis activity and is part of this category as well, although it will not be considered in the subsequent analysis due to lack of information. ${ }^{2}$ The subsequent sections will apply the five categories to the analysis of Latvian coping strategies.

\footnotetext{
"Note that we do not consider credits received in order to buy durable goods. Borrowing money is a crisis activity if the money is needed to cover basics only, such as food. In all other cases, such as inwestment or borrowing to buy durables, borrowing money is a regular conomic activity. But if the installments cannot be paid anymore, we can talk again or coping strategy. Including this possibility in our classification allows to apply it to Western societies as well.
} 


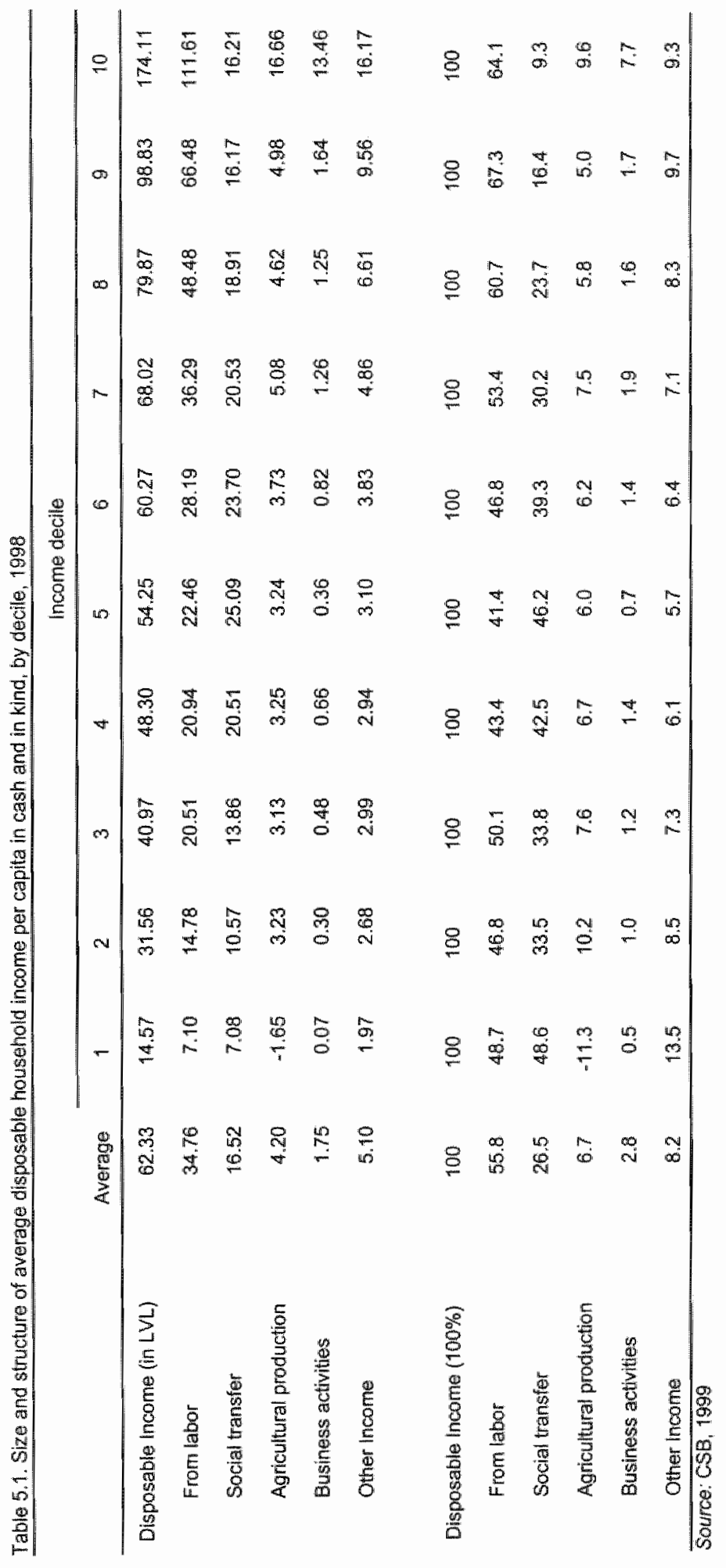




\subsection{Coping with poverty and low incomes in Latvia}

Based on data collected in 1994, Aasland (1996) observed two main coping strategies applied by Latvian houscholds. They had an extra job or worked long hours in order to make ends meet. This practice was especially common in large households. Additional income was also generated by carrying out personial services for payment, or by selling vegetables, flowers and fruits on the local market. In the participatory poverty assessment carried out in 1998 (Institute of Philosophy and Sociology, 1998), the authors identified coping and survival strategies applied in Latvian households through interviews with poor households. According to this study, urban households tend to be involved in self-employment strategies such as petty commerce, work in the service sector, make use of formal training, arts and crafts, do construction work, migrate for work or sell recyclables. In rural areas, subsistence agriculture, cash farming, gathering of berries and mushrooms, forestry and work in agriculture are mentioned as the most prevalent survival strategies. In a real crisis situation, households will sell or pawn assets, exchange goods and services, economize and cut back on expenditures, juggle with debts, exchange housing for assistance and even prostitute themselves if necessary. The same study also highlighted the various ways that Latvian households deal with increasing housing costs. Although rent is not necessarily the foremost problem compared to utility bills, poor households run debts on both if necessary. Other ways to deal with housing costs are to substitute cheaper fuel, do without heat, gas or electricity, pay only half the bill with the hope of not getting cut off or evicted, move to cheaper housing, install meters or tap illegally from the gas- or electricity network. According to the assessment, families with children tend to prioritize food and school-related expenditures while taking the risk to run large debts for housing. Pensioners, on the other hand, do not want to create debt. They rather save on heating (they do not heat the whole apartment) or cut back on food.

Before we start analyzing the coping strategies in Latvia, we first have a look at the size and importance of various income sources for poor and rich households. The figures presented in Table 5.1 are calculated by the Central Statistical Bureau of Latvia based on the HBS. The table presents the awerage disposable household income per capita for each income decile. However, we have to keep in mind that the real GDP per capita in 1998 was only $60 \%$ of the value in 1989 (EBRD, 1999).

Again, the rather tight income distribution up to the ninth decile is confirmed. The poorest $10 \%$ of households have Jess than LVL 15 per capita per month of disposable income ${ }^{3}$ Looking at the composition of disposable income (the lower half of table 5.1), the table shows that income from labor provides a relatively larger share to the total in the upper deciles. For the poorest $20 \%$, income from labor contributes less than $50 \%$ to total disposable income. Social transfers are equally important for the households of the poorest decile (48.6\%). However, in absolute figures the average social income transfer to the poorest is also the lowest of all deciles. The generally low incone level in Latvia leads us to expect that coping strategies are important for most Latvian households. The subsequent analysis confirms this hypothesis and shows that the use of coping strategies is not a characteristic of poor households only.

\subsubsection{How prevalent are coping strategies in Latvia?}

The poverty questionnaire started from the observations as summarized above. The questions have been formulated in order to quantify and thereby measure the significance of the mentioned strategies. The remaining part of this section presents the results of the survey with respect to

\footnotetext{
"We lhave to be aware of the fact that the CSB includes the values of goods from own production as thousehold reverute.

SSee chapter four for a description of the survey, und Amnex $B$ for the questionnaire
} 
coping strategies and analyzes some of the outcomes in more detail. The questionnaire contained eleven questions encompassing different coping strategies. The collected data allow us to quantify and analyze the observations from the participatory assessment. The categories identified in section 5.2 .2 provide the framework for the presentation of the results. In this section, we will present the main results from the survey questions. More sophisticated analysis is part of subsequent sections where the determinants of various coping strategies and their importance are considered.

\section{a) Incone-generating activities}

Households can choose to supplement their incomes by activities that provide some additional monetary means. The questionnaire (see question B04 of the questionnaire in Annex B) distinguished between thirteen different activities, such as selling vegetables, cattle, cars, or books, working for a master ${ }^{5}$ or in the forest, working in a shop, selling services, working as a taxi driver, etc. For the analysis, three main activities have been created:

- Selling goods: farm and non-farm items (B04/1.4. \& 9.);

- Additional work for money (B04/5.-8. \& 11.);

- Other activities (B04/12 \& 13).

Respondents were asked to indicate whether their household was engaged in any of these activities and the approximate amount of income earned per week. Table 5.2 shows that only a minority of households is involved in any of these activities. Almost $85 \%$ of the households is not engaged in any activity. $12 \%$ is applying one activity, i.e. the household is either selling goods, working additionally, or doing something else. Only about $2.5 \%$ of households is involved in two of three possible activities. Of the poorest quintile, $78 \%$ of the households are still not engaged in any of these activities, while 16\% say that they employ at least one, and $6 \%$ two activities. At first sight, these figures seem rather low. We expected that more households would engage in incomegenerating activities. On the other hand, the figures may not be that low after all. Imagine the following: $8 \%$ of all household indicate that they sell goods in order to generate some additional income (see Table 5.2). If $8 \%$ of the households of Riga would do that, then more than 24,000 people would sell some goods either on the market or on the streets, assuming that only one person per household would be engaged in this activity. Even for Riga, this is a considerable number of (street-) vendors. Therefore, we can conclude that the number of households involved in any incomegenerating activity is not so small after all.

The more activities that are used, the higher the average income per household per week. An average of nearly LVL 17 per week can be eamed additionally by employing one activity. The most lucrative activity is trade. According to Table 5.2 the average income earned per week is highest for households engaged in selling goods. Taking into account the average hours worked for the income, trade provides the best hourly average. Although additional work provides an only slightly lower income on average, it takes almost ten hours more work per week.

Who is involved in such activities? Is it really the least wealihy that engage in selling goods or additional work? Table 5.3 presents the percentage of households engaged in each of the three activities by quintile. Note that a household can take part in more than one activity. Households of the poorest quintile are indeed eaming additional income relatively more often through trade

\footnotetext{
"Many of the people who became unemployed when collective fams were dissollwed and who do not have access to the ir own land work for local famers. The farmers pay them a small salary, give them aneal and sometimes goods winind (Institute for Philosophy and Sociology, 1998:30\%,
}

The rumbers refer to the questionnaire. B04 is the question, $1-4,9$ arm the numbers of the sub-items of the question. 
Table 5.2. Number of income-generating activilies, average income and hours worked

\begin{tabular}{|c|c|c|}
\hline W of different actiwltes mployed & $\begin{array}{c}\% \text { of housenolds engaging in zero. } \\
\text { one or more actwithes }\end{array}$ & $\begin{array}{l}\text { Average income per } \\
\text { household in LVL }\end{array}$ \\
\hline No actuity & 84.82 & $x_{n-\infty}^{\infty}=-$ \\
\hline Orie inicome-generating activity & 12.57 & 16.92 \\
\hline Two incorne-generating activities & 2.46 & 23.92 \\
\hline Three income-generating activities & 0.15 & 44.23 \\
\hline income generating activity & $\begin{array}{l}\text { average income per household } \\
\text { engaged in the activity, in LVL }\end{array}$ & $\begin{array}{l}\text { average number of hours of } \\
\text { engagement per housthold }\end{array}$ \\
\hline selling goods (farm and non-farm! $1-4,9^{\text {\# }}$ & 16.7 .4 & 15.69 \\
\hline additional work for money $5-8,11$ & 14.80 & 25.3 .4 \\
\hline other 12,13 & 13.10 & 9.54 \\
\hline
\end{tabular}

(1) Numbers refer to the different liems in question $\mathrm{B} 04$ of the poverty questionnaire (see Annex B) Source: Powerty Survey 1998.

Table 5.3. Percentage of households engaged in various income-generating activities, per quintile

\begin{tabular}{|c|c|c|c|c|c|c|}
\hline \multirow[b]{2}{*}{ Activily } & \multicolumn{5}{|c|}{ Quintites } & \multirow[b]{2}{*}{ total } \\
\hline & 1 & 2 & 3 & 4 & 5 & \\
\hline selling goads (farm and non-farm) $1-4,9^{1}$ & 13.36 & 8.53 & 742 & 7.42 & 5.7 & 8.31 \\
\hline additional work for money $5-8,11$ & 11.34 & 6.46 & 6.18 & 5.33 & 5.99 & 6.93 \\
\hline other 12,13 & 2.53 & 1.92 & 2.45 & 1,37 & 2.83 & 2.22 \\
\hline
\end{tabular}

(1) Numbers refer to the different items in question $\mathrm{BO} 4$ of the poverty questionnaire (see Annex B)

Saurce. Poverty Survey 1998.

Table 5.4. Number of different products from own production

\begin{tabular}{|c|c|c|c|c|c|c|}
\hline \multirow[b]{2}{*}{ \# of different products produced } & \multicolumn{5}{|c|}{ Quintlies: } & \multirow[b]{2}{*}{ Total } \\
\hline & \# & 2 & 3 & 4 & 5 & \\
\hline \multirow[t]{2}{*}{ No ovirim production } & 10.24 & 17.97 & 22.13 & 22,79 & 26.87 & 100 \\
\hline & 17.12 & 26.36 & 32.12 & 31.06 & 33.90 & 28.61 \\
\hline \multirow[t]{2}{*}{ One product } & 16.56 & 21.51 & 18.97 & 21.02 & 21.94 & 100 \\
\hline & 20.01 & 22.83 & 19.92 & 20.73 & 20.03 & 207 \\
\hline \multirow[t]{2}{*}{ Two productis: } & 17.85 & 20.36 & 16.69 & 20.77 & 24.33 & 100 \\
\hline & 19.63 & 19.66 & 15.94 & 18.63 & 20.21 & 18.83 \\
\hline \multirow[t]{2}{*}{ Three products } & 19.59 & 17.52 & 20.51 & 20.65 & 21.72 & 100 \\
\hline & 17.56 & 1379 & 15.97 & 15.10 & 14.70 & 45.35 \\
\hline \multirow[t]{2}{*}{ Fouf products } & 25.20 & 21.67 & 19.43 & 18.67 & 15.03 & 100 \\
\hline & 14.53 & 10.97 & 9.73 & 8.78 & 6.54 & 9.87 \\
\hline \multirow[t]{2}{*}{ Fuve or more products } & 28.73 & 18.74 & 18.75 & 18.02 & 15.77 & 100 \\
\hline & 11.15 & 6.318 & 6.32 & 5.70 & 4.62 & 6.64 \\
\hline
\end{tabular}


Table 5.5. Percentage of households engaged in production for own consumption

\begin{tabular}{|c|c|c|c|c|c|c|}
\hline \multirow[b]{2}{*}{ Pronuct } & \multicolumn{5}{|c|}{ Quintiles } & \multirow[b]{2}{*}{ Total } \\
\hline & 1 & 2 & 3 & 4 & 5 & \\
\hline grow vegetables & 22.16 & 21.59 & 21.42 & 22.19 & 21.69 & 21.81 \\
\hline raise animals & 8.82 & 8.48 & 8.89 & 6.61 & 5.72 & 7.88 \\
\hline chop word & 6.54 & 4.73 & 4.40 & 3.53 & 4.33 & 4.71 \\
\hline gather plants & 27.68 & 26.54 & 24.53 & 25.57 & 25.45 & 25.98 \\
\hline Tisihinunt & 7.55 & 6.22 & 6.38 & 6.26 & 7.02 & 6.70 \\
\hline Sewithrill & 19.32 & 19.66 & 18.64 & 20.26 & 17.87 & 19.15 \\
\hline
\end{tabular}

Sotrce: Poverty Survey 1998.

(selling goods) or work, while the richest quintile is least likely to be involved in such activities. $13 \%$ of the poorest households sell some kind of good or service and $11 \%$ do additional work in order to earn some money. Rural households are relatively more often involved in incomegenerating activities as compared to urban households. $13 \%$ of rural households (urban: $6 \%$ ) are involved in trade and 11\% (urban: $5 \%$ ) have some supplemental income from work. This is in contrast to the findings from the qualitative assessment (Institute of Philosophy \& Sociology, 1998).

\section{b) Household production}

The production of goods or services for the household's own consumption is much more popular than activities that generate income. More than $70 \%$ of Latvian households are engaged in one or more activities that produce goods or services to be consumed by the household itself. We find these househoids all across the income distribution although there is a clear negative relationship between the number of different activities and the wealth of the household: the poorer the household, the larger the number of goods produced by the household. But even in the fitth quintile (the wealthiest $20 \%$ of the population), only one third of the households is not engaged in one or more activities for own consumption (see Table 5.4).

Table 5.5 shows that the share of households involved in the home production of certain goods is of almost equal size across the income distribution. For example, about one fifth of each quintile grows wegetables for own consumption. This also explains why having access to a plot of land is not a decisive factor for poverty in chapter three since 'everybody' is using land independently of the rank in the income distribution. Having access to land is an important asset for a significant share of households all across the income distribution. Having produce form own land helps to make ends meet and is a more than welcome addition to the diet of the people. On the other hand, raising animals, gathering plants (berries, mushrooms, etc.) and chopping wood are relatively more prevalent among households of the first quintile. Overall, growing vegetables, gathering plants and sewing or knitting for household members are rather popular activities: one fourth to one fifth of households say that such activities are of some importance to their household (see question B05)."

There are differences between urban and rural households in the kind of activities employed. Growing vegetables, raising animals and chopping wood are more frequently part of a rural household's strategy, while gathering plants and sewing or knitting is relatively more often observed in urban households. Nevertheless, $19 \%$ of urban households still indicate that they grow their own wegetables (rural: $25 \%$ ). These results confirm the observations of other countries: the extent of oxn production cannot be explained by economic factors only. The traditional aspect should not be underestimated either. For example, to stroll through the forest in autumn and pick mushrooms is part of the Latvian culture and a yearly returning family event.

\footnotetext{
${ }^{7}$ An independence test (Pearson $\chi^{*}$ ) confirmed that the observed differences between the groups are significant.
} 


\section{c) Economizing}

Economixing is another widely used strategy in Latvia. Only $9 \%$ of all households indicate that they are not using any of the possible economizing activities in the survey. Question B06 is used to create four different forms of "economizing". Three groups represent different proper economizing activities properly spoken, while the fourth is the accumulation of debt in a household. The latter is included in Table 5.6 as a reference group. Accumulating debt as a form of coping will be discussed as a crisis activity in detail below. The following groups have been created based on question $B 06:^{8}$

- Activities to reduce food expenditures (B06/1. \& 2.);

- Activities to reduce expenditures related to non-food items (B06/4.-7. \& 18);

- Activities to reduce housing expenditures, e.g, rent, gas, electricity, etc. (B06/3. \& 8.-11.).

Trable 5.6 presents the percentage of households engaged in the various economizing strategies per quintile. $47 \%$ of all households said to economize on food. The surprising result is that except for housing cost measures (and debt accumulation) relatively fewer households of the poorest quintile apply expenditure reducing activities compared to other households. Almost half of the households in the two richest deciles save on food expenditures by storing enough food for the winter or by looking for the cheapest products to buy compared to $43 \%$ of the poorest households. On the other hand, it is obvious from Table 5.6 that saving on housing expenditures, e.g. by heating only one room or by not or only partially paying the utility bills, is relatively more often done by the poorest households: $6 \%$ confirmed to have used this strategy during the last year.

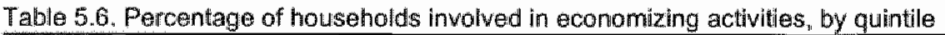

\begin{tabular}{|c|c|c|c|c|c|c|}
\hline \multirow[b]{2}{*}{ Economizing activilles } & \multicolumn{5}{|c|}{ Quintiles } & \multirow[b]{2}{*}{ Total } \\
\hline & 1 & 2 & 3 & 4 & 5 & \\
\hline Expenditure reduction food & 43.66 & 47.13 & 47.48 & 49.12 & 48,81 & 47.28 \\
\hline Expenditure reduction non-food & 36.59 & 38.49 & 39.86 & 38.24 & 39.18 & 38.49 \\
\hline Expenditure reduction energy & 6.37 & 4.73 & 4.35 & 5.20 & 3.46 & 4.81 \\
\hline Accumulating debts 13.38 & 9.43 & 8.15 & 7.14 & 7.95 & 9.17 & \\
\hline
\end{tabular}

"Note: accumulating debts is not considered to be an economizing activity

Source: Poverty Survey 1998.

Table 5.7. Number of Economizing activities employed by households - without delbt accumulation, \% of households, by quintile

\begin{tabular}{|c|c|c|c|c|c|c|}
\hline \multirow{2}{*}{$\begin{array}{l}\text { of different activilies employed per } \\
\text { thousehold: }\end{array}$} & \multicolumn{5}{|c|}{ Quintiles } & \multirow[b]{2}{*}{ Total } \\
\hline & 1 & 2 & 3 & 4 & 5 & \\
\hline No economizing activity & 4.98 & 6.64 & 8.13 & 10.56 & 15.29 & 9.43 \\
\hline One economizing activity & 45.73 & 48.98 & 44.40 & 44.97 & 43.16 & 45.36 \\
\hline Two oconomizing activities & 45.51 & 42.40 & 43.77 & 41.38 & 38.23 & 42.04 \\
\hline \multirow[t]{2}{*}{ Three economizing activitîes } & 3.79 & 1.98 & 3.71 & 3.09 & 3.33 & 3.17 \\
\hline & 100 & 100 & 100 & 100 & 100 & 100 \\
\hline
\end{tabular}

Source: Povery Survey 1998.

\footnotetext{
"Note; B06/12,-14. ate not included at all since they are out of the control of the household and cannot comsidered to be an economizing activity: power was cut off, gas supply was disconnected, water supply was disconnected
} 
Rural households apply food expenditure reducing strategies relatively more often while urban households tend to save on non-food expenditures relatively more frequently. Household size is another determinant with respect to the 'choice' of the economizing activity. Larger households tend to save on food expenditures while one- or two-person households have a proportionally higher propensity to economize on non-food items.

The above points towards a situation where richer households use economizing strategies more often than poorer households. Looking at single activities this does indeed seem to be the case. A slightly revised picture emerges when counting the number of different economizing activities a household applies. In Table 5.6 households could appear in more than one activity. Table 5.7 therefore shows the percentage of households per number of activities. Here we see, that only $5 \%$ of all households of the first quintille do not employ one or more economizing activities compared to $15 \%$ of the richest quintile.

The larger the household, the larger the share of households not applying any economizing strategy, but also the larger the share of households that uses one economizing strategy. Smaller households with one or two members are found to apply two or three of these strategies relatively more often than larger households.

\section{d) Assistance from the social network}

About 50\% of Latvian houseliolds say that they receive some kind of assistance on a more or less regular basis from family or friends not living in the same household. ${ }^{16}$ Food and cash are the most prevallent forms of assistance. $26 \%$ of all households indicate that they receive cash and $13 \%$ receive food. We would expect a relatively larger share of the poor households to be among the recipients. But as Table 5.8 shows, all but the richest quintile's shares are almost equal, while the wealthiest $20 \%$ receive relatively more often assistance. Only clothing and school or medical supplies are relatively more often received by poorer households. Of the various categories of goods given, urban households report a relatively larger proportion of money and food, while rural households 'outperform' urban households with work and firewood or durables.

Four-fifths of the assistance is provided by family and only one-fifth comes from friends or other acquaintances. Table 5.9 presents the share of assistance received from family or friends by category. Especially cash gifts seem to be given to family members. Only $8 \%$ of cash gifts come from persons not related by family ties. The highest share of assistance coming from persons outside the family is related to work (30\%). The poorest $20 \%$ receive assistance from outside the family ties relatively more often. $27 \%$ of their assistance comes from friends, or other acquaintances, but their is no specific pattern observable with increasing income. In urban areas, assistance comes from family relatively more often, while in rural areas assistance from other persons is slightly more prevalent than in urban areas.

The information provided so far indicates that the probability that a household receives assistance is not dependent on the income level. This is confirmed by the fact that households of the richest quintile belong to the beneficiaries of assistance relatively more often than the average. The fifth quintile has the lowest share of households that have not received any assistance at ail. $(47 \%)$. It has the highest share of households that received one or two forms of assistance compared to other quintiles $(32 \%$ and $13 \%$ ). The question arises wether poor and rich households evaluate the received assistance as equally relevant. We would assume that poor households value the received

In this section we will concemtrate on the results of the question related to assistance received from family or fricnds: Ifing outside the household (B02) and the importance of this help (B03). Domor households will be the subject of analysis in a later section.

Nowe that we do not differentiate between the assistance that is receved very freguently or omly iregularly. 
assistance as having a greater impact on their daily survival. Table 5.10 summarizes the importance of the assistance for all households in general according to their answers to question B03.

The answers to question B03 have been reduced to three categories: "we could do without assistance" (1. \& 2.), "we would be much worse of? (3.), and, "it would be difficult without" (4. \& 5.). In general, the answers are spread rather evenly. Each valuation receives approximately one third to one fourth of the responses with the exception of work ( $52 \%$ could do without). Money, firewood or durables and school or medical supplies have the lowest shares of households answering that they could do without this kind of assistance. Concerning school supplies and medicine, this is most probably due to poorer households benefitting relatively more often from this kind of assistance. The fact that money is important already became evident in chapter four, where it was proven that $91 \%$ of all households indicate that they think about money all the time. For households of the first and second quintile cash is relatively even more important. Only $20 \%$ and $14 \%$ respectively, of these households respond that they could do without it. But cash remains important also for the richest households. This is not so much the case when considering food assistance: $55 \%$ of the richest quintile answer that they do not really need it, while only $25 \%$ of the first and $27 \%$ of the second quintile share this opinion. Of the poorest quintile, $35 \%$ would be in a. difficult situation without this aid.

Table 5.8. Assistance received from outside the household, \% of households

\begin{tabular}{|c|c|c|c|c|c|c|}
\hline \multirow[b]{2}{*}{ Assistance received } & \multicolumn{5}{|c|}{ Quintiles } & \multirow[b]{2}{*}{ Tolat } \\
\hline & 1 & 2 & 3 & 4 & 5 & \\
\hline money (cash, bills) & 12.92 & 13.38 & 12.56 & 12.73 & 14.62 & $13: 30$ \\
\hline food & 25.13 & 25.87 & 23.89 & 25.90 & 28.26 & 25.91 \\
\hline clothîng & 8.25 & 6.59 & 4.48 & 4.61 & 5.18 & 5.77 \\
\hline firewood, durables & 3.95 & 4.60 & 3.21 & 3.02 & 4.03 & 3.77 \\
\hline work & 9.49 & 10.25 & 9.99 & 9.70 & 8.69 & 9.55 \\
\hline school supp, med. & 4.67 & 4.46 & 3.46 & 2.66 & 3.60 & 3.75 \\
\hline
\end{tabular}

Source: Poverty Survey 1998.

Table 5.9 . Share of assistance received from family or friends by categary

\begin{tabular}{lccr}
\hline & from family & from friends & tolal \\
\hline money (cash, bills) & 92.11 & 7.89 & 100 \\
fond & 77.42 & 22.58 & 100 \\
clothing & 73.41 & 26.59 & 100 \\
fircwood, durables & 7.59 & 25.41 & 100 \\
wrork & 69.83 & 30.17 & 100 \\
school supp, med. & 81.86 & 18.14 & 100 \\
Tatal & 79.12 & 20.88 & 100 \\
\hline
\end{tabular}

Source: Poverty Survey 1998.

Table 5.10 . Importance of the assistance for the receiving household, \% of households

\begin{tabular}{|c|c|c|c|c|}
\hline & we could to without & $\begin{array}{c}\text { we would be worse off } \\
\text { without }\end{array}$ & $\begin{array}{c}\text { It would be difficult } \\
\text { without }\end{array}$ & \\
\hline monay (cash, bills) & 26.14 & 37.55 & 36.31 & 100 \\
\hline food & 39.43 & 35.20 & 25.36 & 100 \\
\hline clothing & 34.38 & 31.20 & 34.42 & 100 \\
\hline firewood, durables & 25.92 & 36.31 & 37.77 & 100 \\
\hline work & 52.40 & 26.48 & 21.12 & 100 \\
\hline School sulpp. med. & 26.28 & 33.28 & 40.44 & 100 \\
\hline Total & 37.82 & 33.68 & 28.50 & 100 \\
\hline
\end{tabular}

Sounce: Poverty Survey 1998. 
Informal redistribution occurs in all layers of the Latwian society, no matter the rank along the income distribution. The fact that the assistance is also of significant importance for a considerable part of the wealthiest households could be another indication of the tight income distribution with only relatively few very rich households.

\section{e) Crisis activities}

The poverty survey provides information on debt accumulation and social assistance. On average, $9 \%$ of all households indicate that they have accumulated debts with respect to rent and utility payments with the first quintile having a relatively higher propensity to create debt (13\%; see Table 5.6). Table 5.11 differentiates between three types of debts: rent, utilities and other (mainly durables). The probability that a household has a debt for rent or utilities is negatively correlated with its welfare position, while having other debts is rather characteristic of the richest households. On average, $17 \%$ of all households have a debt related to the payment of utility bills and $12 \%$ for rent. In the first quintile, these shares are $17 \%$ for rent and $23 \%$ for utility debts. The share of households with debt is higher in urban areas than in rural areas. Only $7 \%$ of rural households have outstanding rent (urban 13\%), and $7 \%$ have debts related to utility payments (urban 20\%).

The outstanding anounts are considerable as Table 5.12 shows. This table presents in the first row the share of households having accumulated debts for either rent or utilities. The second row provides the average amount owed. These figures are based on the estimates given by the respondents themselves (question B08). Again, we note that not only the poorest households accumulated debts for rent and wtility. The highest average amount owed per household is found among the richest quintile of households $(276 \mathrm{LVL})$, followed by the first and second quintile.

Table 5.14. Percentage of households having debt per category

\begin{tabular}{lrrrrrr}
\hline & \multicolumn{3}{c}{ Quintilles } \\
\cline { 2 - 7 } Debt & 1 & 2 & 3 & 4 & 5 & total \\
yent & 17.22 & 10.75 & 11.58 & 11.44 & 8.33 & 11.70 \\
Utilitives & 23.47 & 18.93 & 16.11 & 14.33 & 12.24 & 16.78 \\
other & 8.59 & 6.24 & 4.92 & 5.38 & 10.58 & 7.18 \\
\hline
\end{tabular}

Source: Powerty Survey 1998.

Table 5.12. Rent or utility debt

\begin{tabular}{|c|c|c|c|c|c|c|}
\hline & \multicolumn{5}{|c|}{ Quintiles } & \multirow[b]{2}{*}{ Total } \\
\hline & 1 & 2 & 3 & 4 & 5 & \\
\hline Hawing chebt for rent or utilities & 31.60 & 23.12 & 20.26 & 18.115 & 15.29 & $2 \| .20$ \\
\hline Amoun an average & 222.47 & 225.85 & 183.49 & 153.77 & 276.75 & \\
\hline
\end{tabular}

Source: Poverty Survey 1998 .

Applying for social assistance is considered another form of crisis behavior. Table 5.13 summarizes the answers to question CO5, providing only an indication of whether a household tumed to the local Social Assistance office for help. It does not say whether the assistance was granted or not. The whole issue of social assistance policy and the role of the safety net in Latvia is discussed in Chapter Six. What we can say so far, is that not even one fourth of the poorest households have visited the Social Assistance Office during the last twelve months. Even if they have, it does not automatically mean that they applied for social assistance benefits. The table does show, that there is a negative correlation between wealth of the household and the probability that the household visits the local office pointing to the fact that poorer households are more inclined to ask for help in case of need. 
Tabite 5.13. Percentage of housetholds visiting the Social Assistance Office

\begin{tabular}{lrrrrrr}
\hline & \multicolumn{5}{c}{ Quintiles } \\
\cline { 2 - 7 } Did you visit the SA office? & 1 & 2 & 3 & 4 & 5 & total \\
\hline No & 56.5 & 59.91 & 68.16 & 67.34 & 80.34 & 67.15 \\
Yes, during the last 12 months & 23.12 & 21.84 & 18.43 & 17.91 & 8.54 & 17.54 \\
Yes, more than a year ago & 20.39 & 18.25 & 13.41 & 14.75 & 11.12 & 15.31 \\
\hline
\end{tabular}

Source: Powerty Survey 1988.

\subsubsection{Coping strategles and standards of living}

The previous paragraphs have shown that certain coping strategies are widely used in Latvia. Therefore, it would be interesting to know whether the application of a coping strategy is relevant for a household"s standard of living. Does it make a difference to a household"s ability to make ends meet? In this section we will define a model in order to evaluate the significance of the various coping strategies for a household's living standard. Rose (1996) preformed a similar exercise when analyzing the importance of money for the welfare of Russian households. He included indicators for various coping strategies next to a range of other welfare determining variables." Rose"s models explained only between one and two percent of the variance, and many variables proved not to be significant.

We will estimate two main models using two different variables in order to express a household's well-being. First, the households" own assessment of their standard of living is used as the dependent variable on which the effects of various determinants is estimated. In the second model, the quintile distribution will serve as dependent variable. "It allows to assess the impact of the various coping strategies on subjective and objective household welfare. Consider the following models:

$$
\begin{aligned}
& s_{i}^{*}=\beta x_{i}+\epsilon \\
& Q_{i}^{*}=\gamma X_{i}+\epsilon
\end{aligned}
$$

where $S^{*}{ }_{i}$ represenis an index of the self-assessment of the household $i$, and $Q^{*}{ }_{i}$ the index of a household's monetary liwing standard. $X_{\mathrm{i}}$ is a vector of explanatory variables that are classic welfare determining factors such as houschold size, employment, education of the breadwimner, age, gender, the presence of children or elderly persons, nationality, income source and location. The more important variables within vector $\mathrm{X}$ in the current context are those that represent the various coping strategies households apply: income generating activities, own production, economizing activities, receiving assistance from other households, accumulating debt for rent or utilities, and visiting the social assistance office. $\beta$ and $\gamma$ are vectors of unknown parameters to be estimated, and $\epsilon$ represents the error terms. Since the dependent variables are of a ordered multinomial nature, the models are estimated by ordered probit maximum likelihood methods. The values that $\mathrm{S}$ can take range from one to five, with one representing a bad standard of living and five a wery good living standard according to the household's own assessment. Q takes on the quintile values, with one

\footnotetext{
"Rose calls them "modem influences" as opposed to "nonmmarket influenced" coping strategies (1996:80).

${ }^{12}$ The self-assessment question is part of the regular HBS questionnaire: "How would you evaluate the present living. conditions of your household? bad, rather bad, average, rather good, very good (see Annex A).
} 
Table 5.14. Does the use of coping strategles influence a household's standard of living?

\begin{tabular}{|c|c|c|c|c|c|c|}
\hline & \multicolumn{2}{|c|}{ Model la } & \multicolumn{2}{|c|}{ Model $1 \mathrm{~b}$} & \multicolumn{2}{|c|}{ Model 2} \\
\hline & Colst. & tratio & Coef & twratio & Coof. & tratio \\
\hline Incom generating; trade & $-0.199^{\prime *}$ & -2.75 & -0.194 & -2.77 & -0.003 & -0.04 \\
\hline work & $-0.170^{* *}$ & -1.97 & $-0.177^{* * *}$ & -2.11 & -0.107 & -1.15 \\
\hline other & -0.175 & -1.43 & -0.105 & -0.91 & 0.196 & 1.50 \\
\hline Dwn production & 0.064 & 1.07 & 0.049 & 0.82 & -0.041 & -0.76 \\
\hline Ecomomizing on food & $-0.357^{\text {tand }}$ & -3.27 & $-0.499^{* 4 * 4}$ & 4.58 & $0.620^{*-* *}$ & -5.58 \\
\hline on won-food & $-0.350^{\ldots * x}$ & -3.65 & $-0.458^{* k 1 k}$ & -4.73 & $-0.469^{* * *}$ & -5.16 \\
\hline on utillities & $-0.239^{\text {m**⿻丷木 }}$ & -4.35 & $-0.265^{* * 2}$ & -4.93 & $-0.138 *$ & -2.70 \\
\hline Assistance received: inoney & -0.053 & -0.73 & -0.069 & -0.96 & -0.058 & -0.85 \\
\hline food & $-0.110^{*}$ & -1.74 & -0.120 & -1.92 & -0.063 & -1.11 \\
\hline work & 0.115 & 1. & $0.159^{n+k}$ & 2.06 & $0.159^{* * *}$ & 2.25 \\
\hline bther & .0 .013 & -0.17 & -0.033 & -0.43 & -0.089 & -1.23 \\
\hline Assistance from family & $0.135^{* *}$ & 1.98 & $0.195^{\text {t*d }}$ & 2.93 & $0.224^{\text {mitum }}$ & 3.70 \\
\hline from others & 0.053 & 0.30 & -0.001 & .0 .04 & $0.3588^{* 4 *}$ & -2.25 \\
\hline Wisited Social Assistance Office & $-0.289^{*+1 ;}$ & -4.80 & $-0.325^{\cdots * * *}$ & -5.54 & $0.164^{1+6 x}$ & -3.01 \\
\hline Accumulated delois & $-0.489^{2 k \hbar}$ & -7.88 & $-0.538^{* \text { *tinti }}$ & -8.80 & $-0.271 *$ & -4.77 \\
\hline Quintile $\quad 1$ & $-0.548^{*+4 *}$ & -6.94 & & & & \\
\hline 2 & $-0.158^{*}$ & -2.19 & & & & \\
\hline 4 & $0.158^{\text {tita }}$ & 2.17 & & & & \\
\hline 5 & $0.610^{\text {mint }}$ & 7.82 & & & & \\
\hline Age of breadwinner in years & $0.051 \|^{*}$ & -5.28 & $-0.047^{* \times *}$ & -4.88 & 0.006 & 0.68 \\
\hline Age-squared & $0.000^{k \hbar t}$ & 4.97 & $0.000^{* * *}$ & 4.53 & 0.000 & -0.95 \\
\hline Household with children & -0.063 & -0.89 & $-0.159^{* 4}$ & -2.27 & $-0.357^{\text {\#* }}$ & -5.47 \\
\hline Household with elderly & 0.017 & 0.26 & -0.013 & -0.20 & -0.095 & -1.56 \\
\hline Log (household size) & $0.291 \cdots$ & 4.55 & 0.041 & 0.69 & $-0.850^{\text {*i. }}$ & -14.19 \\
\hline Rural locallion & $0.345^{*+* * *}$ & 5.96 & $0.256^{\text {t** }}$ & 4.53 & $-0.255^{m}$ & -4.67 \\
\hline Breadwwinner with high education & $0.240^{+\infty}$ & 3.49 & $0.313^{4+4}$ & 4.54 & $0.307^{7 *}$ & 4.61 \\
\hline wocationall training & 0.098 & 0.80 & -0.003 & -0.03 & $-0.341^{\text {tillite }}$ & -3.06 \\
\hline primary education & -0.066 & -0.96 & $-0.159^{* *}$ & -2.30 & $-0.323^{\text {w.2*** }}$ & -5.51 \\
\hline less than primary & -0.047 & -0.43 & $-0.174^{*}$ & -1.66 & $-0.439^{\text {tin }}$ & -4.65 \\
\hline Russian nationality & $-0.228^{*+4 x}$ & -4.30 & $-0.259^{*}$ & -4.89 & $-0.143^{\text {trith }}$ & -2.89 \\
\hline Otfere nationality & $-0.149^{*}$ & -1.92 & $-0.163^{*}$ & -2.13 & -0.094 & -1.30 \\
\hline Breadwinner is unemployed & $-0.738^{\text {***t* }}$ & -4.70 & $-0.843^{\text {it } 4: 4}$ & -5.43 & $.0 .508^{* * *}$ & -3.30 \\
\hline employed, above work agle & $0.319^{4 *}$ & 2.52 & $0.347^{* 4 \cdot k}$ & 2.87 & 0.144 & 1.27 \\
\hline other & -0.017 & -0.16 & -0.0046 & -0.43 & -0.104 & -1.02 \\
\hline Income from employment & $0.450 \%$ & 1.67 & $0.222^{* \text { 曲 }}$ & 2.47 & $0.312^{+2.8}$ & 3.62 \\
\hline Female: breadwinner & $-0.215^{* * 4}$ & -4.41 & $+0.258^{*}$ & -5.36 & $-0.201^{* * * *}$ & -4.42 \\
\hline & & St.error & & Sterror & & St.error \\
\hline - cedtut & -3.275 & 0.304 & -3.752 & 0.290 & -3.490 & 0.268 \\
\hline$-\cos 2$ & -1.911 & 0.302 & -2.449 & 0.287 & -2753 & 0.268 \\
\hline cull 3 & 0.227 & 0.303 & -0.421 & 0.287 & -2.157 & 0.267 \\
\hline callu & 1.690 & 0.325 & 0.979 & 0.306 & -1.452 & 0.265 \\
\hline No. of observaltions & 3018 & & 3018 & & 3018 & \\
\hline Pseudia R2 & 0.155 & & 0.121 & & 0.1102 & \\
\hline Log likelihood & -2879.747 & & -2995.544 & & $-4351,368$ & \\
\hline
\end{tabular}

Note: a. Model 1 a and 1b: dependent wanable is seff-assessment of living conditions (1-5); Model 2: dependent variable: is quintile based on expenditures per capita.

b. Omitted dummy wariables: quintile 3, uban location, secondary education, Latwian nationality, employed, male.

c. $* 0<0.01 ; 00.05$; $p<0.1$.

Source: Poverty Survey 1998. 
representing the poorest and five representing the richest quintile. The self-assessment is estimated twice: once with inclusion of the quintile as monetary indicator for the household welfare lewel (Model la), and once without (Model $1 \mathrm{~b}$ ).

Income-generating activities such as trade or work have a negative impact on a household"s self-assessment, while the same variables are insignificant if the quintile is used as dependent variable. We could say, that the need to engage in such activities creates a feeling of subjective deprivation. Economizing activities are highly significant in all three models. Their application has a sirong negative effect on a household's welfare level both subjectively and objectively. It indicates that poorer households are more inclined to employ economizing coping strategies in order make ends meet. The same effect is attributed to visits to the social assistance office and to the accumulation of debt. Both variables are significant at the $1 \%$ level and the coefficients have a negative sign as expected in all three model variants. The fact that a household is receivung assistance is not that clear-cut. The variables are hardly significant, leading to the conclusion that assistance is not related to the relative position of a household. It confirms the findings above that assistance is spread evenly across the income distribution. The source of the assistance received makes a difference according to the estimates. Receiving assistance from family members living outside the household has a positive influence on the household's well-being. The variable for own household production is not significant at all. Apparently, the fact that a household engages in own production is no determinant of the welfare rank of the household. This confirms the earlier finding that own production is hardly related to welfare ranking.

Of the classic welfare determinants, gender, unemployment, Russian nationality, high education and having income from employment are all significant for both subjective and objective household welfare. Only the latter two (high education of the breadwinner, income from employment) have a positive effect and increase the probability that a household feels better-off or that it belongs to the upper part of the income distribution. The age of the breadwinner has a negative effect on the subjective welfare level. This coincides with the feeling of the elder generation that they are worse off. The variable age-squared has been included in order to test for the probability that the young and the elderly show a different behavior to the middle-age generation. Although the coefficient is almost equal to zero, the variable is significant at the $1 \%$ level in the case of subjective welfare assessment, indicating that age and welfare assessment have a U-shaped correlation. The coefficients for rural location and household size change signs when moving from the subjective to the objective wellare assessment. Rural households evaluate their situation more positively than their actual welfare level would indicate. The same is true with respect to household size. Living together with others may have a psychological effect in the sense that it makes the world look rosier than it actually is and the misery can be shared. The fact that the sign in Model 2 is negative could also indicate that their might be a case for economies of scale. The effect of including the quintile distribution as an explanatory variable in Model $1 \mathrm{a}$ and not in Model $1 \mathrm{~b}$ results in a change of significance of the variables accounting for household size and the presence of children. The ranking of the household in the welfare distribution is significantly and positively related to the selfassessment.

Overall, the models only explain between 10 and $15 \%$ of the variance in the well-being of households. Between eight (Model 2) and ten (Model 1b) coping strategy variables turned out to be significant determinants of a household's standard of living. Most of them are negatively correlated with both the subjective and objective welfare measure. However, as the previous paragraphs already indicated, the estimates do not point to the conclusion that there is an important link between the income position of a household and the coping strategies. We will discuss this important conclusion in the last section of this chapter. 


\subsubsection{Determinants of coping strategies}

The above has shown that most coping strategies are negatively correlated with a household's wellbeing, be it subjectively or objectively measured. It indicated that poorer households apply coping strategies as a means to make ends meet (as do the less poor households). In this section we want to anallyze in more detail the determinants of the coping strategies, i.e. we approach the question from the other angle. Since a household can make use of more than one coping strategy simultaneously, we have to model each activity separately. For each coping strategy, three different models have been estimated: the full model (as shown in Table 5.15), a restricted model with the quintiles as only explanatory variable, one model without the quintiles and another model without variables representing the quintiles and the educational level of the breadwinner. The dependent variables present a binary choice, therefore, the models are estimated using probit maximum likelihood methods. The joint hypotheses that the coefficients of all omitted variables are equal to zero is tested with likelihood ratio tests. The models using the quintiles as explanatory variables only are rejected based on the likelihood ratio test in all cases. ${ }^{13}$ Table 5.15 presents the results of the full model.

\section{a) Income generating activities}

Whether a household is involved in income-generating strategies does not depend on its welfare level nor on the educational level of the breadwinner. Likelihood ratio tests for the two alternative models confirm this conclusion. ${ }^{14}$ Access to one's own land as well as a rural location increase the probability that a household employs such strategies. Access to own land allows one to grow food and the surplus can be sold for money. As far as rural areas are concerned, the chance of finding additional work in farming may explain the result. Having an unemployed breadwinner increases the chance by $13 \%$ that the respective household will generate additional income. It may be a way to provide the necessary income if the unemployed person is not eligible for unemployment benefits. On the contrary, if a household has income from employment, the involvement in additional income-earning activities decreases with $13 \%$. Household size is also positively correlated with such strategies. It could mean that the more people available in a household, the sooner a member has the chance and time to earn some additional income, e.g. by selling selfproduced goods or services.

\section{b) Own production}

Own production was not at all significant as a determinant of well-being. Therefore, it is especially interesting to find its determinants. The probability that a household produces goods and services for own consumption increases with $8 \%$ when the household belongs to the poorest $20 \%$ of the population. Having access to own land is the variable with the highest marginal effect. It increases the probability that a households engages in own production by $42 \%$. A rural location on the other hand, has a positive marginal effect of $11 \%$. Also positively rellated to own production is the age of the breadwinner and the size of the household, while completed higher education of the breadwinner has a negative effect on the probability of a household engaging in own production. ${ }^{\text {s. }}$

\footnotetext{
We will not refer to this most restricted model anyrrore in the text. Subsequently, we will only discuss the two other restricted models, i) without quintile wariables, and ii) without quintile and education variables, in corruparison to the full modet:
}

Whe hypothesis that the varables representing quintiles and educational attainment are equal to zero cannot be rejected.

"The joint hypothesies that the coefficients of the onitted variables are equal to cero are rejected for both restricted models. This holds for the ather models as well, unless otherwise stated in the texi. 


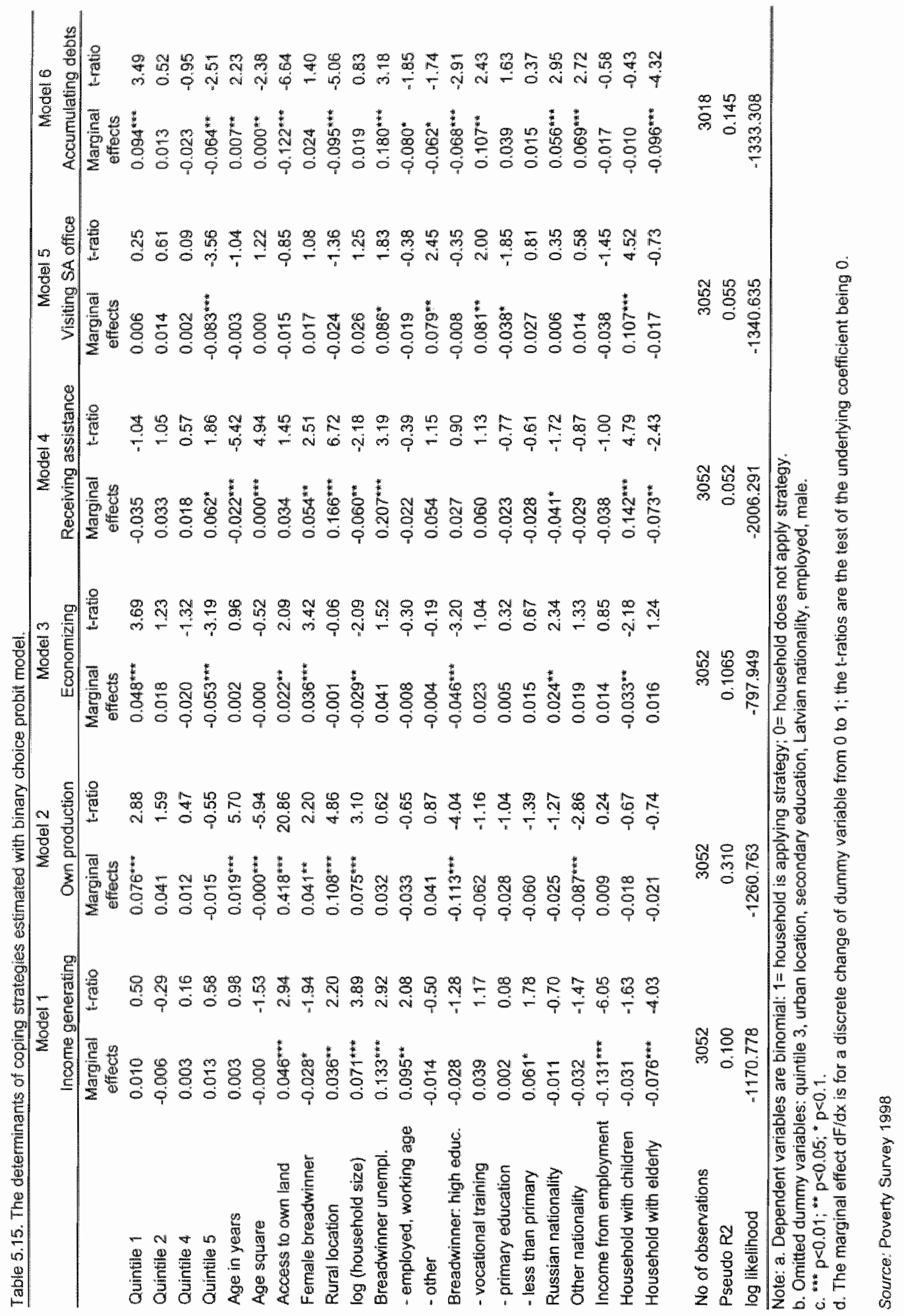




\section{c) Economuzing}

The opposite ends of the welfare distribution are significant deteminants for econonizing activities. As we would expect, the results indicate that being a member of the poorest $20 \%$ increases the chance that the household economizes by almost $5 \%$. On the other hand, households of the richest quintile have a lower probability of $5 \%$. This is also the case for households with a highly educated breadwinner. Interesting is the fact that households with children are less inclined to economize, while we know from previous chapter that these households belong to the groups most at risk. On the other hand, we know from the participatory assessment that especially families with children rather accumulate debt than that they reduce, for example, food expenditures. This outcome loses its strength when considering the restricted models, where the variable for children is no longer significant. The same applies to household size and access to land.

\section{d) Recening assistance}

Again, we find evidence that receiving assistance from persons outside the household is not related to the actual welfare level of a household. None of the variables are significant. On the other hand, certain risk groups such as households with an unemployed breadwinner or bouseholds with children have a significantly higher probability of receiving assistance from outside the household. For households with an unemployed breadwinner the chance of receiving assistance is $21 \%$ higher, and for households with children $14 \%$. Rural households have a $17 \%$ increased probability of receiving aid from others. On the other hand, the age of the breadwinner is negatively correlated with the chance of receiving assistance. This is sonewhat confirmed by the negative and significant marginal effect for households with elderly persons. It will be interesting to see later on whether these households are the donors.

\section{-) Social Assistance}

Although social assistance and debt accumulation are both considered crisis activities, we modeled them separately. Only two variables prove to be statistically significant at the $1 \%$ level when visits to the social assistance office are analyzed: being in the fifth quintile decreases the probability of a visit by $8 \%$ and the presence of children increases the chance by $11 \%$. The latter is obvious considering the fact that these households have to go to the local office in order to apply for child benefits. Therefore, we do not know whether a visit is also intended for the receipt of some kind of income support. Interesting is the fact that households with a breadwimer with primary education are also less likely to visit the social assistance office, although they are one of the most vulnerable groups in Latvia. It could be related to knowledge about the possibilities a local social assistance office has to offer. Chapter six will devote some attention to this issue. Howsehold size and having an unemployed breadwinner are significant variables in the restricted versions. In the full model, the quintille dummy variables may have diffused part of the effect of houschold size and unemployment on the probability that a household is visiting the Social Assistance Office.

\section{1) Accumulating debt}

As in the case of economizing, the first and the fifth quintile have inverse probabilities of accumulating debt. The former has an increased chance to create debt, while the latter has a lower probability to have debt for rent and utilities. Access to one's own land has a significant negative effect on debt accumulation. The question is how these two variables are related. One possible argument is that households with own land can save on expenditures for food and therefore, have more money available for other payments. Rural households are also less likely to run into debt compared to urban households. Households with an unemployed breadwinner have a $18 \%$ higher probability to accumulate debt, all else being equal. Money must be a serious problem in these 
households, and one survival strategy is the non-payment of rent and utility bills. For the first time, nationality is an explaining factor. Non-Latvians have a significantly higher chance to accumulate debt compared to ethnic Latvians. With respect to the restricted models, household size is significant in both cases while the variable representing age lose some of their significance in the model without education and quintile dummies.

Concluding, we can say that no variable is significant in all models. Access to one's own land, the rural location and the household size are significant in four of the six full models of coping strategies. We also see that in most models only five to ten percent of the wariance is explained. There are either other deterninants explaining household behavior, or we have to conclude that coping strategies are employed by all groups across the whole Latvian population. Considering the various models together, we find weak support for the findings of the qualitative poverty assessment (Institute for Philosophy and Sociology, 1998). Households with children are less likely to conomize, while households with elderly persons are less likely to accumulate debt. Household welfare represented by the quintiles is surprisingly seldom significant and does hardly explain why a household engages in coping strategies. This confirms the findings of section 5.3.1, where we saw that the differences between the quintiles are often only small. We discuss the overall findings more extensively in the last section.

\subsubsection{Giving and receiving: who is doing what?}

In this section we want to analyze in greater detail the exchange of goods and services between households, $c_{\text {.q. }}$. the importance of the social network. So far, we found that being a recipient of assistance is not dependent on the welfare level of the household. Here we will include the information we have on households that give assistance. Based on answers to questions B01 and B02 we created a categorical variable identifying whether a household is a pure recipient, a pure donor or whether it is both giving and receiving assistance (a G\&R household). Table 5.16 presents the percentage of households in each category by quintile.

Table 5.16. Giwing and receiving assistance, percentage of households per quintile and catteglory

\begin{tabular}{|c|c|c|c|c|c|c|}
\hline \multirow[b]{2}{*}{ Giving and receiving assistance } & \multicolumn{5}{|c|}{ Quintilles } & \multirow[b]{2}{*}{ Total } \\
\hline & 1 & 2 & 3 & 4 & 5 & \\
\hline \multirow[t]{2}{*}{ neilher donor nor recipient } & 20.83 & 20.84 & 21.91 & 21.53 & 14.90 & 100 \\
\hline & $39.2 甘$ & 34.45 & 35.82 & 33.10 & $2 * .20$ & 32.25 \\
\hline \multirow[t]{2}{*}{ Pure donor household } & 10.15 & 14.54 & 19.27 & 22.63 & 33.41 & 100 \\
\hline & 10.32 & 12.99 & 17.03 & 18.80 & 25.69 & 17.43 \\
\hline \multirow[t]{2}{*}{ Pure raciplent housethold } & 19.91 & 23.15 & 19.27 & 20.56 & 17.12 & 100 \\
\hline & 21.32 & 21.76 & 17.93 & 17.98 & 13.86 & 18.34 \\
\hline \multirow[t]{2}{*}{ Giving and receiving houswhold } & 15.62 & 18.79 & 18.02 & 19.75 & 27.81 & 100 \\
\hline & 29.15 & 30.80 & 29.22 & 30.11 & 39.25 & 31.98 \\
\hline \multirow[t]{2}{*}{ Total } & 17.13 & 49.51 & 19.72 & 20.97 & 22.66 & 100 \\
\hline & 100 & 100 & 100 & 100 & 100 & 100 \\
\hline
\end{tabular}


Table 5.17. Detaminants of households involved in exchanging assistance

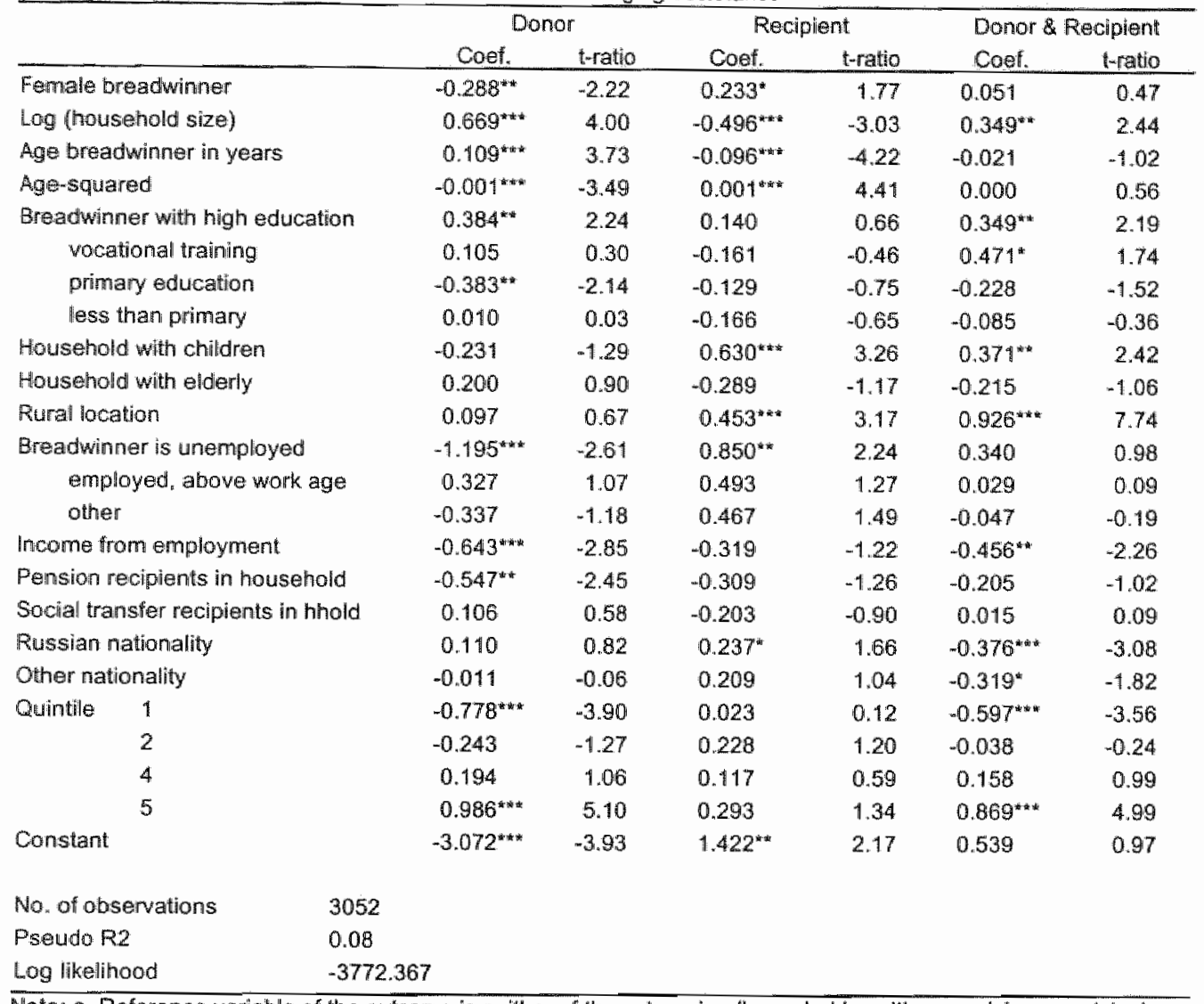

Note: a. Reference variable of the oufcome is neither of the categories (households neither receiving nor giving). b. Omitted dumnyy variables: quintile 3 , urban location, secondlary education, Latvian nationality, employed, male.

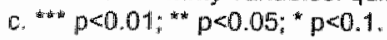

Source: Poverty Survey 1998.

Almosi $40 \%$ of the poorest households are neither donors nor recipients. They seem to have fallen out of the social network. In the richest quintile, this is only the case for $21 \%$ of the households. The wealthicr, the larger the share of pure donors (from $10 \%$ in the first quintile to $25 \%$ in the fifth quintile). An opposite relationship is found when considering pure recipient households. In general, households of the fifth quintile seem to be involved in a much nore active network than the rest. A.most $40 \%$ are G\&R households as compared to about $30 \%$ of the other quintiles.

In order to find possible determinants of assistance, several multinomial logit models have been estimated. The full model is summarized in Table 5.17. In addition, three restricted models have been estimated and tested with respect to the fill model: i) without dummy variables representing the welfare quintiles, ii) without variables representing the educational level of the breadwinner, and iii) without quintiles and educational level. Based on likelihood ratio tests, the hypotheses that the coefficients of the omitted variables in the restricted models are equal to zero have been rejected in all cases. In case of the model estimated without education, no change at all can be observed. In the other wo restricted versions, we observe changes in the significance level of some variables. Household size and having income from employment are not significant anymore in the restricted 
versions for donor and D\&R households. The same applies to the presence of children in the case of $D \& R$ households. The resulis of the full model are summarzed in Table 5.17 .

Factors that increase the probability that a household is a donor are related to the wealth of the household and to its demographic characteristics. Being a household of the fifth quintile increases the chance it is a pure donor or $a \& \& D$ household as expected. The poorest $20 \%$ have a much lower probability to be donors only. The fact that households with breadwinners with completed higher education are rather donors or G\&D households relates to the relative wealth of these households. The opposite is the case when the breadwinner is unemployed. These households are clearly recipients only considering the sign and significance of the respective variables. Pure donorship is also related to the age of the breadwinners. The older the breadwinner the larger the probability that the household is a donor, and the smaller the chance that it is recipient only. The significance of age-squared and the sign of the coefficient indicate that young and old households are rather recipients than donors. Households with children are either receiving or giving and receiving. Goods exchanged in that case are clothes for the children and/or school supplies. Rural households show an equal pattern while we can only guess on the nature of goods they are receiving. Work seems to be the most obvious exchange in nural areas. But again, these results have to be treated with caution regarding the fact that the full model explains only $8 \%$ of the variance. Other determinants seem to be more important in explaining the probability that a household is involved in the exchange of assistance. The question is whether Latwian households do have working social networks. The results (see also Table 5.16) indicate that the poor are lacking a well functioning network and that serious poverty in Latvia might be related to the fact whether someone is socially "included".

\subsubsection{Consumption habits}

Economizing on food, changing the diet or producing goods and services for own consumption have already been analyzed to some extent in section 5.3.1. All data used so far came from the poverty survey. Since we have more detailed data on expenditure patterns from the HBS diary, this section provides a more detailed description of Latvian food consumption habits using data from 1996 and 1997. The food-bundle, the share of food received free of charge or from own production and the sources of food are presented below. Figures $5.1 \mathrm{a}-\mathrm{d}$ show the changes in the food-bundle of the first, the second, the fifth and the tenth decile. ${ }^{16}$ Considering our findings in chapter three that point to the worsened poverty situation in Latvia in 1997 compared to 1996, we expect to find changes in the composition of the food-bundle consumed. It would provide support to our assumption that households engage in coping strategies such as expenditure reduction and consumption of goods from own production or received free of charge.

The households of the fifth and tenth decile hardly show any changes in the composition of the basket, while the first decile provides visible evidence of some significant changes in the share of goods consumed even over the relatively short period of observation (one year). The consumption of bread decreased by half (from $22 \%$ to $11 \%$ ) and that of meat from $17 \%$ to $10 \%$ in households of the first decile. This reduction is substituted with products that can be grown in the garden or gathered, such as fruits (including berries), wegetables and potatoes. The consumption of vegetables increased from $9 \%$ to $26 \%$, and the share of potatoes grew from $10 \%$ to $13 \%$. "The second decile shows a similar pattem but not to such an extent.

\footnotetext{
sGe Table A 5,1 , in Appendix $5 A$; which contains all figures.

"We assume that cubbage is the largest share of vegetables, since cabloge can be stored and kept easilly through the winter and it is a common and cheap vegetable in Latvia.
} 


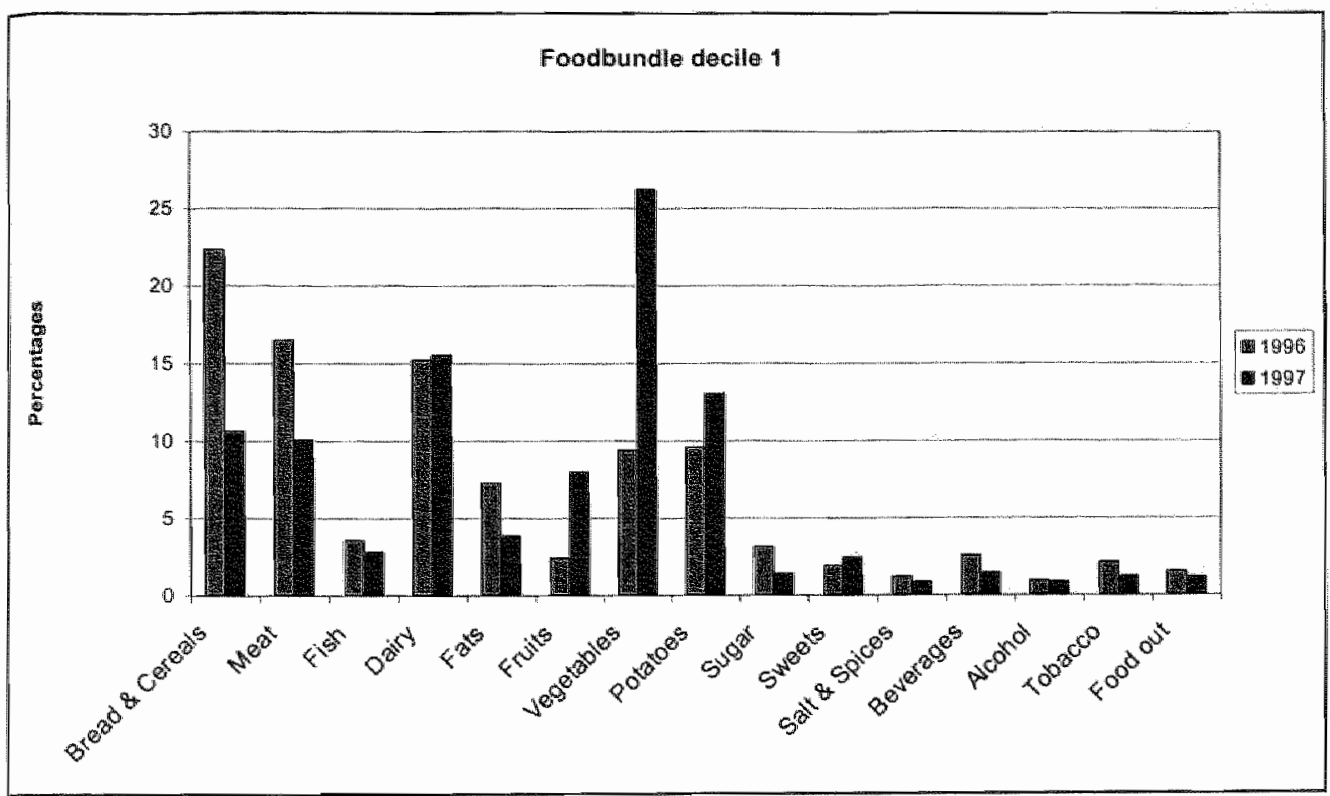

Figure 5.1-a. Shares of food in total food baskel, 1996-1997, first decile.

Source: HBS $1996,1997$.

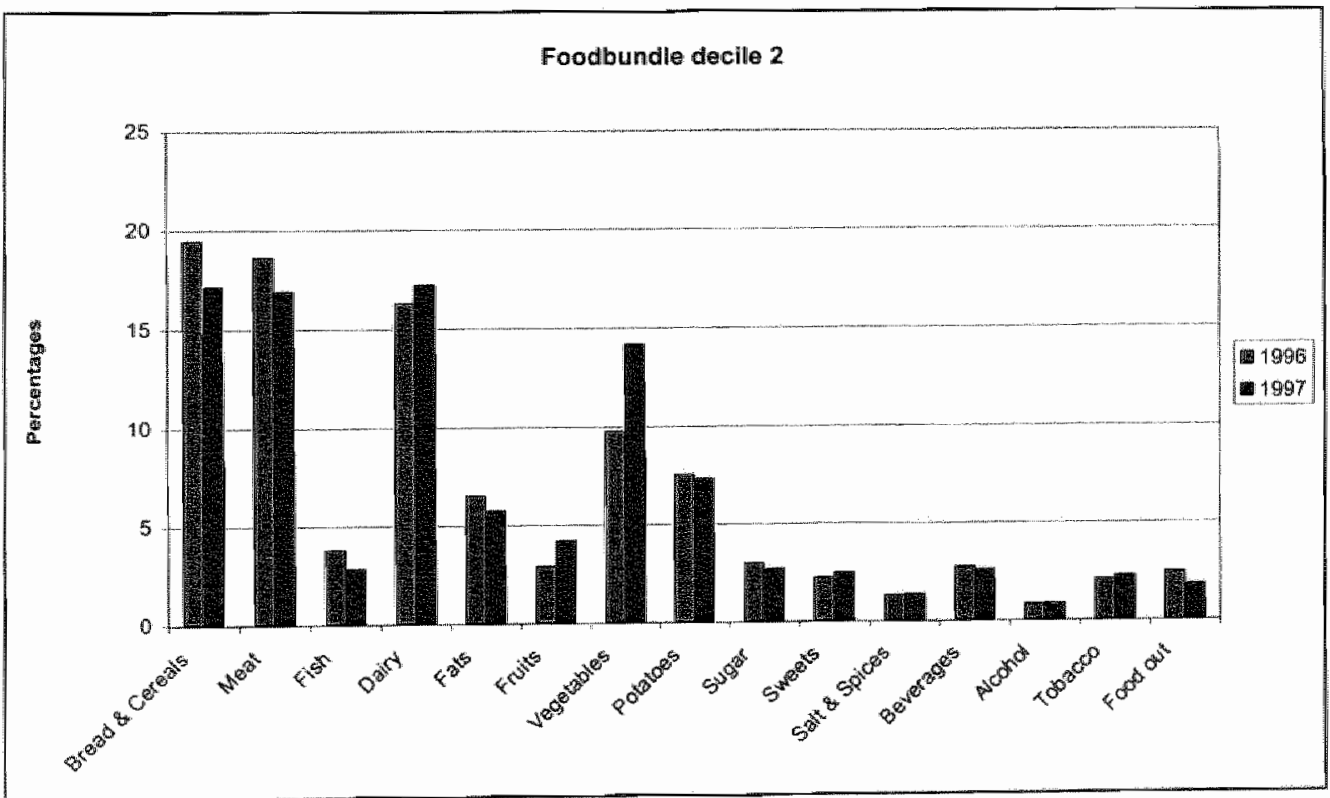

Figure 5. 1-b. Shares of food in total food basket, 1996-1997, second decile.

Source: HBS 1996, 1997. 


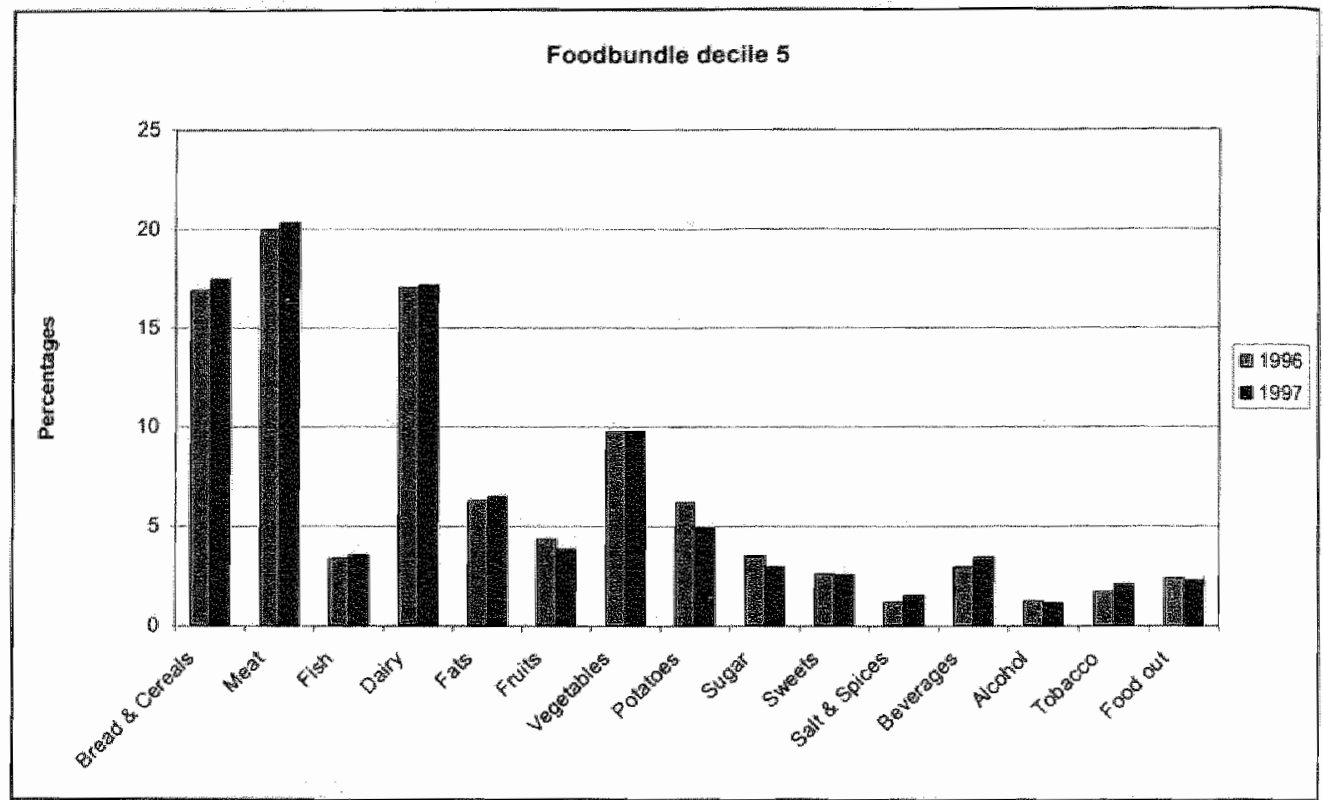

Figure 5.1-c. Shares of food in total food baskel, $1996-1997$, fifth decile. Source: HBS 1996,1997.

Foodbundle declle 10

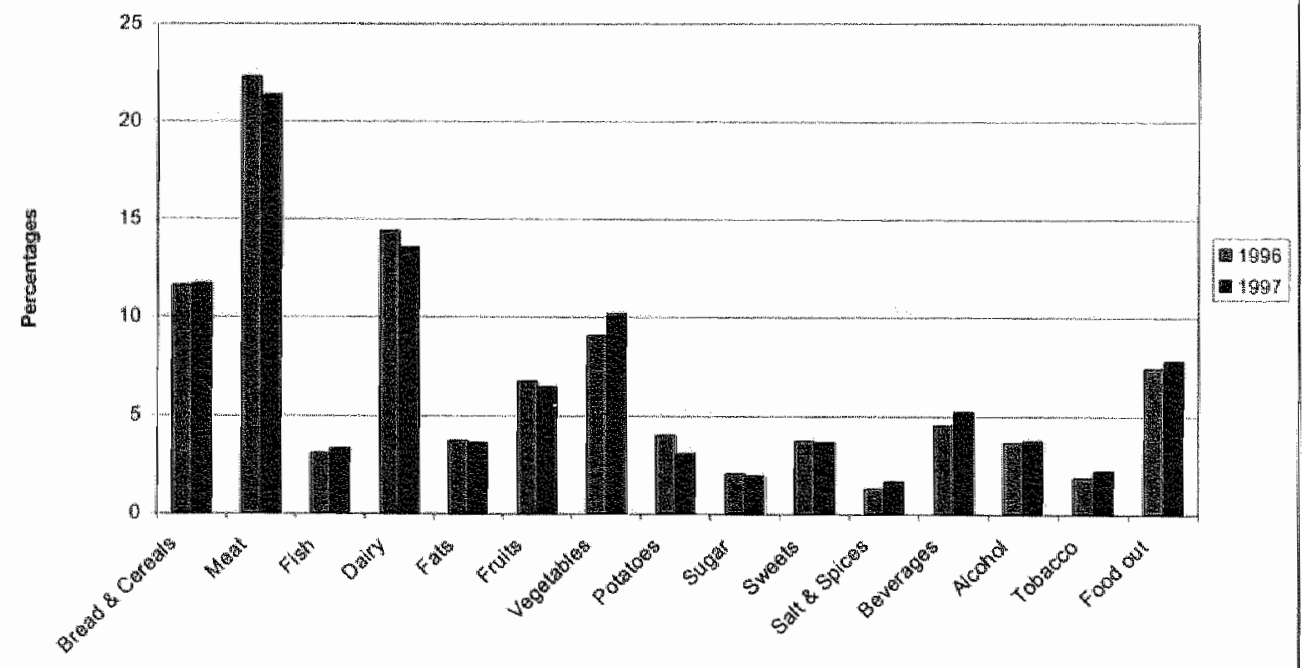

Figure 5 . 17 whares of food in total food basket, 1996-1997, tenth decile.

Source: HBS $1996,1997$. 
The fact that substitution took place with products from own production (or received free of charge) is confirmed by Table 5.18. From this table we see that there was an overall increase in own produced goods, but that the shift in the first decile to own production was significantly larger, while across households of e.g., the fifth or the tenth decile, the shares decreased slightly. The increase is not only for vegetables, potatoes and fruits, but it encompasses more or less the whole food basket. It confirms the findings above that own production is a coping strategy applied in case of need.

Table 5.18 shows that not only own production substitutes purchased goods. For food in total, the share of owr produced goods almost tripled from $17 \%$ to $43 \%$ in the first decile, and doubled with respect to food received from family members (from $9 \%$ to $18 \%$ ) and received free of charge from other sources (from $5 \%$ to 10\%).

Table 5.18. Sources of food, 1996-1997

\begin{tabular}{|c|c|c|c|c|c|c|c|c|}
\hline \multirow[b]{2}{*}{ Decille } & \multicolumn{2}{|c|}{ Own production } & \multicolumn{2}{|c|}{ From family } & \multicolumn{2}{|c|}{ From others } & \multicolumn{2}{|c|}{ Purchased } \\
\hline & 1996 & 1997 & 1996 & 1997 & 1996 & 1997 & 1996 & 1997 \\
\hline 1 & 45.66 & 43.13 & 9.23 & 18.22 & 5.38 & 10.03 & 69.73 & 28.63 \\
\hline 2 & 15.74 & 23.09 & 7.84 & 10.36 & 3.89 & 4.97 & 72.53 & 64.58 \\
\hline 3 & 14.02 & 18.34 & 8.05 & 8.91 & 3.39 & 3.90 & 7.4 .54 & 68.85 \\
\hline 4 & 13.54 & 15.12 & 7.10 & 7.21 & 2.72 & 3.37 & 76.63 & 74.31 \\
\hline 5 & 13.63 & 12,90 & 7.64 & 5.77 & 2.76 & 2.57 & 75.97 & 78.76 \\
\hline 6 & 15.32 & 13.77 & 7.50 & 7.95 & 2.50 & 3.38 & 74.68 & 74.90 \\
\hline 7 & 13.88 & 13.72 & 8.02 & 7.90 & 2.89 & 3.82 & 75.22 & 74.56 \\
\hline$\hat{8}$ & 16.55 & 13.90 & 8.02 & 8.36 & 3.52 & 3.24 & 71.91 & 74.49 \\
\hline 9 & 15.05 & 14.63 & 10.53 & 8.31 & 3.07 & 3.07 & 71.35 & 73.98 \\
\hline 10 & 13.84 & 12.11 & 9.29 & 8.95 & 4.44 & 4.02 & 72.46 & 74.92 \\
\hline Tolal & 14.70 & 17.43 & 8.35 & 9.03 & 3.42 & 4.12 & 73.53 & 69.42 \\
\hline Urban & 6.77 & 8.84 & 8.72 & 9.53 & 3.40 & 4.32 & 81.11 & 77.31 \\
\hline Rural & 34.33 & 38.37 & 7.42 & 7.79 & 3.48 & 4.12 & 54.76 & 50.20 \\
\hline
\end{tabular}

Saurce: HBS 1996, 1997

\subsection{Conclusion}

To answer the question posed in the introduction as to how poor households cope with the little means they have, they seem to cope by applying several coping strategies simultaneously. From the last section we allso have evidence that a change in consumption is a way to deal with worsening living standards. The poorest change their diet and increase the share of goods from own production or received through the social network. But this is maybe not the most important conclusion of this chapter.

The interesting result of the poverty survey is that not only poor households use the indicated strategies. Certain coping strategies are employed by all layers of the society independent of the welfare level. Economizing is such an activity, or own production of goods, or the receipt of assistance from other households. We were not able to detect a strong correlation between the standard of living and the prevalence of a certain strategy. This is a very broad statement, and it needs some refinement. Although more than $90 \%$ of the total population is economizing on something, the poor economize on more than one item. On average, poor households produce more than one good on their own, they engage in more than one income-generating activity, they receive more than one sort of assistance. The age pattern is more distinctive than the income distribution. The older generation has accumulated less debt than young households. The old are also least often 
engaged in income-generating activities, and they economize most. Middle-age households engage more in own production than the young or the old, while young households are clearly more often recipients of assistance.

The fact that almost every household uses coping strategies says something about the general welfare level of Latvia. It actually confirms our earlier findings that living standards dropped considerably after the transition and that poverty increased. The majority is experiencing rather hard times and uses every possible instrument to generate additional income and to make ends meet. Since we focus in this study mostly on the poor, it is easily overlooked that the general welfare level is relatively low. Although everybody uses some coping strategy, the poor households distinguish themselves in that they apply several strategies simultaneously. On the other hand, the findings in this chapter can also be interpreted to mean that the very poor are the ones that have fewer coping strategies at their disposal. They have nothing left to economize on because they already live on as little as possible, and the social network of the poorest seems to be rather weak. They have fewer "weallhy" relatives who could support them with, for example, money. The poorest are less likely to be recipients of assistance as we have seen. The existence of a functioning social network as well as the ability to apply coping strategies may be the explanatory factor for a household's position in the Latvian welfare distribution. Households with a well-functioning social network and the ability to employ effective coping strategies are the ones that are relatively better off. Considering the characteristics of the most vulnerable groups as indicated in chapter three, this explanation nay be appropriate. Take for example the unemployed. Being out of work usually reduces the size of the social network considerably, and the longer the unemployment spell, the weaker the network among non-relatives and the less information reaches the unemployed. It seems as if those capable of applying coping strategies successfully are in a relatively better position, while those households which have no means to generate additional income or reduce consumption are the ones most at risk.

For Latvia these findings imply that the general welfare level is low. Everybody has to cope with the little means available and exhaust each available strategy. The poorest are doing the same but not as successfully because their initial endowment of labor, capital or relationships necessary to apply a certain strategy is low. They have no capital to start own production, for example by buying seeds or fabrics, they are too poor to economize on food or ather goods, or they do not know many people who could support them or who could offer them some work. It is this group, the poorest, to which social policy should address its social assistance programs. In a climate of tight government budgets, priorities for help have to be set and assistance should be targeted at those households that cannot cope on their own, that have exhausted their means to make ends meet. In the next chapter we will analyze the effectiveness of the Latvian social assistance system in reaching and assisting the poorest households. 


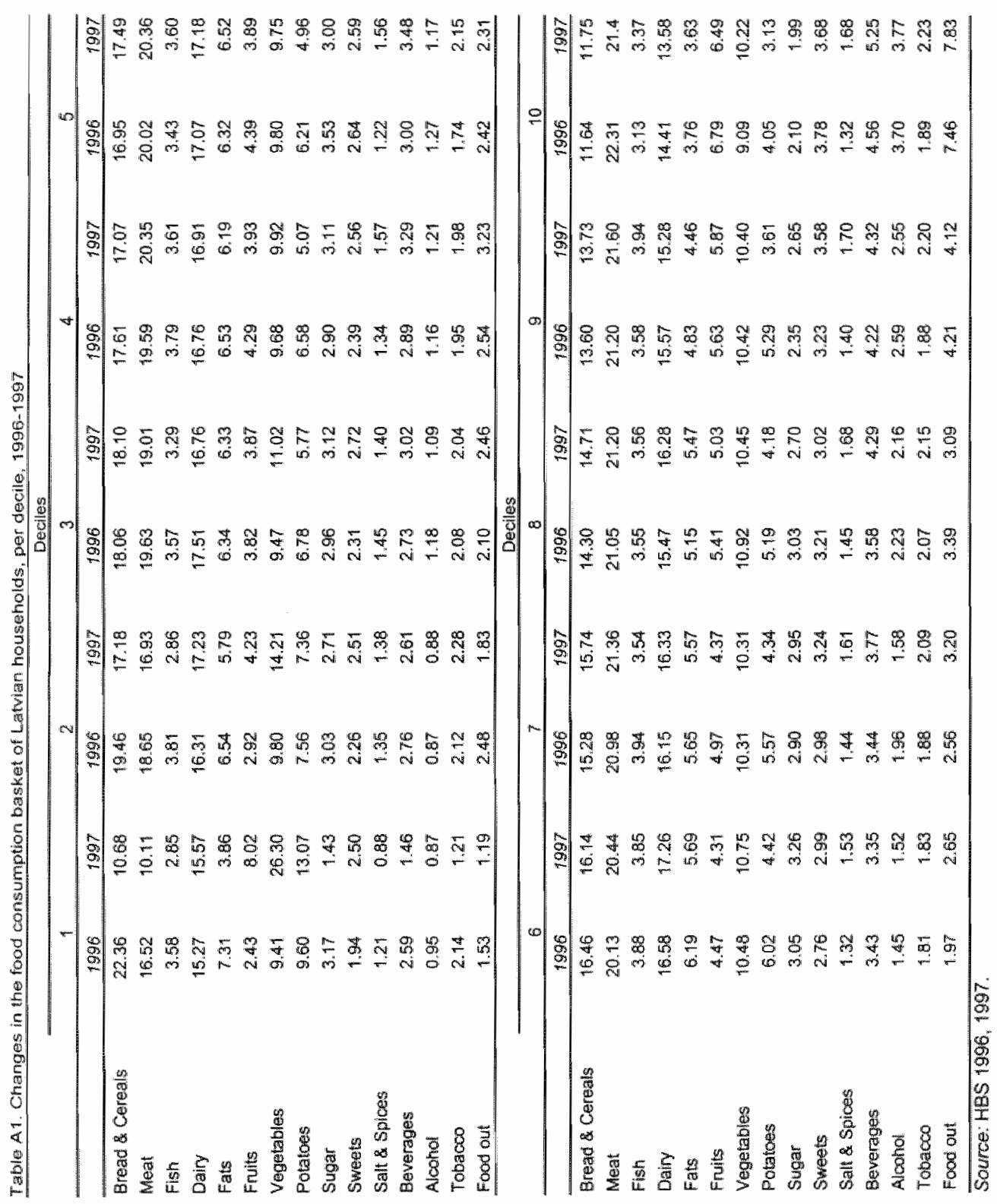





\section{TURNING TO THE STATE FOR HELP}

\subsection{Introduction}

The last chapter has shown that people can be very inventive in developing and employing coping strategies in order to make ends meet. But such strategies may not be enough in the daily battle to stay out of poverty. When all possible income sources are exhausted and still insufficient to keep a household at a minimum standard of living, the safety net of the state can come into action and support the household in question. The Law on Social Assistance regulates the Latvian social safety net, delineating the responsibilities of the state, the regions and the municipalities. The objective of social assistance is to ensure social safety and protection to those inhabitants of the country that are not able to support themselves, are not provided for by others or do not get the necessary assistance from the social insurance system. Two main questions are addressed in this chapter: i) is the Latvian social assistance system effective in reaching the poor and does it indeed work as a safety net and ii), do Latvians turn to the state for help when they are in need.

The problems the countries in CEE and FSU were confronted with at the start of the transition were tremendous. Declining output, increasing unemployment and falling real incomes demanded a reaction from the state. Suddenly, an effective safety net was needed for those that could not adapt quickly enough to the changed situation. The govemments had to set up a new social system while the population (thus the voters) was still thinking in old terms. The command economies were famous for their social systems. The communist safety net consisted in principal of guaranteed employment (although at a low wage), generous family benefits, social insurance linked to employment and free or subsidized basic requirements. There was no need for unemployment benefits or social assistance as known in Western Europe. The impression was of a cradle-to-grave protection of the imhabitants. In reality, the situation was different. The slow-down of the Sowiet economy in the 1980s showed the first holes in the safety net (Atkinson \& Micklewright, 1992). Nevertheless, the govermments in the transition countries were not prepared for the rapidly changing circumstances. The existing safety nets collapsed while there was not yet anything else in place. In this context Latvia had already undertaken several reforms to the initial system that was in place after independence. The current system is at discussion here.

The chapter starts with a description of the current social assistance system from a more administrative point of view, followed by a section from the point of view of the Latvian population. The results of the poverty survey questions with respect to social assistance are presented there. The current situation will be evaluated in section four, summarizing the main problems and policy issues. A proposal to simplify the current system is elaborated on in section five, followed by a conclusion. 


\subsection{The current system}

The Latrian government describes social assistance as follows: "The goal of social assistance is to guarantee social protection to those inhabitants who are not able to overcome certain difficulties of life and who do not receive sufficient help from any other person. Social assistance activities creade a safety network for persons who do not receive sufficient income from work, social insurance payments or state social benefits, and who fulfill the duty of co-participation. Social assistamce encompasses material help, social care and rehalbilitation and promotes self-help and re-integration into the society' (MoW, 1998:59).

In this chapter we confine ourselves first to "sociall assistance" in the form of 'material help" according to the Latvian law (assistance in cash or in kind)." This encompasses, in addition to means-tested benefits, also universal and categorical benefits. In many publications social assistance is limited to the former category of benefits. However, we follow the Latvian law here and support the position that in many cases universal benefits (by definition not means-tested) are important social safety net instruments and therefore can play a significant role in the alleviation of poverty. In later sections, social assistance at the municipal level is of most interest since it is the municipalities" responsibility to prowide social assistance to poor families.

\subsubsection{What has happened since independence?}

Shortly after independence in 1991, the Republic of Latvia embarked on a radical change of its social security system. Prior to independence, the social system was characterized by low wages, subsidies, family benefits and pensions as well as institutional care for elderly and disabled individuals. The needs of an economy in transition proved to be different from a command economy with regard to the social safety net since employment was no longer guaranteed and price subsidies were removed. The first changes to the benefit system were adopted by the Government of Latvia in 1991, splitting central, regional and local responsibilities for social assistance and social care provision. On the one hand the 1991 legislation tried to take away the heavy stigma attached to social assistance by setting decent standards for the safety net and on the other hand it tried to deal with anti-centralistic sentiments dating back to the Soviet period by giving the municipalities discretion in the actual benefit disbursements and the obligation to co-finance paid benefits by 50 percent. A means-tested social assistance benefit was introduced, based on a consumption basket adding up to 73 percent of the average wage in December 1992 (and actually exceeding average wage by the second quarter of 1993)(IMF, 1993). The muricipalities faced several difficulties in implementing the law: they allocated few resources for benefits; they saw the minimum consumption basket as meaningless given its high level and they regarded the regulations on system administration as overly complicated and unenforceable. This was the starting point for the formulation of the new laws currently used and described below.

Since the new system proved to be ineffective, the Ministry of Welfare started to prepare new legislation in 1994. Seven new laws on social security were accepted in October 1995, and most of them became effective by January $1,1996^{2}$. In addition, the government initiated an administrative reform encouraging municipalities to merge and to phase out the regional level of

\footnotetext{
For a complete description of all aspects of the Latvian Social Assistance, the reader is referred to the Ammual Social Reports of the Mituistry of Weltare (MloW 1998, MoW 1999a).

${ }^{2}$ Law on Social Security, on Social Tax, on State Pensions, on Soctial Assistance, on Matemity and Sickness Bernefits, on Mandatory Social Insurance Against Unemployment, and on Mandatory Imsurance againgt Work. Injumies and Occupational Diseases.
} 


\section{Goverrment in $1998 .^{3}$}

The aim of the social security system is to guarantee social security for the Latvian population, increasing the responsibility of the individual and to provide a safety net for those that are not able to support themselves or do not get the necessary assistance from social insurance. The social insurance legislation regulates the financial support of insured persons in case of old age, sickness, disability, matemity, unemployment, work injuries as well as of their dependants in case of death of the insured individual. The administrative responsibilities of social insurance rest at the central lewel (policy design, benefit administration, budgeting, monitoring and evaluation) and the local level (lax collection, application processing, eligibility determination) and benefits are financed from social tax revenues (contribution-based).

Social assistance is provided through the state and municipal governments. State social assistance benefits are mainly categorical benefits, whereas the municipalities act as a lender of last resort granting benefits based on means tests. The central government level is responsible for policy design, adjudication of disputes over local benefits, licensing of institutions and the monitoring, evaluation and implementation of social assistance policies. The administration of state and municipal benefits, financing of municipal benefits, entitlement and eligibility are responsibilities of the local government.

\subsubsection{Social assistance schemes}

The Law on Social Assistance delineates the responsibilities of the state, 26 regional, 7 city and 562 municipal governments. The objective of social assistance is to ensure social safety and protection to those inhabitants of the country who are unable to support themselves, are not provided for by others or do not get the necessary assistance from the social insurance system. The administration is divided between different responsibility levels with the seven cities performing the functions of both the region and the municipality.

\section{a) State financed benefits}

Most state social assistance benefits are categorical benefits with the exception of guardian benefits that are means-tested with respect to the child's "income". The level of all allowances is set by the Cabinet of Ministers. Family state benefits are the most prominent state allowances. Famity allowances are paid for each child up to the age of 15 or later if the child is still attending school. A flat-rate tax deduction per child supplements the allowance. After the birth of a child, a birth grant is paid to one of the (adoptive) parents. Child care benefits (extended maternity leave) are granted to unemployed or part-time working care providers with children up to age 3 if they are not eligible for maternity benefits from social insurance. Appointed guardians are entitled to a guardian allowance. Other state benefits are transportation allowances, funeral allowances and the state social security allowance. In addition, the Ministry of Welfare has the discretion to provide special grants for various purposes. Table 6.1 provides an overview of the various state financed social benefits

\section{b) Municipal/city financed benefits}

Social assistance allowances are targeted at poor families to raise their income to a minimum standard level which is set by the Cabinet of Ministers. These benefits are means-tested and can be paid either in-cash or in-kind upon the discretion of the municipality. A housing benefit supplements the social assistance bertefit. It is means-tested and aimed at assisting poor families with rent and utility payments. Funeral allowances for those with no other entitlements and special care allowance supplement the municipal/city financed social assistance benefits (see Table 6.2).

\footnotetext{
Ant the time of writing, this reform ha not yet been completed.
} 


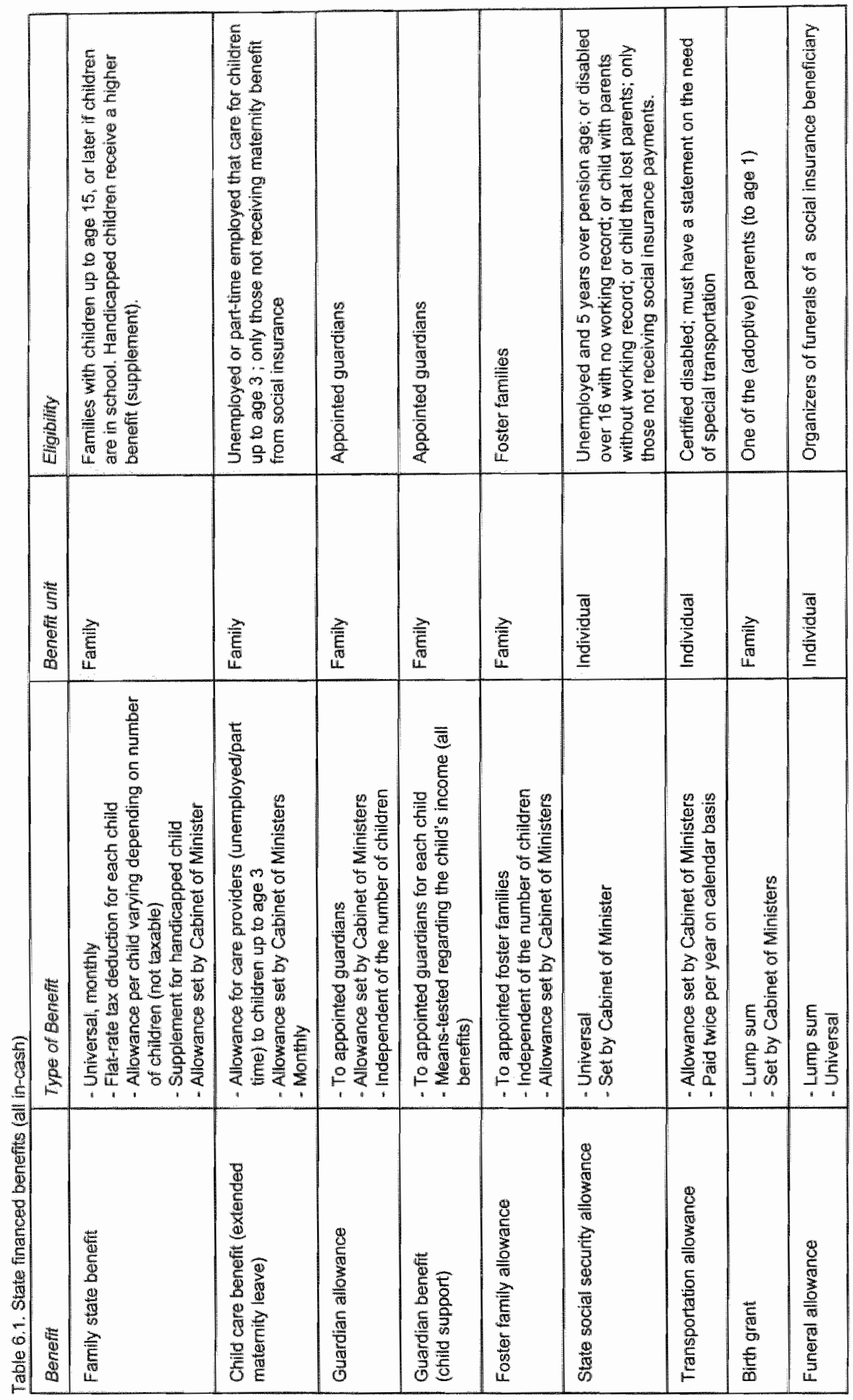



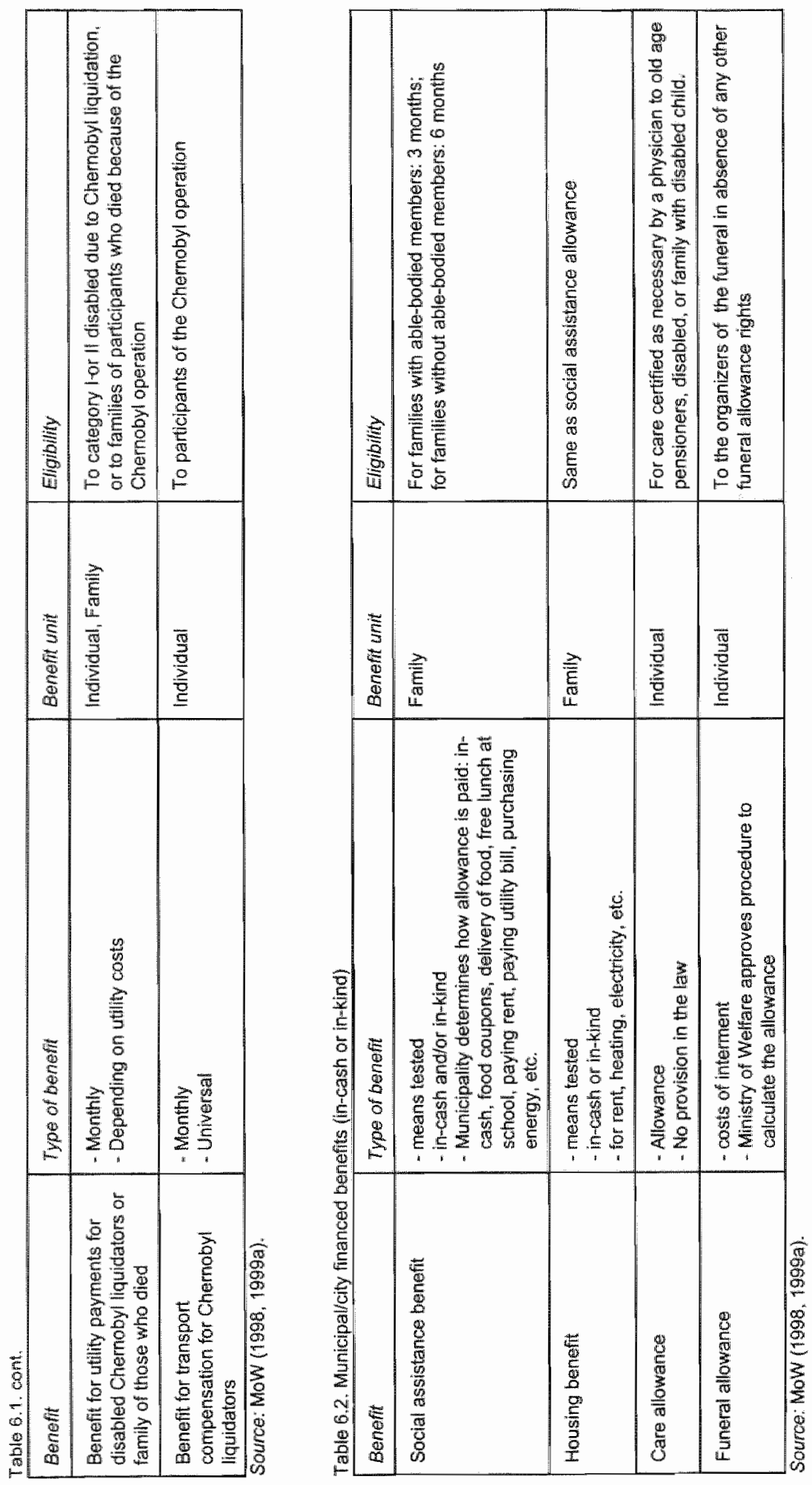
Each municipality/city is free within the boundaries of the law to determine the kind of benefits it provides. This results in a great variation between the services and benefits offered to the poor. Whether a specific benefit is paid in-cash or in-kind is also at the discretion of the mumicipality. Some examples of specific local social assistance benefits (which can be limited to specific groups) are the repayment of medical care expenses (e.g. reimbursement of hospital fees, drugs, dentist services), home care, birth allowances in addition to the state birth grant, purchase of shoes, clothing, school equipment, Christmas and anniversary presents, events organized for specific groups (e.g. Christmas celebration for pensioners), or a transportation refund (Wulf \& Berkovich, 1997). Municipalities tend to prefer in-kind benefits assuming that they prevent abuse of public money and ensure that the benefit is used for the targeted purpose. As far as housing benefits are concerned, municipalities usually transfer the money directly to the billing institutions.

Column 4 in Tables 6.1 and 6.2 describe the eligibility criteria under the different sections of the social assistance arrangements. It is striking that it is difficult to detect a generall philosophy in setting the criteria, except for the cross references and exceptions referring to other sections. This points to the way in which the social assistance arrangements are designed. Often, a general benefit was set, but then gaps were detected und subsequently 'repaired' by an additional benefit with specific eligibility criteria.

Most state financed benefits are set by the Cabinet of Ministers and the municipality/city financed benefits by the municipalities. This indicates a large degree of discretionary power for these institutions and a lack of guarantees for the population. The levels of entitlement can easily be changed by decree, thus leaving the potential beneficiaries in uncertainty regarding their rights and/or potential income. Given the (chosen) budget constraints within municipalities this means that in fact very few people are certain that they will receive benefits even if there exists a provision under the law. In an attempt to guarantee a benefit at least to the most needy, the Ministry of Welfare defined a list of priorities for benefit disbursements for municipalities in the second half of 1997. However, few municipalities are aware of this decree (Ministry of Welfare, 1997c).

\subsubsection{Administration and financing}

The administration of social assistance schemes takes place on different government levels: the state, regions and municipalities and the seven largest cities with the latter performing the functions of both regions and municipalities. Legislation and regulation of social assistance is the state's responsibility. The Cabinet of Ministers sets the Ievel of state cash allowances. Within the Ministry of Welfare, the Social Assistance Department (SAD), the Social Assistance Fund (SAF) and the Social Policy Development Department (SPDD) are responsible for various aspects of social assistance policies. The SAD's functions are policy design and legislation, the regulation of benefits administration including the determination of minimum standards of social assistance. The tasks

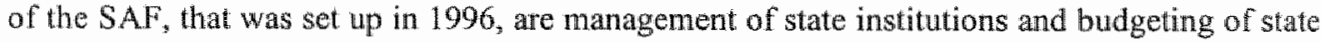
benefits.

Regional and city governments manage social care institutions that are under regional auspices. Coordination of social assistance policies within the region, the support of municipalities in executing their functions and the collection of information are tasks of the regionall level as well.

The Law on Social Assistance requires every municipality/city to open a local social assistance office. The size and organization of such an office is left to the discretion of the municipalities. Administration of both municipal and state social assistance benefits is done at the municipal/city level. Most state social benefits are paid through the Social Insurance Fund offices (except guardians' and transportation allowance). Income tests are performed by the local offices. Municipalities are autonomous in determining eligibility and benefit levels (within the law), they decide on the nature of municipal social assistance benefits, whether they are paid in-kind or in- 
cash. The proportion of the municipal budget spent on social assistance is also at the discretion of the local gowemment.

There is no general procedure in Latvia to determine the level of means-tesied benefits. The state usually determines a minimum standard level and municipalities set the level and sort of beneffit. Means tests and eligibillity levels vary between municipalities as well. The general mission of social assistance is to support those who are not able to support themselves. How this objective is achieved is at the discretion of each municipality.

State benefits are financed from the state budget with most revenues coming from value-added and profit taxes. The SAF budget makes provisions for the financing of state social security allowances. Municipal/city social benefits are financed from the municipal/city budgets. Municipalities keep most of the income tax revenues (72\% in 1997). The remaining tax income is transferred to the Ministry of Welfare to cover health care expenditures ( $28 \%$ in 1997). In addition, revenues from land and property taxes and a part of the natural resource tax and income from cutting fees go to the municipalities. The income tax revenues represented over $50 \%$ of municipal income in 1995 and the trend is increasing. A national equalization fund intends to minimize per capita differences in revenues and expenditures across municipalities.

\subsubsection{Effectiveness of the current system}

a) Measures of effectiveness

After decentralizing spending autonomy to the municipal level, expenditures on social assistance decreased. Whereas in 1994 spending on social assistance and care amounted to LVL 37.87 million (1.9\% of GDP), in 1995 expenditure fell to LVL 33.82 million (1.4\% of GDP). Taking only social assistance expenditure, the drop was from LVL 24.79 million in 1994 to LVL 14.66 million in 1995 (CSB, 1998b:54). In nominal terms, the expenditure for local social assistance seems to have stopped around LVL 13.5 million per year (see Table 6.3), while state financed social benefit expenditure slightly increased from 1997 to 1998 . Looking at local social assistance benefits in more detail, we see that the social benefit intended as income support decreased from LVL. 4.3 million in 1996 to LVL 1.2 million in 1998. Other benefits seem to have replaced the expenditure for social assistance benefits. Allowance for medical service payments and other expenses (education related benefits account for $30-50 \%$ of this item) increased between 1996 and 1998 .

The decentralization of spending power to municipalities is considered the main reason for this decline. Municipalities set their own budgets and other spending needs crowd out social assistance. Looking only at local social assistance expenditures (see Table 6.4), we see that the total increased slightly in nominal terms from LVL 18.45 million in 1996 to LVL 19.01 million in 1998 . But expenditure on institutional care crowd out expenditure on benefits.

While total spending on social assistance in real terms has declined significantly since 1994 , data on the characteristics of the spending are problematic and should be interpreted with the greatest care. The Ministry of Welfare uses a quarterly municipal questionnaire and an annual municipal questionnaire in order to figure out how much is spent on what and for whom. The instrument, however, is highly deficient and detailed field research has demonstrated that the municipalities have enormous difficulties answering the questions. Moreover, and more importantly, they interpret the questions as well as the underlying definitions and concepts, very differently (Wulff \& Berkovich, 1997). This implies that classifications are not used consistently across municipalities and that the data obtained from these surveys can only serve as a rough estimate. Analysis on municipal level reveals that local practices differ enormously; some municipalities clearly prefer to give cash benefits, while others limit their interventions to benefits 
in kind only. All in all, little can be concluded on the effectiveness of the social assistance arrangemenis from the administrative data that are available, although it is safe to conclude that poor families are treated very differently depending on the municipality they live in.

Table 6.3. Average annual expenditures and number of bereficianes per month for state and local social benefits, $19905-$ 1998 , nominal valueg

\begin{tabular}{|c|c|c|c|c|c|c|}
\hline \multirow[t]{2}{*}{ Benefit } & \multicolumn{3}{|c|}{ Avarage annual expenditures } & \multicolumn{3}{|c|}{$\begin{array}{l}\text { Average rumber of } \\
\text { beneficiaries per month }\end{array}$} \\
\hline & 1996 & 1997 & 1998 & 1996 & 1997 & 1998 \\
\hline State social benefils: & \multicolumn{3}{|c|}{ in million LVL: } & \multicolumn{3}{|c|}{ in thousands of bemeficidertes: } \\
\hline State social security allowance & 3.28 & 3.27 & 4.16 & 9.92 & 10.43 & 10.86 \\
\hline Child care benefit & 6.50 & 5.68 & 8.17 & 85.40 & 46.75 & 45.40 \\
\hline Family benefit & 30.59 & 30.51 & 30.25 & 540.0 & 522.34 & 499.89 \\
\hline Supplement for disabled children & - & 2.26 & 3.15 & $\infty$ & 7.02 & 7.59 \\
\hline Guardian allowance & 0.75 & 1.00 & 1.14 & 1.96 & 2.24 & 2.51 \\
\hline Foster family allowance & - & - & 0.00 & - & - & 0.002 \\
\hline Guardian benefit & 0.82 & 1.18 & 1.33 & 4.09 & 4.71 & 5,03 \\
\hline Chemolnobl benefit & 0.13 & 0.26 & 0.27 & - & 2.18 & 2.41 \\
\hline Chernobyl transportation allowance & 0.05 & 0.05 & 0.05 & - & 279 & 262 \\
\hline Total state social benefits & - & 46.63 & 52.19 & & & \\
\hline Local social assistance benefils & \multicolumn{3}{|c|}{ in million LVL: } & \multicolumn{3}{|c|}{ in thousands of beneficiaries: } \\
\hline Social assistance benefit & 4.29 & 1.23 & 1.20 & 156.9 & 106.9 & 70.5 \\
\hline Housing benefit & 6.20 & 5.47 & 5.85 & 184.1 & 243.5 & 192.9 \\
\hline Care allowance & 0.03 & 0.04 & 0.07 & 2.3 & 1.4 & 11. 4 \\
\hline Fumeral benafit & 0.47 & 0.50 & 0.52 & 18.3 & 15.8 & 15.0 \\
\hline Allowance for food purchase (cash/kind) & 0.44 & 0.46 & - & 49.6 & 77.0 & - \\
\hline Free meals & 2.41 & 2.68 & 2.68 & 157.2 & 130.3 & 168.2 \\
\hline Allowance for medical service payments & 0.40 & 1.15 & 1.17 & 32.9 & 102.6 & 107.7 \\
\hline Other beneftis & 0.00 & 2.01 & 9.81 & 0.0 & 192.0 & 125.2 \\
\hline Tolal local asisistance belnefits & 14,24 & 13.53 & 13.69 & & & \\
\hline
\end{tabular}

Source: MoW (1999a:Tables 8.2 \& 8.5).

Table 6.4. Distribution of local government expenditures for social assistance activities, 1996-1998 (municipalities and cities:

\begin{tabular}{|c|c|c|c|c|c|c|c|c|}
\hline \multirow[b]{2}{*}{ Yerar } & \multirow{2}{*}{ 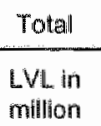 } & \multicolumn{3}{|c|}{ Benefits } & \multicolumn{2}{|c|}{ Home care } & \multicolumn{2}{|c|}{ Institutional care } \\
\hline & & $\begin{array}{l}\text { LVL in } \\
\text { mililion }\end{array}$ & $\%$ of total & $\begin{array}{l}\% \text { of } \\
\text { GDP }\end{array}$ & $\begin{array}{l}\text { LWL in } \\
\text { million }\end{array}$ & $\%$ of total: & $\begin{array}{l}\text { LVL in } \\
\text { milliom }\end{array}$ & tho of total \\
\hline 1996 & 18.45 & 14.24 & 77.2 & - & 0.65 & 3.5 & 3.56 & 19.3 \\
\hline 1997 & 17.73 & 13.53 & 76.3 & 0.4 & 0.71 & 4.0 & 3.49 & 19.7 \\
\hline 4998 & 19.01 & 13,69 & 71.7 & 0.4 & 0.83 & 4.3 & 4.57 & 23.9 \\
\hline
\end{tabular}

Source: MoW (1999a:Tables 8.4, 8.3).

Household Budget Survey data can be used in order to investigate whether social assistance is provided to the families most in need. Again a caveat on the figures applies: the number of families that report to have received social assistance benefits in the sample is limited and data should be interpreted with care. Nevertheless, the distribution of the social assistance benefits (in cash and in

${ }^{4}$ Even various govemnent publications publish different results. For example, the data presented by the CSB (19985:54) are not exactly the same as those presented by the MoW (1999a:88-90). 
kind) over the income deciles can be judged to be relatively trustworthy. The composition of disposable income of households per decile indicates that local social assistance benefits do not reach the target group. On the contrary, average per capita local assistance benefits are highest in the $10^{\text {th }}$ decile (in the highest income-group). This means that the "richest" households receive the highest benefits. This even holds for "humanitarian aid". State social benefits do seem to reach the poor somewhat more effectively, with family benefits being highest in the lowest income deciles (CSB 1997b, 1998a). These observations are confirmed by Milanovic (1999) who analyzed the incidence of social transfers in Latvia using data from the Latvian HBS 1997 and 1998. He concludes that social assistance and unemployment benefits are either neutral or slightly pro-rich oriented, while the only consistent pro-poor transfers are family allowances (p. 4). Assuning an eligibility line of L VL 28 per capita per month, Milanovic further concludes that the probability that a poor persons receives local social assistance is equal to $2 \%$ compared to a non-poor person's probability of $1.4 \%$. It seems that while only a few households receive something, what they receive is substantial. The average recipient household received LVL 26 (p. 10).

The Ministry of Welfare reached similar conclusions in an analysis of a pilot project in the context of the World Bank Welfare Reform project. According to this note (MoW, 1999b) households with children and able-bodied household members are the poorest and receive the least support compared to the pensioners and disabled persons which are wealthier on average and receive more assistance. The MoW concludes: 'Thus, the one who has the most receives the most. (1999b:1).

\section{b) Experiences with the decentralized system}

The decentralization program of 1994 provided the municipalities with full autonomy in spending as well as full responsibility for financing and administering social assistance. The state issues detailed regulations on benefit provision which are rarely employed at the local level. Some municipal benefits outlined by the regulations are "optional" further increasing the confusion at the local level. Although eligibility criteria for the social assistance allowance are set by the Cabinet of Ministers, the federal government cannot force the municipalities to follow these guidelines relying on unfunded mandates.. There are almost no fiscal levers to ensure compliance with central regulations and national program targets are unclear or missing. A recent decree of the Cabinet of Ministers concerning priorities to be given to certain categories of families at the municipal level, for example, was issued and published, but largely ignored by the responsible municipal authorities (Ministry of Welfare, 1997). Little effort was made at the central level to enforce the implementation of the decree.

This municipal autonomy leads to much variety in the national system. Eligibility criteria, benefit levels and application procedures vary between the municipalities. Formal application procedures for social assistance are usually followed in larger municipalities and the cities. But, even then, the amount of information asked from the applicant can vary between one to fourteen pages that have to be filled in. Subjective judgement of applicants is more prominent in small municipalities, where the social worker or the municipal officer responsible for social assistance knows his or her clients personally. Social control determines the right to receive social support. Roles and responsibilities as currently defined lead to an uncoordinated network of 595 local, regional and city offices. Provision of social assistance is characterized by large variation and there is no guarantee that the poor or other vulnerable groups receive the same treatment in different areas.

\footnotetext{
SA detaled account of the workings of a local Social Assistance Office can be found ir Fumee \& Loza (1999).
} 
Families in need may have to apply at several levels of administration for assistance (municipal office, employment office, social insurance office, social care institutions). This may entail that they are sent from one office to the other in search of relief of their need. Each of these institutions has different poventy programs and provides different kinds of services. Communication and administrative links between the various assistance providers are often absent. Nearly absent communication links enhances the chance of duplication of benefits as well as possible fraud. Moreover, there is no way to guarantee equal treatment, quite the contrary.

According to statistics on municipally-administered social assistance benefits aggregated at the regional level, the amount spent in $1996 \mathrm{in}$ each region (city/region) on cash and in-kind benefits per inhabitant ranged from a low of LVL 3.2 in Riga to LVL 12.7 in Ventspils, with a mean of LVL. 6.7. The range increases when benefits are calculated per economically inactive person (as a proxy for regional differences in the number of persons in need) from LVL 6.7 in Bauskas to LVL 29.8 in Ventspils. Moreover, spending patterns across regions suggest an adverse relation: the higher the number of potential persons in need (measured as economically inactive persons) the lower the average spending on each of these persons in the region. Urban areas spend $60 \%$ more per benefit administered per economically inactive inhabitant than rural areas (Goldman, 1997).

The variation that is observed in the disbursement of the benefits can also be seen in the quality of the municipal services. Only $44.6 \%$ of the municipalities have a social assistance office. Often, the offices are not able to provide the full range of assistance as described by legislation and regulations. Staff lack professional training, are owerburdened by the number of services they are expected to provide and the administrative demands they have to comply to and are therefore often unable to develop new forms of social care (only seven of 686 socia], assistance system employees have a social work degree). In the remaining municipalities, the duties are executed by a municipal office, e.g. the secretary (Goldman, 1997).

From an administrative point of view, we have to conclude that the Latvian social assistance system is not very effective in reaching the poor. The variation in benefit provision across municipalities and the discretion with which eligibility and benefit amounts are applied have resulted in a system that is hardly understandable and unfair. The next section will be devoted to the perception of the Latvian population of their social assistance system.

\subsection{Latvian perceptions}

In the third part of the poverty survey, the respondents were asked fourteen questions related to social assistance provided by local governments. We wanted to know i) whether and how people are informed about the existence of social assistance services, ii) whether they apply for assistance in case of need, and iii) their attitude to the local social assistance office. It is important to know whether the lindings on the policy level are confirmed by the inhabitants.

\subsubsection{What people know about local social assistance}

Knowledge about the location of the Social Assistance Office (SAO) in the community gives the first indication of the familiarity with local public institutions. Asked about the location of the local social assistance office (SAO), $68 \%$ of the respondents know where to find it. Still, almost one third does not know where the SAO is located in their municipality. There are considerable differences between urban and rural areas as well as between regions with respect to the proportion that answered the question positively.

The share of the population that is not familiar with the location of the local SAO is larger in urban than in rural areas ( $35 \%$ in urban versus $22 \%$ in rural areas). On the one hand, this can be 
explained by the fact that cities are larger settlements making it more difficult to know the location of all the various institutions. On the other hand, urban households are richer on average and therefore the need for social assistance services may not be that urgent. Anallyzing the same data regionally, Kurzeme has the lowest share of people that do not know the location of their local SAO (16\%). In the region around Riga, this share increases to $41 \%$. The same question has been analyzed in order to check whether certain characteristics of the respondent or of his or her household has an influence on the outcome. We would expect that households with children, pensioners or elderly people are more likely to be aware of the avallability of social assistance services and also of the location of the local SAO since the probability is higher that such a family has applied for a specific categorical benefit.

Table 6.5. Knowledge of the location of the local SAO, in percentages

\begin{tabular}{|c|c|c|}
\hline Household characteristics & Does not know location & Knows lociation \\
\hline \multicolumn{3}{|l|}{ Chilatrem' } \\
\hline with children & 27.55 & 72.45 \\
\hline without children & 32.95 & 67.05 \\
\hline \multicolumn{3}{|l|}{ Elderly } \\
\hline with elderly & 28.50 & 71.50 \\
\hline without elderly & 33.81 & 66.19 \\
\hline \multicolumn{3}{|l|}{ Pension recipients ${ }^{3}$} \\
\hline with recipients & 27.98 & 72.02 \\
\hline without recipients & 34.59 & 65.44 \\
\hline
\end{tabular}

1 younger than 15 years"

260 years and older;

3 households with at least one imember receiving a pension.

Siaunce: Poverty Survey 1998.

Table 6.6. Knowledge of the lacation of the local SAO, in percentages

\begin{tabular}{|c|c|c|}
\hline & Does not know location & Knows location \\
\hline 1. Quintile & 25.56 & 74.44 \\
\hline Ii. Quintile & 25.49 & 74.51 \\
\hline Ifl. Quintile & 29.20 & 70.80 \\
\hline WW. Quintitite & 32.91 & 67.09 \\
\hline Y. Quintile & 41.90 & 518.40 \\
\hline Totar & 31.52 & 618.48 \\
\hline
\end{tabular}

Sotnce: Powerty Survey 1998.

Indeed, the presence of children or elderly persons in a household as well as the presence of pension recipients results in relatively more affirmative answers to the question about the location of the local SAO (see Table 6.5). All differences proved to be statistically significant (Pearson"s Chisquare). As to the characteristics of the respondent herself, women are slightly better informed than men, as are recipients of pensions or other social transfers and those working in agriculture."

From the point of view of the standard of living of households, Table 6.6 shows that a larger proportion of poor households knows where to find the SAO. Familiarify and welfare level are monotonously inversely related. Nevertheless, still more than one fourth of the lowest two quintiles does not know where the local SAO is. We assume that they may also not be informed of the possibility of getting assistance.

This last variable is obvitously closely related to the better score of rural areas in this respect. 
Tabie 6.7. Percentage of respondents giving positive answer, urban and rurall

\begin{tabular}{lccc}
\hline Benefits and services & Urban areas & Rural areas & Total \\
\hline Benefit for people without money & 19.68 & 27.95 & 21.96 \\
Payment of school transport costs & 21.32 & 48.96 & 28.95 \\
Frea iunch at school & 37.40 & 41.86 & 38.63 \\
Assistance to setile debts & 20.29 & 10.77 & 17.67 \\
Provisian of frewood durng winter & 33.84 & 39.04 & 35.27 \\
Provision of other fuel during winter & 15.64 & 07.44 & 13.38 \\
Provision of wheelchairs & 21.31 & 16.53 & 19.99 \\
Assistance to health care payments & 33.95 & 52.52 & 39.07 \\
\hline
\end{tabular}

Source: Powerty Survey 1998

Respondents were also given a list of benefits and services that local SAO's provide, and asked whether they think that the local government can help by providing these various forms of assistance. All presented benefits/services do legally exist in Latvia, which means that people would have a right to receive the services if they fulfill certain requirements. The following tables give the shares of the respondents that answered positively, i.e., they acknowledge or know that the SAO can provide the stated services.

The results as summarized in Table 6.7 are remarkable. There is not one single benefit that more than $50 \%$ of the population is aware of. Considerable differences exist with respect to the various social assistance services and whether people think that they are provided by law. Relatively well known (39\%) is the assistance provided to settle health care payments. In rural areas, $52 \%$ of the respondents are aware of this service. Almost half of the respondents know about school transport in rural areas (only $21 \%$ in urban areas). This is possibly due to larger distances between home and school in tural areas. The provision of free lunches for children at school and of firewood during the cold season belong to the better known services as well. On the other hand, the possibility of receiving monetary assistance in case of need is not very widely known. Only $22 \%$ of the respondents are aware that the SAO could provide cash benefits in case of need. This percentage increases to $28 \%$ in rural areas. The opposite is the case for assistance with respect to debt settlements. These debts mostly concern delays in utility payments. The availability of this service is known by $20 \%$ of the urban respondents as compared to only $11 \%$ in rural areas.

Regional differences are observed as well. Respondents living in Latgale or Rigas region do not seem to be particularly well informed about the possibility of cash benefits or the provision of firewood during winter. Also the assistance with health care payments is not that well-kmown in Latgale. On the other hand, more than half of the households in Kurzeme are aware of this possibility. Kurzeme scores relatively well in most of the provided benefits.

From a welfare point of view (Figure 6.1), we see that respondents of the first quintile, the poorest households, are relatively better informed about the possibility of receiving cash benefits, free lunches for children at school and assistance to cover school transport costs. Nevertheless, the rates remain below the $50 \%$ level. Services such as assistance to settle utility debts or to receive firewood during the cold season are least known among the poorest respondents.

With respect to the educational level, the data confirm that higher educated respondents are better informed than the other groups. Respondents with lower than primary education are least aware of the services the local SAO could offer. The presence of children in a household does affect the information level of the respondent. The proportion of affirmative answers is generally higher than for respondents living in households without children. Obviously, school transport cost benefits and the possibility of free lunch at school score highest ( $40 \%$ and $53 \%$ respectively).

\footnotetext{
Themember that municipalitic have a lot of freedom to apply the law at their owm discretion. The menu of available bemulits and services therefore varies across municipalities (see previous section).
} 


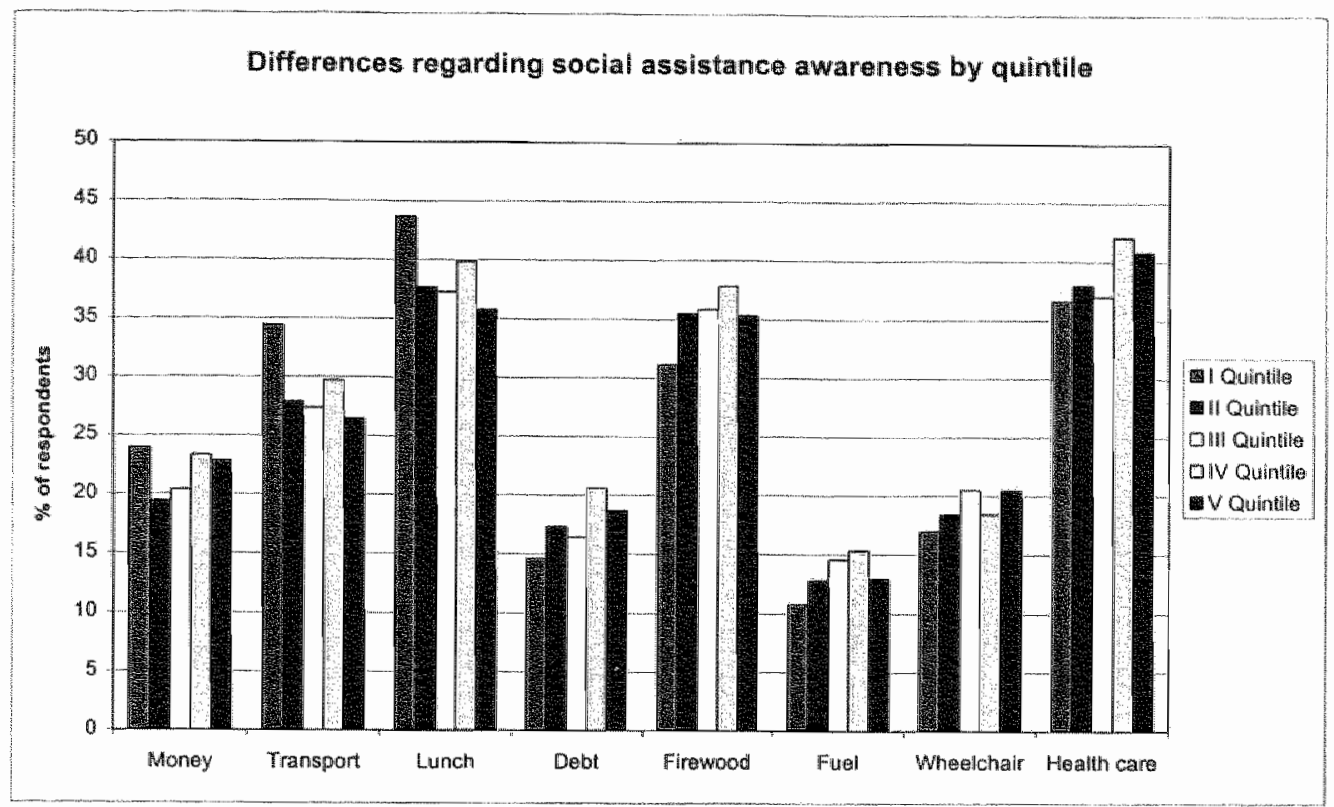

Figure 6.1. Local social assistance benefit awareness, by quintite, in percentages Source: Powerty Survey 1998.

As a final test, we counted the number of benefits for which respondents gave a positive answer. $37 \%$ of all respondents are not certain of any benefit at all, while $4 \%$ are positive about all eight serwices the questionnaire asked about.

In conclusion, it can be stated that people are in general badly informed. The scores that measure the familiarity with a certain type of assistance should be higher. The question is why the information level is rather low. There are several problems involved. On the one hand, the variety of mumicipal benefits may be confusing to the citizens. They do not kmow anymore what is legally possible. On the other hand, local SAO as well as the government are not very effective in informing the public about their rights and about the various ways that social assistance can help them to make ends meet. These arguments are also confirmed by the results of the qualitative assessment (Institute of Philosophy \& Sociology, 1998: $\mathrm{xv}, 42$ ), which state that rules and policies are often unclear to the respondents. Especially urban respondents did not even know where the local SAO was located, or what sort of assistance they could apply for. Poor respondents complained that it was difficult to get clear information about entitlements and rights.

\subsubsection{Where people get information about local social assistance services}

Based on the previous results, it is not surprising to find out that $20 \%$ of the respondents say they have no information at all. There is hardly a difference between urban (20\%) and rural (21\% areas), but the data show, that regional differences are significant. Only $13 \%$ of the respondents in Kurzeme indicate that they have no information at all. In Vidzeme, the proportion is $15 \%$, which is still below the national average. Riga has the highest share of uninformed inhabitants. $24 \%$ respondents of the region around Riga do not have any information at all (Zemgale: $21 \%$; Latgale: $19 \%$ ). Considering the various quintiles, the richest households, i.e. those who are supposed to need SA services least, also have the largest proportion of uninformed respondents ( $26 \%$ ). There are no large differences between the remaining quintiles, which all have approximately $18 \%$ of 
respondents with no information. Again, the presence of children or pensioners in a household increases the possibility that a household has some information.

The most "popular' information source the social network. $37 \%$ of respondents indicated that they get information on local social assistance services from "what other people say", followed by newspaper (20\%) and family/friends (16\%). There are considerable urban-rural differences. In rural areas the information received through 'other people's discussions' is even more important. This is also true for the poorest households and for households without childrem. Television has a more prominent role in urban areas and is also more important for respondents with higher education.

Table 6.8. Sources of information on social assistance serwices, various breakdowns, in percentages:

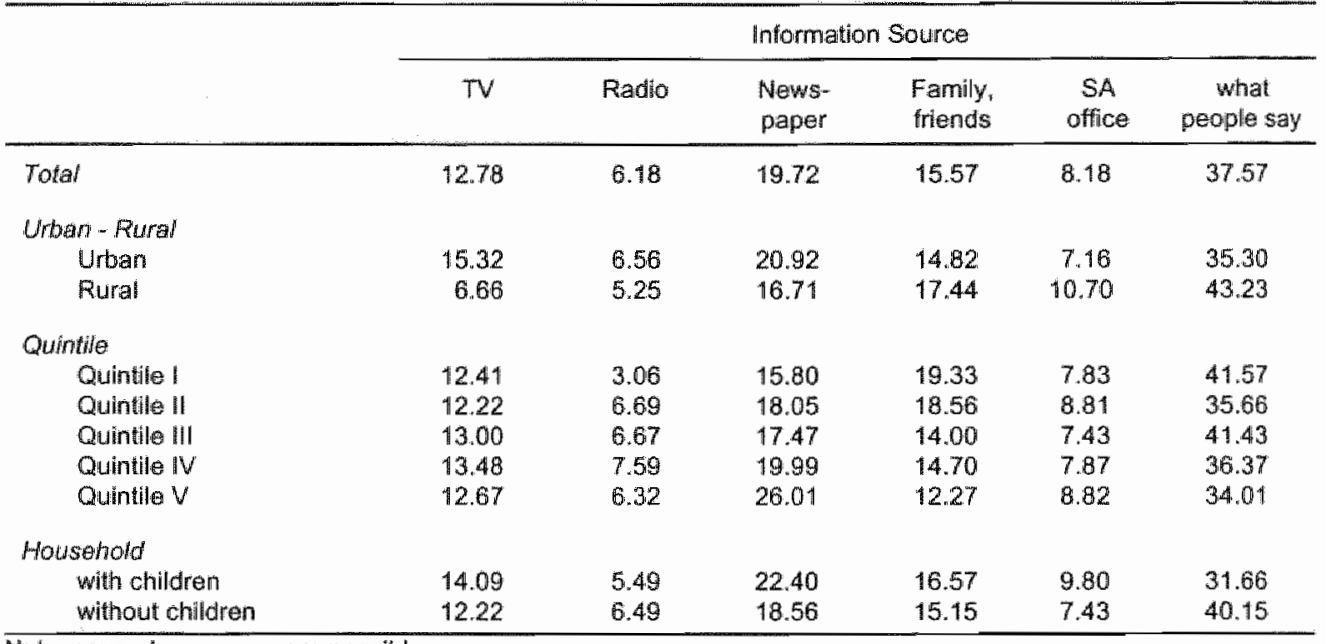

Note: several answers were possible

Source: Poverty Survey 1998.

Table 6.9. Reasons why respondents never wisited the SAO, in percentages

\begin{tabular}{|c|c|c|c|}
\hline & \multicolumn{3}{|c|}{ Position with respect to SA services } \\
\hline & SA was neweir necessary & $\begin{array}{l}\text { SA needed, but I did not } \\
\text { apply }\end{array}$ & $\begin{array}{c}\text { I need SA, but I will } \\
\text { not apply }\end{array}$ \\
\hline \multicolumn{4}{|l|}{ Urban - rural } \\
\hline Urbetn & 59.32 & 16.46 & 24.22 \\
\hline Rulital & 68.65 & 12.56 & 18.79 \\
\hline \multicolumn{4}{|l|}{ Rogions } \\
\hline Rigas rogion & 59.05 & 47.12 & 23.83 \\
\hline Kurzerme & 70.54 & 15.76 & 13.70 \\
\hline Vidzome & 73.04 & 7.07 & 19.89 \\
\hline Zemgale & 70.09 & 94.85 & 15.06 \\
\hline Latgalle & 51.25 & 15.91 & 32.84 \\
\hline \multicolumn{4}{|l|}{ Qundile } \\
\hline Quintlite & 49.17 & 17.93 & 32.90 \\
\hline Quintile II & 51.86 & 16.83 & 31.31 \\
\hline Quintile $\|t\|$ & 53,20 & 19.63 & 27.16 \\
\hline Quintile lV & 66.43 & $\Uparrow 4.81$ & 18.76 \\
\hline Quintile $V$ & 76.57 & 10.23 & 11.19 \\
\hline Total & 61.97 & 15.35 & 22.67 \\
\hline
\end{tabular}

Source: Poverly Survey 1998 
The SAO's also score better in rural areas as far as the information of people is concemed, and with the higher educated respondents. Nevertheless, the SAO itself is not very effective in informing the population. This coincides with the findings of the qualitative assessment, where only few people reported receiving information from the $\mathrm{SAO}$ staff. Their main source of information was friends and acquaintances (Institute of Philosophy \& Sociology, 1998:42). Almost half of the respondents $(46 \%)$ know someone who received assistance from the SA office during the last twelve months. In rural areas, the percentage increases to more than half $(52 \%)$. In $17 \%$ of the cases it is a family menber, in $17 \%$ it is a neighbor, in $32 \%$ someone they know and in the remaining cases (34\%) strangers whom they heard had received assistance.

\subsubsection{Visitors and non-visitors}

Only $18 \%$ of the respondents confirmed that they had paid a visit to the local SAO during the last twelve months. $15 \%$ visited the office more than a year ago, and $67 \%$ of respondents have never visited the SAO. From a poverty point of view, the trend is as expected although the proportion of the poor that visited the SAO remains rather low: the lower the quintile, the higher the share of households that had visited the SAO. Onlly $23 \%$ of the poorest quintile versus $9 \%$ of the fifth quintile visited the $\mathrm{SAO}$ during the last year.

Those that had never visited the SAO were asked about the reason (see Table 6.9). 62\% indicate that it had not been necessary for them to apply for social assistance, i.e they did not visit because there was no need. "The share is lower in urban than in rural areas, and is lowest in Latgale and for the poorest quintile.

The more interesting figures are the ones representing those households that did not apply - or do not apply - although they could use assistance. Almost $25 \%$ of the urban households could currently use assistance, but do not go to the $\mathrm{SAO}$. In rural areas this percentage is $19 \%$. From a regional point of view, Table 6.9 shows that especially households in Latgale that need assistance do not apply for it. As will be shown below, a majority of respondents in Latgale thinks that the SAO will not provide assistance to them. In addition, the attitude towards the SAO is also least positive in Latgale (see below).

An interesting picture emerges when the question is analyzed by level of welfare. Even in the lowest quintile, almost half of the households indicate that they do not need assistance from the local SAO because it is not necessary. One third of the lowest quintile households need social assistance but will not apply for it. On the other hand, there are still $11 \%$ of respondents in the richest quintile that indicate that they could use assistance.

Table 6.10. Reasons why people do not apply for assistance from SAO im case of ned in percentages

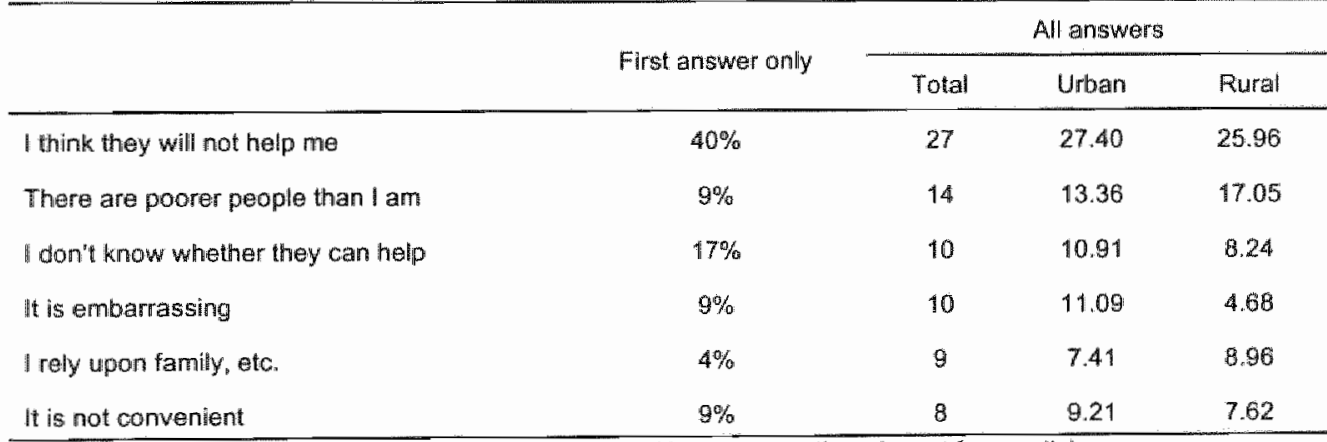

Mote: only six out of 14 possible answers are presented (the ones mentioned mosti frequently).

Source: Poverty Survey 1998. 


\begin{tabular}{|c|c|c|c|c|c|c|}
\hline & \multirow[b]{2}{*}{$\begin{array}{l}\text { Sample } \\
\text { size (N) }\end{array}$} & \multicolumn{5}{|c|}{ Applications for the following assistance } \\
\hline & & $\begin{array}{l}\text { General } \\
\text { benefilt }\end{array}$ & $\begin{array}{c}\text { Child } \\
\text { buenent }\end{array}$ & $\begin{array}{l}\text { Health } \\
\text { services }\end{array}$ & $\begin{array}{l}\text { Covering } \\
\text { debts }\end{array}$ & mokind \\
\hline \multicolumn{7}{|l|}{ Urban- Riral } \\
\hline Urben & 691 & 44.96 & 36.07 & 17.61 & 16.86 & 8.53 \\
\hline Purat & 318 & 40.51 & 43.54 & 19.33 & 6.61 & 10.31 \\
\hline \multicolumn{7}{|l|}{ Quirthe } \\
\hline Quintile & 269 & 45.71 & 54,40 & 10.60 & 16.12 & 10.20 \\
\hline Quintile 11 & 240 & 40.56 & 42.36 & 18.67 & 13.59 & 9.14 \\
\hline Quintille Iti & 986 & 46.99 & 29.11 & 20.55 & 11.11 & 8.14 \\
\hline Quintite IV & 189 & 49.21 & 24.23 & 22.08 & 15.25 & 8.48 \\
\hline Quintile $V$ & 125 & 33.60 & 37.14 & 49.70 & 14.43 & 8.82 \\
\hline \multicolumn{7}{|l|}{ Household } \\
\hline with children & 488 & 32.04 & 77.89 & 8.35 & 9.51 & 5.49 \\
\hline wo children & 521 & 52.69 & 7.94 & 25.40 & 17.65 & 11.66 \\
\hline Total & 1009 & 43.80 & 38.05 & 18.07 & 14.15 & 9.01 \\
\hline
\end{tabular}

Source: Powerty Survey 1998.

Table 6.12. Receipt of the requested assistance (in percentages)

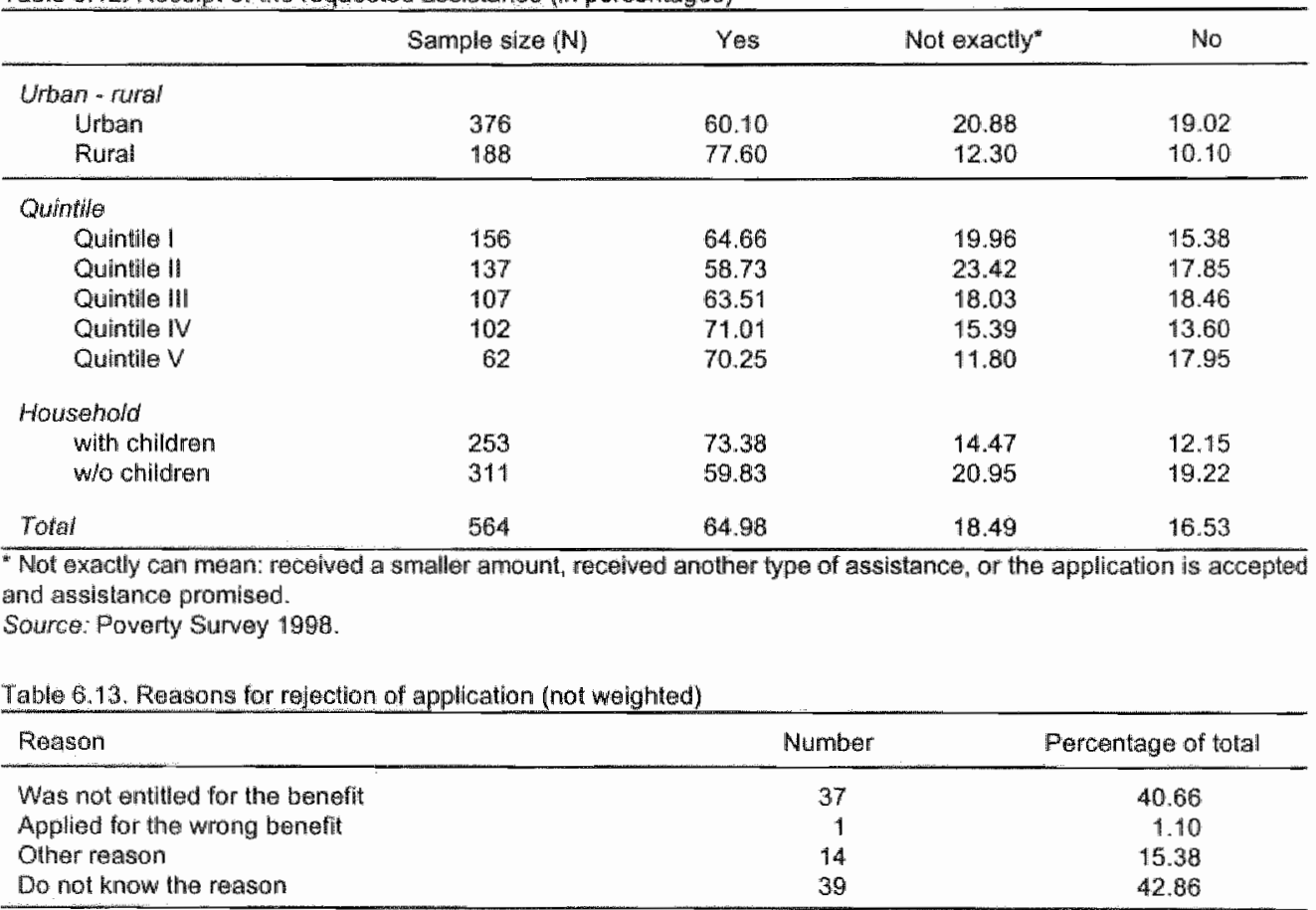

Source: Poveirty Surwey 1998.

As for the reasons why people do not apply for assistance although they need it (or could have used it in the past), the statements in table 6.10 were most popular (several answers were possible). The main reasons are related to a lack of information. The answers " $T$ think they will not help" and 'I don't know whether they can help', which were mentioned most frequently as a first answer, indicate that people have hardly an idea about their rights or the possibilities the local SAO have 
10 assist them in case of need. The former question especially also reflects some kind of resignation, of some lost faith that the state could or would heip them. There are some differences with respect to urban and rural areas. Urban respondents answered more often that they find it embarrassing to apply for social assistance (11\%), while rural respondents more often think that there are even poorer people (17\%). These positions are confirmed in the qualitative assessment which states that "... many respondents found asking help from govermment institutions to be "demeaning" and perceived it as a form of begging", and "even respondents that appeared badly in need of assistance explained they had not applied because they felt others were "even worse of than they" (Institute of Philosophy \& Sociology, 1998:43).

\subsubsection{Social Assistance visitors and the benefits they apply for}

Turning now to the respondents that have visited the local SAO in the past $(n=1009)$. This section will investigate the various benefits they applied for and whether the benefits were granted. Of those that wisited the $\mathrm{SAO}, 44 \%$ applied for a general benefit (family, guardian's, transport, funeral, social assistance, apartment or other benefit). The percentage is slightly higher in urban areas (45\% versus $41 \%$ in rural areas). Up to the fourth quintile, the shares do not vary that much, although the fourth quintile has the largest proportion of households applying for such benefits. In the fifth quintile, representing the wealthiest households, $34 \%$ had applied for general benefits before (note: only of those that indicated that they had visited the SAO office?).

With respect to child benefits, $38 \%$ of the SAO visitors applied for such benefits. In rural areas, the proportion is $44 \%$ compared to $36 \%$ in urban areas. Analyzing by welfare level, Table 6.11 shows that a majority of households in the poorest quintile applied for child benefits. This could be related to the fact that a higher proportion of these households have children, entitling them to child benefits that are mostly universal benefits. It is also consistent with Milanovic"s findings (1999) that family and child benefits are reaching the poor more effectively. Most applications for general benefits were to receive an apartment allowance ( $52 \%$ ), followed by family and social assistance benefits (both 13\%). Next to child benefits (universal), applications for free lunches at school were asked for by $18 \%$ of the applicants for child benefits.

$65 \%$ of households were granted the requested assistance, $18 \%$ received less, or something else or were still on hold, whereas in $17 \%$ of the cases the application was rejected. The difference between urban and rural areas is considerable in all categories, with a higher share of assistance granted in rural areas. 92 respondents indicated that they did not receive assistance.

The fact that 39 households (more than $40 \%$ ) do not know why they did not receive the requested assistance is rather disturbing. It indicates again that the communication between the local $\mathrm{SAO}$ and the public could be improved.

The benefits most often provided are state benefits (283) followed by social assistance benefits in cash (111 'money') (see Table 6.14). There are some urban-rural differences with respect to the importance of the various benefits. In rural areas, state benefits ( $44 \%$ of all benefits in rural areas) and money (22\%) are relatively more often provided than in urban areas (resp. $37 \%$ and $11 \%$ ). Assistance for the payment of rent or other bills (either in the form of money or direct payment by $\mathrm{SAO})$ seems more important in urban areas $(20 \%)$ than in rural areas $(5 \%)$.

As far as the number of times a benefit is payed is concerned, Table 6.14 confirms that state benefits - if received- are payed monthly $(\mathrm{m}=10.45)$. On the other hand, 'money' assistance is a once-off benefit, as seen from the data $(\mathrm{m}=1.33)$. We also see that Milanovic"s findings are confirmed. While the number of beneficiaries is relatively small, the size of the allocated benefits is relatively large (Milanovic, 1999). 
Tabia 6.14 . Provision of benefits: number of thes, yearly value and average size

\begin{tabular}{|c|c|c|c|c|}
\hline Benefit & $\begin{array}{l}\text { 教 thimes benefit } \\
\text { is mentioned (n) }\end{array}$ & $\begin{array}{l}\text { average } \text { t of } \\
\text { times benefit } \\
\text { received (m) }\end{array}$ & $\begin{array}{c}\text { estimated yearly } \\
\text { value of benefit } \\
(y)\end{array}$ & $\begin{array}{c}\text { average size of } \\
\text { one benefit } \\
(y \mathrm{~m})\end{array}$ \\
\hline State benefit & 283 & 10.45 & 135.67 & 24.49 \\
\hline Money & 111 & 1.33 & 38.46 & 30.87 \\
\hline Food vouchers & 14 & 5.71 & 42.99 & 10.33 \\
\hline Food in kind & 2 & 1.00 & 7.15 & 7.15 \\
\hline Fireo lundh & 64 & 3.78 & 50.85 & 36.70 \\
\hline Filfewood/fuel & 32 & 1,00 & 27.51 & 27.51 \\
\hline Payment for heating & 27 & 2.52 & 32.44 & 25.35 \\
\hline Monoy for rent, other bills & 61 & 2.25 & 64.79 & 44.68 \\
\hline SAO paid rent, other bilis & 39 & 1.7 .4 & 59.72 & 49.88 \\
\hline Day carra for elderly & 2 & 1.00 & 118.00 & 118,00 \\
\hline Transport services & 22 & 5.86 & 44.12 & 20.56 \\
\hline Other & 50 & 1.94 & 54.55 & 41.40 \\
\hline
\end{tabular}

Sourco: Powerty Survey 1998

Table 6.15. Attitude towards local $\$ A O$ by household characteristics

\begin{tabular}{|c|c|c|c|}
\hline Household characteristics & Index & Household characteristics & Index \\
\hline Urban-ruka! & & Household & \\
\hline Urban & 6.31 & with children & 7.32 \\
\hline Rural & 8.77 & without children & 6.72 \\
\hline Regions & & Quintile & \\
\hline Rigas region & 6.47 & Quimtile & 6.75 \\
\hline Kurzeme & 7.00 & Quintile |I & 6.90 \\
\hline Vidzeme & 7.76 & Quintile III & 6.99 \\
\hline Žemgale & 8.54 & Quintile 1V & 6.79 \\
\hline Latgale & 6.19 & Quintile $\mathrm{W}$ & 7.08 \\
\hline Household size & & Number of chilldren & \\
\hline one person & 6.98 & One child & 7.04 \\
\hline two persons & 6.44 & two children & 7.62 \\
\hline three persons & 7.23 & three children & 7.41 \\
\hline four or more & 7.15 & four or more & 10.61 \\
\hline Pension recipients & & Social transfer recipients & \\
\hline with recipierits & 7.09 & with recipients & 7.43 \\
\hline without reciplents & 6.75 & without recipients & 6.89 \\
\hline Tolal & 6.91 & & \\
\hline
\end{tabular}

Source. Poverty Survey 1998.

\subsubsection{Attitudes towards the local Social Assistance Office}

All respondents were confronted with statements describing local social assistance (Likert-type scale). All the answers together say something about the attitude towards the local SAO and its services. A reliability analysis proved the scale to be relevant (alphat $=0.88$ ). Based on the questions ranging from friendliness of staff, efficiency of the service to questions of prejudices against certain population groups, a positivity index has been created in order to compare the attitude towards local SA in various regions and among different groups. A household received one point for each positive answer to the $2 \rrbracket$ questions on the local SA service. Households that answered all questions with "I don't know" were excluded (1084). One of the remaining 1969 households had the maximum score of 21 . The weighted average score is 6.9 .

Respondents in rural areas are more positive about SA services than those living in urban areas. Inhabitants of Zemgale score highest compared to the other regions, while Latgale has the lowest score. From the weltare point of view, Table 6.15 shows that the poorest quintile has the lowest 
ex value and the richest quintile the highest. Note that all respondents have been asked regardless whether they have ever visited the office before. Assuming that fewer respondents of the fifth ntile visited the office, their score is based mainly on opinion and belief. The qualitative essment indicated that SAO staff have prejudices against certain groups of households. For mple, families with many children felt that they were treated badly. Based on the results from s survey, the reverse has to be concluded; the attitude towards local SA improves with the nber of children. The same is true with respect to household size, and households that have mbers receiving either a pension or social transfers are also more positive towards the SAO.

\subsection{Conclusion}

e results presented in this section indicate that the Latvian social assistance system is currently $t$ very effective in reaching and helping the poor. The information level of Latwian households th respect to local social assistance is rather limited. There is a real task for central and local vernments to improve their communication with the public. Currently, this is no easy endeavor asidering the fact that the system is very complicated and diverse. Almost every municipality uld have to advertise different benefits and services. This also explains why the Latvian pulation does not know what to expect from local social assistance. A significant part of the pulation has lost confidence in the state itself and its willingness and ability to help the citizens. te people are rather pessimistic, and some seem resigned. A simplified system would be more mmunicable, better understood by the public, and easier to implement and monitor. Scarce funds unld be better allocated, thus increasing the efficiency of the system, and eventually re-building ist among the population.

\section{Evaluation of the situation and first attempts towards a solution}

te previous two sections provided two points of view with respect to the Latvian social assistance stem. First, the institutional side, the state, was highlighted and, secondly, the clients provided look from another angle. Both approaches gave a rather somber impression of the current state of ciall assistance policy. The system is too complicated, unstructured and confusing. Transparency lacking. Local governments have no incentives to implement the existing laws and regulations such a way that the system would be effective and reach the poor. It is on the one hand due to a ck of funding but on the other hand, has to do with priorities. The citizen is confused, uninformed, nbarrassed, does not trust the political institutions, and does not expect any help from the state. ne poor do not tum to the state for help out of ignorance and resignation.

Subsequently, some of these issues are discussed in more detail. The lack of transparency and fectiveness, missing incentives and the problems of a decentralized administration are some of e main policy issues. Besides a short evaluation of the problem, some first attempts towards a sssible solution are part of the discussion. The reader will soon notice, that a simplification of the call social assistance benefit system is at the start of the solution of almost every problem entioned. The final section of this chapter will pick up on this point with an elaborate policy oposal.

\section{Transparency and effectiveness for the clients}

he major problem for social assistance delivery in Latvia is the complexity and the lack of ansparency of the existing laws, regulations, arrangements and decrees. The system is built aphazardly, largely reacting to immediate needs or social and political pressure. The decentralized istern is far from transparent. Clients do not know their rights and get lost in a labyrinth of 
regulations and laws: the accessibility of the system is troublesome. There are too many arrangements and the benefit programs are too fragmented. An emergency procedure is lacking and there is no opportunity for immediate response to critical situations.

The first and most important policy step is to simplify the benefit structure in order to better meet the intention of establishing an effective safety net. The logical second step is to consolidate municipal social assistance operations in order to improve more services with the aim of realizing economies of scalle in provision. The most desirable option for the clients would be to have a singte counter at the local level where their needs can be addressed. Apart from these changes, procedures and forms should be simplified and harmonized. The client should be able to think in terms of his/her rights and should be assisted in order to obtain the safety net provisions as foreseen by the law.

Evidently, this is not the type of operation that is easy to carry out. It is clear that the central government level bears the basic responsibility for the development of this policy reform, but it is also obvious that (revealed) stakeholders in the existing system may effectively block changes in the system. The current government activities in this respect are encouraging. The content of the White Paper (MoW, 1997b) and the related Business Plan (MoW, 1997a) should be seen as first steps towards policy changes. Given the fact that the outcome of the process will also depend on the, still uncertain, results of the territorial-administrative reform, it is very difficult for the government to make spectacular progress in that respect. The pilot-project in Kandava under the World Bank Welfare Reform Project (The World Bank, 1997b) is of crucial importance in this context. This pilot will teach the local and central governments how a transparent system for clients may be implemented. Revision of the legislation, however, is something that should be prepared. at the central level envisaging the implementation of a simplified system immediately after the administrative reform is completed.

\section{b) Incentives}

The non-transparency of the existing system results in irrational use of the welfare provisions in general and hides some avoidable incentive problems both for clients and providers. Some of the social assistance programs in Latvia can actually deter individuals or families from exiting poverty. The benefit structure, which potentially brings families to $100 \%$ of the minimum income level, may be an important disincentive to work in so far as each Lat of income earned will result in a corresponding drop of one Lat in benefit. Again the first step is to coordinate benefits. Instituting benefit reduction rates by introducing an earned-income disregard should be considered: each Lat of eamed income should result in only a partial loss of benefit.

On the level of the providers the existing system fails to provide incentives to improve the quality of the services or to realize cost-effective utilization of resources. The major problem is the division of labor between the central authorities and the municipalities. Although this is discussed under the next heading, it should be noted here that the problem of cost-shifting may occur whatever new arrangement may be worked out. Every layer in the administration will try to shift the costs for the implementation of social assistance to another level, whenever responsibilities are not clearly defined. Unfunded mandates as found today under the Latvian system are an invitation to either ignore the central legal requirements or to shift the costs to another part of the administration. Simplifying the benefit structure and consolidating its financing again are crucial in this respect.

Moreover, as already pointed out in the White Paper of the Ministry of Welfare, the new system should no longer discourage NGO's and private providers to contribute to the organization of a true social safety net. Municipalities on the other hand, should be stimulated to organize alternative forms of social care, directed towards both reintegration and self-dependency and ensuring a more cost-effective and dignified implementation of this type of provision. "The way that the assistance 
System is structured and financed has an impact on benefit and service delivery in ways that are not intended by the drafters of the legislation. For example, municipalities have incentives to place individuals in state financed institutions in order to conserve their own resources for other expenditures. The legislation does not allow for the coordination of cash assistance to the disabled, children at risk (locally financed and administrated) and the poor with non-cash forms of social care (centrally financed and administrated). However, this issue is also linked to the centralizationdecentralization issue discuissed in the next section.

\section{c) Centralized versus decentralized administration}

Many problems indicated above are linked with the issue of the definition of central versus local responsibilities in social assistance provision. The issue could be discussed at length trying to spell out the arguments in favor of either organization. Given the actual Latvian policy choices made, it is however more fruitful to take the local organization of the social assistance implementation as a starting point and then investigate what should be done in order to make the system function as well as possible.

The uncoordinated nature of the system and the poor information linkages between the agencies and regions mean that information and accounting systems are not compatible and of limited utility for monitoring benefit administration. In this context again simplifying and streamlining of the benefit structure is the most important need. Without such an operation it is hard to see how municipalities will be motivated to collaborate on the strict implementation of the law. The next step is to secure the financing of the system, taking the decentralized organization as the starting point.

As indicated above, the main problem in the financing is the fact that not enough resources are devoted at the local level to the implementation of the centrally defined social assistance legislation. Other expenditures of the municipalities are crowding out the resources necessary for social assistance. Linking resources directly with responsibilities is not easily organized without opening the incentives for cost-shifting. Shifting responsibilities from the local to the central level would solve this problem but would require an unlikely major policy switch and would introduce the problem of the physical distance between the clients and the decision level. One way to guarantee the implementation of the legislative intentions, is to organize a serious adjudication procedure for the clients (discussed in the next section). At the central level the so-called equalization fund can be used to regulate money-streams according to the needs when the municipalities (partially) fail to implement the obligations towards their clients.

\section{d) Adjudication}

The definition of social assistance as a right of assistance for the population is a crucial step in organizing an effective social safety net in Latvia. Today, there is an appeal possibility with the central administration, but very few people use this possibility, despite the unequal treatment across the country. Lack of information is probably the most important reason, but there are others.

Given the actual division of responsibility for social assistance implementation between the local and the central level, given the budgetary autonomy of the municipalities and given the underdeveloped status of the legall infrastructure in the country (i.e. lack of lawyers), a clear and simple procedure should be worked out to appeal to decisions made at the local level. The adjudication procedure should have two steps: one administrative with a regional or central body and a court appeal procedure. The first step should be simple and easily accessible.

The organization of this procedure is not only important for the clients, but it is probably the only instrument to force the municipalities to allocate sufficient resources to social assistance. However, its introduction is (again) only feasible after a simplification of the benefit system. 


\section{e) Social policy monitoring and evaluation}

Although policy monitoring and evaluation is a priority for the Ministry of Welfare, actual efforts are still in their infancy. The effectiveness of spending on social assistance is poorly documented at present. Policy improvements will require an improved monitoring and evaluation system providing Govemment and Parliament with crucial information needed for their decision-making activities.

At the level of the system, the Ministry of Welfare is developing a monitoning device to picture the effects of all policy actions taken. Within the World Bank Welfare Reform Project an elaborated applied training program in social policy monitoring and evaluation is being organized. In the program civil serwants as well as data prowiders and researchers are trained in social policy research activities. The ministry prepares a yearly Annual Social Report in order to publish their progress in this field and in order to feed the debate on social policy within the country.

At the level of the administrative communication between the central and locall level, a pilot project has started linked up with the Kandava social services program mentioned above. The aim of the pilot is to develop an administrative communication system that would allow the central level to monitor the implementation of social assistance policy at the local level and that would provide the local level with information and assistance in applying the centrally designed system.

At the municipal level finally, a client tracking and monitoring system will be developed within the Kandava pilot project. It is clear that the efforts on the three levels are linked with each other.

The picture that emerges when summarizing the developments of social policy in Latvia is certainly that of a system in transition. The approach clearly has changed since 1991 , but the changes are ongoing and it is not yet clear how the situation will look when the transition matures into a more stable situation. It is even more difficult for the citizens to keep track of all the changes and to know the rights and possibilities valid at a point intime. The frequent changes contribute to a large extent to the uncertainty of the population and 'support' feelings of resignation and the loss of confidence. A lot of observations are puzzling, but the will of the policy makers to develop an intemally consistent and externally viable system, is outspoken. The White Paper on Social Assistance published by the government (Ministry of Welfare, 1997b) reviewed the problems and set policy objectives in order to improve the situation. The administrative reform is continuing, and the Ministry of Welfare is seriously thinking about a new benefit system. The next section will provide input to this latter objective and propose a simplified benefit system. ${ }^{8}$

\subsection{Keep it simple but effective}

Before we start with introducing a proposal to revise the local social assistance benefit system in Latvia, we consider first the objective of social assistance system as well as the ingredients necessary to make a system successful.

The aim of social assistance benefits is usually to provide those families that are not able to generate sufficient income to make ends meet with support. ${ }^{9}$ It is immediately obvious, that this goal contains at least two concepts which need to be defined. What is support, and what is sufficient income to makke ends meet. The latter refers to a poverty line or minimum income line considered to be necessary to cover the most basic needs in a society. Support, on the other hand, can relate to the form, in-cash or in-kind, or to the amount of support provided. Sipos (1994) distinguishes between two types of social assistance policies: i) type A policies that aim to prevent poverty, i.e.

\footnotetext{
${ }^{8}$ By the time of writing, the Latvian government had already taken the decision to implement the proposed system.

SSee, e.g., the Law on Sacial Assistance in Latvia (MoW, 1998).
} 
they would support families up to the "sufficient income" level; and ii) type B policies that aim to cure the most extreme poverty by reducing the poverty gap, i.e. they support a family up to a fraction of the "sufficient income" level. Type A policies are hardly affordable in CEE and FSU countries, wnless the subsistence level is set at a very low level. ${ }^{10}$ Type B policies require at least three additional decisions: the size of the gap to be eliminated, the groups that will be supported, and whether specific needs are emphasized or not (Sipos, 1994:237). Type B policies can be the result of a government decision of only supporting families up to a certain level in order, for example, to stimulate labor market participation, or it can be out of pure necessity due to insufficient funding for a type A policy. The latter is characteristic for many CEE and FSU countries and it is the case for Latvia as well. For a better distinction between the two purposes a third type should be added for policies that are truly budget-driven. A type $C$ policy would then ask "how much of poverty can we afford to eliminate." This third type of policy will underlie our proposal for Latvia below.

Several authors identified ingredients for an effective and efficient social assistance system for countries in transition. According to de Neubourg and Morris (1999:36), a viable social assistance system in CEE and FSU transition countries consists of the following five main elements:

- streamlining all existing social assistance benefits into a single means-tested basic benefit;

" guaranteeing universal child benefits;

- smoothing the transition from subsidized to market prices for basic goods and utilities;

- defining a benefit and guaranteed access to health services for life-time disabled;

- discouraging institutional care and where unavoidable guarantee sufficient funds.

Sipos provides more comprehensive, though more general, characteristics of a workable social assistance system: "... it should be universal (eligibility should not depend on whether a person is in the work force); it should provide an acceptable level of income (the exact level of which will depend on whether a type A or a type B policy is being pursued); it should be flexible; it should be simple to understand and administer; and, to the maximum extent consistent with political realities, it should have a national framework. ... the legislative framework should be national; implementation could be locial ' (1994:251f). UNDP (1999) stresses again other aspects of social policy that are indispensable for an effective social assistance system: a professional public administration, mechanisms to monitor and evaluate the policies, clear objectives of what the system should (and can) achieve, and the involvement of non-governmental organizations (NGO's) to support the implementation of state policies.

Some of these issues have already been discussed in the previous section where we discussed policy issues of Latvian social assistance. The country has already embarked on an administrative reform, which will also contribute to the professionalism of the administration, and the Ministry of Welfare started with the development of a montioring and evaluation system. The main objective of this section is to propose an altemative for the current system of local social assistance benefits in order to streamline the benefit provision throughout the country.

\subsubsection{Introducing a Unified Monthly Benefit (UMB)}

The discussion on the simplification of the Latvian social assistance benefit system started already some time ago." So far, the eligibility criteriat have been the main target of simplification efforts

\footnotetext{
Which makes the term 'subsistence' redundant.

"The Latvia Welfare Reform Project of the World Bank started in 1997. One componemt (Component 3) ils dedicated to whe reform of Social Assistance provision in the country, aiming at the improvertent of the development and
} 
leaving the benefit structure as such intact. We argue in this section for a simplification of the various local benefits that are currently available. We also argue for a budget-driven minimum income line that determines eligibility for means-tested benefits. The intention is to make the system transparent, fair and effective. The basic aim of the reform is to provide a basic social assistance scheme for the poorest part of the population. It has to replace the numerous municipal benefits and privileges that currertly exist and that try to channel assistance in cash and in kind to families in need. In addition, the system has to be financially sustainable.

\section{a) Recapitulating the current system}

The current system of local social assistance is very complicated and not transparent. Many different benefits exiat next to each other. The menu of benefits and services varies between municipalities. What is provided in cash in one municipality may be provided in kind or not at all in another municipality. Local officials have decisive power in determining eligibility rules as long as they are within the boundaries of the social assistance law. Nevertheless, arbitrariness with respect to eligibility decisions easily enters the system due to this authoritative power.

Social assistance should provide a safety net to the poor and wulnerable in a society. In section 6.4 we have shown that people do not know their rights. Only about one fourth of households of the lowest income quintile (the poorest $20 \%$ of the population) is aware of the fact that the local Social Assistance Office (SAO) has the right to provide cash to people without money. The system needs to be improved since the results of the actual practices are not wery satisfying in another respect as well. Through the existing regulations a lot of resources are allocated to the less needy parts of the population as has been shown in section 6.3. The analysis of the Household Budget Survey data shows that even households of the highest deciles are receiving local social assistance benefits. In 1998 , households of the tenth decile (the $10 \%$ richest households) received on average $0.56 \mathrm{LVL}$ per capita per month local social assistance, while households of the poorest decile received only 0.07 per capita per month (CSB, 1999c). Compared to the results from 1997, the situation has since worsened. In 1997, the poorest households received $0.13 \mathrm{LVL}$ per capita per month and the richest ten percent received $0.31 \mathrm{LVL}$ per capita per month (CSB, 1998a). The richest households do indeed successfully apply for social assistance services (see section 6.4). This is partly because the menu of social assistance services and benefits is very extensive, varying from cash assistance to the provision of a wheel chair and assistance in paying for health services (to mention only a few).

The basic idea for reform is to replace most of the existing local benefit schemes with a single benefit targeted towards to poorest part of the population. It is meant to be a temporary form of assistance to families in need. Such a unified monthly benefit is easier to administer and to communicate. $^{12}$

\section{b) The concept}

The new benefit introduces a Guaranteed Minimum Income (GMI). ${ }^{13}$ It is an income level below which no family should fall. If a family has fewer resources than the guaranteed minimum income, public authorities (be it the state or the municipalities, or both) provide a benefit up to the level that would bridge the gap between the actual resources of the family and the GMI. It is important to note that the GMI is not a poverty line. The GMI is the income that the public authorities can guarantee

inplementation of social assistance policy at the central level and the development of community based social services at the local lewel (The World Bank, 1997b).

\footnotetext{
${ }^{12}$ Note again that we do not talk obout state benehts. Only the local social assistance benefits are at stake.

Wote: the GMI here is not defined as the one used in Milanovic (1998) or Sipos (1994). The GMI as used in this section is not by definition equal to the subsistence inoome level. It is set according to other principles (see below).
} 
in the light of the state of the economy and the budgetary situation of the state and/or the municipalities. ${ }^{14}$

The starting point is not to define how much a family should have in order to survive, but how much the budget can afford to guarantee as a minimum income to the population, i.e. the GMI is budget-driven. This is an essential point for severall reasons:

i) It is unrealistic to assume that Latvia could afford to guarantee a minimum poverty standard that would cover basic needs (i.e. rights driven).

ii) Poverty lines are never undisputed. There is no correct way to set a poverty line and thus there will always be political pressure on the government to set a higher poverty line.

iii) The income distribution of middle income countries and especially of transition economies is so compact in the lower eight deciles of the income distribution that small measurement errors in setting the poverty line or seemingly small increases in the level of the poverty line due to political decisions, may and will almost certainly have huge consequences both in terms of the number of families falling below the poverty line and in the budget needed to guarantee the poverty line. This is also the case in Latvia.

Figures 6.2 and 6.3 present the welfare distribution in Latvia in 1997 according to the HBS data. Figure 6.2 shows that the Latvian distribution is rather skewed to the left. The bulk of the population lives at the lower end of the distribution, while the tail on the right side is very thin and long. This means only a few individuals benefit from a comparatively high standard of living. In higher income countries, the income distribution is closer to a normal distribution with similar tails on both ends. The cumulative distribution function (see Figure 6.3) shows quite well the effect of a small increase in the poverty line on the number of people falling below it. The steeper the function, the more effect that an increase in the poverty line has on the number of people that are situated below. The three vertical lines to the left of the median represent three different values for a possible GMI. On the vertical axis, the increase in the fraction of the population that would fall below the respective GMI can be estimated (see also Table 6.16).

\section{c) An inaginary decision process}

After the concept decision, the question arises how the process of implementing a GMI based benefit system would take place. We propose seven steps that the government should make representing seven decisions. This section describes the decisions shottly, while the following section will simulate the first three steps using actual data.

The first decision is about the menu of benefits to be offered after the introduction of a GMI based benefit to the poor. Which benefits can be abolished after a GMI has been installed; or better, which of the actual benefits can exist without causing trouble when they exist alongside the GMI. This decision has a political dimension as well. Although in some cases it would be logical to abolish a benefit, it may be wise not to do so because the budgetary impact is small and/or disappearing and because the public opposition against it would be large. However, it should be noted that the extent of the budgetary impact should be the crucial element in the decision.

Since the GMI is budget-driven, the decision on the budget allacation is crucial and decisive for further implementation. The govemment has to decide on the budget that can be allocated to the newly defined GMI-benefit. As a rule of thumb, niddle income countries like Latvia should be able to allocate approximately one percent of GDP to income support to the poor. Of course the actual

\footnotetext{
"An most middle and low income countries the GMI will be well below an absolute and a relative poverty line, however defrined (see also Gassmann, F., Note on Poverty Limes, written for the Latwian SAD, February 1999).
} 
budgetary room available is also defined by the decision taken about the menu of benefits. The more benefits remain in the program, the less funding will be available for the GMII benefit. Benefits usually crowd out each other.

Another important decision is about the mechanism used to set the GMI. Our proposal is to make it entirely budget driven in a situation such as the Latvian one. That means that after at decision is taken on the budget to be allocated, a technical procedure determines what the GMI level for a certain year will be. This is done by estimating the budgetary allocation first and secondly by estimating the level of GMI that can be guaranteed given the actual resources of families under the existing income distribution (see the simulation below and Table 6.16).

A well-designed betiefit alone is no guarantee that the targeted population will be reached. Eligibility rules and procedures have to be streamlined and adjusted for the system to be workable and effective. The procedure to be used at the local level in order to decide who will get the benefit has to be the same all over the country abandoning the current diversity. This includes decisions on application procedures, on the calculation of the family income (what is taken into account and how), on benefit disbursement procedures (length of allocation period, who will distribute the benefit and how, reconsideration procedures, etc.), on the training of the local staff, the monitoring and evaluation system, etc. All these decisions have to be prepared carefully and in consultation with the rnunicipalities.

The decision on mechanisms to index the GMI is next. The most logical index mechanism is to relate the GMI to nominal GDP growth. It is a fair approach since the GMI is then adjusted according to both inflation and the growth of welfare in the country.

Many existing benefit systems generate poverty traps because with every lat or dollar eamed above the eligibility level, the benefit is reduced with one lat or dollar. It is therefore important for the decision-makers to decide on a mechanism to avoid disincentives to work for beneficiaries under the GMI-benefit system. Such a mechanism should ensure that not every lat earned is deducted from the GMI benefit immediately. Assume that the benefit for an individual is calculated as follows: B $=\left[\mathrm{GMI}-\left(\mathrm{Y}_{\mathrm{O}}+\mathrm{Y}_{\mathrm{L}}\right)\right]$, with $\mathrm{B}$ for benefit and $\mathrm{Y}$ for the family"s labor income $\left(\mathrm{Y}_{\mathrm{L}}\right)$ and other income $\left(\mathrm{Y}_{\mathrm{O}}\right)$. With no other regulation this would mean that as soon this family's income is larger than the GMI, they would loose the right for the benefit. In other words, there would be a $1.00 \%$ marginal tax on every additional lat earned. This poverty trap can be avoided by changing the formula and including a labor income disregard. For example: $\mathrm{B}=\left[\mathrm{GMI}-\left(\mathrm{Y}_{\mathrm{O}}+0.75 \mathrm{Y}_{\mathrm{L})}\right]\right.$. Suppose the benefit recipients finds work. Now only $75 \%$ of his new labor income would be used for the calculation of the benefit. There is still an incentive to look for work because not every lat will be deducted and the total income of this person will increase. The labor income disregard in this example is $25 \%$ and is arbitrarily chosen.

\section{d) Simulation of a possible GMI level for Latvia}

The above has been a theoretical exploration of how a benefit system can be simplified and adjusted to the needs and possibilities of a country. In this section we calculate the possibilities for a GMI in Latvia based on several assumptions using data from the HBS 1997. We will run through the first three steps as described above in order to model the GMI and define the underlying assumptions.

We suggest the replacement of all local social assistance benefits which are meant to suppont the income of poor families with one unified monthly benefit (UMB) to be payed in cash. Note that this will only support the poorest families since this assistance will be means-tested. Some additional services to vulnerable groups may be necessary as well. ${ }^{15}$ The UMB will be payed to all families/households with a per capita income below the GMI as defined below.

\footnotetext{
An example would be the provision of school equipment.
} 


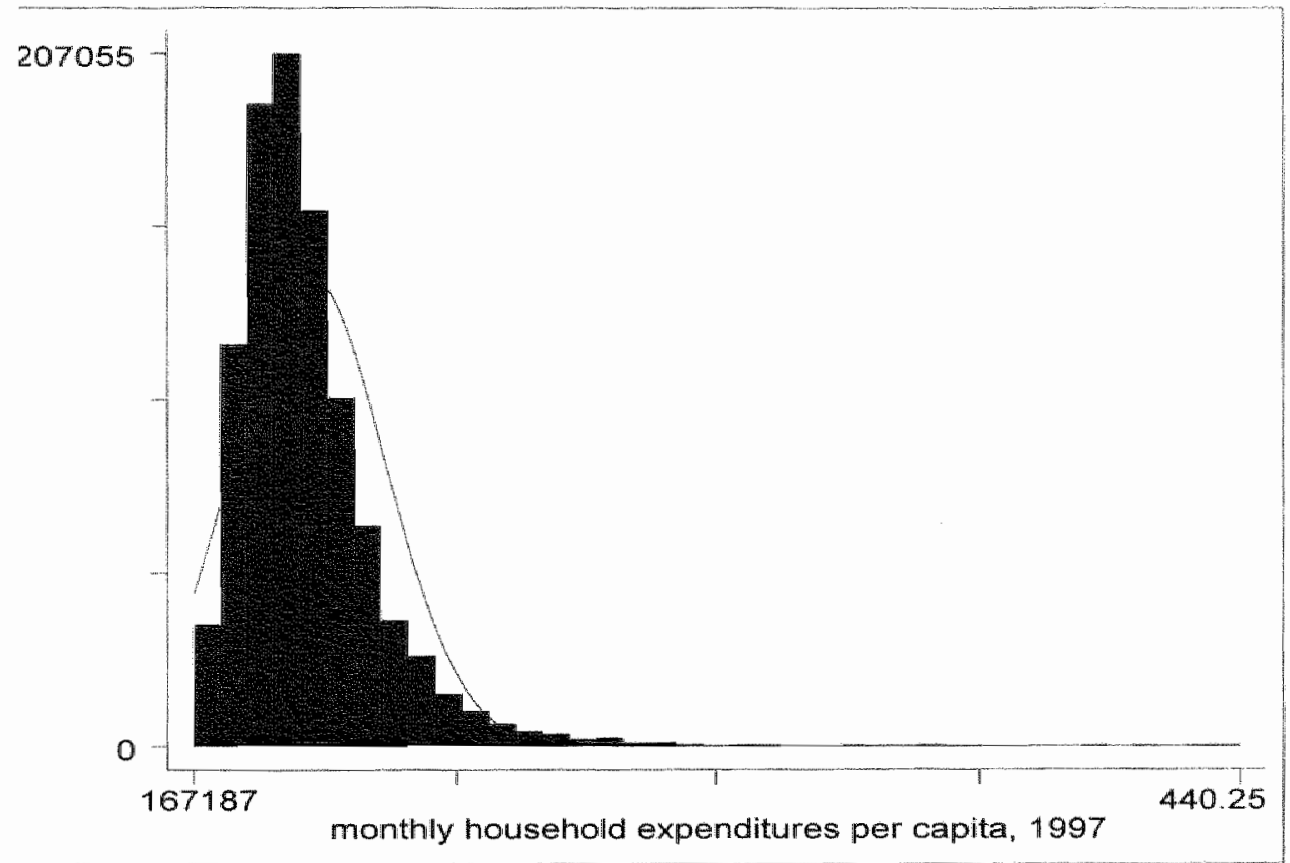

Ire 6.2. Distribution of monthly per capita household expenditures (in LVL), Latvia, 1997 roe: HBS 1997.

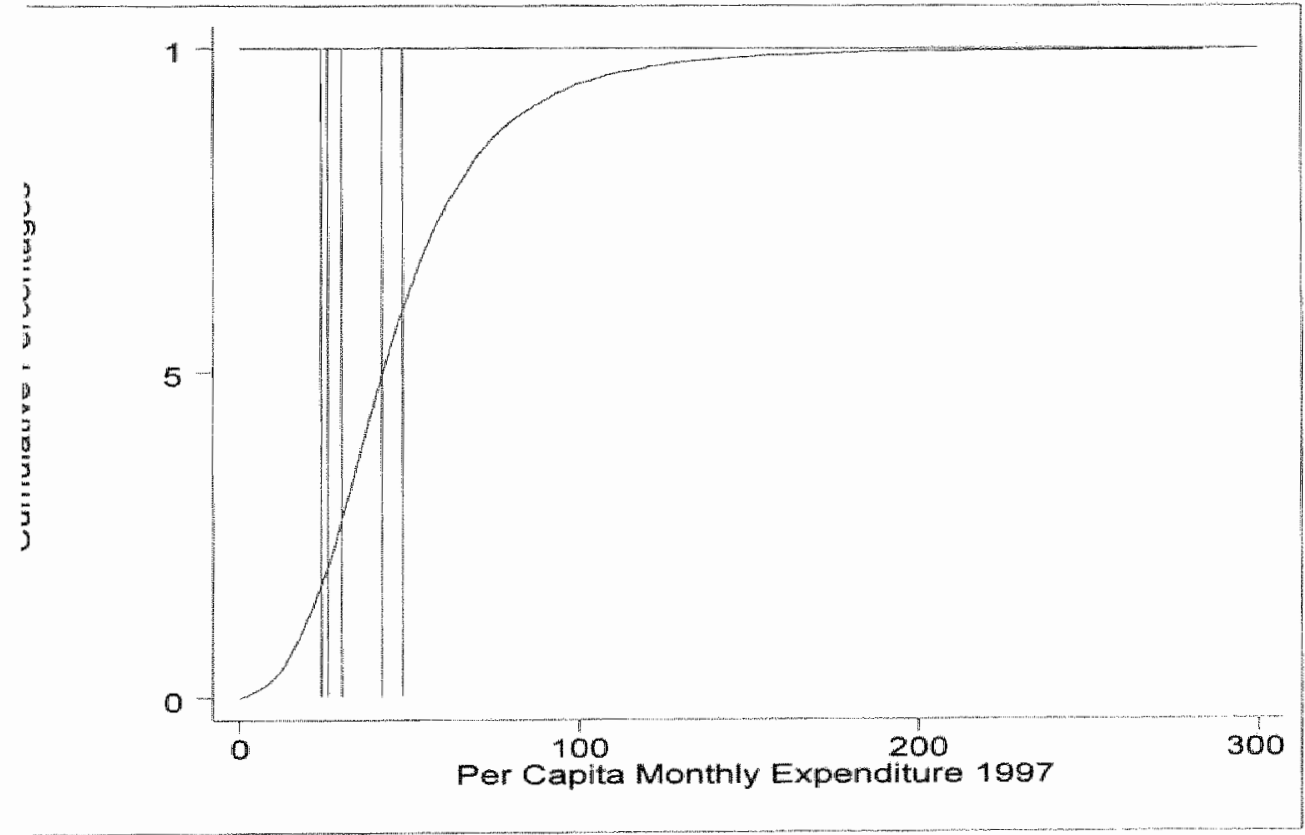

Jre 6.3: Cumulative distribution function, per capita monthly expenditures (LVL), Latvia, 1997.

e: The first three vertical lines from the $y$-axis are GMI lines for 24,26 and 30 LVL. The next vertical line is the dian, followed by the mean. moe: HBS 1997. 

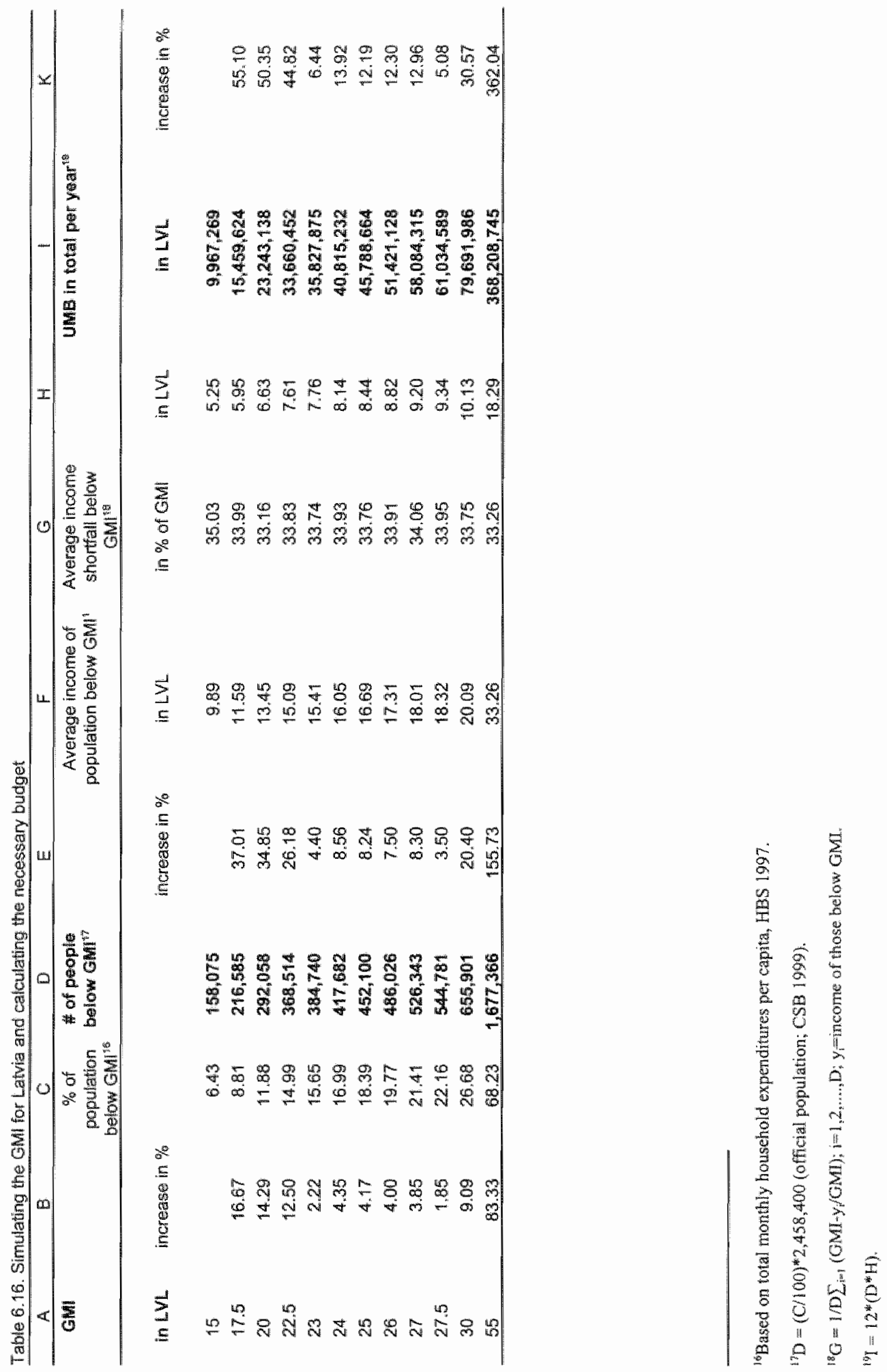
In 1998, Latvian municipalities spent in total LVL 13.7 million on social benefits, an amount accounting for $0.4 \%$ of GDP (MoW, 1999:89). Following our earlier argumentation, at least one percent of GDP allocated to targeted benefits should be affordable and politically sustainable for Latwia. Or, to put it differently: in 1998, 10\% of the municipalities" total expenditures was equal to about $1.2 \%$ of GDP. If this amount would be spent on targeted benefits, about 38 to 42 million Lats would have been available in 1998. We therefore assume that Latvia will spend an amount of this magnitude ( $+1-1 \%$ of GDP) on targeted benefits in order to determine the appropriate GMI.

Using data from the HBS 1997 and assuming that total expenditure on targeted benefits should not exceed 40 million Lats, we calculate the respective GMI. The HBS data were used to estimate the number of individuals that would be eligible for a targeted benefit under various GMI lines. Table 6.16 provides a summary of the calculations. Note that these calculations are based on total monthly household expenditures per capita. It is not unusual that average income per capita is lower than expenditures for the poorest $20 \%$ of households. This means that the figures presented in the table are even underestimated. All calculations are on a per capita basis, i.e. a household of four persons would have a GMI of four times the GMI. On the other hand, the take-up rate may never be $100 \%$ as is implicitly assumed in the simulation.

Assuming total expenditures not exceeding $1 \%$ of GDP, the GMI would have to be set at LVL 24 as Table 6.16 shows. This would create expenditures for a UMB of about LVL 40.8 million. Table 6.16 also shows that a small increase of the GMI (column $B$ ) does result in above proportionate increases of the eligible population (column E) and total UMB expenditures (column K). For example: an increase of the GMI from LVL 20 to LVL $22.5(12.5 \%)$ results in an increase of $26.2 \%$ of the people living below this line. It causes an even greater increase in total expenditure for the UMB of $44.8 \%$. This proves that eligibility levels are elastic and the income distribution tight. The table also shows, that a rights-driven poverty line is currenty not affordable for the Latvian state. Taking LVL 55 (the value of the crisis consumption basket in 1997) as the GMI line for the UMB would cost the state, c.q. the municipalities LVL, 362 million, which is approximately $10 \%$ of GDP and only slightly less than total municipal expenditures in $1998 .^{20}$

In the Latvian context a budget-driven target line is advisable. In the future when the economy grows it is not impossible that a GMI set by political rules will come closer to an actual poverty standard, as is already the case in many mature West-European countries. Issues to be taken into consideration relate then to the relationship between the GMJ and the minimum wages, for example. For the time being, Latvia should work with a budget-driwen procedure to set the GMI. A budgetary allocation of about one percent of nominal GDP seems to be appropriate for countries like Latvia and showld be affordable and politically sustainable.

Once the decision has been taken, the Law on Social Assistance may have to be adjusted in order to encompass the new benefit. Municipalities have to be trained in order to be able to administer the new benefit according to the rules, and incentives have to be created obliging the municipalities to implement the new law. Regular monitoring and evaluation will provide the necessary feedback to the centrall as well as to the local level. The public has to be informed appropriately. An information campaign should communicate the available benefits and services to the public. Neither the best-designed benefit nor good intentions alone can guarantee that the take-up rate is close to the maximum, ensuring that the support reaches those in need.

${ }^{20} 68 \%$ of the population falls below a GMI line of LVL 55 in 1997 


\subsection{Conclusion}

The social assistance systems in CEE and FSU countries were certainly put to test when the transition from a command to a market economy started to take effect. No one prepared them for the drop in output and the resulting misery due to rocketing unemployment rates and falling real incomes. Suddenly, a safety net became necessary in order to soften the hardest impact. A new system had to be set up while the minds of the designers were still thinking in old terms. Soon, the first corrections had to be made and reforms implemented. What resulted was a rather complicated social assistance systems with a wide range of different benefits and services. Parallel reforms, such as the decentralization in Latvia, contributed to the confusion and blurred the communication between the different govermment layers. While the central level was issuing rules and regulations, most local governments were either not aware of the changes, or did not care and pursued their own policy. The central level, on the other hand, had hardly an idea of what was going on at the local level.

As a result, the current Latvian social assistance system is not very effective in reaching the target population and it does not achieve its objective of providing a safety net for the poor. The numerous benefits, the differences between municipalities in implementing the existing law and the arbitrariness of local decisions with respect to eligibility all contribute to the current situation. Two other important reasons are the lack of funding, i.e. the steadily decreasing share of local expenditure spent on social assistance benefits, and the lack of monitoring and control at the central level. The latter inhibits the central level effectively in assisting local governments with the implementation of the laws and regulations and intervening when necessary. The administrative capacity is limited due to the use of old-fashioned administrative methods in large parts of the country. Many offices are not computerized, or even if they are, the computers are used for peripheral work only. Paper filing systems are still common.

From the point of view of the population, we have to conclude that people are not turning to the state for assistance. Either they are not informed about the possibility, or they are resigned to and "settled" in their situation. This result is closely related to our first conclusion on the ineffectiveness of the system. It is difficult to communicate a social assistance benefit system such as the one currently in place in Latvia. The communication between government and public is milssing. With the breakdown of the Soviet systern, Latvians have lost a rather comprehensive social protection system. Now they have a government still struggling to find a new way to organize a social assistance system which is capable of dealing with the new challenges the population is confronted with. As daily life became harder; people lost trust and confidence in the state and its ability to support them in times of need. They feel that they have lost in the sphere of social protection compared to the situation before independence. The results of the survey confirm this loss of fatth in the state. Latwians do not expect a lot: maybe this prevents them from being disappointed, maybe it expresses past experiences. The state is not considered capable of providing effective assistance. The state has failed to keep the trust of the population on certain accounts Assuming good intentions, social assistance has not been able to work as an effective social safety net so far. The benefits do not reach the target group. The system as designed failed at the financial and administrative level. It partly explains why the population does not expect anything anymore.

It is not the objective of the Latvian social assistance system that is to blame, but the structure and its implementation. The Latvian government acknowledges the difficulties and clianges are slowly taking place. The following recommendations serve as an input on how to deal with the current policy problems. First of all, the local social assistance benefit system needs to be simplified. We suggest the introduction of a unified monthly benefit based on a budget-driven guaranteed minimum income concept. The total funds allocated to local assistance need to be 
eased up to about one percent of GDP in order to provide a meaningful contribution to the viation of the deepest poverty. A monitoring and evaluation system at the central lewel with Ilar input from the local level will keep the policy makers informed about the effectiveness or rtcomings of the implemented policies. The dialogue between central and local level can be roved through a regular feedback from the central level. An information campaign at the local 1, preferably by direct mailing, can be used to inform the public about the benefits and services ilable at the local social assistance office. It can also help to reduce the initial resistance of the $r$ to come to the office and apply for assistance. Local social assistance offices should be made ly accessible. A simplified system would be more communicable as well.

Rome was not built in one day, and neither will the Latvian social assistance system be rrmed at that speed. Changes take time and this time is necessary in order to make wellsidered reform proposals that will find a broad acceptance among civil servants, politicians and but not least the public. But not even the best system will achieve its objectives if no one knows ut it. 



\section{SUMMARY AND CONCLUSION}

The main question of this study is how the economic transition from a centrally planned to a market economy affected the standard of living of the population in general, and poverty in particular. The country used for this analysis is Latvia. Although the country is relatively small, the findings of this study are relevant for other countries in transition as well, and especially for those in the region.

The simple answer to this question has to be that the transition had a disastrous effect on the welfare of the majority of the Latvian population be it physiologically or psychologically. Although quantitative household data over the whole period are not available, we can conclude from the data we have analyzed, that poverty is widespread in Latvia and that it is even increasing. The fact that real GDP per capita in 1998 was only $59 \%$ of the value it had in 1989 indicates the sharp decline in incomes and living standards Latvians had to face. The qualitative information gathered among the population confirms this result. Most Latvians perceive the change in the standard of living during the last decade as negative, indicating that they can consume much less nowadays than before the transition. They feel that they have lost and this contributes to widespread pessimism within the society.

It would be too easy and also not wery satisfying to leave this answer undifferentiated. The various chapters in this study highlighted different aspects involved in poverty research and welfare analysis. In the second chapter, we explained the whole process of creating a welfare indicator starting from raw data from the Latvian Household Budget Survey. It provided the theoretical and empirical background for the subsequent chapters. The indicator that was chosen and tested in the end for its robustness served as the main tool for the poverty analysis in chapter three. The choice on the issues involved in the creation of a welfare indicator remain subjective to a certain extent. We decided to use a consumption based indicator with the following characteristics: The indicator is based on total monthly househoid expenditures for all goods and services purchased, from own production and received free of charge. Excluded are expenditures for durable goods, taxes and social security contributions. Missing observations for housing, electricity, gas and water are imputed and heating expenditures are seasonally adjusted. This total is adjusted for regional price differences and inflation. The final measure is the household average per capita. Some may argue that not all adjustments were really necessary while others are missing. It remains the researcher's decision, but at least we can say that the decision was an 'informed" one. It is not THE most important choice in poverty analysis. Although the exact poverty numbers might change due to a change in the indicator, ${ }^{1}$ the aim of a poverty analysis lies never in the determination of exact poverty numbers. This is not possible, because poverty is a multi-dimensional concept and secondly, the true ranking of all households will never be known. It will always remain an estimate. The main aim of the poverty analysis is to identify the groups that are most at risk of living in poverty.

Chapter three tried to achieve exactly this goal: identify the wulnerable groups in Latwia. More than $50 \%$ of the Latwian population lives somewhere in between the lowest and highest poverty line

\footnotetext{
'An interested reader will see the difference when comparing the results presented in chapter three with the ones published earlier in Gassmann, 1998.
} 
used in this study. Except for the region around Riga which has a lower than average poverty rate, poverty is quite uniformly distributed among the other regions. What does make a difference, is whether someone lives in an urban or a rural area. The larger the town, the smaller the poverty risk. However, in absolute tems, most of the poor live in and around Riga since one third of the Latvan population is living in the metropolitan area. The groups facing an above average risk of being poor are large households, households with three or more children, households where the breadwinmer is young or unemployed or has a low education, and households that depend mainly on income from agriculture or social transfers (except pensions). The results confirmed the hypotheses derived from. the relevant literature. As in other transition countries, the working poor form a large part of the poor although the headcount ratios are lower for this group. This is most probably due to low wages. in the economy and underemployment. The poverty profile does indeed resemble other CEE countries such as Poland, Hungary, Lithuania and Estonia. Comparing the results from 1996 with 1997, we also conclude that poverty in Latvia has been increasing. It not only increased, which resulted in a higher headcount ratio, but it also deepened and became more unequal, which means that more poor people are at the very low end of the income distribution. Still, we have to be aware of the fact that this is only a snapshot in time even with two years covered. We do not know whether the poverty is transitory or permanent. In the former case, we would not have to worry so much, since we would know that better times lay ahead for these groups. The state would newertheless still have a role to facilitate the endurance of such difficult times. Even though the poverty rates in Latvia are high in our Westem eyes, Latvian households are surviving because they employ every possible means to make ends meet.

Although chapter three provided detailed information on the extent of material poverty in Latvia over two years, we were not able to draw any conclusion about the dynamics and developments of living standards over the last decade. Neither could we say anything about how people cope with the little means they have. These questions were the center of attention in the two subsequent chapters.

An additional data-set provided the empirical input for the analysis in chapter four, five and six. For this purpose we designed a special poverty survey which was carried out in 1998. It aimed at collecting information from the Latvian population on how they perceive the developments over the last decade, how they compare their current situation with the past, how they cope and whether the local social policies are achieving their intended objectives. This data-set finally allowed the study of the impact of the transition at the household level. It broke new ground in the study of the effects of the transition from a planned to a market economy, focusing on people's own perception of the developments of the last decade in tems of their standard of living and the way they currently cope.

Chapter four concentrated on the dynamics of the transition and the identification of winners and losers. The overall conclusion on the dymamics of gaining and losing during Latwia"s transition should be that more than $75 \%$ - an overwhelming majority - of the population feels that they have lost. Whether this feeling corresponds to actual developments, is difficult to judge from this study. There are some indications that reality has indeed become harsh. There is the real decline in incomes, also reflected by the drop in real GDP per capita until 1995, and chapter three provided evidence of decreasing real living standards for the majority of the population between 1996 and 1997.

Although the big majority feels that they have lost, the analysis in Chapter Four allowed us to draw some differentiating conclusions. Not all groups perceive their situation as equally pessimistic. The current perception of the past and its changes depends on where one stood before the transition. Those that had a lot to lose, feel that they have lost relatively more often than those that did not have so much to lose. For example, pensioners have a relatively negative view on the "gains" of the 
transition, although they are currently not worse off compared to the national average Feelings of insecurity may be responsible for the negative perception. The argument is supported by the equally pessimistic feelings of the group that had a well-paid job in 1991. On the other hand, those that had an influential position (outside the job) before 1991 evaluate their current position relatively more optimistically, The same applies to the younger generations and families with children. Although they have been identified as vulnerable groups both in the poverty profile for Latvia and in the respective literature on other CEE and FSU countries, their perception is relatively more often a positive one. It could be an expression of a conviction that their currently low living standards are only of a transitory nature. Those that feel that they have lost most, i.e. the losers, are either currently unemployed, farmers, or belong to the poorest $20 \%$ of the population. Those that feel most positive, i.e. the winners, are either self-employed, have higher education, or belong to the richest $20 \%$ of the Latvian population. The fact that a large group in the population feels that they have lost is a political reality. It should cause concern to learn that most Latvians feel that they have lost, that they are worse off than ten years ago. A main conclusion from the survey is that life has become more difficult and insecure, and that the future is uncertain. People have not only become poorer, but also more pessimistic.

While chapter three provided quantitative information about poverty in Latvia, Chapter Four confirmed the main conclusions from a more subjective point of view. In chapter five, we investigated the strategies that poor (and non-poor) households apply in order to make ends meet. We defined five categories of coping strategies: income-generating activities, household production, economizing activities, assistance from the social network, and crisis activities. Using this classification, chapter five analyzed the significance of these strategies for survival. An important result of the poverty survey was that not only poor households use the indicated strategies. Certain coping strategies are employed by all layers of the society independent of the welfare level. Economizing is such an activity, as is the own production of goods, or the receipt of assistance from other households. We were not able to detect a strong correlation between living standard and the prevalence of a certain strategy, but we found a relation between the number of coping strategies applied and the welfare level. This means that poor households seem to cope by applying several coping strategies simultaneously. Although more than $90 \%$ of the total population economizes on something, the poor economize on more than one item. Poor households produce more than one good on their own, and they engage in more than one income-generating activity. The age pattem is in some cases even more decisive than the income distribution. For example, the older gencration has less debt accumulated than younger households. The old are also least often engaged in incomegenerating activities, and they economize most. Middle-age households engage more in own production than the young or the old, while young households are clearly more often recipients of assistance. The fact that almost every household uses coping strategies says something about the general welfare level in Latvia. It actually confirms our earlier findings that living standards dropped considerably after the transition and that poverty increased. Since we focus in this study mostly on the poor, it is easily overlooked that the general welfare level is relatively low. On the other hand, the findings in chapter five can also be interpreted as indicating that the very poor are the ones that have fewer coping strategies at their disposal: They have nothing left to economize on because they already live on as little as possible, and their social network seems to be rather weak. The poorest are less likely to be recipients of assistance as we have seen. The existence of a functioning social network as well as the ability to apply coping strategies may be the explanatory factor for a household's position in the Latvian welfare distribution. It seems as if those capable of applying coping strategies successfully are in a relatively better position, while those households which have no means to generate additional income or reduce consumption are the ones most at risk. For Latvia these findings imply that the general welfare level is low. Everybody has to cope 
with the little means available and exhaust each available strategy. The poorest are doing the same but not as successfully because their initial endowment of labor, capital or relationships necessary to apply a certain strategy is low.

Chapter six changed angles and approached the problem from the soclal policy perspective. The chapter aimed at answering two questions: is the Latvian social assistance system effective in reaching and helping the poor and do Latvians turn to the state for help when they need it. We concluded that the current Latyian social assistance system is not very effective in reaching the target population. The numerous benefits, the differences between municipalities in implementing the existing law and the arbitrariness of local decisions with respect to eligibility all contribute to the problem. Two other important reasons are the lack of funding, i.e. the steadily decreasing share of local expenditures spent on social assistance benefits, and the lack of monitoring and control at the central lewel. The latter inhibits the central level effectively assisting local governments with the implementation of the laws and regulations and intervening when necessary.

From the point of view of the population, we concluded that people are not turning to the state for assistance. Either they are not informed about the possibility, or they have resigned to and 'settled' in their situation. This result is closely related to the first conclusion on the ineffectiveness of the system. It is difficult to communicate such a fragmented social assistance benefit system such as the one in Latvia. With the breakdown of the Soviet system, Latvians have lost a rather comprehensive social protection system. Now they have a government still struggling to find a new way to organize a social assistance system which is capable of dealing with the new challenges the population is confronted with. As daily life became harder, people lost trust and confidence in the state and its ability to support them in times of need. They feel that they have lost in the sphere of social protection compared to the situation before independence. The results of the survey confirm this loss of faith in the state. Latvians do not expect a lot: maybe this prevents them from being disappointed, maybe it expresses past experiences. The state is not considered capable of providing effective assistance.

It is not the objective of the Latvian social assistance system that is to blame, but the structure and implementation. We recommended a simplification of the local social assistance benefit system. We suggested the introduction of a unified monthly benefit based on a budget-driven guaranteed minimum income concept and the increase of the total funds allocated to local assistance up to about one percent of GDP. A monitoring and evaluation system at the central level with regular input from the local level keeps the policy makers informed about the effectiveness or shortcomings of the implemented policies. An information campaign at the local level, for example by direct mailing, can be used to inform the public about the benefits and services available at the local social assistance office and improve the communication between state and public.

We should not forget that research on the effects of the transition is rather new. Only ten years have passed since the transfomation started in CEE and the FSU. From a research perspective, this is still a short period. It also indicates why we hardly know what happened to the people living in these countries. We know how the economies developed and we have a rather good view on the macro econonic impact of the transition. On the household level, the situation is different. Although there have been numerous studies on poverty in these countries, the time frame analyzed usually covers a one-year or even shorter period. They are snapshots. We know only little about the effects of the transition at the household level, and we hardly know how the households have been dealing with the presumably harsh economic situation in their daily life. Parts of our study are so new that we have no benchnark against which we can relate and evaluate our findings. To our knowledge, this is the first study of this kind providing evidence of the dynamics of the transition at the household level and of the perception of the households with respect to their current situation in relation to the past. We think that this study contributes to the understanding of the problems at 
stake not only in Latvia, but also in other countries in similar circumstances. We provided detailed information about the poor in the country and about the way people perceive the changes they were confronted with during the last decade. Nevertheless, more research is needed in the future. In order to fully understand how households are affected and how they react, time series analyses would be necessary. Unfortunately, the initial design of the Latvian HBS which also foresaw the creation of panel data had to be canceled due to budgetary problems and disappointing response rates. The NORBALT Living Condition Survey will be repeated in 1999. It will definitely provide more insight into the current living conditions as well as the developments since 1994, when the first round of the survey was held (FAFO, 1995). From the scientific point of view of this study, more fundamental research is needed on the subject of equivalence scales. This is one area of poverty and inequality research, where no satisfying approach is available so far.

Another open, though hypothetical, question which we still cannot answer is whether people would choose again to go through the transition if they would have the choice and the knowledge of what really awaits them. In other words, was the price they had to pay worth. Of course, these questions are only rhetorical. However, they indicate that several aspects have to be considered. We think we can definitely agree that the price of freedom was high. Was the price also equally distributed among the population? Was it the same for everybody? For Latvia we can say that the majority had, and still has, to endure difficult periods, and that most have to think twice before spending money. We in the West expected the people in the East to be happy no matter what price they would have to pay, and that no price would be too high for values such as freedom and democracy. This attitude was rather arrogant considering the developments over the last decade and the still lasting negative effects of the transition on living standards. It took the Latvian economy five years to produce positive growth rates and the price for the Latvian people was tremendous. For the poorest Latvians, the standard of living was still declining seven years later. Only a small proportion of the Latvian population managed to recover completely and benefit fully from the new market economy with its opportunities. The majority had to give up a lot. Next to the fact that wages and incomes were declining and norms and values were changing rapidly, it was the loss of everyday security that contributed to the individually perceived (social) well-being. People are still struggling, and most of them are hardly in a position to take advantage of the gains of the transition. Those that have exhausted all means to make ends meet are the ones that need assistance, but it is the whole population that needs support and encouragement to continue and hold on until better times come.

For policy makers, the result of this study should provide input into the design of social assistance policies and to the development of a communication strategy with the population. We have not even spoken about economic growth and the creation of employment which are key factors for further development. In this study we consider this as self-evident. Latvia is definitely on the right track regarding the ongoing projects and policy developments. But as Rome was not built in one day, it will take a long-term perspective to fully adjust to the "new" economic and political situation. Or as Barr quotes a former French Prime Minister: '.... [he] inwited fellow citizens to imagine France having only a few years to go through the Revolution of 1789 , the Industrial Revolution of the nineteenth century and the decolonization of the 1960s. This, he pointed out, was precisely what the world community was asking Russia to achieve "(1996:57). Latvia is just the same example on a smaller scale. 



\section{BIBLIOGRAPHY}

Aasiand, A. (ed.) (1996), Latvia: The Impact of the Transformation, The Morball Liwing Conditions Project, Fafo report 188, Fafo.

Aasland, A. (1999), Ethnicity and Powerty in Latwia, UNDP Latwia, Riga.

Aasland, A., Cesnuityte, V. (1997), Liwng Conditions in the Battic Countries Compared, Fafio paper 1997:15, Fatio.

Aasland, $A_{1,}$ et al. (eds.) (1997), The Baltic Counthes Revished: Liwing Conditions and Comparatrue Challenges. The Norbalt Living Conditions Project, Fato Report 230, Forskningsstiftelsen Fafo.

Ackland, R. (1999). Poventy in the Republic of Latwia in 1997/98, Background paper prepared for the Latwia Poverty Assessment of the World Bank, Draft.

Anand, S., Harris, C.J. (1994), "Choosing a Welfare Indicator', in American Economic Rewiew, 84(2), $2261-231$.

Aslanbeigü, N. Pressman, S., Summerfield, G. (eds.) (1994), Women in the Age of Econamic Transfomation, Routledge, London and New York.

Atkinson, A.B. (1983). The Economics of hiequality, Clarendon Press, Oxford.

Atkinson, A.B. (1987), 'On the Measurement of Poverty", in Econometrica, 55(4), pp. 749-764.

Atkinson, A.B. Micklewright ${ }_{1}$ J. (1992), Economic Transformation in Eastern Europe and the Distribution of hcome. Cambridgle University Press, Cambridge.

Baneriee, B., et al. (1995), "Road Maps of the Transition: The Baltics, the Czech Republic, Hungary, and Russia", MF Occasional Paper, 127, International Monetary Fund, Washington DC.

Barfuß, G.S., Caunitis, K., Loza, Z. (1997), Labar Markat in Latvia 1996: Developmemt and Analysis, Ministry of Welfare of the Republic of Latwia, Uniwersiteit Maastricht, Stockholm School of Economics Riga, mimeo.

Barr. N. (4993), The Economics of the Welfare State, $2^{\text {nd }}$ edition, Oxford University Press, Oxford.

Barr, N. (1994). 'The Forces Driwing Change', in Barr, N. (ed.), Labor Markets and Sacial Policy" in Central and Eastem Europe, Oxford University Press. New York, pp. 77-88.

Barr, N. (ed.) (1994), Labor Markets and Social Policy in Central and Eastern Europe, Oxford University Press, New York.

Barr. N., (1996), Income Transfers in Transition: Constraints and Progress, MOCT-MOST, 6(1), pp. $57-74$.

Benerla, L. Feldman, S. (eds.) (1992), Unequal Burden. Economic Crises, Persistant Poventy, and Women's Work, Westview Press, Boulder and Oxford.

Bingley, P., Walker, I. (1997), There"s No Such Thing as a Free Lunch: Evidence of Altuilsm from the Effect of InKand Transfers. Aarhus and London, mimeo.

Blackwood, D.L., Lynch" R.G. (1994). "The Measurement of Inequality and Poverty: A Policy Maker"s Guide to the Literature", World Development, 22(4), pp. 567-578.

Btundell, R., Preston, Il., Walker, I. (1994), 'An introduction to applied welfare analysis', In Blundell, R., Preston, I., Walker, I. (eds). The measurement of household welfare, Cambridge University Press, Cambridge, pp. 1-50.

Bomstein, M., (ed.) (1994), Comparative Economic Systems - Models and Cases, 7th ad., IRWIN, Burr Ridge Illinois.

Braithwaite, J. (1995). 'The Old and New Poor in Russia: Trends in Poverty', ESP Dircussion Paper Series, 57. The Wordd Bank, Washington DC.

Braithwaite, J. (1995). 'Armenia: A Poverty Profile" PSP Discussion Paper Series, BO, The World Bank, Washington DC. 
Braithwate, J., Grootaert, C. Milanovic, B. (1998), Determinants of Powenty and Targeting of Social Assistance in Eastern Europe and the Former Sowet Urion, The Word Bank, Washington DC, mimeo.

Brown, A.A. Neuberger, E. (1994), 'The Traditional Centrally Planned Economy and Its Reform', in Bornstein, M. (ed.), Comparative Economic Systems-Models and Cases, 7th ed., IRWIN, Bum Ridge lllinois, pp. $357-383$.

Callan, T. Nolan, B. (1991). "Concepts of Poverty and the Powerty Line", in Journal of Economic Surveys, $5(3)$, pp. 243-261

Central Statstical Bureau of Latwia (1995), Statistical Yearbook of Latva 1995, CSB, Riga.

Central Statistical Bureau of Lania (1996), Monthly Bulletin of Latwan Statistics, 31996. Riga.

Central Statistical Bureau of Lawia (1997). The Household Budget Surwey Individual Data Sets User MamualHousehold Budget Survey 1996, CSB, Riga.

Central Statisticall Bureau of Latwia (1997b), Household Budget in 1996, Statistical Bulletin , Riga.

Central Statistical Bureau of Latwa (1997c), Consumer Price Indices, Statistical Bulietin "8(52), Riga.

Central Statistical Bureau of Latwia (1997d), Monthly Bufletin of Latvian Statistics, 8(39), Riga.

Central Statistical Bureau of Latwia (1997e), Demographic Yearbook of Latwia 1997, Riga.

Central Statisticall Bureau of Latvia (1997), Macroeconomic Indicators of Latvia, 11997, Riga.

Central Statistical Bureau of Latwia (1998a), Household Budgef in 1997, Statistical Bulletin, Riga.

Central Statistical Bureau of Latvia (1998b), Social Trends in Lafwa, Appendix, Riga.

Central Statisticall Bureau of Latvia (1999). Monthly Bulletin of Latvian Statistics, 3(58) , Riga.

Central Statisticall Bureau of Latvia (1999b), Consumer Price Lndices, Statistical Bulletinn, $3(74)$, Riga

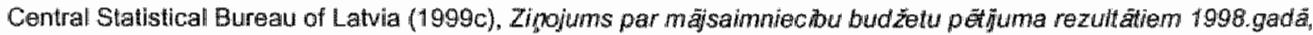
Riga (Household Budget in 1998).

Chaudhuri, S., Ravallion, M. (1994), "How Well Do Static Indicators Identify the Chronically Poor?' in Journal of Public Economics, 53, pp. 367-394.

Chu, K. Gupta, S. (1996), 'Social Protection in Transition Countries: Emerging Issues", MOCT-MOST, 6(3), pp.107123.

ClA (1999), The Word Factbook 1999 - Latwa, thttpl/www odci.gow/cia/publications/factbook/g.htm

Clarke. 5. (1998). Making ends meet in a nonmonatary market aconomy. Paper presented to Conference on Barter, Cambridge, December $1998_{\text {ii }}$ milmeo.

Conniffe, D. (1992). "The Non-Constancy of Equivalence Scales", in Review of Ircome arnd' Weallh, 38(4), December "pp. 429-443.

Cornian, G.A (1987), Adjustment at the household level: Potentials and limitations of survival strategies", in Comia, G.A., tolly, R. Steward, F. (ads.). Adjustment with a Human Face, Clarendon Press "New York, chapter 4.

Conta, G.A. (1994), Poverty, Food Consumption, and Nutrition During the Transition to the Market Economy in Eastern Europe', in American Economic Review, 84(2), May, pp. $287-302$.

Cornia, G.A., Jolly, R. Stewand, F. (ads.) (1987), Adjustment with a Human Face, Clarendon Press, New York.

Coulter, F. et al., (1997). "Social security reform for econamic transition" the case of the Czech Republic", vournal of Public Economics, 66, pp. $343-326$.

Deaton, A. (1997). The Analysis of Household Surveys. A Microeconomic Approach To Development Policy. John Hopkins University Press, Baltimore and London. 


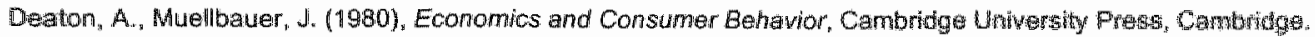

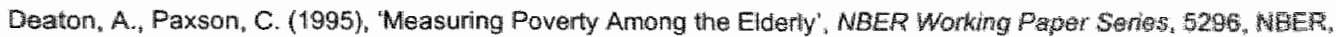
Cambridge $M A^{*}$

Desal, M. Shah, A. (1988), "An Economethic Approach to the Measurement of Powery", wh Oxtord Eeonowic Papers. 40 . pp. $505-522$.

Dudwick, N. (1995), A Qualitative Assessment of the Living Standards of the Amenan Populaticn. Gawhround whang paper for the Amenia poverty assessment, The World Bank, Washington DC, mimeo.

Esping-Andersen, G. (1990), The Three Worlds of Wellare Capitalisn, Polly Press, Cambridge, 1900.

European Bank for Reconstruction and Development (1999), Transidion Report 1999, EQRO, London.

FAFO (1995), The NORBALT Project. A Presentation, Oslo, Appendix D (drafti).

Feriber, M.A. (1994), "Czech Women in Transition", in Monthly Labor Review, 117(1), pp. 32-36.

Ferge, Z. (1993), 'Social Policy in Transition in Eastem Europe', in Simpson, R, Walker R. (eds.), Eunope for Fether or Poorer?, CPAG, London, pp. 78-91.

Ferreira, M.L., Buse, R.C., Chavas, Ju.P. (1998), "Is There Bias in Computing Household Equalence Scales?" in Rewiew of Income and Wealth, 44(2), pp. 183-198.

Festinger, L. (1954), "A Theory of Sacial Comparison Processes', Human Relations, 7. pp. 17-140.

Flk, R.J., Van Praag, B.M.S. (1991), "Subjective Poverty Line Definitions", in De Economist, 139(3), pp. 311-329.

Foster, J.E. (1984), "On Economic Poverty". A Survey of Aggregate Neasures" in Advances in Econometrics, 3 , pp. $215-251$.

Foster J.E. (1998). "What is poverty and who are the poor? Redefinition for the United States in the 1990 's" in American Economic Review, 88(2), May pp. 335-341

Fox. L., Mclsaac, D., Palmer, E. (1996), Latvian Social Insurance Reform: Issues and Options for the Next Stege, mimeo, The World Bank, Washington $\mathrm{DC}_{\text {. }}$

Furné, C., Loza, Z (1999), Latwian Welfare Reform Evahuation of the Pilot Project in Kandava (Component 30$)$, Report Phase 1, mimeo, The World Bank, Riga.

Gassmann, F. (1995), Puzzling Poverty - An Analytical Sumey of Concepts and Methods, Master's Thesis. Wa

Gassmann, F. (1998), Who and Where are the Poor in Lawia? An exploration based on existing data, UNDP Latvia, Riga.

Gassmamn, F. (1999), Note on Poverty Lines, written on behalf of the Latvian Ministry of Welfare Social Assigtance Department, mimeo. Maastrichu/Riga, February 1999.

Gassmann, F., and C. de Neubourg (1999), Coping with little means th Lativa. Qwantitative analysis of qualitative statements, UNDP' Riga, Latwia, mimeo.

Gassmann, F., and C. de Neubourg (1997), Social Assistance in Latwia, Background Paper for the OECD Technical Workshop on Social Assistance Schemes in Central and Easterm European Countries, Stockholm, 27-28 Nowember 1907 , mimeo.

Gassmann, F., and C. de Neubourg (1997), Social Assistance in Lithuania, Background Paper for the OECD Technical Workshop on Social Assistance Schemes in Centrall and Eastem European Countries, Stockholm, $27-28$ Nowember 4997 , mimeo.

Gerberding, E. Kuhn, E., Gulens, I. (1995), Balthum. Litauen, Lettland. Estland, DuMant, Koun.

Gewwe, P. Van der Gaag, J. (1990), "Identifying the Poor in Developing Countries: Do Different Definitions Watter?" in World Development, 18(6). pp. 803-814. 
Goldman, P. (1997). Managing Social Assistance Under Regronal Decentratization. Balancing Mational and Community Prionties in Latwa. The Wortd Bank, draft.

Greane, W.H. (1997), Econometric Anafysis, $3^{\text {mo }}$ edition, Prentice-Hall lintemational, Inc. London.

Grosh, M.E., Munoz, J. (1996). "A Manual for Planning and Implementing the Living Standards Mteasurement Study Survey" LSMS Working Paper, 126. The Wortd Bank, Washington DC.

Hagenaars, A.J.M, van Praag, B.M.S. (19g5), 'A Symthesis of Powerty Line Definitions", in Review of Income and Woalth, 3(1), pp. 139-1154.

Hagemaars, A.J.M., de Vos, K. (1988). 'The Definition and Measurement of Poverty', in The Jownal of Human Resources, $23(2)$, pp. $211-221$.

Hamilton, K. (1994), 'Gireen Adjustments to GOP', in Resources-Policy, 20(3), pp. 155-168.

Hentschel, J., Lanjouw, P. (1996), "Constructing an indicator of Consumption for the Analysis of Poverty. Principles and Ulustrations with Reference to Ecuador", LSMS Working Paper, 124, The World Bank, Washingtom DC.

Institute of Philosophy \& Sociology (1998), Listening to the Poor: Socjal Assessment of Poverty in Lafvia, UNDP, Figa.

Intertational Monetary Fund (1993), "Latvia:, IMF Economic Review, 6/1993, IMF, Washington DC.

International Monetary Fund (1999), Latwia: Selected 1ssues and Statistical Appendix. MF Staff Country Report 99/99. HWF, Washington DC.

Internathonal Monetary Fund (1999), Latwa: Selected Issues and Statistical Appendix, IMF Staff Country Report No. 99/99, IMF. Washington DC.

Jadiz, T. (1994), 'Seasonality" economic data and model estimation', in Monthly Labor Review, December 1994, pp. 17-22.

Jorgenson, D.W. (1998), 'Dic We Lose the War on Poverty?', in Joumal of Economic Perspectives, 12(1), Winter." pp. $79-96$.

Kakwani, N. (1995), 'Income Inequality, Welfare and Poverty: an llustration using Ukrainian Datai" Policy Research Working Paper, 1411, The World Bank.

Klugman, J. Braithwaite, J. (1998), "Poverty in Russia during the Transition: An Overview", in The World Bank Reseanch Obsenver, $13(1)$, February, pp. $37-58$.

Kuddo, A. (1998), Social Transition: Siocial and Employment Policies in the Former Soviet Union States, draft, mimeo.

Kutsar, D. ("997). "Multiple Welfare Lasses and Risk of Sacial Exclusion in the Batic States during Societal Transition', in Aasland, A., al. (eds.). The Batic Countries Revisited: Living Conditons and Comparative Challenges. The Norbalt Liwing Condithons Project, Fafio Report 230, Forskningsstiftelsen Fafo, pp. $79-104$.

Lanjouw, P. Fravallion, M. (1995), "Powerty and Household Size", in The Economic doumal, 105 (Nowember), pp. $145-1434$.

Lanjouw. P. Milanovic, B., Patemostro, S. (1999), Economics of Scale and Poverty: The Impact of Relative Price Shifts Durng Economic Transition.

http./Www worldbank.org/htmi/dec/Publications/Workpapers/Wps2000series/wps2009/wps2009.pdf.

Lapins, J., Vaskis, E. (1996). 'The New Household Budget Survey in Latvia', Statistics in Transition, 2(7), pp. 10851102

Lazulka, R. (1999), Assessing Powerty and Preconditions for Reducing R, UNDP, Vilnius.

Latwian Development Agency (LDA) (1999), Latvia. Background,

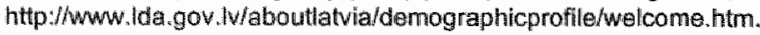


Lieven, A. (1994). The Battic Revolution. Estonia, Latwia, Lithuania and the Path to fndependence, $2^{\text {ne }}$ ed., Yale Uriversity Press, New Haven and Londion.

Lipton, M. Ravallion, M. (1995), "Poverty and Policy", in Dehrman, J., Srinivasan, T.N. (eds.), Mandibook of Development Economics, Vol. Mll, Elsevier Science B. W. Amsterdam, pp. 2551-2657.

Milanowic, B. (1998), Income, Irequalty, and Povesty during the Transition from Planned to Makel Economy, The World Bank, Washington DC.

Muthinowic B. (1999), Social Transfers and Social Assistance. An Empincal Analysis Lsing Latwian Household Swmeys. Background paper for the World Bank Poverty Assessment, draft, mimeo.

Miner, U.B. (1980), Theories of Organizational Behavior, The Dryden Press, Hinsdale, Hlinois, chapter 2.

Ministry of Economy of the Republic of Latvia (1997), Economic Dewelopment of Lalva, Report, Riga.

Ministry of Economy of the Republic of Latvia (1998), Economic Development of Latwa, Report, Riga.

Ministry of Weltare of the Republic of Latwia (1997a), Social Assistance Depantment and Sochal Assistance Fund Business Plan, mimeo, Latvia.

Ministry of Welfare of the Republic of Latwia (1997b). Administration of Social Assistance - White Paper, mimeo, Rigia.

Ministry of Welfare of the Republic of Latuia (1997c), Decree on Rules on Social Assistance Benefits and Assessment of Financial Situation of the Families in Need, Riga.

Ministry of Welfare of the Republic of Latvia (1998), Social Report, Riga.

Ministry of Welfare of the Republic of Latwia (1999a), Social Report 1999, Riga.

Ministry of Welfare of the Republic of Latwia (1999b), Overview on Pilot Project Devalopment, draft note, mimeo. Riga.

Moerle, T.G. (1994), 'Seasonal adjustment of quarterly consumer expenditure series', in Month/y Labor Review, December 1994, pp. $38-46$.

Moser, C.O.N. (1996), Confronting Crisis. A Comparative Study af Household Responses to Poverty and Vunerability in Four Poor Urban Communities, ESD Series No. 8, The World Bank Washington DC.

Nelson, d.A. (1992), "Methods of Estimating Household Equivalence Scales: An Empirical investigation', in Review of income and Mealth, 38(3), September "pp. 295-310

Weubourg de, C., Morris, S. (1999), Safety Nets and Lifelines: social assistance policy in transiltiom aconomies. Transcriptions in minor, Background study prepared for the ILO. World Labour Report 1999, International Labour Organization, Geneva, mimeo.

Pahmer, 1. (1977), 'Rural women and the basic-needs approach to development", in Intemational Labour Review, 15(1), pp, $97-107$.

Panning, W.H. (1983), "Inequality, Social Comparison, and Relative Deprivation", in American Pollicat Science Rewiew, $77(2)$, pp. 323-329.

Praag wam, B.M.S. (1994), "Ordinal and cardinal uttity: an integration of the two dimensions of the welfare concept". in Blundell, R., Preston. 1. Walker, l. (eds). The measurement of howsehold welfare, Cambridge University Press, Crambridge pp. $86-110$

Ravallion, M. (1994) "Poventy Comparisons, Fundamentals of Pure and Applied Economics, 56, Hanwood Academic Press, Chur.

Rawallion "M. (1996). 'Issues in Measuring and Modeling Powerty', in The Economic Joumal, 106 (September), pp. $1328-1343$.

Ravallion, M., Bidani, B. (1994), "How Robust is a Poverty Proflie?", in The World Bank Economic Review, 8(1), pp. $75-102$ 
Riga In Your Pocket (Feb-Mar 1998), The Uitimate City Guide, SIA "RIYP", Riga.

Rose, R. (1995), "Addaptation, Resilience, and Destitution. Afternative Responses to Transition in Ukraine" ${ }^{*}$ in Problems of Posi-Communism, NovemberiDecember, pp. 52-61.

Rose, R., McAllister, 1. (1996), "is Money the Measure of Welfare in Russia?", in Review of Mncome and Wealth, 42(1), March, pp. 75-90.

Runciman, W.G. (1966), Relative Deprivation and Social Justice, Routledge \& Kegan Paul, London.

Samorodov, A.T. (1992). 'Transition "powerty and inequality in Russia", in Intemational Labour Review, 131 (3), pp. $335-353$

Seeth, H.T. al al (1998), 'Russian Powerty: Muddling Through Economic Transition with Garden Plots', in Wortd Dewelopment, 28(9), pp. $1611-1623$.

Sen, A. (1981), Poverty and Famines. An Essay on Entitlement and Deprivation, Clarendon Press, Oxford.

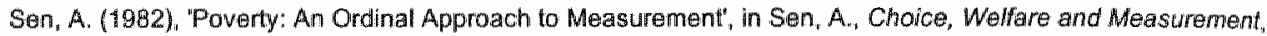
Basill Blackwell, Oxford, pp. 373-387.

Sen, A. (1984), Resources, Values and Developments, Harvard University Press, Cambridge.

Sen, A. (1987), The Standard of Living "Cambridge University Press, Cambridge UK.

Sen, A. (1992), Inequality Reexamined, Harvard Universily Press, Cambridge.

Sen, A., Foster, J. (1997), "On Economic Inequality after a Quarter Century', in Sen, A., On Economic Inequality. Chapendon Press, Oxford, pp. 107-219.

Sipos, S. (1994), "Income Transfers: Family Support and Poverty Relief", in Barr, N. (ed.), Labor Markets and Socia Pollicy in Central and Easterm Europe, Oxford University Press, New York, pp. 226-259.

Slesnick, D.T. (1994), "Consumption, Needs and Inequality", in Intemational Economic Review, 35(3), August, pp. $677 \times 703$.

Spéder, Z. (1998), "Poverty dynamics in Hungary during the transformation', in Economics in Transition, 6(1), 1-21.

Stiglitz, J.E. (1988), Economics of the Public Sector, $2^{\text {nd }}$ edition, W.W. Norton and Company, New York, London.

Streelen, P. (1984), 'Basic Needs: Some Unsettled Questions', in Wontd Development, 12(9), pp. 973-978.

Tchernina, N. ("1998), Dle Bevölkerung Russtands in der Transformationsphase. Sozjale Exklusion und

Adapufionssitrategien, Berichte des Bundesinstituts für ostwissenschaftliche und internationale Studien, 27, Köln

(Russsia's population during the transformation. Social exclusion and coping strategies).

The World Bank Group (1999), Countries: Latvia, hitp://wnw worldbank.org/htm/lextdr/offrep/eca/lv2.htm

Townsend, P. (1980), 'Research on Poverty', in Alkinson, A.B. (ed). Wealth, Income and Inequality, Oxford University Press, Oxlord, pp. 298-305.

Trapenciere, I., Pranka, M. Rungule, R. (1998), "Bright sides of the transition overshadowed by new social problems", in Moskatewicz, J., Tigerstedt, C. (eds.). Public Opinion on Social Prablems. A survay around the Battic Sea, NAD Publication No. 36, Helsinki, pp. 43.66.

Trapenciere, h, ef all, (2000), Listening to the Poor: Social Assessment of Poverty in Latwia, Social Policy Research Series, Ministry of Welfare of the Republic of Latvia, UNDP, Riga.

Triest, R.K. (1998), "Has Poverty Gotten Worse?", in Joumal of Ecanomic Perspectives, 12(1), Winter, pp. 97.114. United Nations Development Programme (1990), Human Development Report 1990, UNDP, New York. United Nations Development Programme (1995), Human Development Report 1995, UNDP. New York. United Nations Development Programme (1996), Latvia Human Devolopment Report 1996, UNDP. Riga. 
United Nations Development Programme (1997), Latvia Human Devolopment Report 1997, UNDP, Riga. Unithed Nations Development Programme (1997b), Human Development Report 1997, UNDP. New York. Untited Nations Development Programme (1998a). Poverty in Transition?. Regional Bureau for Europe and the CIS, UNDP, New York.

Uníted Nations Development Programme (1998b). Azerbajan: Humavi Development Report, UNDP, Baku.

United Nations Development Programme (1998c), Belans: State, Gowernance, People. National Human Development Report 1998, UNDP, Minsk.

United Nations Dewelopment Programme (1998d). "The State of Transition and Transition of the State", National Human Development Report: Bulgaria 1998, UNDP, Sofila.

United Nations Development Programme (1998e), Hungany: Human Development Report 1998, UNDP, Budapest. Uritied Nations Development Programme (1998f), Lithuania: Human Development Report 1998, UNDP, Vilnius. United Nations Development Programme (1998g), Uzbekisian: Human Development Report, UNDP. Tashkent. Uniled Nations Development Programme (1998h), Latwia Human Development Report 1998. UNDP. Riga. United Nations Development Programme (1998i), Tajkistan Human Development Report 1998, UNDP. Dushanoe. United Nations Development Programme (1999). Muman Development Repont For Central and Eastern Europe and the CIS, UNDP, New York.

Vasaraduze, I. (1996), "Health', in Aasland, A. (ed.). Latvia: The Impact of the Transformation, The Norbalt Living Conditions Project, Fafo report 188, Fafo, pp. $71-94$.

Vecernilk, J. (1996), Markets and People. The Czech Reion Experience in a Comparative Perspectiwe, Avebury. Aldershot.

Venesaar, U., Hachey, $\Downarrow r .$, G.A., (eds.) (1995). Economic and Sacial Changes in the Baltic States in 1992-1994, Estonian Academy of Sciences, Institute of Economics, Tallinn.

Walle van de, D. Nead, KK. (eds.) (1995), Public Spending and the Poor, Johns Hopkins Uniwersity Press, Baltimore, London.

Word Biank (1993), Latwia. The Transition to a Markef Economy, A World Bank Country Study, The World Bank, Washington DC.

Worlid Bark (1995), Understanding Poverty in Potand, A World Bank Country Study, The World Bank, Washington DC.

Wortd Bank (1996a), Armenia: Confroming Poverty Isswes, Report No. 15693-AM, The World Banlk, Washington DC.

World Bank (1996b), Estonia: Living Standards During the Transition. A Poverty Assessment, Report Mo. 15647. EE, The World Bank, Washington DC.

Word Bank (1996c). Poverty in Ukrane, Report Mo. 15602-UA, The World Bank, Washington DC.

World Bank (1997a), Azerbajan: Poverty Assessment, Volume A: Main Repart, Report No. 15601-AZ, The Wortd Bank, Washington DG.

Worid Bank (1997b), Repubic of Latvia Welfare Reform Project - Project Appraysal Document, Report no. $164 \mathrm{~B}$ LV. The World Bank, Washington DC.

World Bank (1998a), Update on Powerty in the Kyrgyz Republic. Discussion Drate, DECRG, Washington DC mineo.

World Bank (1998b), Kazakhstan: Living Standards During the Transition, Report Wo. 17520-KZ, The World Bank, Washington DC. 
World Bank (1999), Georgia: Poverty and income Distribution, Volume 1: Main Report, The World Bank, Washington $\mathrm{DC}$.

Wulf, F., Berkovich, J. (1997), Municipal Social Assistance in Latwa: The Monitoring Instrument - Evaluation and Recommendations for Improvement, Ministry of Welfare of the Republic of Latvia, Universiteit Maastricht, Stockholm School of Economics Riga, mimeo.

Zohoor, N, et al. (1998), "Monitoring the Economic Transition in the Russian Federation and its Implications for the Demographic Crisis - the Russian Longitudinal Monitoring Survey", in World Development, 26(11), pp. 1977-1993. 


\section{NEDERLANDSE SAMENVATTING}

De probleemstelling van dit onderzoek is hoe de economische transitie van een planeconomie naar een markteconomie de levensstandaard van de bevolking beinvloedt. Letland dient als casus in de voorliggende analyse. Hoewel het een klein land is, zijn de resultaten van deze studie toch relevant voor andere landen in transitie en met name voor de landen in de regio.

In het allgemeen heeft de transitie zowel in fysiologisch als in psychologisch opzicht een catastrofaal effect gehad op de wellvart van een groot deel van de Letse bevolking. Weliswaar beschikken we niet over voldoende data van huishoudens over de gehele periode, toch kunnen we uit de geanalyseerde data concluderen dat de armoede in Letland alomtegenwoordig is en zelfs toeneem. Het feit dat het reele BNP per capita in 1998 nog steeds niet meer dan $59 \%$ van de waarde in 1989 bedraagt, zegt veel over de neerwaartse trend van de inkomens en de levensstandaard waarmee de Letse bevolking werd geconfronteerd. Kwalitatieve informatie verkregen door middel varn een enquête bevestigt dit beeld. De meeste Letten ervoeren de verandering in laun levensstandaard tijdens het afgelopen decennium als negatief. Ze zeggen tegenwoordig minder te kunnen consumeren dan woor de transitie. Men voelt dat men erop achteruit is gegaan en dit gevoel draagt bij aan het pessimisme onder de bevolking.

Het zou te gemakkelijk zijn en niet bevredigend om dit antwoord zonder enige differentiatie aan te nemen. Dit proefschrift belicht de verschillende aspecten in het onderzoek van armoede en welvaart. Het tweede hoofdstuk legt de theoretische en empirische basis door middel van het ontwikkelen van een welvaartsindicator op basis van data uit de Letse huishoudens-enquête ( $L a$ vian household budget survey). De uiteindelijk gekozen indicator vormt het belangrijkste instrument voor het opstellen van een gedetailleerd armoedeprofiel in hoofdstuk drie. De gemaakte keuzes bij het creëren van de welvaartsindicator blijwen altijd subjectief. De indicator gaat uit van de consumptie van huishoudens en is gebaseerd op de totale maandelijkse huishouduitgaven voor goederen en diensten, gekocht, uit eigen productie of gratis verkregen. Niet meegenomen worden uitgaven voor duurzame goederen, belasting en sociale verzekeringen. Wanneer waarden voor woonkosten, gas, water en licht ontbreken, worden ramingen gebruikt. Seizoeninvloeden zijn hierbij gecorrigeerd, evenals regionale prijsverschillen en inflatie aanpassingen. De uiteindelijk gebruikte waarde is het gemiddelde per capita van het huishouden. Sommigen zullen beweren dat niet alle aanpassingen strikt noodzakelijk zijn, terwijl anderen zullen zeggen dat er nog steeds niet genoeg gecorrigeerd is. Welke aanpassingen wel of niet worden gedaan, is echter niet de meest belangrijke beslissing in de anallyse van armoede. Uiteindelijk zullen de exacte getallen misschien verschillen, mar het hoofddoel van het onderzoek is nooit de berekening op zichzelf. De nauwkeurigheid wan de armoede indicatoren is niet het meest belangrijk, aangezien amoede een meerdimensionaal concept is en we de ware rangschikking van alle huishoudens in temen van welstand nooit zullen weten. Het betreft altijd een schatting. Het primaire doel wan armoedeonderzoek is de identificatie van risicogroepen met betrekking to die armoede.

Hoofdstuk drie heeft precies deze doelstelling; het identificeren van kwetsbare groepen in Letland. Meer dan 50\% van de Letse bevolking leef tussen de laagste en hoogste armoedegrens die in dit onderzoek zijn gebruikt. Met uitzondering van de regio rond de hoofdstad Riga, waar het armoede risico llager is dan gemiddeld, komt armoede in het hele land in dezelfde mate voor. De ernst van de armoede is echter afhankelijk van het feit of een huishouden zich op het platteland of in een stad bevindt. Hoe groter de stad des te lager het armoede risico. Desalniettemin leeft de meerderheid van de arme bevolking in en om Riga omdat een derde wan de Letse bevolking in het gebied rond de hoofdstad woont. De meest kwetsbare groepen zijn grote huishoudens, huishoudens met drie of meer kinderen, huishoudens met een jonge of werkloze kostwinner of met een 
kostwinner met een laag opleidingsniveau. Huishoudens die voomamelijk afhankelijk zijn van inkomen uit de landboww of van sociale uitkeringen (met uitzondering van pensioenen) behoren ook tot de risicogroepen. Zoals in andere landen die een soortgelijke transitie ondergaan, zijn de "wokking poor "talrik hoewel hun risico op amoede gemiddeld lager is. Dit is met name te wijten atur lage lonen werborgen werkloosheid. Het armoedeprofiel van Letland is vergelikbaar met dat van landen zoals Polen, Hongarije, Litowwen en Estland. Wanneer we de resultaten van 1.996 en 1997 met elkaar vergelliken, moeten we vaststellen dat de armoede in. Letland zelfs is toegenomen. Naast de numerieke toename van het aantal mensen beneden de amoedegrens moeten we ook constateren dat de afstand tussen de armoedegrens en de gemiddelde welvaart van de amen groter is geworden en dat meer mensen aan de laagste kant van de verdeling leven. Hoewel in dit onderzoek wee achtereenvolgende jaren de revue passeren, mag men niet over het hoofd zien dat het hier een momentopname betref. Deze studie geeft geen uitsluitsel over de vraag of de amoede permanent is of slechts tijdelik. In het laatste geval zijn de zorgen minder omdat men weet dat er betere tijden zullen komen. Dit neemt echter niet weg dat deze groep ook gedurende een tijdelijke welvaartsachterstand hulp van overheidsinstanties kan gebruiken.

Het derde hoofdstuk geeft heel gedetailleerde informatie geeft over de mate en omvang van materiële armoede in Letland, maar het is niet mogelijk iets te zeggen over de dynamiek en de ontwikkeling van de levensstandaard over de afgelopen tien jaar. We weten niet hoe de mensen de eindjes aan elkaar hebben kunnen knopen met het weinige wat ze bezitten of verdienen. Deze vragen staan centraal in de hoofdstukken vier en vijf.

Een additionele dataset geeft de nodige empirische informatie voor de analyses in de hoofdstukken vier, vijf en zes. Voor dit doel hebben we een speciale enquête ontworpen die in 1998 is uitgevoerd. Doelstelling van de enquete was het vergaren van informatic over de perceptie onder de Letse bevolking van de ontwikkelingen in het laatste decennium: hoe zien ze de huidige situatie in vergelijking met voor de transitie, wat zijn hun overlevingsstrategieẻn, en heeft het sociale bijstandsbeleid zijn doelstellingen vervuld. Deze dataset maakt het mogelijk om de effecten van de transitie op hel niveau van huishoudens te bestuderen. Het is een absoluut nieuwe benadering in de studie van de transitie en de levensomstandigheden van de bevolking. De nadruk ligt op de perceptie van de bevolking zélf van de ontwikkelingen in de afgelopen tien jaar met betrekking tot hum welvart en hoe ze daarmee omgaan.

Hoofdstuk vier concentreert zich op de dynamiek van de transitie en op de identificatie van winnaars en verliezers. De uiteindelijke conclusie is dat meer dan $75 \%$ van de bevolking zich tot de verliezers van de transitie rekent. Of dit gevoel de realiteit weerspiegelt, is moeilijk te zeggen op basis van de woorliggende resultaten. Er zün indicaties dat de levensomstandigheden inderdaad heel moeilijk zijn geworden. Dit wordt bevestigd door de achtenuitgang van het reële inkomen en de neerwarste trend van het BNP per capita tot het jaar 1995. Uit hoofdstuk drie bleek al dat de levensstandaard van een meerderheid van de bevolking tussen 1996 en 1997 verder daalde.

Hoewel een ruime meenderheid van de Letse bevolking stelt nadeel te hebben ondervonden van de transitie, zijn niet alle groepen even pessimistisch over hun situatie. Door middel van de analyses in hoofdstuk vier kunnen we een meer gedifferentieerd beeld laten zien. De huidige waarneming van het verleden wordt beînlloed door iemands positie in dat verleden, dus vóór de transitie. Degene die veel te verliezen had, voelt zich vaker een verliezer dan degene die niet veel te verliezen had. De gepensioneerden bijvoorbeeld, hebben een relatief negatieve kijk op de voordelen van de transitic, ondanks het feit dat zij er tegenwoordig niet slechter aan toe zijn dan de gemiddelde Letse inwoners. Gevoelens van onzekerheid zouden deze relatief negatieve perceptie kunnen verklaren. Dit argument wordt bevestigd door de soortgelijke negatieve waarneming van mensen die in 1991 een goedbetaalde baan hadden. Hiertegenover staat de groep die cen invloedrijke positie bekleedde. Zij hebben een redelijk optimistische kijk op hun tegenwoordige situatie. Hetzelfde geldt woor de 
jongere generatie en voor families met kinderen. Deze laatste groepen zin weliswaar heel kwetsbaar volgens het armoedeprofiel in hoofdstuk drie en ook volgens de literatuur over andere landen in de voormalige Sovjet-Unie, maar hun waarneming is vaker positiever. Dit zou een weerspiegeling kunnen zijn van het gevoel dat de tegerwoordig harde levensomstandigheden slechts tijdelijk zijn, en dat betere tijden in het verschiet liggen. Tot de groepen die voor hun gevoel voomamelijk verloren hebben, behoren de werklozen, de boeren en diegene die tot de armste $20 \%$ van de bevolking moeten worden gerekend. Het feit dat een mime meerderheid vindt dat ze erop achteruit is gegaan, is een politieke realiteit die niet over het hoofd mag worden gezien. Een van de voornaamste conclusies van deze analyse is dat het leven niet alleen moeilijker is geworden, maar ook onzekerder. De toekomst is ongewis. De mensen zijn armer en pessimistischer.

De in hoofdstuk drie vastgestelde kwantitatieve informatie over armoede in Letland, wordt in hoofdstuk vier vanuit een subjectief standpunt bevestigd. In hoofdstuk vijf wordt onderzocht welke strategieën de arme (en niet-arme) huishoudens toepassen om rond te komen. Wüj definiëren vijf categorieën van dergelijke strategieën: inkomen genererende activiteiten, huishoudproductie, besparende maatregels, ondersteuning door het sociale netwerk en crisis activiteiten. Op basis van deze classificatie wordt in hoofdstuk vijf het belang van deze strategieen voor het dagelijkse overleven geanalyseerd. Een belangrijk resultaat van het onderzoek is dat het niet alleen arme huishoudens zijn die de strategieën gebruiken. Strategieền die in alle lagen van de bevolking worden toegepast, ongeacht het welvaartsniveau van het huishouden, zijn spaamaatregelen, huishoudproductie en het verkrijgen van ondersteuning door andere huishoudens. Het is niet mogelijk een sterke correlatie tussen de levensstandaard en de gangbaarheid van een bepaalde strategie te ontdekken, maar wel tussen de levensstandaard en het aantal van de gebruikte strategieën. Het blijkt dat arme huishoudens om rond te komen vaak hun toevlucht moeten zoeken tot meerdere strategieën tegelijkertijd. Terwijl meer dan $90 \%$ van de bevolking probeert op één onderdeel te besparen, doen de armen dat op meerdere onderdelen. Arme huishoudens produceren meerdere goederen en diensten thuis en ze hebben meer dan éen activiteit die additioneel inkomen genereert. Soms is leeftijd een sterker bepalende factor dan de inkomensverdeling. De oudere generatie heeft bijwoorbeeld over het algemeen minder schulden dan huishoudens met jongere kostwinners. Ouderen zijn ook minder vaak bezig met inkomen genererende activiteiten, maar ze proberen wel het meest te besparen. In huishoudens met een kostwinner van middelbare leeftijd wordt vaker thuis geproduceerd dan in huishoudens met een jong of een oud hoofd. Jonge huishoudens kunnen vaak op hulp van buitenaf rekenen. Het feit dat bijna elk huishonden in Letland een of andere strategie toepast om het in het dagelijkse leven te redden, zegt iets over het algemene welvaartsniveau in dit land. Het bevestigt de eerdere bevinding dat de levensstandaard flink is gedaald na de transitie en dat de armoede is toegenomen. Omdat we ons in dit onderzoek hoofdzakelijk op de armen concentreren, dreigen we te vergeten dat de algemene welvaart relatief laag is. Aan de andere kant kumnen we de conclusies van hoofdstuk vijf ook zodanig interpreteren dat de armsten diegenen zijn die juist géén of minder strategieên ter beschikking hebben. Zij zijn niet in staat verder te besparen omdat ze al op het minimum leven en bovendien is hun sociaal newwerk vaak zwak. Ze krijgen duidelijk minder hulp van buitenaf dan andere huishoudens. De beschikbaarheid van een functionerend sociaal netwerk alsmede de mogelijkheid om overllevingsstrategieën toe te passen, zijn mogelijk verklarende factoren voor de positie van een huishouden bimen de Letse inkomensverdeling. Het lijkt alsof degenen die een strategie succesvol kunnen toepassen, zich in cen relatief betere positie bevinden dan personen die geen mogelijkheden meer hebben om additioneel inkomen te genereren of de consumptie te reduceren. Dit impliceert dat het algemeen welvaartsniveau in Letland relatief laag is. Iedereen moet rondkomen van het weinige wat ter beschikking staat en alle mogelijke strategieën exploiteren. De armste huishoudens doen weliswar hetzelfde maar het resultaat is minder effectief omdat ze geen toegang hebben tot 
meer kapitaal, meer werk of betere relaties, noodzakelijk bij het volgen van een bepaalde strategie.

In hoofdstuk zes verschuift het perspectief naar het sociaal beleid. Twee vragen staan er certraal: is het Letse sociale bijstandsbeleid effectief in het bereiken van de doelgroep en het ondersteunen wan de armen, en vragen de Letten inderdaad de overheid om thulp in geval van nood? De hoofdconclusie is dat het huidige Letse sociale zekerheidsstelsel niet echt effectief is in het bereiken van de doelgroep. De talnjke uitkeringen, de werschillen tussen de gemeentes bij de handhaving van de wet en de willekeur in de beslissing of iemand bijstandgerechtigd is, maken deel wit van hel probleem. Er is gebrek aan financièn, waardoor gemeentes steeds minder geld beschikbaar hebben voor bijstand. Verder blijkt de centrale overheid niet in staat het beleid op adequate wijze the monitoren en te evalueren. Het gevolg is dat de overheid onvoldoende ondersteuning kan bieden aan de gemeentes bij de implementatie van (niewwe) wetgeving waardoor een tijdige interventie bij voorbaat us uitgesloten.

Vanuit het standpunt wan de bevolking kunnen we concluderen dat de mensen niet bij de overheid aankloppen voor hulp. Ze zijn of niet geinformeerd over het feit dat ze deze mogelijkheid hebben, of ze hebben zich neergelegd bij de situatie. Dit resultaat is gerelateerd aan de eerdere conclusie dat het beleid ineffectief is. Het is moeilijk om de bevolking geïnformeerd te houden over een dergelijk gefragmenteerd sociaal beleid. Met het uiteenvallen van het Sovjet systeem hebben. de Letten een tamelijk omvattend sociaal zekerheidsstelsel verloren. De overtheid is nog steeds bezig. om een nieuwe aanpak te zoeken voor een sociaal beleid waarmee de bevolking kan worden opwangen die geconfronteerd wordt met compleet nieuwe uitdagingen. Naarmate het dagelijkse leven zwaarder werd, verloren de mensen het vertrouwen in de overheid en in haar vermogen de bevolking te helpen wanneer dat nodig is. Voor de burgers lijkt het huidige systeem minder te bevatten dan wat voor de transitie geboden werd. De resultaten van de enquête bevestigen het verlies van vertrouwen in de staat. De Letten verwachten over het algemeen niet al te veel. Dit komt misschien door slechte ervaringen in het verleden. Deze instelling kan hen echter wel behoeden voor toekomstige teleurstellingen. Men acht de overheid niet in staat effectieve hulp te bieden.

Het verwijt gaat niet naar de doelstellingen van het sociale beleid, maar naar de opzet en de implementatic ervan. Daarom stellen wij een vereenvoudiging van het locale sociale bijstandsbeleid voor. Onze aanbeveling is de introductie van een gebundelde maandelijkse uitkering gebaseerd op een minimum inkomen dat gegarandeerd is en afhankeliik van het ter beschikking staande budget. Daarnaast zou het totale budget voor gemeentelijke bijstandsuitkeringen tot één procent van het BNP verhoogd moeten worden. Een monitoring en evaluatie systeem op centraal niveau gevoed door regelmatige imput van het lokaal niveau, schept een instrument warmee de beleidsmakers over de effectiviteit en tekortkomingen van het toegepaste beleid kunnen worden geinformeerd. Een informatie campagne op gemeentelijk niveau kan enerzijds worden gebruikt om het publiek op te hoogte te houden van de beschikbare uitkeringen en diensten en anderzijds de communicatie tussen overheid en bevolking verbeteren.

We mogen echter niet vergeten dat onderzoek naar de gevolgen van de economische transitie vrij nieuw is. Er zijn pas tien jaar voorbij sinds de omwenteling begon in Centraal-en Oost-Europa en de voormalige Sovjet-Unie. Vanuit het onderzoeksoogpunt is dat nog steeds een korte periode on het geeft tegelijkertijd aan waarom we nauwelijks weten hoe het de mensen is vergaan. We weten hoe de economie zich heeft ontplooid en we hebben tamelijk goed zicht op de macro-economische impact van de transitie. Op het niveau van de huishoudens ziet dat heel anders uit. Hoewel er talrijke studies over armoede zijn uitgevoerd in die landen, is het onderzochte tijdsbestek meestal niet langer dan een jaar en kunnen we alleen over momentopnames praten. We weten vrij weinig over het effect van de transitie op de huishoudens en we hebben nauwelijks gegevens over hoe de huishoudens met deze moeilijke economische omstandigheden zijn omgegaan in het dagelijkse leven. Sommige gedeeltes van deze studie zijn zo nieuw dat we geen referentiepunt hebben om onze 
bevindingen te kumnen relateren en evalueren. Voor zover wij weten is dit de eerste studie over de dynamiek van de transitie op huishoudniveau en over hoe de mensen hun huidige situatie ervaren in vergelijking tot het verleden. Wij denken dat deze studie ertoe bijdraagt de problemen in landen in transitie beter te begrijpen. We hebben gedetailleerde informatie aangevoerd over amoede in Letland en over de manier watop mensen omgaan met de veranderingen waarmee ze werden geconfronteerd. Meer onderzoek is echter nodig. Analyse wan paneldata zou kunnen bijdragen tot een beter inzicht in de betrokkenheid en de reacties van de huishoudens. Helaas is de aanvankeijke opzet van de Letse huishoudenquête verandend. Oorspronkelijk voorzag de opzet in het opbouwen van een dergelijk panel. Budgettaire problemen alsmede een lage response hebben het CSB doen besluiten dit panel stop te zetten. De 'NORBALT Living Condition Survey' wordt in 1999 herhald. Daarmee zullen we een beter inzicht krijgen in de huidige levensomstandigheden en de ontwikkelingen sinds 1994. Vanuit wetenschappelijk oogpunt is meer fundamenteel onderzoek op het gebied van de equivalentieschalen nodig. Binnen het armoede en ongelijkheidsonderzoek bestaat daarvoor nog steeds geen bevredigende methode.

Een andere open vraag wellicht hypothetisch en die we nog steeds niet kunnen beantwoorden, is of de mensen dezelfde keuzes nog eens zouden maken nu ze weten wat ze tijdens de transitie te wachten staat. Met andere woorden: was de prijs de moeite waard? Hoewel deze vraag puur retorisch is, geeft ze toch een indicatie dat meerdere aspecten moeten worden meegenomen in de beschouwing. We menen te kunnen stellen dat de prijs voor de vrijheid hoog was. Maar waren de kosten ook evenredig verdeeld onder de bevolking? Was de prijs hetzelfde voor iedereen? Wat Letland betreft, kumen we stellen dat de meerderheid door moeilijke economische tijden heen moest en nog steeds moet. De meesten moeten één dubbeltje twee keer omdraaien woordat ze het uitgeven. Wij in het Westen dachten dat men nu gelukkig zou zijn, ongeacht de prijs ervoor zou worden betaald, en dat geen prijs te hoog zou zijn voor waarden als vrijheid en denocratie. Deze houding is uitermate arrogant, gezien de ontwikkelingen over de laatste tien jaar en de onveranderd negatieve uitwerkingen op de levensstandaard van de mensen. Het duurde vijf jaar voordat de Letse economie eindelijk weer positieve groeicijfers produceerde. Voor de anmste Letten is de levensstandaard zelfs na zeven jaar nog steeds dalend. Slechts een kleine minderheid van de bevolking wist zich te herstellen en zelfs van de nieuw markteconomie te profiteren. De meeste mensen moesten zeer veel opgeven. Niet alleen daalden lonen en inkomens en veranderden nomen en waarden, maar vooral het verlies van een bepaald gewoel van zekerheid weegt zwaar in het waargenomen welzijn. De mensen zijn nog steeds aan het worstelen en slechts weinigen zijn in een positie om wan de voordelen van de transitie te profiteren. Niet alleen degenen die alle bromnen hebben uitgeput om te kunnen overleven in het dagelijks bestaan hebben behoefte aan concrete ondersteuning. De hele bevolking heeft morele ondersteuning en aanmoediging nodig om vol te houden totdat betere tijden komen.

Voor beleidsmakers geeft deze studie aanknopingspunten bij de opzet van een sociaal zekerheidsstelsel en bij de ontwikkeling van een communicatiestrategie met de bevolking. We hebben het helemaal niet gehad over economische groei of het scheppen van werkgelegenheid, alhoewel dit sleutelfactoren zijn voor de verdere ontwikkeling van Letland. Wij beschouwen dit als een gegeven uitgangspunt. Letland is zeker op het juiste pad gezien de lopende projecten en beleidsontwikkelingen. Maar net zoals Rome niet in éen dag is gebouwd, zo zal het ook in Lefland nog lang duren voordat men zich volledig heeft aangepast aan de 'nieuwe' economische en politieke situatic. 



\section{Curriculum Vitae}

Franziska Gassmann was born in St. Gallen (CH) on April 21, 1962. She grew up in Switzerland and visited the teacher training college after she had finished the high-school in Immensee. Some years of working, first at a public school and then in the priwate sector, in and around Zurich were followed by her emigration to the Netherlands in order to live together with her Dutch husband. In 1991 she started to study economics at the Universitent Maastricht, and received the Master in International Economic Studies in 1995 with distinction. Already towards the end of her study, she has been involved in projects of the World Bank in Latvia and Lithuania. During the course of her dissertation at the Universiteit Maastricht she continued to work as a consultant for the World Bank and other international organizations, and to teach at the Universiteit Maastricht. 



\section{Annex 1}

Household Budget Survey Questionnaire and Diary 



\section{HOUSEHOLD QUESTIONNAIRE}

Household Budget Survey.

1997

\begin{tabular}{|l|l|}
\hline Year & \\
\hline Month & \\
\hline Including in panel & \\
\hline PSU \# & \\
\hline Household \# & \\
\hline
\end{tabular}

\begin{tabular}{|l|}
\hline Interviewer code \\
\hline Operator code \\
\hline
\end{tabular}

Type of household

DEPARTMENT OF SOCIAL STATISTICS

CENTRAL STATISTICAL BUREAU 


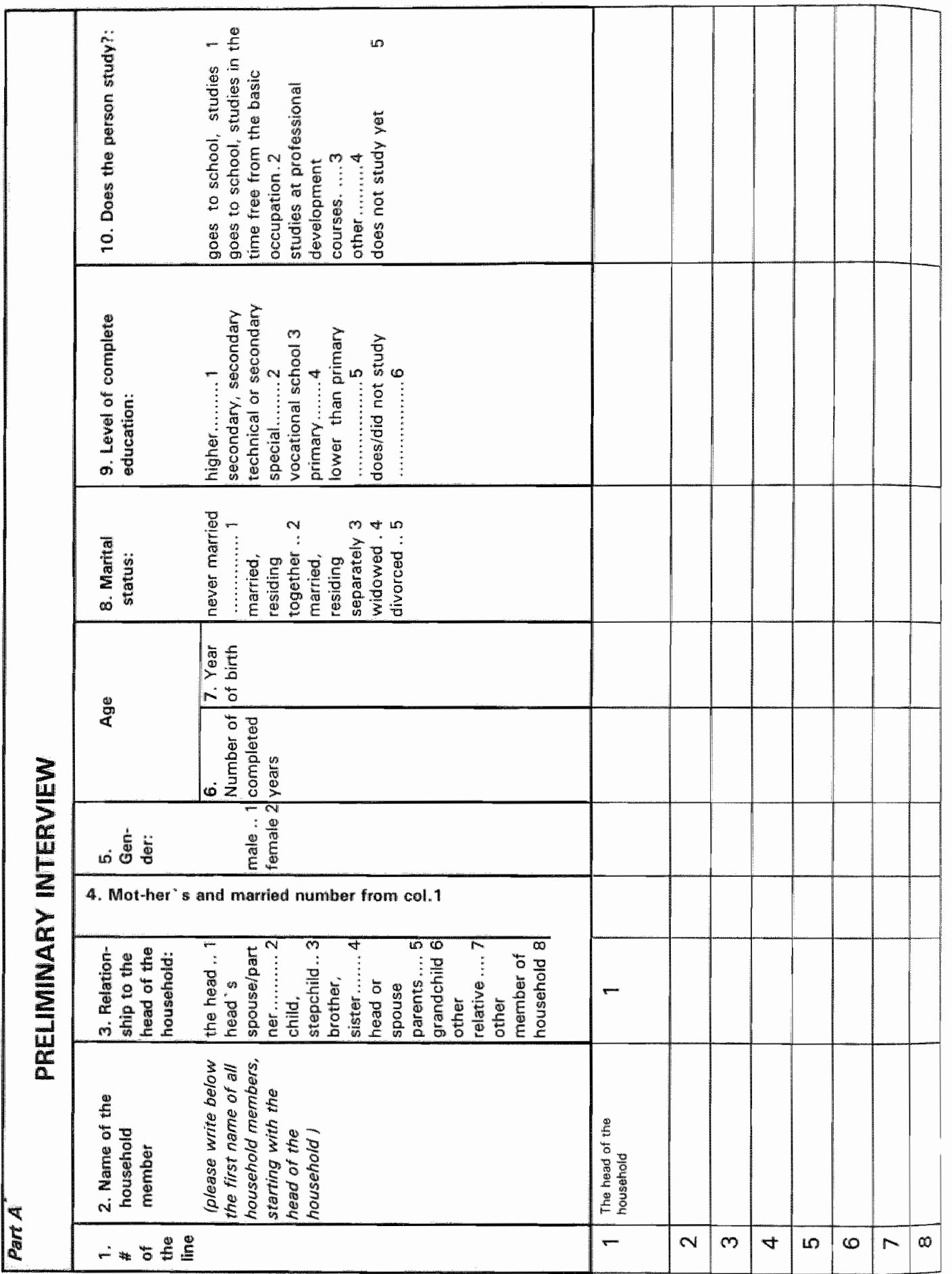




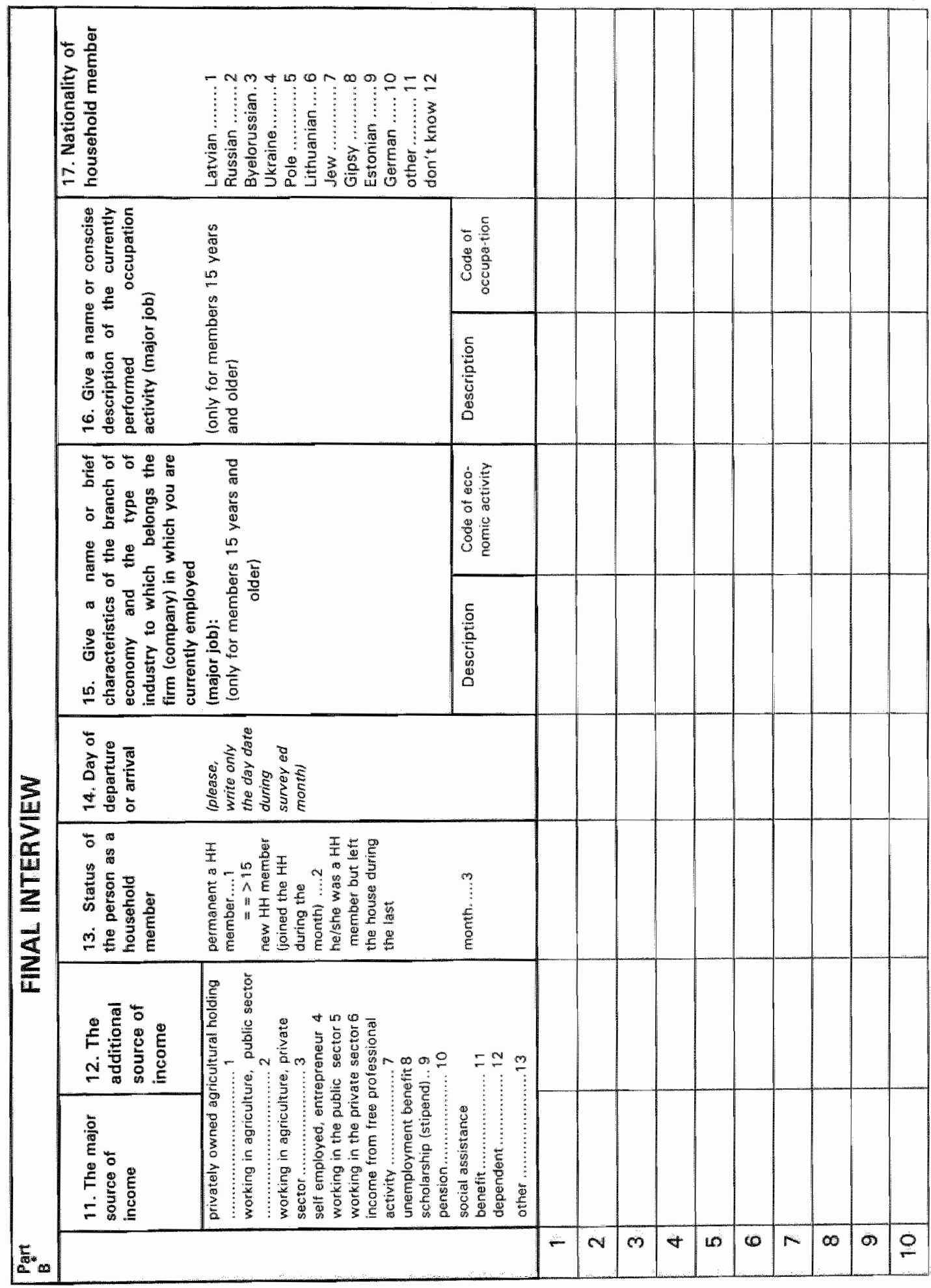




\section{HOUSING CONDITIONS}

\begin{tabular}{|c|c|c|}
\hline $\begin{array}{l}\text { 1. } \\
\text { of } \\
\operatorname{lin} \theta\end{array}$ & 2. then & $\begin{array}{l}\text { 3. Piease. } \\
\text { inusert symbol } \\
\text { of proper } \\
\text { category }\end{array}$ \\
\hline 1 & 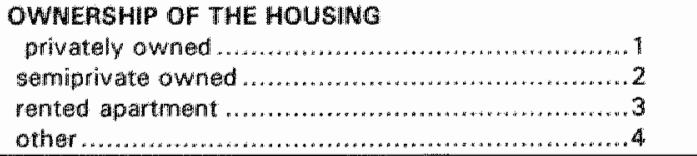 & \\
\hline 2 & 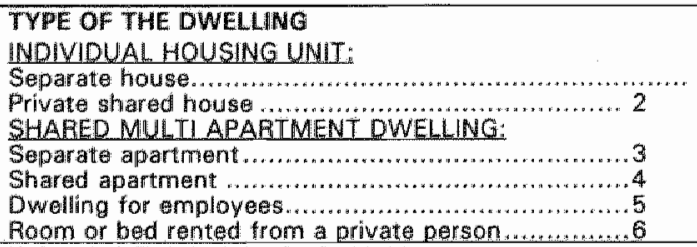 & \\
\hline 3 & 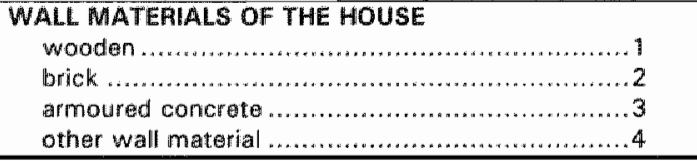 & \\
\hline 4 & FACILITIES AVALABLE AT THE HOUSING UNIT & $\begin{array}{l}\text { insert "if if } \\
\text { YES and " } 2 \text { " if } \\
\text { NO }\end{array}$ \\
\hline & 1. Electricity & \\
\hline & 2. Water supply & \\
\hline & 3. Sewarago & \\
\hline & 4. WC & \\
\hline & 5. Hot water supply & \\
\hline & 6. Central heating system & \\
\hline & 7. Shower, bath & \\
\hline & 8. Separate kitchen & \\
\hline & 9. Gas Irom network & \\
\hline & 10. Gas fiom container & \\
\hline & 11. Elloctric ovan & \\
\hline & 12. Tutephone: & \\
\hline
\end{tabular}

\begin{tabular}{|r|ll|l|}
\hline 5 & How many rooms does whe household live in? & rooms \\
\hline 6 & The total area of the housing of the household & $\mathrm{m}^{2}$ \\
\hline 7 & of which living space & $\mathrm{min}^{2}$ \\
\hline
\end{tabular}

\section{THE AREA OF LAND USED BY THE HOUSEHOLD}

\begin{tabular}{|c|c|c|}
\hline $\begin{array}{l}\text { 1. Does Your household own a plot of land? } \\
\qquad \begin{array}{l}\text { yes }-1, \text { no }-2=>4 \text { tab. }\end{array}\end{array}$ & & \\
\hline Characteristics of the land & $\begin{array}{l}\text { Total area } \\
\text { (ha) }\end{array}$ & $\begin{array}{l}\text { Agricultural } \\
\text { area (ha) }\end{array}$ \\
\hline 2. Agricultural land of a farmer & & \\
\hline 3. Plot of land beside the house & & \\
\hline 4. Rented land & & \\
\hline 5. Plot of lland beside a summer house, small garden & & \\
\hline 6. Other & & \\
\hline
\end{tabular}




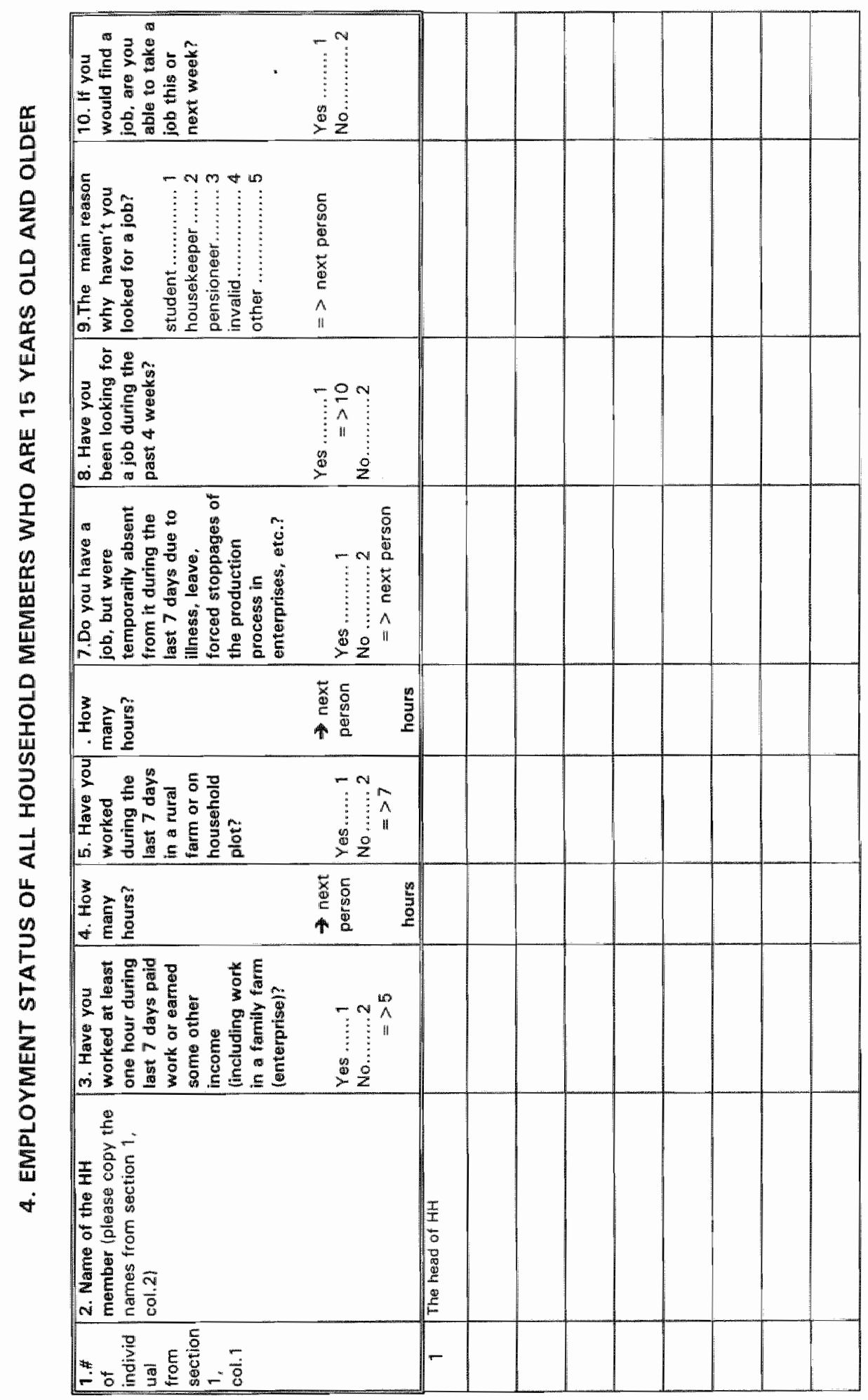




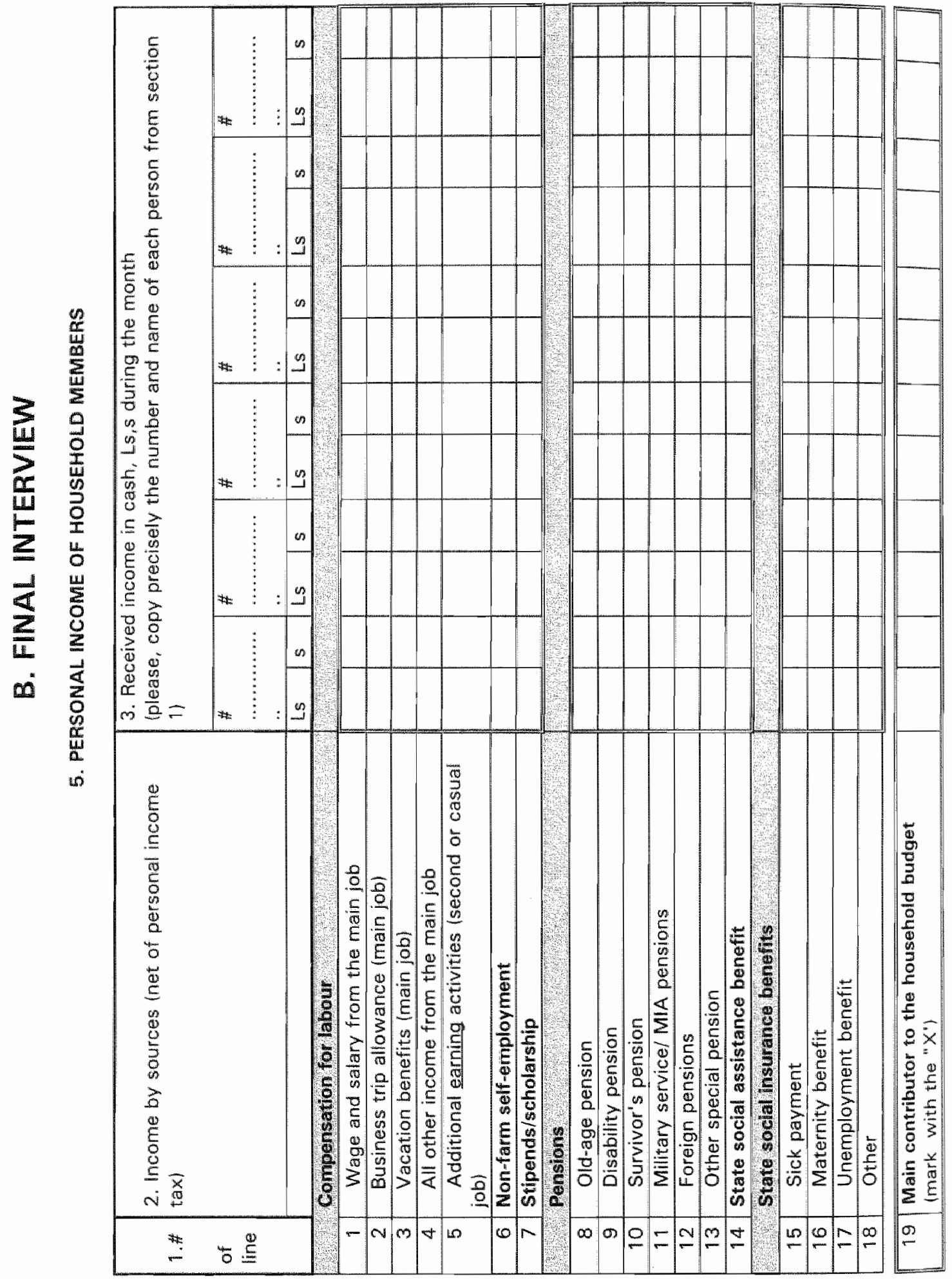




\section{INCOME OF THE HOUSEHOLD AS A WHOLE}

\begin{tabular}{|c|c|c|c|}
\hline \multirow[t]{2}{*}{$\begin{array}{l}\text { 1. \#. } \\
\text { of } \\
\text { line }\end{array}$} & \multirow[t]{2}{*}{ 2. Item } & \multicolumn{2}{|c|}{$\begin{array}{l}\text { 3. Received } \\
\text { income in } \\
\text { cash during } \\
\text { the month }\end{array}$} \\
\hline & & Ls & s \\
\hline & $\begin{array}{l}\text { State social secuifity and assistance } \\
\text { benefits: }\end{array}$ & & \\
\hline 1 & Family allowance & & \\
\hline 2 & Child care allowances & & \\
\hline 3 & Birth grant & & \\
\hline 4 & Funeral grant & & \\
\hline 5 & $\begin{array}{l}\text { Other state social assistance benefits } \\
\text { (not included in section 1) }\end{array}$ & & \\
\hline \multicolumn{2}{|r|}{ Local municipalities assistance benefits } & & \\
\hline 6 & Housing benefit & & \\
\hline 7 & Cash benefit for improving the health & & \\
\hline 8 & Cash benefit to low-income families & & \\
\hline 9 & $\begin{array}{l}\text { Other local municipalities assistance } \\
\text { benefits }\end{array}$ & & \\
\hline 10 & $\begin{array}{l}\text { Other benefits from charity and } \\
\text { humanitarian institutions }\end{array}$ & & \\
\hline 11 & Private alimonies & & \\
\hline \multicolumn{2}{|r|}{ Ineome from own property: } & & \\
\hline 12 & rent of housing & & \\
\hline 13 & rent of other property & & \\
\hline 14 & rent of land & & \\
\hline 15 & interest on bank deposits & & \\
\hline 16 & dividends & & \\
\hline 17 & other & & \\
\hline \multirow{2}{*}{\multicolumn{2}{|c|}{$\begin{array}{l}\text { Income from selling of own property: } \\
\text { commodities }\end{array}$}} & & \\
\hline & & & \\
\hline 19 & real estate & & \\
\hline 20 & land, forest & & \\
\hline 21 & other & & \\
\hline \multicolumn{2}{|r|}{ Other income from selling: } & & \\
\hline 22 & berries, mushrooms, fish, etc. & & \\
\hline 23 & scrap-iron, bottles, papers etc. & & \\
\hline 24 & other & & \\
\hline 25 & Lotteries, other gambling & & \\
\hline 26 & Other income & & \\
\hline
\end{tabular}




\section{FINANCIAL TRANSFERS}

\begin{tabular}{|c|c|c|c|}
\hline \multirow[t]{2}{*}{$\begin{array}{l}\text { 1. \# of } \\
\text { line }\end{array}$} & \multirow[t]{2}{*}{ 2. Trem } & \multicolumn{2}{|c|}{$\begin{array}{l}\text { 3. Received in } \\
\text { cash during the } \\
\text { month }\end{array}$} \\
\hline & & LS & $\mathrm{s}$ \\
\hline & Bank credit/loan / withdrawal & & \\
\hline 1 & - taken & & \\
\hline \multirow[t]{2}{*}{2} & - withdrawal & & \\
\hline & Public non bank credit/loan / withdrawal & & 3 \\
\hline 3 & - taken & & \\
\hline \multirow[t]{2}{*}{4} & - withdrawal & & \\
\hline & Private non-bank credit/loan & & \\
\hline 5 & - taken & & \\
\hline 6 & - regained & & \\
\hline 7 & Security/shares (sold) & & \\
\hline 8 & Foreign currency (sold) & & \\
\hline 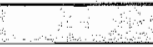 & Insurance indemnities & 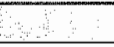 & 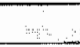 \\
\hline 9 & life & & \\
\hline 10 & private pensions and other funds & & \\
\hline 11 & household equipment & & \\
\hline 12 & housing & & \\
\hline 13 & vehicles & & \\
\hline 14 & other insurance & & \\
\hline 8 & Gifts/inheritance & अं। & 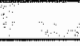 \\
\hline 15 & from parents & & \\
\hline 16 & from children & & \\
\hline 17 & from relatives/friends & & \\
\hline 18 & from employer & & \\
\hline 19 & Other & & \\
\hline
\end{tabular}




\section{EQUIPMENT IN DURABLE GOODS}

\begin{tabular}{|c|c|c|c|c|}
\hline $\begin{array}{l}\text { 1. Nr of } \\
\text { line }\end{array}$ & 2. Item & $\begin{array}{c}\text { 3.Does } \\
\text { your } \\
\text { household } \\
\text { own } \\
\text { any item ? } \\
\text { YES } \\
\text { NO....1 } \\
\ldots . . . .2\end{array}$ & $\begin{array}{c}\text { 4. How } \\
\text { many of } \\
\text { them are } \\
\text { in } \\
\text { applicabl } \\
\text { e state? }\end{array}$ & $\begin{array}{l}5 . \text { Of } \\
\text { which } \\
\text { hovw } \\
\text { many are } \\
\text { purchase } \\
\text { d in last } \\
5 \text { years? }\end{array}$ \\
\hline & LEISURE AND CULTURAL GOODS: & & & \\
\hline 1 & - TV set: colour & & & \\
\hline 2 & - TV set: black and white & & & \\
\hline 3 & - Video recorder & & & \\
\hline 4 & - Tape recorder & & & \\
\hline 5 & - Record player & & & \\
\hline 6 & - Hi-fi stereo, radiogram & & & \\
\hline 7 & - CD player & & & \\
\hline 8 & - Radio set, tuner & & & \\
\hline 9 & - Film camera & & & \\
\hline 10 & - Video camera & & & \\
\hline 11 & - Photo camera & & & \\
\hline 12 & - Slide/film projector & & & \\
\hline \multirow[t]{2}{*}{13} & - Piamo & & & \\
\hline & \multicolumn{4}{|c|}{ ELECTRIC APPLIANCES FOR HOUSEHOLD PURPOSES: } \\
\hline 14 & - Refrigerator & & & \\
\hline 15 & - Deep freezer & & & \\
\hline 16 & - Washing machine & & & \\
\hline 17 & - Sewwing machine & & & \\
\hline 18 & - Vacuum cleaner & & & \\
\hline 19 & - Air conditioner & & & \\
\hline 20 & - Microwave oven & & & \\
\hline 21 & - Dishwasher & & & \\
\hline \multirow[t]{2}{*}{22} & - Electric floor polisher & & & \\
\hline & \multicolumn{4}{|l|}{ MEANS OF TRANSPORTATION OR RECREATION: } \\
\hline 23 & - Bicycle:-adult & & & \\
\hline 24 & - Bicycle:- children & & & \\
\hline 25 & - Moped & & & \\
\hline 26 & - Motorcycle, scooter & & & \\
\hline 27 & - Car & & & \\
\hline 28 & - Boat & & & \\
\hline 29 & PERSONAL COMIPUTER & & & \\
\hline
\end{tabular}




\section{RESPONDENT SELF ASSESSMIENT OF THE HOUSEHOLD LIVING CONDITIONS}

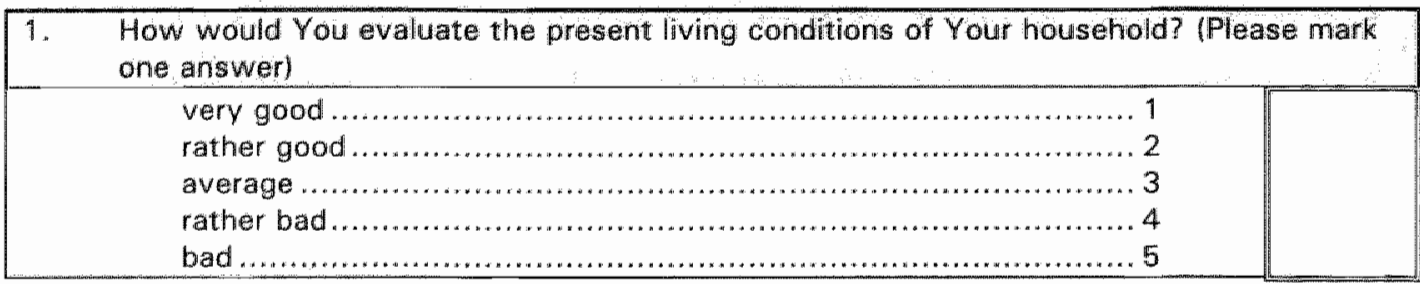

2. What is the minimum amount of money your household needs to make ends meet? 

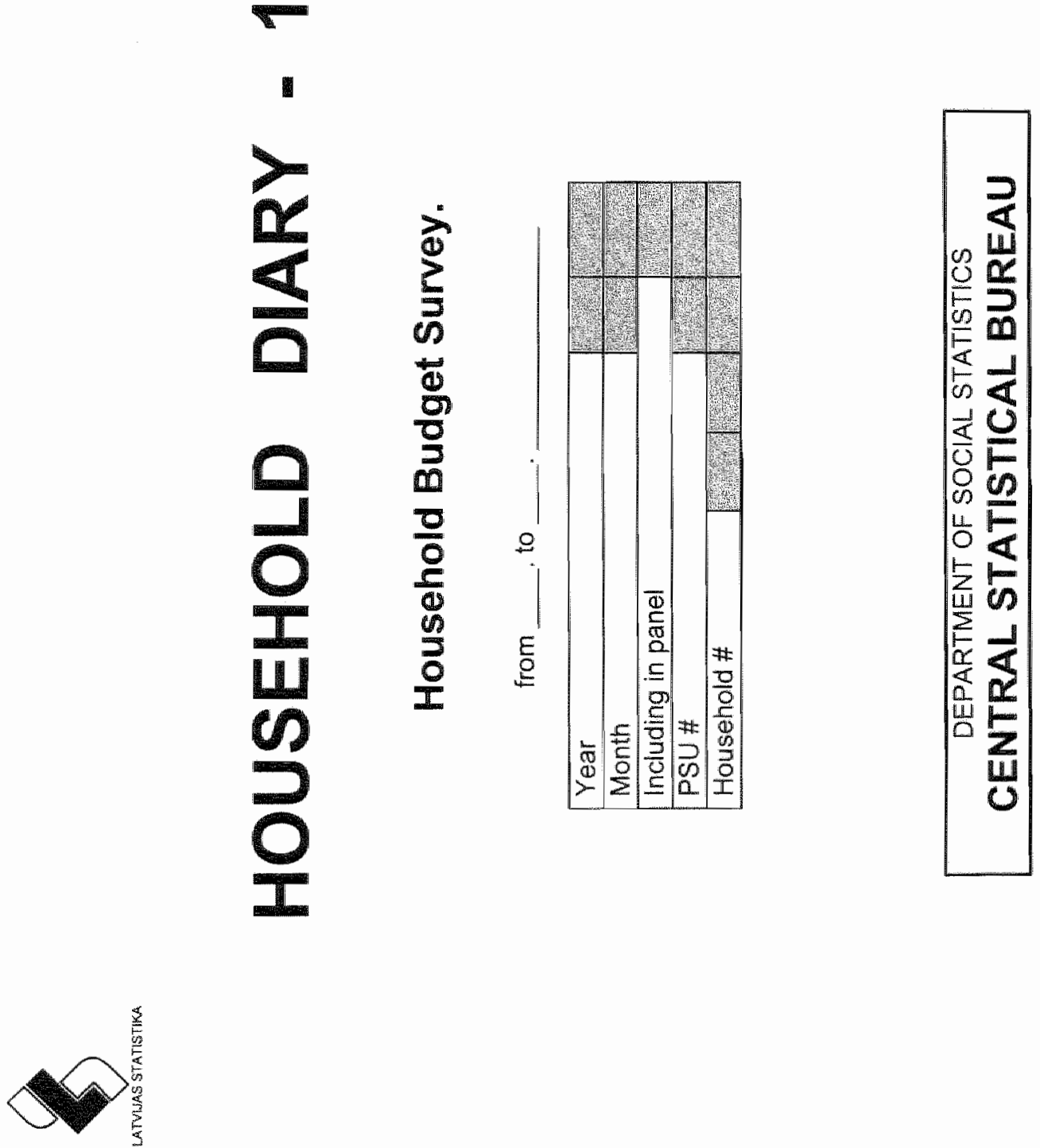


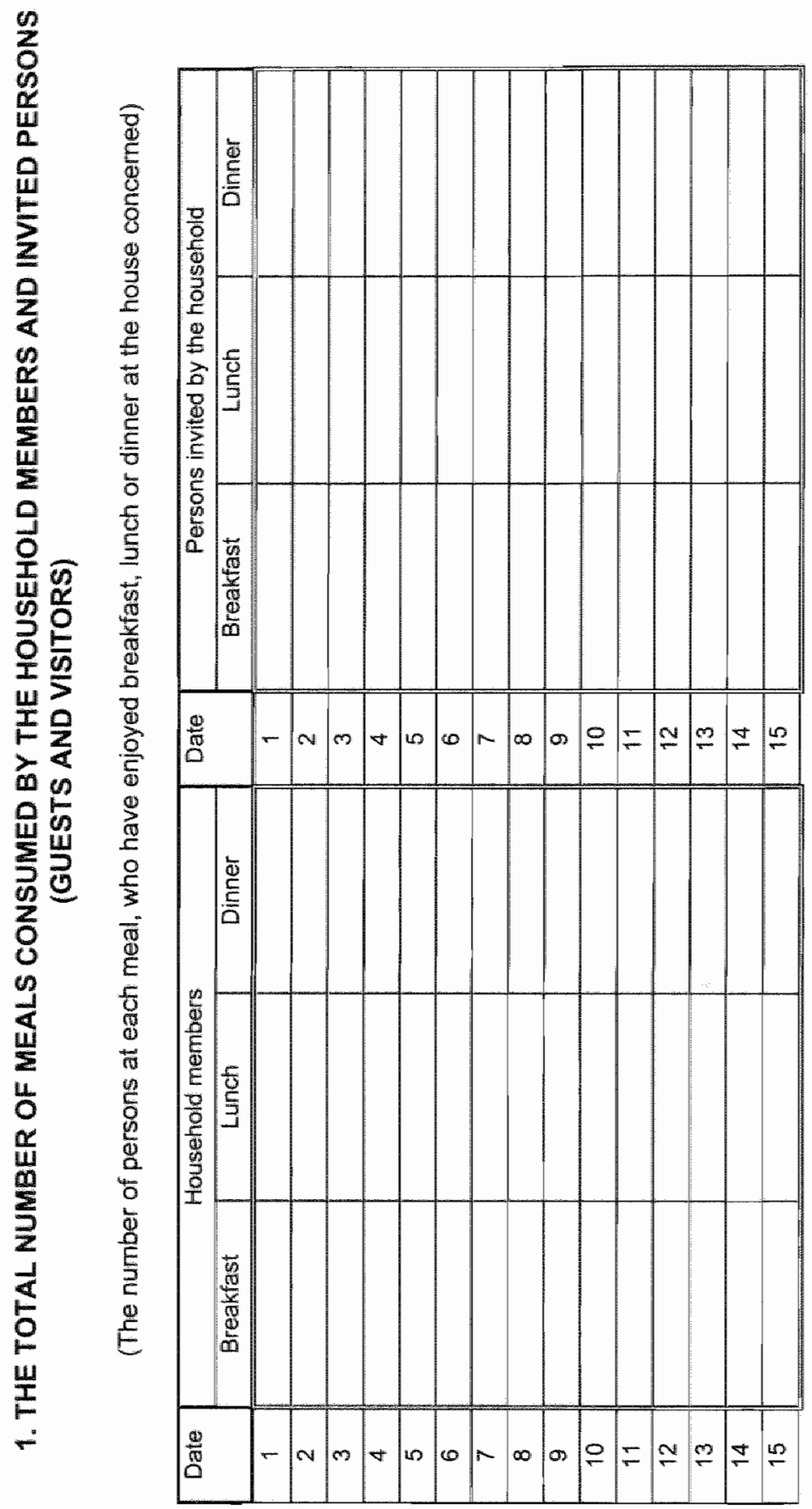




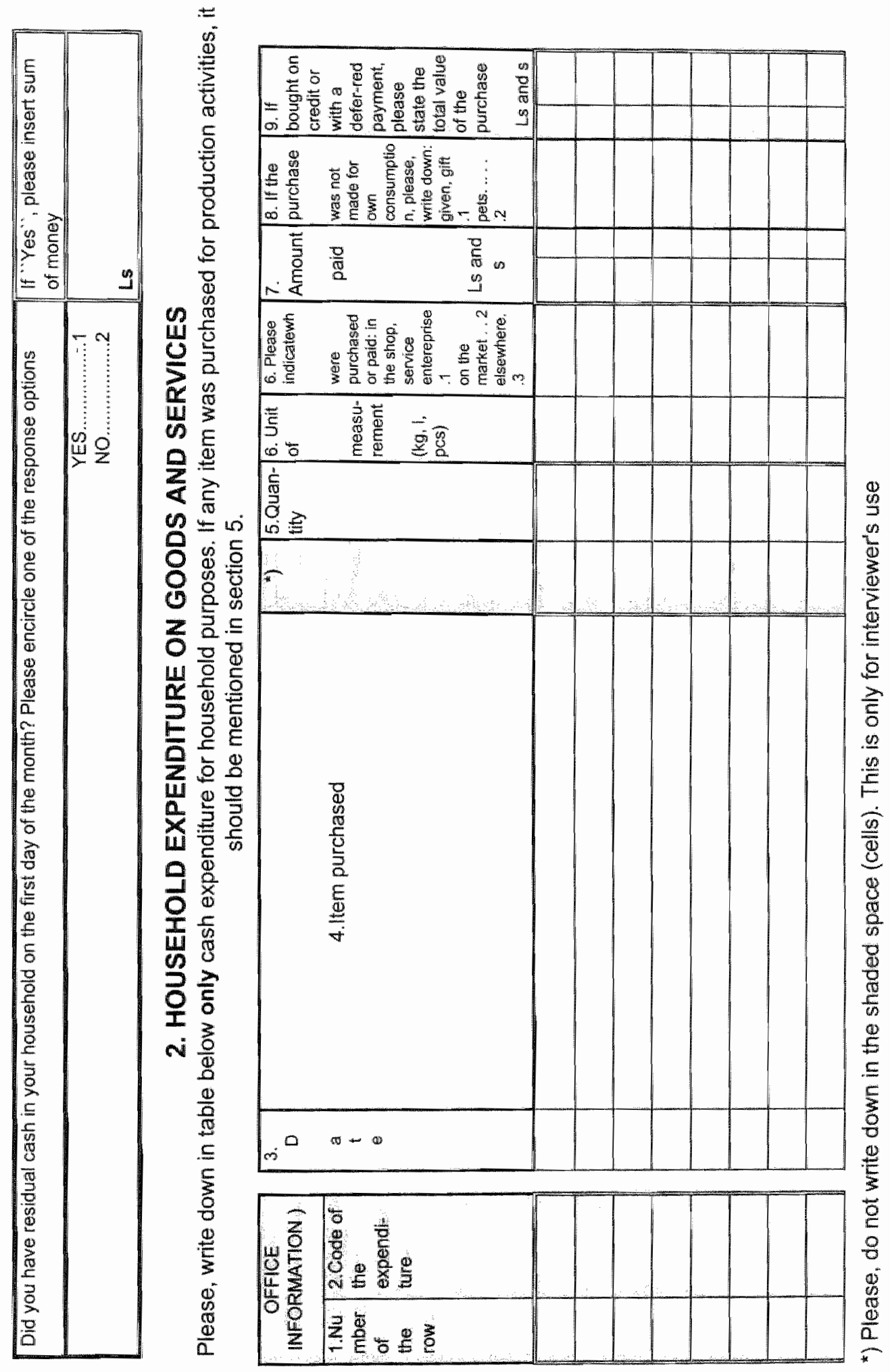




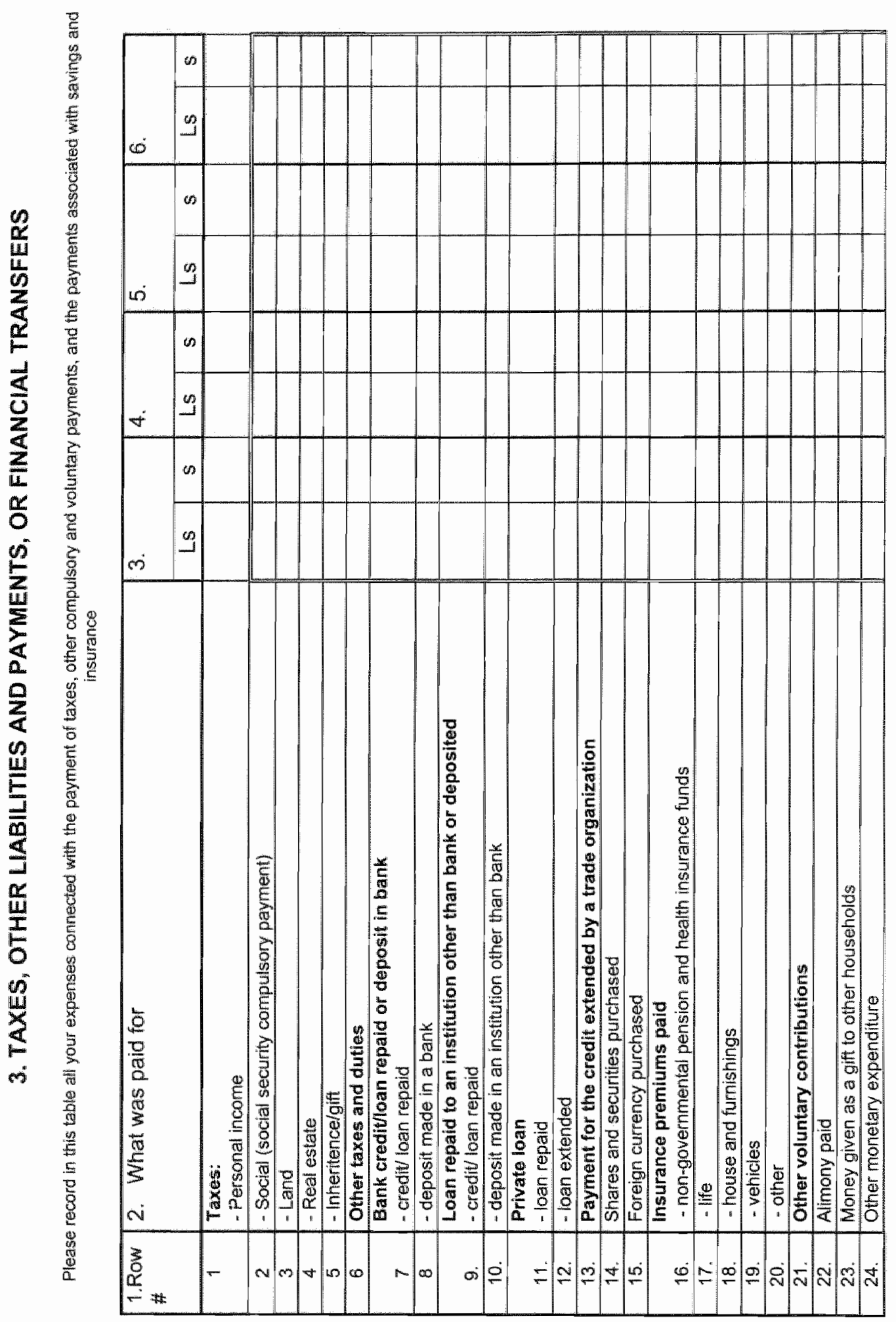




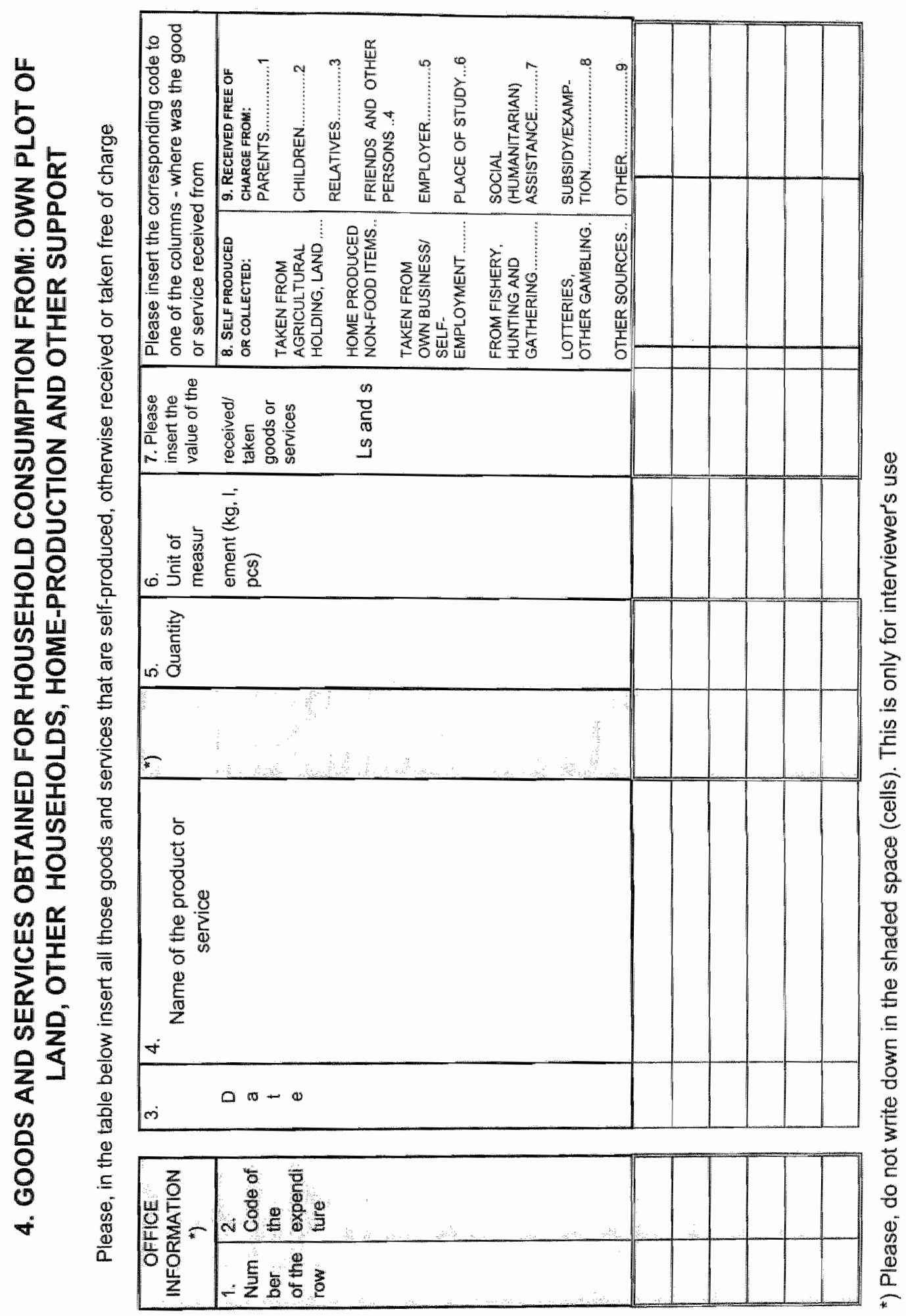




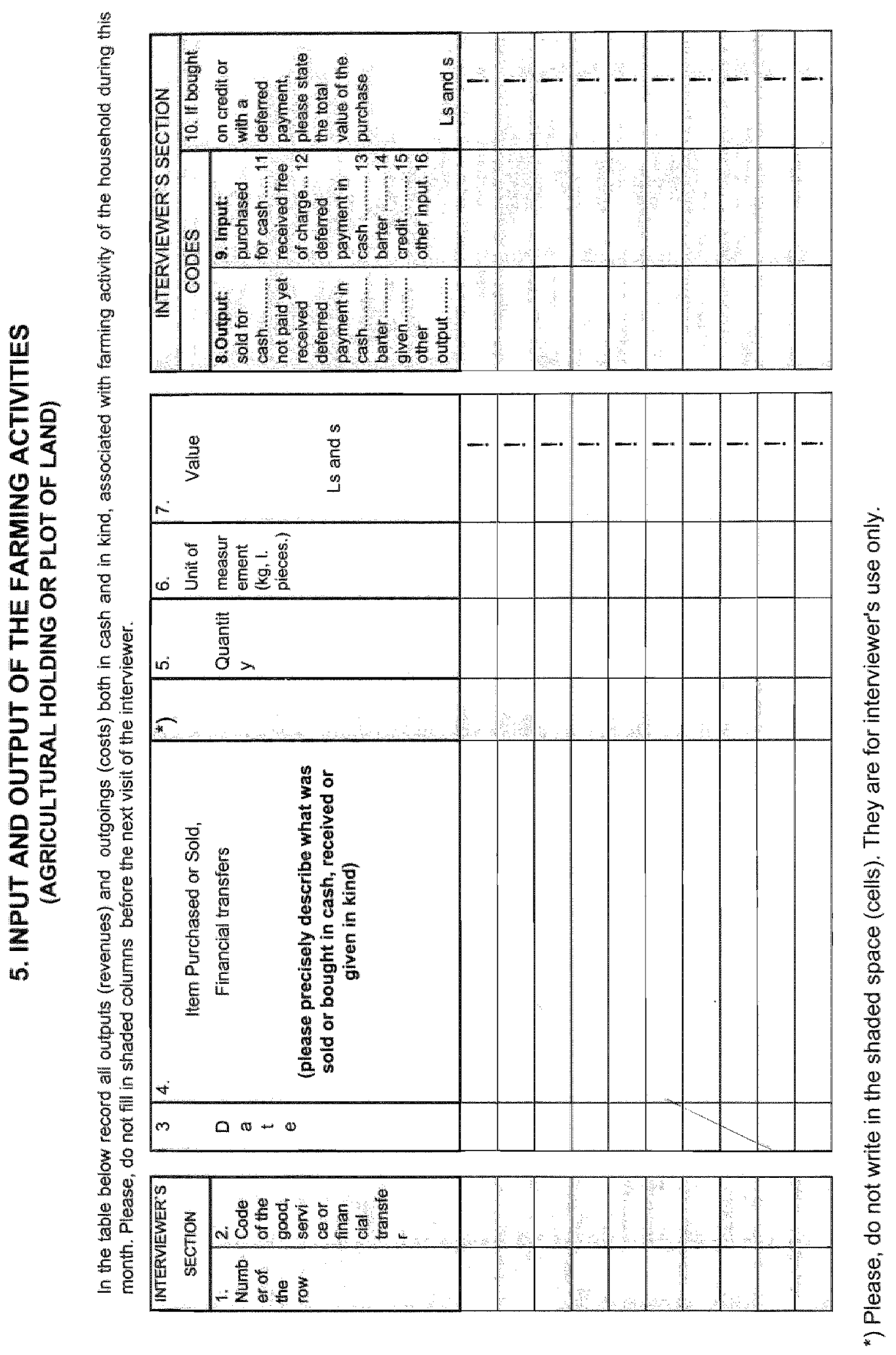




\section{Annex 2}

Poverty Survey Questionnaire 



\section{Family and its problems in} the present socio-economic

\section{situation}

Questionnaire

1998

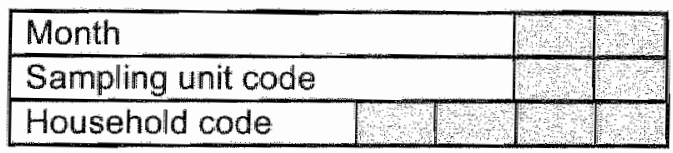

Interviewer code

Operator code 


\section{RESPONDENTS AND QUESTIONNAIRE}

(Please, encircle corresponding code)

\begin{tabular}{|c|l|}
\hline \multicolumn{2}{|l|}{ Questionnaire answered by } \\
\hline 1 & Randomly selected individual \\
\hline 2 & Substitute \\
\hline
\end{tabular}


With the following set of questions we try to understand what kind of changes households in Latha experienced since the country regained independence and what are the expectations for future developments. Some of the questions ask you to try to remember events and changes that took place quite some time ago. We would appreciate if yon could be as specific as possible; this will help the researchers to understand the changes and their background.

A. 01 .

When has your household been established?

1 Before 1991

2 Between 1991 and now

please indicate the year......

We would like you to think about the living conditions of your household before 1991 and now. When we say living conditions, we mean in particular your consumption possibilities. In case your household started to exist after 1991, compare your situation with the start of your household and now.

A 02

If you compare the consumption possibilities of your household before 1991 (or at the start of your household) and now, which answer would apply? Please mark one.

$1 \quad$ Now we can buy and afford much more than before

2 Now we can buy and afford a little bit more than before

3 Our consumption possibilities remained more or less the same

4 Now we can buy and afford somewhat less than before

$5 \quad$ Now we can buy and afford much less than before

6 Don't know

A 03 .

We would be interested to know how your living conditions have changed over these years, whether it was an ongoing upward or downward development, or whether you were confronted with up's and downs. Please indicate the answer that applies to your household.

Have your consumption possibilities changed the same way over the years since 1991 (or since the start of your household?

1 Yes; they constantly went down

2 Yes; they constantly went up

3 They stayed more or less the same

$4 . \quad$ No, they first went up and then down

$5 \quad$ No, they first went down and then up

6 No, they dropped immediately and then stayed the same

$7 \mathrm{No}$, they increased immediately and then stayed the same

8 Don"t know 
A 04 .

We now list a lot of events that can happen in a persons life and influence the consumption possibilities. We would like you to indicate whether these events occurred in your household (or family) since 1991 (or since the start of your household). If nothing is indicated it refers to all members of your household.

\begin{tabular}{|c|c|c|c|c|}
\hline & & No & $\begin{array}{l}2 \mathrm{Yes}_{0} \\
\text { once }\end{array}$ & $\begin{array}{l}3 \text { Yes, } \\
\text { several } \\
\text { times }\end{array}$ \\
\hline 1 & marriage of a household member & & & \\
\hline 2 & diwoice of a household meniber & & & \\
\hline 3 & child born & & & \\
\hline 4 & $\begin{array}{l}\text { motherifather died (also refers to respondent"s } \\
\text { spouse) }\end{array}$ & & & \\
\hline 5 & spouse died & & & \\
\hline 6 & child died & & & \\
\hline 7 & $\begin{array}{l}\text { mother of fatther come to live with the } \\
\text { household }\end{array}$ & & & \\
\hline 8 & child left household to live independently & & & \\
\hline 9 & $\begin{array}{l}\text { someone in the household got serious health } \\
\text { problems or accident }\end{array}$ & & & \\
\hline 10 & we moved to a cheaper house/apartment & & & \\
\hline 11 & we moved to a more expensive house/apartment & & & \\
\hline 12 & a household member lost job & & & \\
\hline 13 & $\begin{array}{l}\text { a household member did not receive wage for } \\
\text { more than } 3 \text { months }\end{array}$ & & & \\
\hline 14 & $\begin{array}{l}\text { a household member got unemployed for more } \\
\text { than } 6 \text { months }\end{array}$ & & & \\
\hline 15 & $\begin{array}{l}\text { a household member got a new job with lower } \\
\text { payment }\end{array}$ & & & \\
\hline 16 & $\begin{array}{l}\text { a lousehold member got a new job with higher } \\
\text { payment }\end{array}$ & & & \\
\hline 17 & we started a priwate business & & & \\
\hline 18 & $\begin{array}{l}\text { we lost our savings due to banking crisis or } \\
\text { monetary reform }\end{array}$ & & & \\
\hline 19 & we inherited a substantial sum of money & & & \\
\hline 20 & we got access to private plot of land & & & \\
\hline 21 & we received assistance from relatives/friends & & & \\
\hline 22 & $\begin{array}{l}\text { lwing abroad } \\
\text { a household member started school/shudies }\end{array}$ & & & \\
\hline 23 & a household member finished schoolstudies & & & \\
\hline 24 & $\begin{array}{l}\text { we lost support from family not living in the } \\
\text { same household }\end{array}$ & & & \\
\hline 25 & $\begin{array}{l}\text { we had to take care of family not living in the } \\
\text { same household }\end{array}$ & & & \\
\hline 26 & $\begin{array}{l}\text { we started to sell things that we make, collect or } \\
\text { grow }\end{array}$ & & & \\
\hline 27 & we were confronted with bad harvest & & & \\
\hline 28 & were able to pay off debts during the last years & & & \\
\hline 29 & were able to save money during the last years & & & \\
\hline 30 & we had to sell the privatization vouchers & & & \\
\hline 31 & we used the vouchers to buy property & & & \\
\hline 32 & $\begin{array}{l}\text { our entrepreneurial activities were not } \\
\text { successful }\end{array}$ & & & \\
\hline
\end{tabular}


We now would hike you to compare your situation in 1991 with pour shation in 1998 in some spectic respects. The questions all refer to your household.

A 05 .

If you compare your situation now with your situation before independence (1991), then which of the following statements apply to your household:

\begin{tabular}{|c|c|c|c|c|}
\hline & & 1 applies & $\begin{array}{l}2 \text { does not } \\
\text { apply }\end{array}$ & $\begin{array}{l}3 \text { don't } \\
\text { know }\end{array}$ \\
\hline $\begin{array}{l}13 \\
14 \\
15 \\
16 \\
17 \\
18 \\
19\end{array}$ & $\begin{array}{l}\text { we still live in the same house/apartnent } \\
\text { nowadays we eat more or less the same } \\
\text { quantity of food } \\
\text { nowadays the quality of our food is worse } \\
\text { then before } 1991 \\
\text { nowadays we have less cloths for the adults in } \\
\text { the household } \\
\text { nowadays we bave less cloths for the children } \\
\text { nowadays we have better equipment in the } \\
\text { household } \\
\text { (television, kitchen, cleaning, etc. } \\
\text { nowadays we have a better car } \\
\text { we did not have a car in } 1991 \\
\text { we buy less books than in } 1991 \\
\text { we buy less luwary goods than in } 1991 \\
\text { nowadays we go more often on holiday } \\
\text { we go less to the theater, opera, concert } \\
\text { nowadays } \\
\text { nowadays we have a computer at home } \\
\text { nowadays the children lave more possibilities } \\
\text { we have to work tharder nowadays } \\
\text { we work less hours nowadays } \\
\text { money never used to be a real problem before } \\
\text { 1991 } \\
\text { nowadays we always have to think about } \\
\text { money } \\
\text { we can save more today than before } 1991\end{array}$ & & & \\
\hline
\end{tabular}

Now, we would like to ask you about the job or function you, the respondent, had in 1991.

A 06

Did you have a paid job/function in 1991?

1 yes
2 no - Go to next section 
A 07

Which of the following statements applied to your job and/or function in 1991 ?

\begin{tabular}{|c|c|c|c|c|}
\hline & & 1 applies & $\begin{array}{l}2 \text { does not } \\
\text { apply }\end{array}$ & $\begin{array}{l}\text { 3. donst } \\
\text { know }\end{array}$ \\
\hline 1 & I had a job that gave me a good wage & & & \\
\hline 2 & $\begin{array}{l}\text { I had a job that allowed me to make some } \\
\text { money on the side }\end{array}$ & & & \\
\hline 3 & $\begin{array}{l}\text { I had a job or function that gave me some } \\
\text { influence even outside my workplace }\end{array}$ & & & \\
\hline 4 & $\begin{array}{l}\text { My job allowed me to bring home now } \\
\text { and then things that were difficult to get } \\
\text { for other people }\end{array}$ & & & \\
\hline 5 & $\begin{array}{l}\text { My job allowed me to earm some extra } \\
\text { money now and then }\end{array}$ & & & \\
\hline 6 & $\begin{array}{l}\text { In my job/function I had the possibility to } \\
\text { rise in wage and status. }\end{array}$ & & & \\
\hline 7 & People used to listen to my adwice & & & \\
\hline 8 & $\begin{array}{l}\text { I could travel outside the country (former } \\
\text { USSR) now and then }\end{array}$ & & & \\
\hline 9 & $\begin{array}{l}\text { Due to my job/function I knew people that } \\
\text { always wanted to help me }\end{array}$ & & & \\
\hline
\end{tabular}




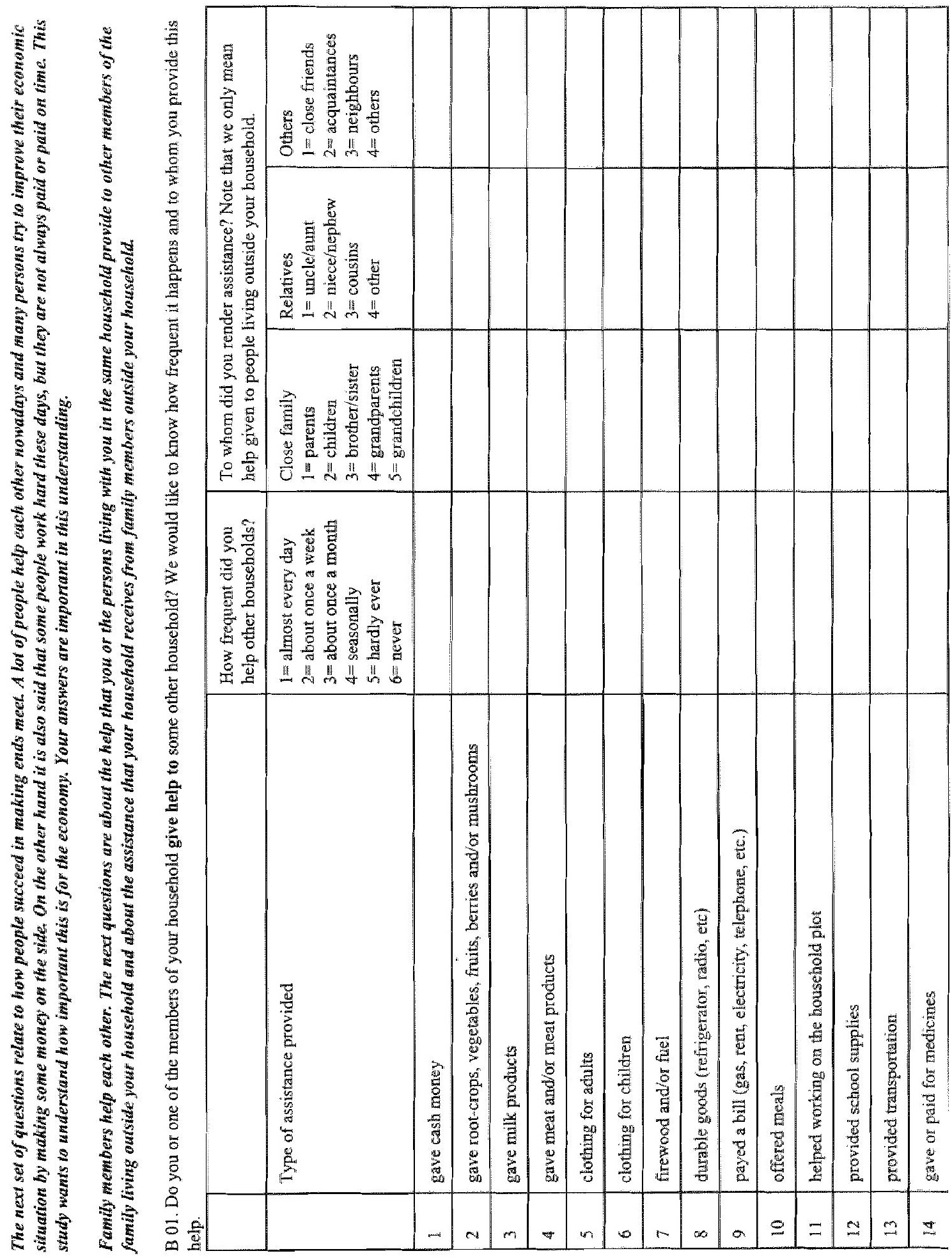




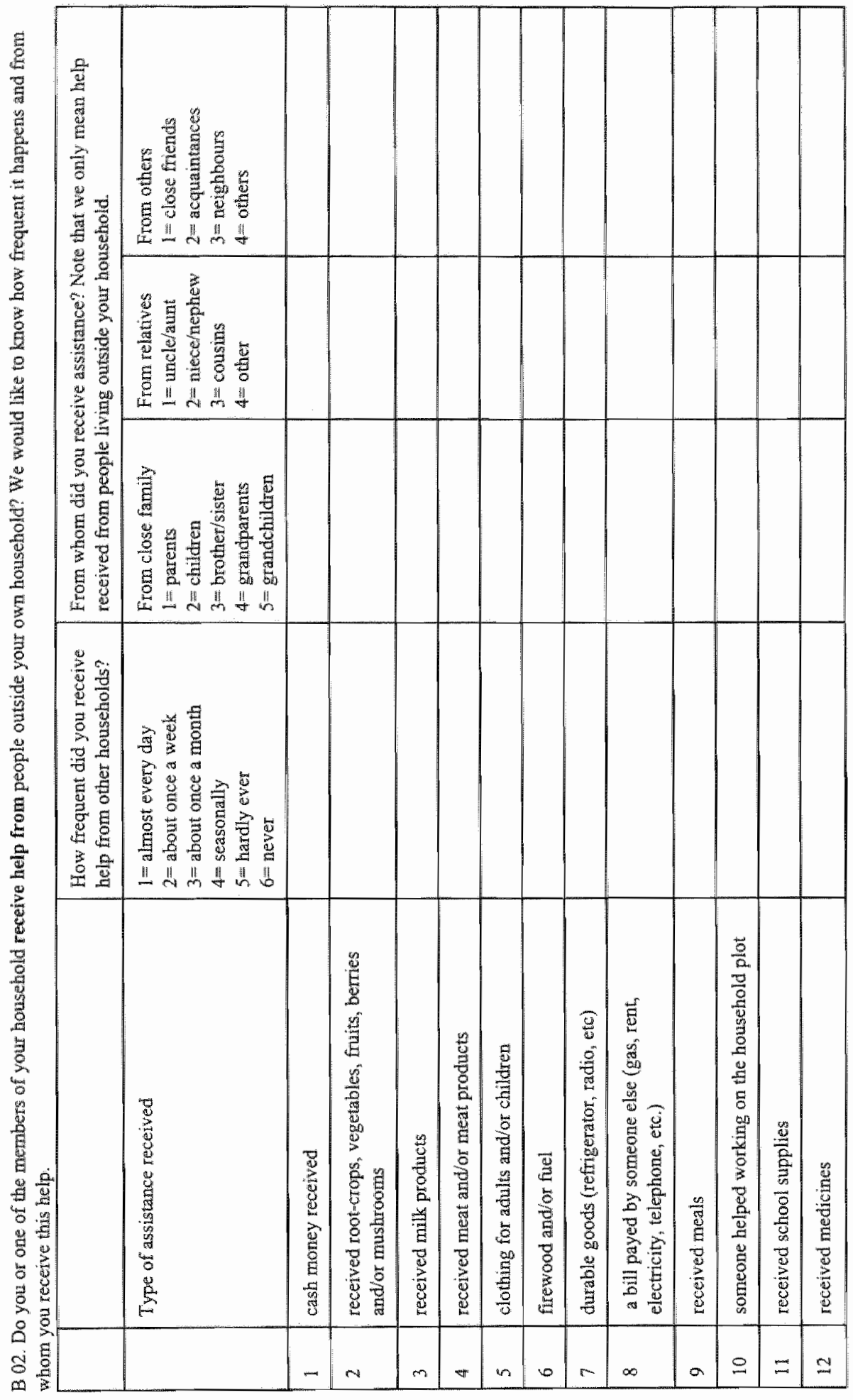



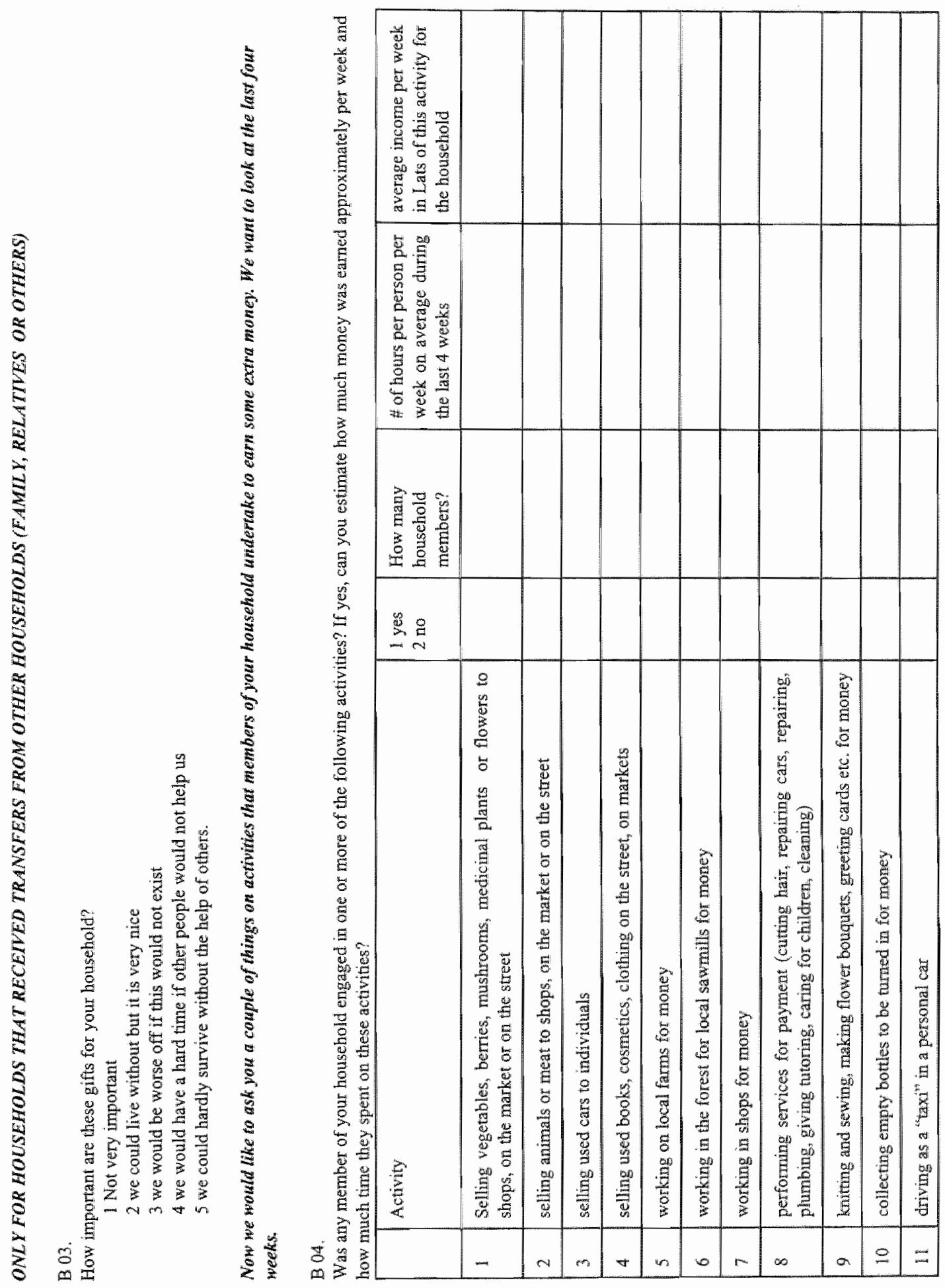


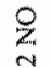

$\stackrel{5}{0}$

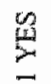

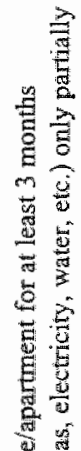

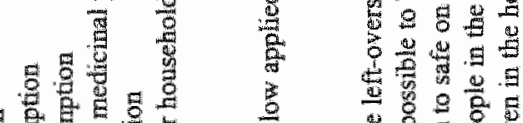

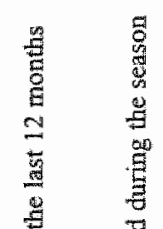

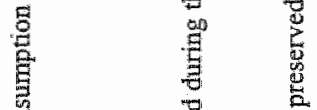

봅 뭉

si

递

官

胥

20

药

.

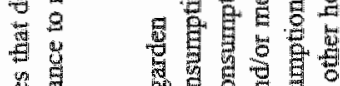

U.

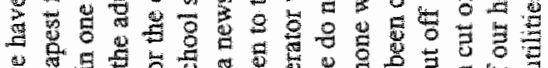

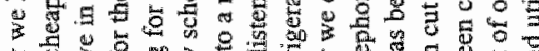

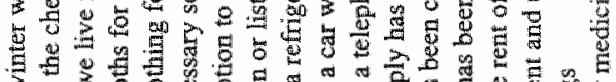

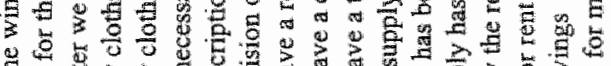

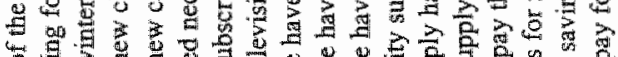

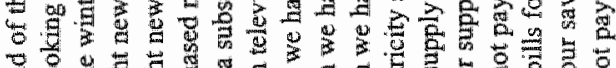

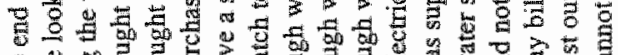

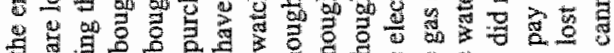

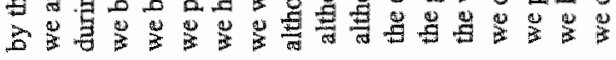




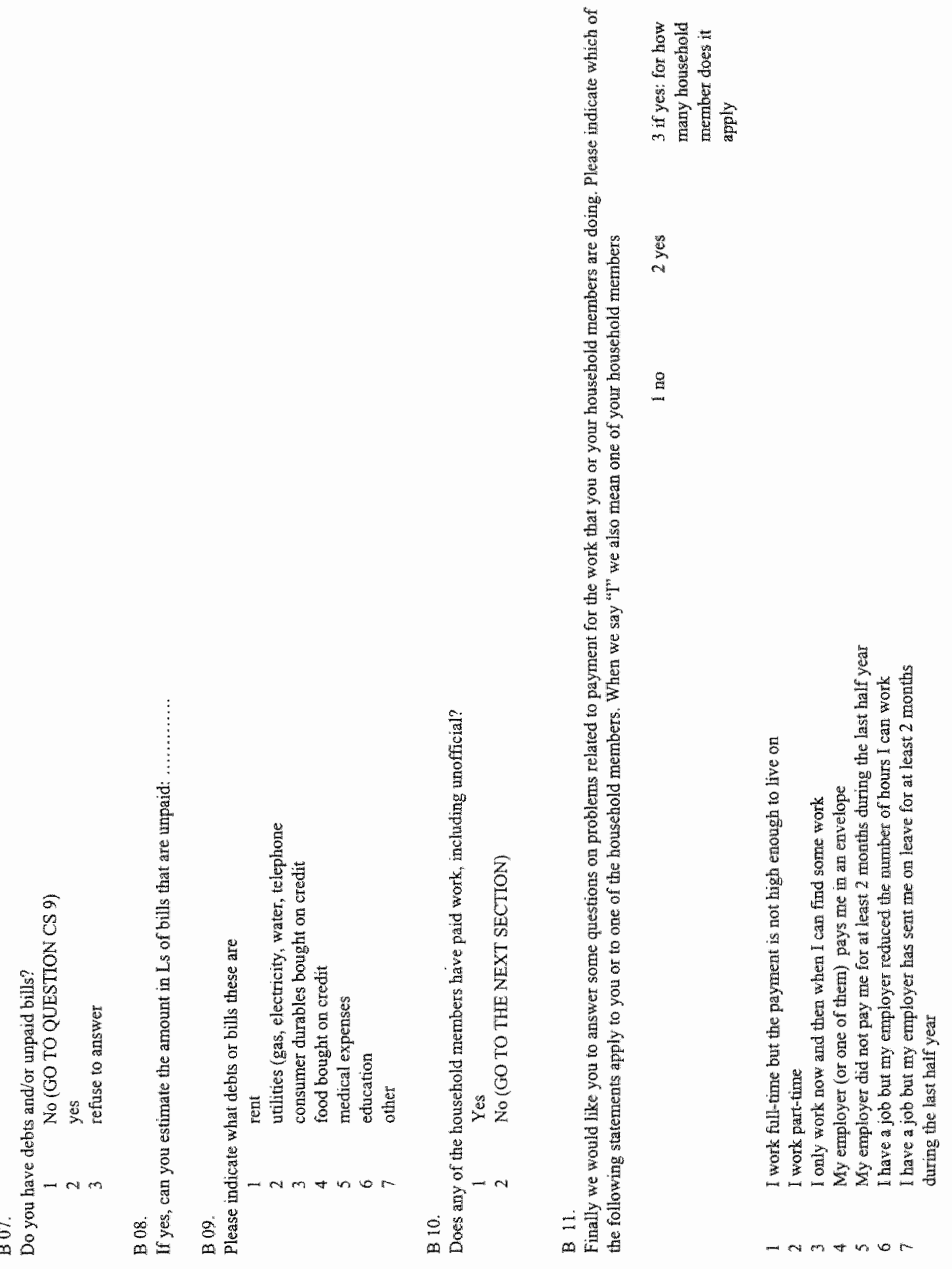




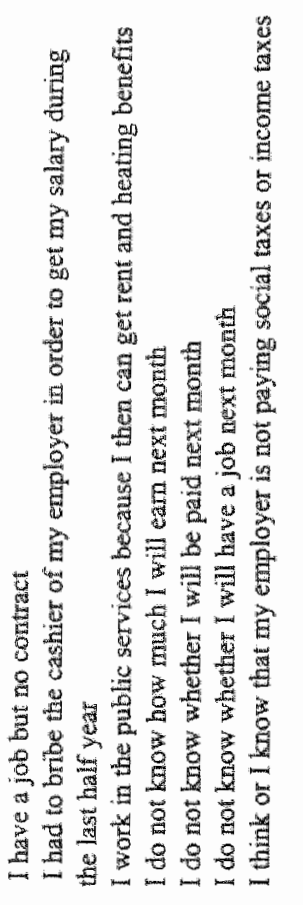

- o $0=0 \pm$ 
We now want to ask you a couple of questions about the social survices prowided by the muthithathes and the state. We are particularly wherested in what kind of information you hawe abow these surwices, in yowr experiences wh these services and in your opintons about then.

Col.

Do you know where the Social Assistance offee in your municipality is located?

1. Yes Can you tell us the approximate location?

2 mo

C. 02 .

Do you think that according to the law the municipal Social Assistance office can help anybody with providing the following services: no don't knowy

1 providing benefis when people have no money

2 helping to pay for the transportation for the children to go to school.

3 providing free school luaches for children.

4 assisting household to pay off debts.

$S$ providing firewood for the winter.

6 providing fuel subsidies for the winter

7 providing a wheelchair to someone who needs it.

8 assistance in paying for health services.

C 03 .

How do you get information on the municipal Social Assistance services? (several answers are possible)
1 From television.
2 From radio
3 From newspaper
4 from friends and family members
5 from information provided by the Social Assistance office
6 from what people say
7 have no information

C 04 .

Do you know someone who has received a benefit or other forms of help from the nunicipal Social Assistance office during the last 12 nonths?

1 No
$2 \mathrm{Yes}$, (several answers possible)

2.1 someone in my family received assistunce

22 someone in ny neighbourhood received assistance

23 some one else I know received assistance

241 heard from some people I do not know that they received assistance

C 05 .

Did you ever visit the Social Assigtance Office yonrselves?
1 No (GOTO QUESTION 10 )
2 Yes during the last 12 months
3 more than one year ago 
ONLY FOR RESPONDENTS THAT VISITED THE SOCLAL ASSISTANCE OFFICE

Co6.

What was your request to the Social Assistance Office?

\begin{tabular}{|c|c|c|c|}
\hline Request & $\begin{array}{l}1=y e s \\
2=\text { no }\end{array}$ & which kind of benefri? & Codes \\
\hline Apply for general benefit & & & $\begin{array}{l}1=\text { family benefit } \\
2=\text { guardian allowance } \\
3=\text { transportation allowance } \\
4=\text { funeral allowance } \\
5=\text { sociall assistance benefit } \\
6=\text { aparment allowance } \\
7=\text { other }\end{array}$ \\
\hline $\begin{array}{l}\text { Apply for specific benefit for } \\
\text { children }\end{array}$ & & & $\begin{array}{l}1=\text { Child care benefit } \\
2=\text { Birth grant } \\
3=\text { Child support } \\
4=\text { free schooll lunch } \\
5=\text { other }\end{array}$ \\
\hline $\begin{array}{l}\text { Apply for assistance in kind (food, } \\
\text { clothing, firewood, etc) }\end{array}$ & & not applicable: & \\
\hline $\begin{array}{l}\text { Apply for assistance with payment } \\
\text { of utilities or debts }\end{array}$ & & not applicable & \\
\hline $\begin{array}{l}\text { Apply for assistance with health or } \\
\text { related services }\end{array}$ & & not applicable & \\
\hline $\begin{array}{l}\text { Apply for other types of assistance } \\
\text { or asking information }\end{array}$ & & & $\begin{array}{l}1=\text { other types of benefit } \\
2=\text { information }\end{array}$ \\
\hline
\end{tabular}

C 07 .

Did you receive the assistance you applied for

1 yes

2 no, but I received a smaller amount of assistance

3 no, but I received another type of assistance

4 not yet, but my paperwork is processed (GO TO QUESTION 10)

5 no, $Y$ did not receiwe any assistance

\begin{tabular}{|c|c|}
\hline why not: & $\begin{array}{l}51 \text { If was not entitled to receive the benefit } \\
52 \text { I applied for the wrong benefit } \\
53 \text { Other } \\
54 \text { II don't know why }\end{array}$ \\
\hline & ON 10) \\
\hline
\end{tabular}

ONLY FOR RESPONDENTS THAT VISITED THE SOCIAL ASSISTANCE OFFLCE DURING THE LAST 12

MONTHS (OTHERS GO TO QUESTIION 10) 
C 08 .

Over the last year - 12 months - how much assistance or help did you receive from the Social Assistance office:

\begin{tabular}{|l|l|l|}
\hline Type of assistance & $\begin{array}{l}\text { H of times that benefit has been } \\
\text { received }\end{array}$ & average anount per period \\
\hline $\begin{array}{l}\text { State benefit (family benefit, child } \\
\text { benefit, guardian allowance, birth } \\
\text { grant) }\end{array}$ & & \\
\hline Cash benefit & & \\
\hline Food coupons & & \\
\hline Food in kind & & \\
\hline Free lunch & & \\
\hline Firewood/fuel in kind & & \\
\hline Fuel subsidy in casth & & \\
\hline $\begin{array}{l}\text { Cash benefit to pay for rent and/or } \\
\text { utilities }\end{array}$ & & \\
\hline $\begin{array}{l}\text { Rent and/or utility bills paid } \\
\text { directly by SA office }\end{array}$ & & \\
\hline Home care & & \\
\hline Day care for elderly & & \\
\hline Transportation subsidy in cash & & \\
\hline Other & & \\
\hline
\end{tabular}

$\mathrm{C} 09$.

I (or one of my housebold members) have or had to work in public works in order to get the assistance from the Social Assistance office

Yes:

C 10.

Below we list a couple of things that people may think of the Social Assistance Onfee and its services. Can you please indicate whether you agree strongly, agree, neither agree nor disagree (neutral), disagree or strongly disagree with the statements?

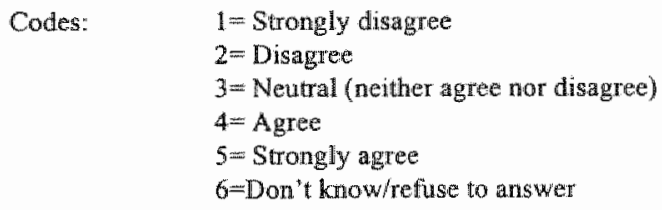


I people working at the SAl office are

11 friendly

12 competent.

13 effective.

14 rude.

is uncaring.

2.The service at the $S A$ office was

21 effective.

22 fast.

23 too slow

3. the level of benefit or help was

31 adequate.

32 too low

4 The law is applied in a fas way

5 The benefits are dimtributed in a fair way.

$61 \mathrm{had}$ to stand in a long queue at the office.

7 The people at the SA office do what they can

8 The people at the SA office only help their friends

9 In other municipalities the SA office works better.

10 The murricipality has enough money

10 pay for Social Assistance.

11 The people at the SA office are not helpful

if you are $\quad 111$ old

112 a single mother.

113. a family with many children

114 not a Latvian speaking persons.

(ONLY FOR RESPONDENTS WHO NEVER WENT TO SA OFFICE - OTHERS GO TO QUESTION

C 11 .

What statement describes your position in the best way?

1 I newer visited the Social Assistance office because I did not need it (GO TO NR 13)

2 In the past I could have needed to go the Social Assistance office but I never visited it

3 I am currently in need but I did not visit the Social Assistance office.

C 12.

Why then didl you not go to the Social Assistance office; which answers are describing your position in the best way (several answers possible):

1 I did noll know that they could help me

2 I thought they would not help me

3 It is not convenieat to go to the Social Assistance office

$4 \quad$ It would be embarrassing to go to the Social Assistance office

5 The Social Assistance office is there not for people like me

6 The Social Assistance office is too far away

Transportation to get to the Social Assistance office is too expensive

The Social Assistance office is not accessible for me

The Social Assistance office is unfair and I will not get help anyway

9

The Social Assistance office has always long quenes

I do not trust the people at the Social Assistance office

I do not go because there are people more in meed than I am

13 I rather rely on my family, my friends or my neighbours than going to the $S A$ office 
C 13.

Some people receive help and sacial assistance from non-governmental organisations such as churohes, save the Children and/or other helping institutions. Did you receive assistance from such organisations during the last 12 months?

1 No

1 Yes in cash;

how much during the last 12 months ...Ls...................

3 Yes in kind;

31 food

32 firewood

33 clothes

34 transportation

35 medicines

36 school supplies

37 other 
Finally we would bice to ask you some questions on your chitdren and the schools, and on your health and the heallh of the household wewhers.

D) 01 .

Are there school-age children living in your household?
1 No (GO TO QUESTION Ga?
2 Yes
How many

D 02.

How far is the schoo (are the schools) of your children from your home? In kilometers (please indicate as precise as possibles

\section{Chind}

Child 2 :

child 3 :

Chilid 4 :

D 03

How do your children go to school? (Indicate the number of children per cotegory)

\section{On foot}

by bicycle

by car (a bring them myself)

by car (they go together with other children in another persons' car

by bus, tram, trollay, other forms of public transport

by special school-bus

of hiner

D 04.

Did all your children attend school remgularly the last six months (except for shorl interuptions due to nonmserious illness $)$ ?

I Yes (GO TO QUESTION qa S.)

$2 \mathrm{No}$ How many?......

D 05 .

Why did they not attend school regularly? (More than I answer is possible)

1 Too expensive

2. school too far away

3 they learn mothing useful ath school

4 sehool is for rich people only

5 we cannot pay for books, equipment

6 we cannot pay for appropriate clothing, shoes

7 they are too old for the grade they are in

8 no transport to school availabile

9 transport is too expensive

to we cannot give them a decent lunch package

11 we cunnot pay for school lunches

12 we canmon afford the 'cionations' to the school

13 cluild was needed at home to help/work

14 child was needed at home to care for sick household member

15 child is not registered at mumicipality

16 child was scriously ill

D 06

What was the nature of children's illness that preveruted them to attend school regularly? (If it applies to more than one child, indicate the number of children per category)

1 chronic cold or respiratory illness

2 inwalid of the twird category

3. other serious illness 
D 07 .

How much do you spend on school and related expenditures per child on average? You can indicate it per month or per year.

1 Nothing at all

Per month Per year

2 transport

3 equipment (books, clothing, etc)

4 special activities (excursions, music school, etc.)

5 'Donations" to the school

6 (private) tutoring

D 08

Which language do you speak to your children or other at home?

1 Latvian

2 Russian

3 Other which one:

I am now going to ask some questions about access to health serwices and related isswes.

D 09.

Did you or another member of your household have any acute illness or any injury which lasted for 3 days or more during the last two months?
1 No
2 Yes, one adult household member
3 Yes, two or more adult household menbers
4 Yes, a child
5 Yes, two or more children

D 10.

In case of illness of one of the household members, have you been able to wisit a doctor or other health care institution?

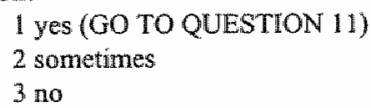

Di11

What prevented you or the other household members in case of illness to visit a doctor of other health care institution?

2 we lacked the money to pay for the needed service

3 the health care institution/doctor is too far away

4. we could not get transportation

5 we don't trust these institutions

5 because of other reasons 
$\mathrm{D} 12$.

We are interested in knowing whether you, or someone in your household, have been in contact whth instiutions for health care during the last 2 months, for evther prevention or treatment of disease. We would like fo know Which wind of health service you have been using, how many times, and why you have been using the services.

No contact with any heatth care institutions during the last 2 months (GO TO THE NEXT QUESTION) Yes (FIL TN THE TAELE)

\begin{tabular}{|c|c|c|c|c|}
\hline $\begin{array}{l}\text { Congullations with health personinel } \\
\text { type of contact }\end{array}$ & $\begin{array}{l}\text { Number of } \\
\text { himes }\end{array}$ & For whom & Why & Paymant \\
\hline \multicolumn{5}{|l|}{$\begin{array}{l}\text { Hospitalized in private/public } \\
\text { hospitalclinic. Please indicate number } \\
\text { of days in accond column. }\end{array}$} \\
\hline \multicolumn{5}{|l|}{$\begin{array}{l}\text { Consulltation with doctor by teleptione } \\
\text { (no appointment) }\end{array}$} \\
\hline \multicolumn{5}{|c|}{ Visil toby doctor (general practitioner, local polyclinic, other non-specialist) } \\
\hline \multicolumn{5}{|l|}{ Frrst ume visit to the doctor } \\
\hline \multicolumn{5}{|l|}{ First time wisit by the doctor (at home) } \\
\hline \multicolumn{5}{|l|}{ Revisit the doctor } \\
\hline \multicolumn{5}{|l|}{ Rewisit by the doctor (at home) } \\
\hline \multicolumn{5}{|l|}{ Company doctor } \\
\hline \multicolumn{5}{|l|}{ Visit to/by speciolist } \\
\hline \multicolumn{5}{|l|}{ First time visif to the specialist } \\
\hline \multicolumn{5}{|l|}{$\begin{array}{r}\text { Furst time visit by the specinalist (at } \\
\text { home) }\end{array}$} \\
\hline \multicolumn{5}{|l|}{ Revisit to the specialist } \\
\hline \multicolumn{5}{|l|}{ Revisit by the specialist (at home) } \\
\hline \multicolumn{5}{|l|}{$\begin{array}{l}\text { Visit to doctor at hospital or } \\
\text { specialized clinic }\end{array}$} \\
\hline \multicolumn{5}{|l|}{ Visil by a murse } \\
\hline \multicolumn{5}{|l|}{$\begin{array}{l}\text { Visit toby a healer on traditional } \\
\text { doctor }\end{array}$} \\
\hline \multicolumn{5}{|l|}{ Received and filled prescriptions } \\
\hline Other kind of service & & & & \\
\hline
\end{tabular}

\section{Coditig:}

liOR WHOM: $\quad 1=$ myself $\quad 2=0$ hier lnousehold member $>18$ years $\quad 3=c h i l d r e n$ in household

WHY: I preventive, check-up, wccination, etc 2=preventive incl $x-1 a y$, laboratory services 3 -becatise of illness, injury $\quad 4$ wiliness or injury, incl $x$-ray, laboratory services

PAY: $\quad 1$ sedid not pay, service for free $\quad 2$ =did not pay, covered entirely by insurance 3 -paid a user charge $\quad 4$-paid the docton directly $\quad 5=$ paid by municipality 
D 13.

How much did your medical service cost you in total, inchuding services billed by the hospital, payments made to the doctors, nursing staff, attendants, charges for food or linen, costs of your own food and linen brought in, and the money value of any presents (food and non-food items) you may have givea to the staff in gratitnde for taking care of the patient

How much did your household spend on health care during the last two months in Lats? Please include informal payments, such as gratuities

\begin{tabular}{|l|l|l|l|l|}
\hline & & \multicolumn{2}{|l|}{ If possible, specify } \\
\hline Health care service & Total & $\begin{array}{l}\text { Paid to the } \\
\text { doctor or } \\
\text { specialist }\end{array}$ & $\begin{array}{l}\text { Paid to the } \\
\text { hospital }\end{array}$ & $\begin{array}{l}\text { Paid to } \\
\text { the } \\
\text { pharmacy }\end{array}$ \\
\hline in-patient care & & & & \\
\hline outpatient in hospital & & & & \\
\hline outpatient in clinic & & & & \\
\hline purchase of prescribed drugs & & & & \\
\hline Purchase of not prescribed drugs & & & & \\
\hline dental care & & & & \\
\hline optical care & & & & \\
\hline other & & & & \\
\hline
\end{tabular}

D 14.

Do you have any kind of health insurance, and if yes, what kind of health insurance do you have?

No (FINISH WITH THIS PART)

Yes, public or state health irnsurance

Yes, company provided health insurance

Yes, private health insurance

D 15.

Do you have to pay for this health insurance yourself?

No

Yes, but onlly a part of the cost

Yes, the total cost

D 16.

Does the health insurance(s) you have in your household cover all the household members?

Yes

No

Not relevant

Do not know 